Henrik Müller

\title{
Wechselkurspolitik des Eurolandes
}

Konfliktstoff für die neue währungspolitische Ära 


\section{Henrik Müller}

\section{Wechselkurspolitik des Eurolandes}

Die Europäische Währungsunion bedeutet eine Zäsur: Neben dem US-Dollar entsteht eine zweite große Weltwährung. Neue Spielregeln bilden sich innerhalb der Europäischen Union, aber auch im internationalen Währungssystem heraus. Darin steckt ein erhebliches Konfliktpotential. Schlimmstenfalls droht die Renaissance einer handelspolitisch motivierten Wechselkurspolitik. Diese Arbeit analysiert, welche wirtschaftspolitischen Handlungsspielräume die gemeinsame Währung den Regierungen der Euroland-Staaten eröffnet. Sie beleuchtet, unter welchen Bedingungen das Worst-case-Szenario eines transatlantischen "Wirtschaftskriegs“ einzutreten droht. Und sie untersucht, welche institutionellen Innovationen des internationalen Währungssystems in der Lage sind, solchen potentiellen Konflikten vorzubeugen.

Henrik Müller, geboren 1965, studierte in Kiel Volkswirtschaftslehre und absolvierte die Deutsche Journalistenschule in München. Er promovierte als externer Doktorant an der Universität der Bundeswehr Hamburg und arbeitet als freier Wirtschaftsjournalist und Autor in Hamburg. 
Wechselkurspolitik des Eurolandes 


\title{
SCHRIFTEN ZUR WIRTSCHAFTSTHEORIE UND WIRTSCHAFTSPOLITIK
}

\author{
Herausgegeben von \\ Rolf Hasse, Jörn Kruse, Wolf Schäfer, Thomas Straubhaar \\ und Klaus W. Zimmermann
}

\section{Band 17}

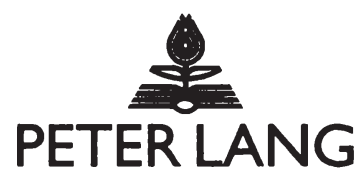

Frankfurt am Main - Berlin - Bern - Bruxelles - New York - Wien 


\section{Henrik Müller}

\section{Wechselkurspolitik des Eurolandes}

Konfliktstoff für die neue währungspolitische Ära

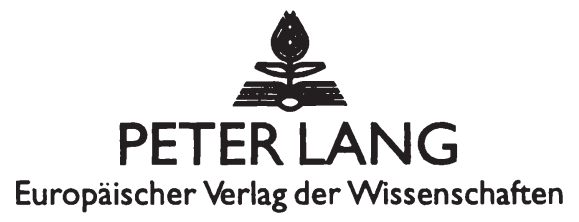


Die Deutsche Bibliothek - CIP-Einheitsaufnahme

Müller, Henrik:

Wechselkurspolitik des Eurolandes : Konfliktstoff für die neue währungspolitische Ära / Henrik Müller. - Frankfurt am Main ; Berlin ; Bern ; Bruxelles ; New York ; Wien : Lang, 1999

(Schriften zur Wirtschaftstheorie und Wirtschaftspolitik ;

Bd. 17)

Zugl.: Hamburg, Univ. der Bundeswehr, Diss., 1999

ISBN 3-631-35555-6

Open Access: The online version of this publication is published on www.peterlang.com and www.econstor.eu under the international Creative Commons License CC-BY 4.0. Learn more on how you can use and share this work: http://creativecommons. org/licenses/by/4.0.

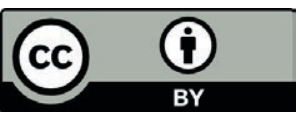

This book is available Open Access thanks to the kind support of ZBW - Leibniz-Informationszentrum Wirtschaft.

Gedruckt auf alterungsbeständigem, säurefreiem Papier.

\author{
D 705 \\ ISSN 1433-1519 \\ ISBN 3-631-35555-6 \\ ISBN 978-3-631-75010-0 (eBook) \\ (C) Peter Lang GmbH \\ Europäischer Verlag der Wissenschaften \\ Frankfurt am Main 1999 \\ Alle Rechte vorbehalten.
}

Das Werk einschließlich aller seiner Teile ist urheberrechtlich geschützt. Jede Verwertung außerhalb der engen Grenzen des Urheberrechtsgesetzes ist ohne Zustimmung des Verlages unzulässig und strafbar. Das gilt insbesondere für Vervielfältigungen, Übersetzungen, Mikroverfilmungen und die Einspeicherung und Verarbeitung in elektronischen Systemen.

Printed in Germany 124567 


\section{Danksagung}

So spannend das Thema auch sein mag: Ständig davon begeistert zu sein, wäre wohl etwas viel verlangt. Zwar befeuerten die Aktualität der anbrechenden EuroÄra und die hitzigen Debatten über die äußere Schwäche der neuen Währung in den ersten Monaten ihres Bestehens das Schreiben dieser Arbeit. Aber natürlich gab es auch Hängepartien, Schaffenspausen, Zweifel, Streß - lauter Unannehmlichkeiten, die gemeinhin als „wertvolle Lebenserfahrungen“ verbrämt werden.

$\mathrm{Da}$ diese Arbeit dennoch so rasch entstehen konnte, verdanke ich vor allem drei Menschen:

- meiner Mutter Vera Müller, ohne deren jahrelange Geduld, ihre Unterstützung und ihr Zureden ich niemals mein Diplom gemacht hätte und die auch diese Arbeit nach Kräften gefördert hat,

- meiner künftigen Frau Urte Josuweit, deren Energie mich überhaupt erst in die Lage versetzt hat, eine Dissertation neben dem normalen journalistischen Broterwerb zustande zu bringen,

- meinem Doktorvater Prof. Dr. Thomas Straubhaar, der den Mut hatte, mich als Externen zu akzeptieren, dem ich viele Anregungen verdanke und der mich mit seinem Enthusiasmus immer wieder motiviert hat.

Daneben haben noch einige andere Anteil am Zustandekommen dieser Arbeit: Prof. Dr. Wolf Schäfer, der als Koreferent Zeit und Zuspruch investierte, Dr. Carsten-Patrick Meier und Prof. Dr. Joachim Scheide, beide vom Institut für Weltwirtschaft in Kiel, deren Kritik einige, wenn auch sicher nicht alle Fehler aufdeckte, die übrigen Doktoranten am Institut für Wirtschaftspolitik der Universität der Bundeswehr Hamburg, insbesondere Stefan Haupt, Dr. Peter A. Fischer, Hubertus Hille und Dr. Stefan Golder, Frau Antje Rudolph, die half, den Kontakt zum Institut zu halten sowie die Teilnehmer eines Workshops am Europa-Kolleg Hamburg.

Ihnen allen danke ich herzlich!

Henrik Müller

Hamburg, im Sommer 1999 
Henrik Müller - 978-3-631-75010-0

Downloaded from PubFactory at 01/11/2019 09:16:41AM

via free access 


\section{Inhaltsverzeichnis}

$\begin{array}{ll}\text { Verzeichnis der Abbildungen } & 11\end{array}$

$\begin{array}{ll}\text { Verzeichnis der Symbole } & 15\end{array}$

$\begin{array}{ll}\text { Verzeichnis der Abkürzungen } & 17\end{array}$

1. Einleitung: Euroland in der Weltwirtschaft 21

2. Zum institutionellen Rahmen der Europäischen Währungsunion 27

2. 1 Ziele, Probleme und Grundkonzeption der EWU 28

2. 1. 1 Ökonomische Vorteile einer Währungsunion 29

2. 1. 2 Ökonomische Nachteile einer Währungsunion 29

2. 1. 3 Asymmetrie in Europa: einige empirische Hinweise $\quad 36$

2. 1. 4 Politische Erwägungen und die Ratio des EWU-Designs $\quad 39$

2. 2 Geldpolitik im institutionellen Rahmen der EWU 42

2.2. 1 Ziele $\quad 42$

2. 2. 2 Zuständigkeit 43

2. 2. 3 Beurteilung 43

2. 3 Institutioneller Rahmen der Außenwährungsund Wechselkurspolitik 45

2.3.1 Ziele $\quad 45$

2. 3. 2 Zuständigkeit $\quad 45$

2. 3. 3 Beurteilung $\quad 50$

2. 4 Haushaltskontrolle und die Vermeidung übermäßiger Defizite $\quad 52$

2.4.1 Ziele $\quad 53$

2. 4. 2 Zuständigkeit $\quad 54$

2. 4. 3 Beurteilung $\quad 55$

2. 5 Sonstige Wirtschaftspolitik im EWU-Design 57

2.5.1 Ziele $\quad 57$

2.5. 2 Zuständigkeit $\quad 57$

2. 5. 3 Beurteilung $\quad 59$

2. 6 Genügt der institutionelle Rahmen den Herausforderungen der Zukunft? 
3. Die EWU-Landschaft: Neue ökonomische Rahmenbedingungen für die Regierungen im Euroland

3. 1 Der Euro als internationale Währung 72

3. 1. 1 Internationale Handels- und Vehikelwährungen 73

3. 1. 2 Vehikelwährungen auf den Devisenmärkten 77

3. 1. 3 Internationale Anlagewährungen 79

3. 1. 4 Zusammensetzung offizieller Währungsreserven 82

3. 1. 5 Internationale Ankerwährungen $\quad 85$

3. 1. 6 Verschafft die Weltwährung Euro den

EWU-Mitgliedsländern neue wirtschaftspolitische Freiheitsgrade? $\quad 90$

3. 2 Die EWU-Länder als Handelsnationen $\quad 91$

3. 2. 1 Auswirkungen des EWU-Beitritts auf die

Exponiertheit im Außenhandel 91

3. 2. 2 Struktur der Exporte der EWU-Länder 94

3. 3 Aspekte der Politischen Ökonomie $\quad 98$

3. 3. 1 „Nachfrage" nach Protektion $\quad 99$

3. 2. 2 "Angebot" an Protektion 101

3. 2. 3 Stärkere Wechselkursschwankungen? 102

4. Ein Konfliktszenario 105

4. 1 Theoretischer Ansatz: eine modifizierte Phillipskurve 105

4. 1. 1 Das Modell für die heimische Wirtschaft 106

4. 1. 2 Die Rolle eines zweiten Landes 121

4. 2 Strategische Konstellationen 124

4. 2. 1 Theoretischer Ansatz: unkoordiniertes wiederholtes Spiel 125

4. 2. 2 Konjunkturpolitisch motivierte Wechselkurspolitik $\quad 129$

4. 2. 3 Stabilisierende Wechselkurspolitik 137

4. 3 Der Entscheidungsprozeß innerhalb der EWU 141

4. 4 Statt eines Abwertungswettlaufs ein Härtungswettbewerb? 145

4. 5 Auswirkungen auf andere Staaten 149 


\section{Internationale währungspolitische Kooperation in Zeiten}

5. 1 Regimewechsel im historischen Überblick 154

5. 1. 1 Einige Charakteristika der Regimewechsel 154

5. 1. 2 Hegemonie, ökonomische Dogmen und Regimebildung 157

5. 1. 3 Drei Phasen seit dem Ende des Zweiten Weltkriegs $\quad 158$

5. 2 Historische Währungssysteme als Vorbilder für die Zukunft? $\quad 165$

5. 2. 1 Das System von Bretton Woods 166

5. 2. 2 Das Europäische Währungssystem (EWS) 172

5. 2. 3 Die Weltwirtschaftsgipfel (G 7) 181

5. 3 Frühere Reformvorschläge im Lichte der Euro-Ära 185

5. 3. 1 Zielzonen für Wechselkurse 186

5. 3. 2 Ein Währungsstandard für die Industriestaaten $\quad 190$

5. 3. 3 Eine Steuer auf Devisentransaktionen 194

5. 4 Ein Sicherheitsnetz für die Euro-Ära 196

5. 4. 1 Fünf Forderungen an das Wechselkursmanagement 196

5. 4. 2 Spezieller Koordinierungsbedarf in der Euro-Ära $\quad 199$

5. 4. 3 Ein G 2-Mechanismus 200

5. 4. 4 Kann ein G 2-Mechanismus tatsächlich funktionieren?

6. Zusammenfassung und Ausblick: Zehn Lehren für die Währungspolitik

7. Literaturverzeichnis 
Henrik Müller - 978-3-631-75010-0

Downloaded from PubFactory at 01/11/2019 09:16:41AM

via free access 


\section{Verzeichnis der Abbildungen und Übersichten}

Abbildung 2-1 Nachfrageschock im Zwei-Länder-Fall (Anpassung der Angebotsseite)

Abbildung 2-2 Asymmetrische Wirkungen eines symmetrischen monetären Impulses

Abbildung 2-3 Asymmetrie im Vergleich USA und EU: Korrelationskoeffizienten des regionalen Output-Wachstums

Abbildung 2-4 Regionale Unterschiede in der EU: BIP pro Kopf

Abbildung 2-5 EU-Wechselkurspolitik bei alternativen

Wechselkursregimen

Übersicht 2-1 Stimmgewichte im Ministerrat

Übersicht 2-2 Assignment ausgewählter wirtschaftspolitischer Bereiche

Abbildung 2-6 Wohlstandsvergleich: die Beitrittskandidaten und die EU 66

Abbildung 2-7 Allokationseffekte der Osterweiterung im H-O-Setting

Abbildung 2-8 Die Osterweiterung als asymmetrischer Schock

Abbildung 3-1 Kerndaten des Eurolandes im internationalen Vergleich

Abbildung 3-2 Internationale Bedeutung der Währungen vor Beginn der Währungsunion

Abbildung 3-3 Die Bedeutung des Eurolandes als Handelspartner für ausgewählte Drittländer

Abbildung 3-4 Devisenmarkttransaktionen in der Prä-EWU-Ära

Abbildung 3-5 Finanzmärkte im internationalen Vergleich 
Übersicht 3-1 Wechselkursarrangements im geographischen Umfeld der EWU

Abbildung 3-7 Denominierungs-Mismatch bei Außenhandel und Auslandsverschuldung

Abbildung 3-8 Offenheit der EU-Staaten vor und nach dem Beitritt zur Währungsunion

Abbildung 3-9 Struktur der Extra-EU-Exporte

Abbildung 3-10 Relevanz des Dollar-Exports aus Sicht der EU-Staaten

Abbildung 3-11 Regionale Struktur des Außenhandels der Europäischen Union nach Staatengruppen

Abbildung 4-1 Die v-Kurve: kurzfristige Beschäftigungseffekte einer Abwertung der heimischen Währung

Abbildung 4-2 Optimale Abwertung aus Sicht der wirtschaftspolitischen Akteure

Abbildung 4-3 Auswirkungen unterschiedlicher wirtschaftspolitischer Präferenzen

Abbildung 4-4 Auwirkungen eines Inflationsziels auf die Wechselkurspolitik

Abbildung 4-5 Auswirkungen verminderter Reputation auf die Wechselkurspolitik

Abbildung 4-6 Wirkung struktureller Reformen des Arbeitsmarktes auf die v-Kurve

Abbildung 4-7 Ansteigende Welle: Wahltermine und Wechselkurspolitik

Abbildung 4-8 Die v-Kurve des Auslands: reale Außenwirkungen europäischer Wechselkurspolitik

Abbildung 4-9 Komplementäre wirtschaftspolitische Präferenzen im Zwei-Länder-Fall 
Abbildung 4-11 Wechselkurspolitisch induzierte

Beggar-thy-neighbour-Politik

Abbildung 4-12 Gegenläufige Konjunkturzyklen: idealtypische Konstellationen einiger makroökonomischer Größen

Übersicht 4-1 Arbeitslosigkeit und Inflation im Euroland

Abbildung 4-13 Sich überlagernde Politikzyklen: Wechselkurspolitik bei zwei Länder mit unterschiedlichen Wahlterminen

Abbildung 5-1 Hegemonie, Dogma und internationale Währungssysteme seit 1870

Abbildung 5-2 Reale Wechselkurse und der „Tequila-Effekt“

Abbildung 5-3 Leitkurse im Europäischen Währungssystem (1979-1993)

Übersicht 5-1 Schätzungen für US-Dollar KKP und FEER 
Henrik Müller - 978-3-631-75010-0

Downloaded from PubFactory at 01/11/2019 09:16:41AM

via free access 


\title{
Verzeichnis häufig verwendeter Symbole
}

\author{
* $\quad$ kennzeichnet Variablen/Parameter des Auslands \\ $U \quad$ Arbeitslosenquote \\ $U_{N} \quad$ natürliche Arbeitslosenquote \\ a Parameter (Lohndruck) \\ $p$ \\ Steigerungsrate des Preisindex für im Inland produzierte Güter \\ $p_{1} \quad$ Steigerungsrate des Konsumentenpreisindex \\ $p_{l}^{E} \quad$ Erwartungswert von $p_{l}$ \\ $\beta \quad$ Anteil inländischer Güter am Konsumgüterbündel \\ $e$ \\ nominaler Wechselkurs (Euro:Dollar) in Preisnotierung \\ $\hat{e} \quad$ Änderungsrate von e \\ $\hat{e}^{E} \quad$ Erwartungswert von $\hat{e}$ \\ $\eta \quad$ Zufallsvariable \\ $v \quad$ wechselkurspolitischer Aktionsparameter (politikinduzierte \\ Änderungsrate des realen Wechselkurses) \\ D Devisenbestand der Zentralbank \\ B monetäre Basis \\ $H \quad$ heimische Komponente von $B$ \\ $M \quad$ Geldmenge \\ $W($.$) \quad Präferenzfunktion der wirtschaftspolitischen Akteure$
}


$W_{0 \mid} v=0, v E$ Gegenwartswert zum Zeitpunkt $t=0$ künftiger Nettoauszahlungen (Differenz aus Nutzen und Kosten) unter der Bedingung, daß das Inland $v=0$ und das Ausland $v^{* E}$ spielt

$k$ durch nichtstaatliche Marktteilnehmer induzierte Abweichung des nominalen Wechselkurses von Kaufkraftparitätenkurs

$b$

Parameter, mit dem vergangene Beobachtungen von $k$ in die Erwartungsbildung eingehen

$c$

Parameter, mit dem vergangene Beobachtungen von $v$ in die Erwartungsbildung eingehen

Auslastungsgrad des Produktionspotentials

$R^{*}$ nichtwechselkurspolitische Retorsionen des Auslands auf eine wechselkurspolitische Maßnahme des Inlands

Zeitindex, Zeitpunkt

Ende des Zeithorizonts

$\delta$

Diskontfaktor

$G$

Benefits einer Abwertung unter der Bedingung, daß das Inland $v$ und das Ausland $v^{* E}$ spielt

C Kosten einer Abwertung unter der Bedingung, daß das Inland $v$ und das Ausland $v^{* E}$ spielt

Zinssatz, Nominalzins

$i_{R}$

realer Zins

$r$

Risikoprämie

$A$

Nettoausgaben des Staates

F

Staatseinnahmen

Schuldendienst des Staates 


\section{Verzeichnis häufig verwendeter Abkürzungen}

AKP Staaten der früheren afrikanischen Franc-Zone(Benin, Burkina Faso, Kamerun, Zentral-Afr. Rep., Tschad, Komoren, Rep. Kongo, Elfenbeinküste, Äquatorial-Guinea, Gabun, Mali, Niger, Senegal, Togo)

ASEAN Association of South East Asian Nations = Vereinigung südostasiatischer Nationen (Mitglieder 1999: Japan, Brunei, Indonesien, Malaysia, Philippinen, Singapur, Thailand, Vietnam)

BIP Bruttoinlandsprodukt

BIZ Bank für Internationalen Zahlungsausgleich

DIW Deutsches Institut für Wirtschaftsforschung

ECOFIN Ministerrat der Wirtschafts- und Finanzminister der EU-Staaten

EFTA European Free Trade Association = Europäische Freihandelszone (Mitglieder 1999: Schweiz, Norwegen, Island, Liechtenstein)

EG Europäische Gemeinschaft

EGV EG-Vertrag (,Maastricht-Vertrag“)

EU Europäische Union (EWU-11 plus Großbritannien, Schweden, Dänemark, Griechenland)

Euro-11 siehe EWU-11

ESZB Europäisches System der Zentralbanken

EWG Europäische Wirtschaftsgemeinschaft (Gründungsmitglieder: Frankreich, Deutschland, Italien, Belgien, Niederlande, Luxemburg)

EWI Europäisches Währungsinstitut

EWS Europäisches Währungssystem 
EWS II Währungssystem zwischen der Eurozone und den übrigen EULändern (Mitglieder 1999: Dänemark, Griechenland)

EWU Europäische Währungsunion

EWU-11 Gruppe der EWU-Teilnehmerstaaten (Mitglieder 1999:

Deutschland, Frankreich, Italien, Spanien, Niederlande, Belgien, Portugal, Österreich, Finnland, Irland, Luxemburg)

EZB Europäische Zentralbank

FSF Financial Stability Forum

GASP Gemeinsame Außen- und Sicherheitspolitik der EU

GUS Gemeinschaft Unahbängiger Staaten (Mitglieder 1999: Rußland, Ukraine, Weißrußland, Moldawien, Kasachstan, Tadschikistan, Turkmenistan, Usbekistan, Georgien, Aserbaichan, Armenien)

IW Institut der deutschen Wirtschaft

IWF Internationaler Währungsfonds

MERCOSUR Südamerikanische Freihandelszone (Brasilien, Argentinien, Chile, Uruguay, Paraguay)

MOEL Mittel- und Osteuropäische Länder (Polen, Ungarn, Tschechien, Slowakische Republik, Slowenien, Bulgarien, Rumänien, Lettland, Litauen, Estland)

NAFTA North American Free Trade Agreement = Nordamerikanisches Freihandelsabkommen (Mitglieder: USA, Kanada, Mexiko)

OECD Organisation for Economic Cooperation and Development = Organisation für wirtschaftliche Zusammenarbeit und Entwicklung (Mitgleder 1999: USA, Kanada, Großbritannien, Italien, Frankreich, Deutschland, Japan, Finnland, Österreich, Belgien, Niederlande, Luxemburg, Dänemark, Schweden, Irland, Portugal, Spanien, Griechenland, Norwegen, Schweiz, Island, Türkei, Neuseeland, Australien, Tschechien, Polen, Ungarn, Korea, Mexiko) 
OPEC Organisation of Petrol Exporting Countries = Organisation erdölexportierender Länder (Algerien, Indonesien, Iran, Irak, Kuwait, Libyen, Nigeria, Qatar, Saudi-Arabien, Vereinigte Arabische Emirate, Venezuela)

ROW Rest of the World = übrige Welt

StWP Stabilitäts- und Wachstumspakt

SZR Sonderziehungsrechte

TOW Theorie des optimalen Währungsraums 
Henrik Müller - 978-3-631-75010-0

Downloaded from PubFactory at 01/11/2019 09:16:41AM

via free access 


\section{Einleitung: Euroland in der Weltwirtschaft}

Kaum ein wirtschaftspolitisches Projekt hat die öffentliche Diskussion im vergangenen Jahrzehnt derart beschäftigt, und kaum eines war derart umstritten: Die Schaffung einer gemeinsamen europäischen Währung entzweite nicht nur die breite Öffentlichkeit, auch der wissenschaftliche Diskurs darüber war von tiefen Gräben durchzogen. Dabei drehte sich die Diskussion nahezu ausschließlich um binnenwirtschaftliche und binnenpolitische Fragestellungen. Zum Beispiel: Wie unabhängig wird die Europäische Zentralbank über den Geldwert wachen können? Oder wird es mit dem Euro eine Renaissance jener Makropolitik geben, die sich am Philippskurven-Trade-off orientiert? Sind die Arbeitsmärkte darauf eingerichtet, langfristig eine Stabilitätspolitik mitzutragen? Werden sich Wachstumseffekte durch den Euro ergeben? Welche Veränderungen in den Mustern von Handel, Direktinvestitionen und Arbeitskräftewanderungen entstehen, wenn zwischen den Ländern der Eurozone Wechselkursrisiken und Transaktionskosten weggefallen sind? Wie wird der neue Währungsraum auf ökonomische Schocks von innen und außen reagieren? Abhängig von den Antworten auf diese Fragen fiel das Urteil über die europäische Währung, über ihre Chancen und Risiken höchst unterschiedlich aus.

„Das wichtigste Ereignis der ganzen Nachkriegszeit”. Eine ganze Gruppe von Fragestellungen hat allerdings lange Zeit kaum eine Rolle gespielt: nämlich die Auswirkungen der neuen Währung auf den Rest der Welt. Dabei ist dies ein durchaus naheliegendes Thema: Indem sich in Europa der größte Wirtschaftsraum der Welt - die Europäische Union - auch monetär zusammengeschlossen hat, ergeben sich zwangsläufig nicht nur interne Folgen, sondern in einer hochgradig integrierten Weltwirtschaft auch ,erhebliche Auswirkungen nach außen” [Europäische Kommission 1997a: 3]. Die Einführung des Euro bedeutet deshalb „Zweifelsfrei einen tiefen Einschnitt im Weltwährungssystem", ja, vielleicht ist sie für die Weltwirtschaft sogar das wichtigste Ereignis "der ganzen Nachkriegszeit" [Issing 1996b: 5].

Bei der Analyse der Veränderungen, die der Euro im internationalen Währungs- und Wirtschaftssystem zeitigt, lassen sich drei Themenkomplexe unterscheiden:

Der Euro

- verändert die internationalen Märkte,

- schafft neue polit-ökonomische Anreize innerhalb und außerhalb der EU,

- beeinflußt das gesamte internationale Wirtschafts- und Währungssystem.

Auf dem Weg zur Weltwährung? Die Bedeutung der neuen Währung erweist sich zunächst auf den internationalen Geld-, Kapital- und Gütermärkten. Sie hängt 
damit zuvörderst von den Entscheidungen privater Akteure ab. Sehen die Privaten Vorteile in der Verwendung des Euro für internationale Transaktionen, für die Vermögensanlagen und die Kreditaufnahme, wird die neue Währung auf internationalem Parkett rasch eine recht bedeutende Rolle spielen. Falls sie ihr allerdings mit großer Skepsis begegnen, wird die Verwendung weitgehend auf die teilnehmenden Länder begrenzt bleiben. Daneben haben auch die Zentralbanken ein Wort darüber mitzureden, wie groß der Auftritt des Euro auf der internationalen Bühne ist, $d$. h. wie stark sie die neue Währung als Reservemedium in ihre Portfolios aufnehmen und ob sie den Euro als monetären Anker wählen.

Neue polit-ökonomische Anreize. Die Errichtung einer großen gemeinsamen Währung beeinflußt aber auch die Anreizstrukturen der wirtschaftspolitischen Entscheidungsträger in der Europäischen Union. Auf eine einfache Formel gebracht: Die Länder des Eurolandes ${ }^{1}$ werden vom Rest der Welt unabhängiger. Aus Sicht europäischer Politiker verlieren deshalb weltwirtschaftliche Beziehungen tendenziell an Bedeutung.

Wenn Intra-EU- zu Binnenhandel und Intra-EU-Kapitalströme zu Binnenströmen werden, nimmt die disziplinierende Wirkung der internationalen Kapitalmärkte ab. Insbesondere kann sich dies auf die Wechselkurspolitik des Eurolandes auswirken. Da der Euroraum eine weit weniger offene Volkswirtschaft ist als es die einzelnen EWU-Länder waren, schwächen sich die negativen Begleiterscheinungen von Abwertungen ab: Zum einen werden die inflationären Folgen bei einem kleineren Anteil des Außenbeitrags am BIP geringer ausfallen. Abwertungen des Euro dürften also nicht notwendigerweise der Stabilitätsorientierung der Europäischen Zentralbank zuwiderlaufen. Dadurch vermindert sich aus EurolandSicht auch die Gefahr, daß die Wettbewerbsvorteile einer nominalen Abwertung binnen kurzem durch Preissteigerungen real zunichte gemacht werden. Zum anderen dürften die resultierenden Zinssteigerungen geringer ausfallen. Dafür spricht auch die Tendenz, daß der Euroraum als zweiter großer Kapitalmarkt neben den USA auf Grund seiner Markttiefe verstärkt internationales Kapital anziehen dürfte [z. B. Seifert 1996: 222ff].

Ein pessimistisches Szenario. Angesichts dieser veränderten polit-ökonomischen Anreize kann es zu einer Kumulation binneneuropäischer Ansprüche kommen, die sich in Form einer protektionistischen Politik nach außen kehren. Dies sei in einem pessimistischen Szenario kurz und schlaglichtartig dargelegt:

Asymmetrische Schocks werden durch eine stärkere regionale Spezialisierung nach Wegfall der Wechselkurse wahrscheinlicher [Krugman 1991a]. Doch weder Wechselkurs- noch Zinspolitik stehen innerhalb des Euroraumes als Anpassungsinstrument zur Verfügung. Die Last verlagert sich auf andere Instrumente

1 Die Begriffe Europäische Währungsunion (EWU), Euroland, Eurozone, Euroraum werden in dieser Arbeit synonym benutzt. 
- auf die Fiskal- und Lohnpolitik, auf Transferszahlungen zwischen den EU-Staaten oder auf den Außenwert des Euro.

Die räumliche Divergenz der wirtschaftlichen Entwicklung könnte die bereits existierenden ökonomischen Zentren fördern, während periphere Gebiete zurïckbleiben. Solche polarisierenden regionalwirtschaftlichen Effekte können sich durch die Intensivierung des Binnenmarktes verstärken. Auch dies könnte zu einem dauerhaften Transferbedarf führen.

Die vollständige Integration der osteuropäischen Länder in die europäische Arbeitsteilung dürfte zu einem politisch induzierten asymmetrischen Schock führen [Vaubel 1996]. Denn der Beitritt dieser Staaten zur Europäischen Union wird auch im Westen des Kontinents zu einigen Verwerfungen führen. Gerade für die strukturschwächeren Regionen der heutigen EU, zuvörderst für die Mittelmeerländer, verschärft sich der Wettbewerbsdruck bei relativ arbeitsintensiven Gütern. Die neuen Konkurrenten aus den beitretenden Staaten verfügen zudem über einen wichtigen Wettbewerbsvorteil: Sie haben noch ihre nationalen Währungen, die gegenüber dem Euro relativ schwach bewertet sind, während die EU-Staaten mit unterdurchschnittlichem BIP pro Kopf auf Basis eines nach außen relativ starken Euro wirtschaften.

Die Politische Union bleibt rudimentär. Die anstehenden Probleme und der steigende Bedarf an Transferzahlungen legen die politischen Defizite der EU offen. Die Politische Union, die eigentlich schon 1992 in Maastricht verwirklicht werden sollte, ist auch 1997 in Amsterdam nicht entstanden. Eine in dieser Situation eigentlich notwendige effiziente Umverteilung unter den EU-Staaten [Sala-iMartin/Sachs 1992] scheitert an einer zu schwachen zentralen Ebene. Insbesondere bleibt dem Parlament das Recht einer effektiven Haushaltskontrolle verwehrt [Peffekoven 1994: 15ff]. Ohne diese Kontrollfunktion dürften die Länder, die sich in einer Nettozahlerposition befinden, voran die Bundesrepublik, aber nicht bereit sein, eine Ausweitung der Transfers zu finanzieren.

Binnenwirtschaftliche Reformen bleiben stecken. Vor allem die großen kontinentalen EU-Staaten Deutschland, Frankreich, Italien und Spanien sind unfähig, ihre Wirtschaftspolitik dem veränderten weltwirtschaften Umfeld anzupassen. Obwohl durch die Integration Osteuropas, Rußlands, Chinas oder Indiens das Arbeitsangebot und die Kapitalnachfrage weltweit dramatisch zunehmen, kommt es weder zur gebotenen Liberalisierung der Arbeitsmärkte noch zu einschneidenden Reformen der sozialen Sicherungssysteme. Bei anhaltend hoher Arbeitslosigkeit könnten nationale Politiker versucht sein, einen Teil des innenpolitischen Drucks auf die internationale Ebene weiterzugeben und eine aggressive Handelspolitik zu betreiben.

Kommt es zu solchen negativen Effekten, dürften die betroffenen Länder (und Branchen) Linderung durch eine Abwertung des Euro gegenüber Dollar und Yen suchen. Auch wenn bei sonst unveränderten Fundamentaldaten Abwertungen nicht von Dauer sein können, so besteht doch für die im Ministerrat versammelten 
Regierungen ständig die Versuchung, sich auf diese Weise immer wieder kurzfristige Wettbewerbsvorteile auf den Weltmärkten zu verschaffen. Die weltwirtschaftlichen Folgen wären erstens eine erhöhte Wechselkursvolatilität, zweitens mögliche protektionistische Gegenmaßnahmen anderer Wirtschaftsgroßmächte (insbesondere der USA), drittens verschlechterte Entwicklungsbedingungen für kleinere Länder außerhalb der Wirtschaftsblöcke. Mittelbar könnte somit die Europäische Währungsunion zu einer Erosion des multilateralen Welthandelssystens führen.

Das Euroland könnte also seine ungelösten wirtschaftspolitischen Konflikte auf die internationale Bühne tragen. Und auch dort verändert die Einführung des Euro einiges: Indem neben den Dollar eine zweite große internationale Währung tritt, ändern sich in der Weltwährungspolitik - und, allgemeiner, in der Weltwirtschaftspolitik - die Spielregeln. Damit steigt das Risiko politischer Konflikte zwischen den großen Blöcken. Die multilateralen Elemente der Weltwirtschaftsordnung drohen in einem solchen pessimistischen Szenario weiter geschwächt zu werden. Eine Erwartung, die regelmäßig mit der Währungsunion verbunden wird, ist die Abnahme der Wechselkursvolatilität [z. B. Europäische Kommission 1997a: 14]. Dagegen stehen jedoch die oben schlaglichtartig aufgeführten politökonomischen Faktoren.

Optimistisches Szenario. Allerdings folgt eine solche Kumulation binnenwirtschaftlicher und -politischer Spannungen keineswegs einem Naturgesetz. Dies sei an Hand des folgenden optimistischen Gegenszenarios skizziert:

Die räumliche Konvergenz der wirtschaftlichen Entwicklung macht deutliche Fortschritte. Die strukturschwächeren Regionen profitieren von Direktinvestitionen aus den Ländern mit hohem Pro-Kopf-Einkommen. Das mit diesen Investitionen verbundene Humankapital führt am Zielort zu positiven externen Effekten („Spillovers”) und erhöht so, gemäß Neuer Wachstumstheorie, dauerhaft die regionalen Wachstumraten in unterdurchschnittlich entwickelten Gebieten [z. B. Wagner 1995b: 85ff].

Eine dauerhafte makroökonomische Stabilisierung gemäß Maastricht-Vertrag und „Stabilitäts- und Wachstumspakt” sowie der Wegfall des Inner-EUWechselkursrisikos führen zu dauerhaft niedrigen Zinsen. Denn die Staaten beanspruchen nun die Kapitalmärkte weniger als in der Vergangenheit (geringeres „Crowding out"), und in den traditionellen Hochinflationsländern sinkt dauerhaft die Risikoprämie auf den Zins. Beide Effekte stimulieren die Investitionen und damit das gesamtwirtschaftliche Wachstum.

Eine allmähliche Integration der osteuropäischen Länder in den Europäischen Binnenmarkt ermöglicht eine Anpassung auf allen Seiten. Der oben skizzierte Schock mit seinen asymmetrischen Wirkungen bleibt aus.

Asymmetrische Schocks spielen weniger auf nationaler Ebene eine Rolle, sondern wirken vielmehr regional oder auf bestimmte Branchen. Dort treffen sie auf eine relativ hohe Mobilität der Bevölkerung [Gros 1996b]. Entgegen der lan- 
gen Debatte über die Relevanz derartiger Schocks stellt ihre Absorbtion weniger ein europäisches als vielmehr ein nationales Problem dar, im Sinne des Subsidiaritätsprinzips sind dafür die betroffenen Mitgliedstaaten zuständig. Der Bedarf an EU-weiten Transferzahlungen bleibt folglich gering.

Die wirtschaftspolitischen Anforderungen an die EU-Ebene bleiben begrenzt - dank makroökonomischer Stabilisierung, realwirtschaftlicher Konvergenz und allenfalls begrenztem Auftreten asymmetrischer Schocks. Zugleich wird die politische Kooperation durch ihre zunehmende Dauer erleichtert: Die Akteure gewinnen Vertrauen zueinander, individuell empfundene Unsicherheit nimmt ab [Keohane 1989]. Unkooperative Partner werden durch die Mehrheit bestraft, was im Sinne einer „Tit-for-tat"-Strategie in einem unendlich häufig wiederholten Spiel langfristig kooperatives Verhalten fördert [Axelrod 1984]. Dadurch kommt es zu einer allmählichen Fortentwicklung der politischen Strukturen der Europäischen Union.

Binnenwirtschaftliche Reformen kommen voran. Im Sinne eines Hayek'schen Entdeckungsverfahrens führt der verstärkte institutionelle Wettbewerb innerhalb der Europäischen Union zu einer Liberalisierung der Arbeitsmärkte, zu effizienteren Systemen der sozialen Sicherung und der Besteuerung. Die Arbeitslosigkeit geht deutlich zurück.

Ein solches optimistisches binneneuropäisches Szenario hätte auch günstige Auswirkungen auf den Rest der Welt. Die Währungsunion würde eine Phase der wirtschaftlichen und politischen Gesundung im Innern einleiten, die nach außen Raum für eine kooperative Politik bietet. Die Chancen stünden gut, zu neuen Formen der internationalen Kooperation zu kommen, denn durch die verminderte Zahl der Mitspieler auf der internationalen Bühne wird die währungspolitische Koordinierung prinzipiell erheblich erleichtert. Insofern bietet der Euro Chancen, das internationale Währungssystem zu stabilisieren.

Auf der Suche nach institutionellen Notbremsen. Die Argumentation dieser Einleitung ist selbstverständlich verkürzt und vertraut allzu sehr der Intuition. Dieser Aufriß verfolgt lediglich das Ziel, den Themenkomplex „Wechselkurspolitik des Eurolandes" in einer kurzen Gesamtschau darzustellen.

Diese Arbeit legt das Hauptaugenmerk auf das Konfliktpotential, das die EWU birgt, und sie sucht nach Notbremsen, um diese Konflikte unter Kontrolle zu halten. Sie gliedert sich wie folgt: Kapitel 2 untersucht den institutionellen Rahmen der Währungsunion vor dem Hintergrund der ökonomischen Herausforderungen.

Kapitel 3 analysiert, inwieweit die diszplinierenden Wirkungen seitens der Märkte aus Sicht der Regierungen der EWU-Staaten nachlassen. Dazu werden die Rolle des Euro als internationale Währung und die Struktur des Außenhandels der EWU-Staaten beleuchtet. Insbesondere geht es darum $\mathrm{zu}$ untersuchen, welche neuen Anreize sich für die politischen Entscheidungsträger in Europa ergeben. Insbesondere wird die Frage gestellt, ob eine Abwertungsstrategie unter den $\mathrm{Be}$ - 
dingungen der Währungsunion weniger negative Folgen zeitigt als unter den Bedingungen der Währungsvielfalt.

In Kapitel 4 wird ein formales Modell entwickelt, das darstellt, wie sich binneneuropäische Konflikte auf die internationale Ebene verlagern können. Kapitel 5 greift dieses Szenario eines „Währungskrieges” auf und untersucht, welche Bedingungen eine internationale Währungsordnung erfüllen muß, um die binneneuropäischen Anreize für eine aggressive Währungspolitik zu eliminieren. 


\section{Zum institutionellen Rahmen der Europäischen Währungsunion}

Am 7. Februar des Jahres 1992 unterschrieben im niederländischen Maastricht die Regierungen der damals zwölf Mitgliedsstaaten der Europäischen Gemeinschaft (EG) den „Vertrag über die Europäische Union (EU)”. Damit wollten sie „eine neue Stufe bei der Verwirklichung einer immer engeren Union der Völker Europas" erreichen, wie es in Artikel A heißt. Die Europäische Gemeinschaft, gewissermaßen das Binnenmarktprogramm der Mitgliedsländer, wollten sie in eine Politische Union einbetten.

Dies gelang allerdings in Maastricht und auch im 1997 folgenden Vertrag von Amsterdam nur ansatzweise. Wichtige Politikbereiche blieben nationaler Hoheit unterstellt, der europäischen Ebene wiesen die Mitgliedsstaaten allenfalls eine verstärkte Koordinierungsfunktion zu, die aber teilweise äußerst schwach blieb. Die Europäische Union stellt sich damit als „Mischsystem” dar [Weidenfeld/Jung 1994: 14]. Teils ist sie als Verbund aus souveränen Nationalstaaten organisiert, teils als auf Einheitlichkeit bedachter Bundesstaat. Einige Politikbereiche sind vergemeinschaftet, hier überwiegen supranationale Elemente; dies gilt insbesondere für jene Fragen, die in engem Zusammenhang mit dem Binnenmarkt stehen. In anderen Bereichen überwiegen intergouvernementale Prozeduren, insbesondere in den beiden in Maastricht neu hinzugekommenen „Säulen” der EU, der Gemeinsamen Außen- und Sicherheitspolitik (GASP) sowie der Innen- und Justizpolitik, aber auch in der Wirtschaftspolitik. So geht auch das Maastricht-Urteil des Bundesverfassungsgerichts von 1993 davon aus, daß es sich bei der Europäischen Union nicht um einen Bundesstaat oder eine eigene Staatlichkeit handelt, sondern nach wie vor um einen „Staatenverbund”. ${ }^{2}$

Während die Entscheidungsverfahren und Zuständigkeiten der verschiedenen Ebenen und Institutionen der EU vielfältig, kompliziert und intransparent gestaltet wurden, setzte der Vertrag von Maastricht auf einem Gebiet einen Meilenstein. Im Teil VI des Vertrags sowie in den einschlägigen Protokollen unterwarfen sich die Mitgliedstaaten einem ehrgeizigen Programm: Sie beschlossen, eine Europäische Wirtschafts- und Währungsunion zu schaffen (im folgenden kurz EWU genannt), indem sie

- einen eng definierten Zeitplan verbunden mit einem Integrationsprogramm festlegten, ${ }^{3}$

- differenzierte Integrationsgeschwindigkeiten festlegten, ein Ansatz, der es ermöglichte, daß nicht alle Mitgliedsländer von Anfang an der

2 Eine verfassungsrechtliche Analyse des Urteils findet sich bei Weber (1994).

3 Insbesondere EGV Art. 109j Abs. 3, 4, Art. 109e und Art. 109j. 
dritten Stufe der Währungsunion teilnehmen dürften oder müßten, sondern nur diejenigen, die die Konvergenzkriterien erfüllen bzw. die keine Sonderregelung (,Opting out”) vereinbart hatten, ${ }^{4}$

- neue Institutionen schufen, nämlich die Europäische Zentralbank (EZB) im System Europäischer Zentralbanken (ESZB) und als deren Vorläufer das Europäische Währungsinstitut (EWI). ${ }^{5}$

In den Jahren nach 1992 entwickelte die EU diesen institutionellen Rahmen weiter. Bedeutsam sind hier insbesondere zwei Regelungen: der Stabilitäts- und Wachstumspakt sowie die Anbindung der zunächst nichtteilnehmenden EU-Währungen an den Euro (EWS II). Für beide Verordnungen faßte der Europäische Rat von Amsterdam im Juni 1997 entsprechende Entschließungen [Europäischer Rat 1997a: 16ff].

Während die EU den binneneuropäischen Rahmen der EWU ausbaute und bestrebt war, Lücken zu schließen, fanden diese Bemühungen keine Entsprechung auf einem anderen wichtigen Gebiet: der Währungspolitik gegenüber Ländern außerhalb der EU. Hier gelten lediglich die einschlägigen Bestimmungen des Maastricht-Vertrags. ${ }^{6}$

Bevor die Kapitel 3 bis 5 die Stellung des Euro im internationalen Währungssystem näher analysieren, scheint es ratsam, zunächst die Ratio des EWUDesigns, insbesondere die Zuständigkeiten für die verschiedenen Bereiche der Wirtschafts- und Währungspolitik und die daraus potentiell erwachsenden Konflikte näher zu beleuchten.

\section{1 Ziele, Probleme und Grundkonzeption der EWU}

Grundlegendes ökonomisches Ziel der EWU ist die Vollendung des Europäischen Binnenmarktes. Indem ein einheitlicher Währungsraum geschaffen wird, sollen die „vier Freiheiten” der EU-Bürger - freier grenzüberschreitender Verkehr von Waren, Dienstleistungen, Kapital und Bürgern - gestärkt werden. Die prinzipielle Begründung dafür sei im folgenden kurz erläutert. ${ }^{7}$

4 Dies gilt für Großbritannien und Dänemark, die vereinbarten, daß ihre Länder nicht der Automatik des Maastricht-Vertrags unterliegen sollten, sondern sich eine gesonderte nationale politische Entscheidung für den Beitritt zur EWU vorbehielten.

5 Insbesondere EGV Art.105, 106, 107, 108a sowie das Protokoll über die Satzung des ESZB und der EZB.

6 Insbesondere EGV Art. 109.

7 Es handelt sich hierbei um Standardargumente [z. B. de Grauwe 1997a: 52ff, Wagner 1995b: 29ff, Willms 1992: 186ff]. 


\section{1. 1 Ökonomische Vorteile einer Währungsunion}

Die Existenz unterschiedlicher Währungen baut in einem Binnenmarkt Hürden auf, es entstehen damit verbundene Transaktionskosten. Der Umtausch ebenso wie Kurssicherungsgeschäfte, die bei Unsicherheit über künftige Schwankungen der Wechselkurse nötig werden, verursachen Kosten. Dazu kommt eine geringere Preistransparenz, die eine Preisdiskrimminierung auf den Gütermärkten zwischen den EU-Ländern möglich macht. Die Folge ist eine - vermeidbare - Segmentierung der Märkte, insbesondere für Kapital und handelbare Güter. Obwohl im Binnenmarkt keine Zollschranken mehr existieren und Produktstandards weitgehend vereinheitlicht sind, ergibt sich eine suboptimale Allokation der Güter und Faktoren.

Die Beseitigung der Währungsvielfalt läßt die damit verbundenen Transaktionskosten verschwinden. Die ökonomischen Vorteile einer Währungsunion ergeben sich folglich aus einer erhöhten Effizienz. Dies gilt zunächst in einem statischen Sinne, analog etwa einer Zollsenkung im neoklassischen Heckscher-OhlinAußenhandelsmodell.

Daneben ist auch eine Steigerung der dynamischen Effizienz zu erwarten. Führt zum Beispiel die Schaffung eines einheitlichen Währungsraumes zu einem langfristig niedrigeren Zinsniveau, ${ }^{8}$ so dürfte dies die Investitionen anregen. Im Investitionsprozeß kann es wiederum zur Produktion von zusätzlichem Wissen kommen, das teilweise den Charakter eines öffentlichen Gutes besitzt und somit, gemäß Neuer Wachstumstheorie, über die investierenden Unternehmen hinaus diffundiert.

Der Wegfall währungsbedingter Transaktionskosten könnte somit einen Prozeß des endogenen technischen Fortschritts in Gang setzen, der zu einer dauerhaften Erhöhung der Wachstumsraten fuihrt. Ähnliche expansive Sekundäreffekte können regional auftreten, falls es zu zusätzlichen Direktinvestitionen kommt: Mit dem physischen Kapital fließt Humankapital ins Empfängerland, das wiederum positive externe Effekte und somit einen endogenen Wachstumsprozeß auslöst.

\section{1. 2 Ökonomische Nachteile einer Währungsunion}

Den ökonomischen Vorteilen einer Währungsunion stehen ökonomische Nachteile gegenüber. Sie werden insbesondere im Rahmen der Theorie des optimalen

8 Hierfür gibt es verschiedene Begründungen: a) Das Wechselkursrisiko entfällt und senkt somit die im Zins enthaltene Risikoprämie. b) Länder mit einem zweifelhaften „Track record” profitieren vom Glaubwürdigkeitsbonus der mit ihnen in die Währungsunion eintretenden Länder mit längerer Stabilitätstradition. Auch dies senkt die Risikoprämie. c) Ein verglichen mit den früheren nationalen Kapitalmärkten größerer Währungsraum fördert den Wettbewerb und senkt damit den „Preis” für Kapital, eben den realen Zins. d) Der größere Währungsraum zieht internationales Kapital an, was wiederum zinssenkend wirkt (siehe unten 3. 1). 
Währungsraumes (TOW) diskutiert. Die TOW stellt die Kosten in den Vordergrund, die damit verbunden sind, daß die teilnehmenden Länder auf zwei wirtschaftspolitische Instrumente verzichten: Weder die Geld- noch die Wechselkurspolitik stehen den nationalen Behörden noch zur Verfügung, um Schocks abzufedern oder unterschiedliche Wachstumsraten zwischen miteinander handeltreibenden Ländern auszugleichen. Die Anpassungslasten müssen nun andere Instrumente auffangen: hinreichend flexible Löhne und Preise, die automatischen Stabilisatoren der nationalstaatlichen Budgets oder Transferzahlungen zwischen den Teilnehmerländern. Die Entscheidungsregel der TOW lautet: Für ein Land ist es vorteilhaft einer Währungsunion beizutreten, wenn die Kosten des Verlusts an Souveränität über die Geld- und Wechselkurspolitik geringer sind als die mit den verminderten Transaktionskosten verbundenen Gewinne.

Entsprechend formuliert die TOW Kriterien für die Auswahl der Teilnehmerländer: Sie sollen eine möglichst homogene Gruppe darstellen, gemessen an realen Konvergenzkriterien wie BIP pro Kopf, Konjunkturverläufen, Arbeitsmarktstrukturen und -institutionen, wechselseitigen Handelsverflechtungen, Migrationsverhalten, Präferenzen bezüglich Inflation, Größe und Struktur des öffentlichen Sektors und so weiter [z. B. Bayoumi/Eichengreen 1996, DIW 1996, Schmidt/Straubhaar 1995]. Unter diesen Bedingungen ermöglichen die Märkte eine Abfederung asymmetrischer Schocks, andernfalls müssen staatliche Ausgleichsmechanismen (etwa interregionale Transferzahlungen durch ein zentralisiertes Staatsbudget) greifen. ${ }^{9}$ Dies sind die klassischen Faktoren, die die Theorie der optimalen Währungsräume benennt [Mundell 1961, McKinnon 1963, Kenen 1969].

Asymmetrische Schocks. Über die Relevanz asymmetrischer und asymmetrisch wirkender symmetrischer Schocks in der EWU ist in den vergangenen Jahren viel geforscht und spekuliert worden. Ausgangspunkt der TOW ist die Anpassung der in einer Währungsunion vereinten Volkswirtschaften an eine abrupten Veränderung exogener Variablen. Das Ursprungsmodell von Mundell (1961) geht in einem keynesianischen Setting von einer plötzlichen Verschiebung der Konsumentenpräferenzen aus: Statt den in Land A produzierten Gütern, ziehen die Verbraucher nun Güter aus Land B vor. Die Nachfragekurve nach Gütern aus Land $\mathrm{A}\left(D_{A}\right)$ in Abbildung 2-1 verschiebt sich nach links, die Nachfragekurve nach Gütern aus Land B $\left(D_{B}\right)$ verschiebt sich nach rechts. ${ }^{10}$ In einer Situation mit

9 Das traditionelle Argument lautet, es sei einfacher, einen einzigen Preis - den nominalen Wechselkurs - anzupassen als das gesamte Preis- und Lohngefüge einer Volkswirtschaft; die Wechselkursanpassung ist somit effizienter.

10 Es handelt sich hierbei um ein simples makroökonomisches Partialmodell des Gütermarktes. Jedes Land produziert ein Güterbündel. Bei steigendem Preis $P_{A}$ bzw. $P_{B}$ steigern die Produzenten im jeweiligen Land ihre produzierte Gütermenge $Y_{A}$ und $Y_{B}$ (steigende Angebotskurven $S_{A}$ und $S_{B}$ ) und vermindern die Konsumenten ihre Nachfrage (fallende Nachfragekurven $D_{A}$ und $D_{B}$ ). Unterstellt wird, daß andere Preise, insbesondere die Löhne, 
flexiblen oder fixierten, aber veränderbaren Wechselkursen könnte eine Abwertung der Währung A`s gegenüber B`s die Handelsbilanzen der beiden Länder ausgleichen.

Innerhalb einer Währungsunion ist dies nicht möglich: Die Handelsbilanz von Land A weist einen negativen Saldo auf. Es werden weniger Güter produziert, die Auslastung des Produktionspotentials und die Arbeitsmarktsituation verschlechtern sich, deflationiäre Tendenzen greifen Raum. Dadurch wirken die automatischen Stabilisatoren der öffentlichen Budgets, insbesondere durch Zahlung von Arbeitslosenunterstützung, so daß A's Budgetdefizit ansteigt. Umgekehrt die Situation in Land B: Dort herrscht ein Handelsbilanzüberschuß. Eine stärkere Auslastung des Produktionspotentials und eine verbesserte Arbeitsmarktsitutation sorgen für inflationäre Tendenzen und eine verbesserte Budgetsituation in Land B.

Abbildung 2-1: Nachfrageschock im Zwei-Länder-Fall
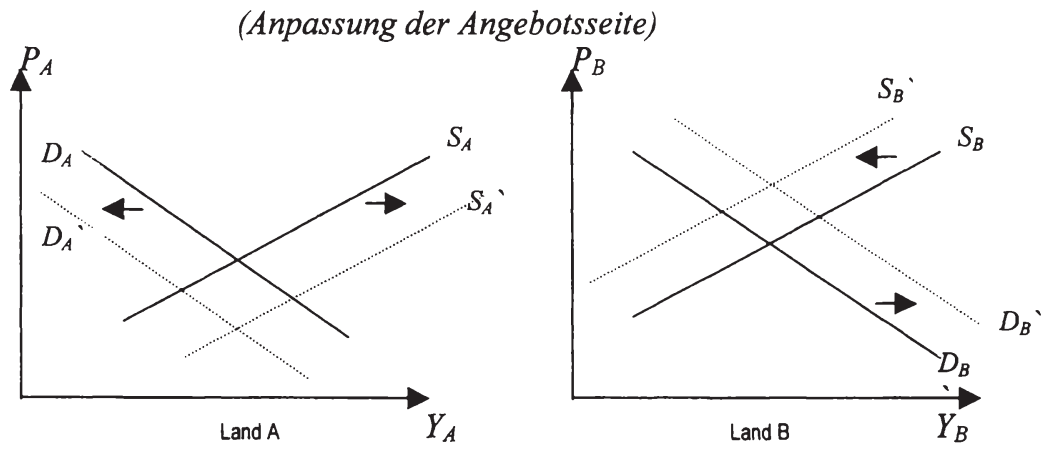

Absorbtion durch Lohnanpassung. Abbildung 2-1 zeigt, wie die Absorbtion dieses Nachfrageschocks ablaufen kann. Dies ist Sache der Arbeitsmärkte. Die größere Arbeitsnachfrage in Land B führt zu steigenden Löhnen, wodurch die Kosten steigen und sich die Wettbewerbssituation der Unternehmen in Land B verschlechtert, graphisch drückt sich das in einer Linksverschiebung der Angebotskurve $S_{B}$ aus. Spiegelbildlich sinken die Löhne in Land A infolge eines Überschußangebots auf dem Arbeitsmarkt. Die günstigere Kostensituation erhöht die Wettbewerbsfähigkeit der Produzenten in Land A, die Angebotskurve $S_{A}$ verschiebt sich folglich nach rechts. Voraussetzung für diesen Anpassungsproze $\beta$ sind allerdings flexible Geldlohnsätze, was in der Realität nicht unbedingt der Fall

zunächst nicht reagieren [Mundell 1961, siehe auch z. B. Willms 1992: 179ff, de Grauwe 1997a: 5ff]. 
sein dürfte, insbesondere nach unten treten Starrheiten auf. Angesichts derartiger Unvollkommenheiten auf dem Arbeitsmarkt kommt es zu Arbeitslosigkeit.

Absorbtion durch Migration. Scheitert die Lohnanpassung an den institutionellen Gegebenheiten des Arbeitsmarktes, liegt eine alternative Option zur Absorbtion eines asymmetrischen Schocks in der Wanderung von Arbeitskräften von Land A nach Land B. Dies ist jedoch mit hohen individuellen und sozialen Kosten verbunden. Insbesondere können Entleerungstendenzen der betroffenen ökonomischen Räume auftreten, die eine Spirale der ökonomischen Abwärtsentwicklung einleiten [Myrdal 1958], insbesondere durch die Abwanderung von Nachfrage [Gros 1996b: 17f], die den Nachfrageschock sogar noch verstärkt statt abfedert. Die Abwanderung von Faktoren - Arbeit, Humankapital - kann sich negativ auf die längerfristigen Wachstumschancen auswirken. Deshalb wird im Falle des Auftretens asymmetrischer Schocks häufig unterstellt, eine Anpassung eines einzigen Preises - des nominalen Wechselkurses - sei einfacher und effizienter als die Anpassung aller Preise, insbesondere aller Lohnsätze.

Absorbtion durch fiskalische Transfers. Gegenüber asymmetrischen Nachfrageschocks, die kurzfristig wirken, sind auch fiskalische Maßnahmen möglich. Ein expliziter intraregionaler Umverteilungsmechanismus wie der deutsche Finanzausgleich zwischen Bund und Ländern sowie unter den Ländern kann in diesem Fall helfen, indem er Überschußnachfrage aus den positiv betroffenen Regionen über Steuern oder Sozialbeiträge abschöpft und diese Gelder dafür verwendet, zusätzliche staatliche Nachfrage in die negativ betroffenen Regionen zu transferieren [de Grauwe 1997a: 9f]. Auch ein gemeinsames Abgabensystem kann ähnliche Lösung zeitigen. Sofern die Staatseinnahmen in ein großes, zentralisiertes Budget fließen und von hier aus in die Regionen rücktransferiert werden, geschieht eine implizite Umverteilung: Boomende Regionen mit hohem Pro-KopfEinkommen zahlen hohe Einkommensteuer, lahmende mit geringer Steuerbasis zahlen relativ wenig Einkommensteuer, bekommen aber Leistungen aus dem Zentralbudget, etwa in Form von Arbeitslosenunterstützung wie in den USA [Inman/Rubinfeld 1991, Sala-i-Martin/Sachs 1992]. Zu beachten ist: Das Handelsbilanzdefizit von Land $A$ ändert sich nicht, es wird aber aus den Überschüssen von Land B via Transfers finanziert.

Politikinduzierte Schocks. Das staatliche Budget spielt nicht nur bei der Abfederung von Schocks eine Rolle, sondern auch bei ihrer Entstehung. Möglicherweise sind asymmetrisch wirkende Nachfrageschocks häufig gar kein marktmäßiges Phänomen, sondern ein politikinduziertes, verursacht durch einen zwischen den Nationalstaaten differierenden Policy Mix [Gros 1996b: 3f] ${ }^{11}$

11 In diesem Fall ist es also nicht ein plötzlicher, exogener Geschmackswandel der Konsumenten, der in Abbildung 2-1 die Nachfragekurven $D_{B}$ nach rechts und $D_{A}$ nach links erschiebt, sondern eine schuldenfinanzierte Staatsausgabenerhöhung. Dies erscheint im übrigen eine plausiblere Erklärung für ein derartiges Phänomen zu sein. Schließlich dürfte ein Geschmackswandel sich kaum auf alle in einem Land produzierten Produkte beziehen (außer im Fall eines Embargos). 
Ein prominentes Beispiel dafür ist die deutsche Einheit [IWF 1997: 62]. Die großzügige Ausstattung der damaligen DDR-Bürger mit West-Mark im Tauschverhältnis $1 \mathrm{zu} 1 \mathrm{bzw} .1 \mathrm{zu} 2$ gegen Ost-Mark sorgte für eine schlagartige Zunahme der realen Vermögensbestände, was in aller Regel expansiv auf die Konsumnachfrage der privaten Haushalte wirkt („Pigou-Effekt”). Zugleich sorgten im Zuge der staatlichen Vereinigung rasch anschwellende Transferzahlungen aus den alten Bundesländern für einen kräftigen staatlichen Nachfragestimulus, verbunden mit inflationären Spannungen, die die Bundesbank zu einer Steigerung der Leitzinsen veranlaßten. Die deutsche Einheit ,[...] changed the mix of monetary and fiscal policies in Europe" [IWF 1997: 62] - die Fiskalpolitik schaltete von kontraktiv auf expansiv um, die Geldpolitik von expansiv auf kontraktiv. ${ }^{12}$

Die reale Wirkung asymmetrischer Nachfragesschocks wird in der Regel recht kurz eingeschätzt [IWF 1997: 62]. Dies dürfte gerade - siehe deutsche Einheit - bei fiskalisch induzierten Effekten der Fall sein: Eine defizitfinanzierte Expansion zieht in Folgeperioden eine kontraktive Fiskalpolitik nach sich, ${ }^{13}$ weil die kumulierte Staatsschuld intertemporal den budgetären Bewegungsspielraum einengt. Zwangsläufig sind steigende Steuern und/oder eine sinkende Staatsausgabenquote die Folge.

Asymmetrische Wirkungen symmetrischer Schocks. Ein sychronisierter Konjunkturverlauf, wie er typischerweise zwischen engverflochtenen Volkswirtschaften bei koordinierter Wirtschaftspolitik zu beobachten ist, sorgt für (positive oder negative) symmetrische Nachfrageschocks. Ein konjunktureller Einbruch der gesamtwirtschaftlichen Nachfrage erfaßt alle Länder zugleich, gleiches gilt für einen Boom. Sie stellen prinzipiell kein Hindernis für das Funktionieren einer Währungsunion dar. Allerdings kann es auch hierbei zu asymmetrischen Wirkungen symmetrischer Impulse kommen. Dies kann zum Beispiel beim Transmissionsmechanismus der Geldpolitik der Fall sein, wenn eine Leitzinsänderung der vereinigten Zentralbank in den beteiligten Ländern unterschiedlich durchschlägt. Wo, wie in Großbritannien, relativ kurze Finanzierungslaufzeiten vorherrschen,

Vielmehr ist der heutige internationale Handel zuvörderst intraindustrieller Natur, gehandelt werden ähnliche Produkte, deshalb sind eher sektorale als regionale oder gar nationale Effekte zu erwarten (siehe unten).

12 Als ein anderer staatlich induzierter Nachfrageschock kann auch die Abwertung des Pfund Sterling infolge des britischen Ausstiegs aus dem EWS 1992 gewertet werden, die, entgegen dem damaligen europäischen Trend, in Großbritannien zu einer vorzeitigen konjunkturellen Erholung führte.

13 Die Hoffnungen auf einen von Anhängern der keynesianischen Theorie häufig vorhergesagten Selbstfinanzierungseffekt von Konjunkturprogrammen haben sich realiter nicht erfüllt. Dazu dürfte es bestenfalls bei stark rezessionären Situationen kommen, in denen ein staatlicher Nachfrageimpuls extrem pessimistische Ertragserwartungen der Unternehmen („Investitionsfalle") aufzuhellen vermag und dadurch einen expansiven Multiplikatoreffekt in Gang setzt, der wiederum in Folgeperioden höhere Steuereinnahmen induziert. 
wirken sich Leitzinsänderungen unmittelbarer aus als in Ländern, in denen relativ lange Laufzeiten die Regel sind. Entsprechend unterschiedlich sind die Wirkungen der Geldpolitik.

In Abbildung 2-2 sind Zins ( $i$ ) und Kreditvolumen der Geschäftsbanken $(K)$ für zwei Länder A und B abgetragen. A's Publikum bevorzugt langfristige Finanzierungen, was sich in einer relativ zinsunelastischen Kreditnachfragekurve $\left(K D_{A}\right)$ niederschlägt, B`s Publikum hingegen finanziert Investitionen eher kurzfristig, woraus eine höhere Zinselastizität der Kreditnachfrage $\left(K D_{B}\right)$ resultiert. Verbessert nun die Zentralbank die Refinanzierungsbedingungen der Geschäftsbanken, typischerweise durch eine Senkung des Zinssatzes für Wertpapierpensionsgeschäfte (Repo-Satz), kommt es zu einer Ausweitung des Kreditangebots, $K S_{A}$ bzw. $K S_{B}$ verschieben sich nach rechts. Obwohl bei perfekter Kapitalmobilität $i_{A}=$ $i_{B}$ gelten muß, weicht das Volumen in beiden Ländern wegen der unterschiedlichen Strukturen auf dem Kapitalmarkt voneinander ab: In B wirkt der - symmetrische - expansive Impuls deutlich stärker $\left(\Delta K_{A}<\Delta K_{B}\right)$.

Abbildung 2-2: Asymmetrische Wirkungen eines symmetrischen monetären Impulses
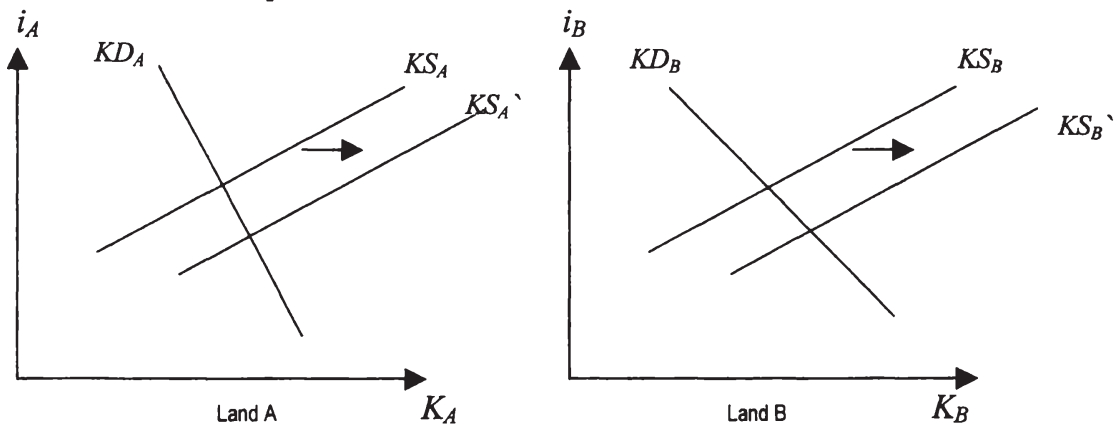

Angebotsschocks. Neben Nachfrageschocks können auch auf der Angebotsseite abrupte, exogene Veränderungen auftreten, so zum Beispiel in der technologischen Entwicklung, durch eine Veränderung der Rohstoffpreise (wie die beiden Ölkrisen in den siebziger Jahren) oder durch einen raschen Preisverfall von Importgütern infolge einer spekulativen (nominalen) Abwertung einer ausländischen Währung (wie im Gefolge der Asienkrise 1997/98). Auch Angebotsschocks können asymmetrisch wirken. ${ }^{14}$ Typischerweise sind die Wirkungen von Angebotsschocks längere Zeit spürbar als die von Nachfrageschocks, und sie sind mit klas-

14 So verzeichneten die Ölproduzenten Großbritannien und Norwegen eine potentiell geringere, mittelfristig sogar möglicherweise positive Wirkung der Ölkrisen, während ihre ölimportabhängigen Nachbarn in Europa schwer getroffen wurden. 
sischen Instrumenten der Markopolitik kaum abzufedern - letztlich ist eine marktmäßige, strukturelle Anpassung erforderlich.

Nationale, regionale oder branchenweit wirkende Schocks. In einer Währungsunion stellen zuvörderst Schocks ein Problem dar, die einzelne Mitgliedstaaten stärker treffen als andere. Nur dann fällt der Verlust der - nationalen wirtschaftspolitischen Steuergrößen Wechselkurs und kurzfristiger Zins ins Gewicht. Schocks hingegen, die sich auf Branchen auswirken, deren Standorte international verstreut liegen, sind prinzipiell in der Währungsunion nicht schlechter abzufedern als ohne. Sofern alle beteiligten Länder breit diversifizierte Produktionsstrukturen aufweisen, wirken entsprechende Schocks symmetrisch und stellen somit kein unüberwindliches Problem dar.

Krugman (1991a) vergleicht die regionale Konzentration einzelner Branchen in den USA und in der EU. Er stellt fest, daß die US-Konzentrationsgrade höher sind. Seine Interpretation dieser Daten führt zu einer eher pessimistischen Vorhersage für die EWU: Die mit der Abschaffung der Währungsvielfalt einhergehende weitere Integration der europäischen Güter- und Kapitalmärkte zieht räumliche Ballungen industrieller Branchen nach sich - die EU wird damit anfälliger für asymmetrische Schocks. Als Begründung nennt Krugman „Economies of scale", die von sinkenden Durchschnittskosten gekennzeichnet sind, sowie positive Agglomerationseffekte. Dadurch entstehe eine gewissermaßen natürliche Anziehungskraft der großen Masse. ${ }^{15}$

Regionale Spezialisierung stellt allerdings nicht notwendigerweise ein nationales Problem dar. Wenn Regionen sich grenzüberschreitend ausbreiten, treffen Schocks mehrere Länder gleichermaßen, sie wirken also symmetrisch. Verfügen Staaten über mehrere unterschiedlich spezialisierte Regionen, ergibt sich durch die unveränderliche Fixierung der Wechselkurse in einer Währungsunion kein zusätzliches Problem. Hinzu kommt, daß offenbar auf nationaler Ebene die Arbeitskräftemobilität bedeutend höher ist als auf internationaler, so daß regional auftretende Schocks besser aufgefangen würden, als es das Grundmodell der

15 Ricci (1997) kommt gerade zum umgekehrten Ergebnis: In einem Modell, das die Standortwahl von Unternehmen bei Unsicherheit über den Auslastungsgrad, kurzfristig starren Güterpreisen und Geldlohnsätzen unter verschiedenen Wechselkursregimen analysiert, kommt er zu dem Schluß, daß bei flexiblen Wechselkursen eine größere regionale Ballung einzelner Branchen auftritt, bei fixen Wechselkursen oder innerhalb einer Währungsunion hingegen eine eher diversifizierte Wirtschaftsstruktur. Dazu kommt ein weiterer - dynamischer - Aspekt, der ein optimistisches Bild eines Währungraumes aus heterogenen Ländern zeichnet: Indem das Wechselkursregime (hier: endgültig fixe Wechselkurse) die Standortentscheidung von Unternehmen beeinflußt und zur Diversifizierung beiträgt, werden die teilnehmenden Länder weniger anfällig für asymmetrische Schocks - die Währungsunion selbst schafft sich also die Bedingungen, unter denen sie funktionieren kann: „More precisely, the net-benefits that can be expected from the creation of a currency area are endogenous to (and rising in) the institution of the currency area as the latter induces industrial dispersion und consequently reduces the degree of asymmetry of shocks" [Ricci 1997: 28]. 
TOW vorhersagt. Andererseits kann eine geringe grenzüberschreitende Mobilität dafür sorgen, daß es nicht zu den von Krugman prophezeiten Konzentrationsprozessen kommt - wenn Menschen nicht wandern, kommt die Industrie eben dahin, wo die Menschen wohnen [Gros 1996b: 13ff].

\section{1. 3 Asymmetrie in Europa: einige empirische Hinweise}

$\mathrm{Ob}$ EU-Europa ein optimales Währungsgebiet ist bzw. welche Teilmenge von EU-Ländern diesem Ideal nahekommt, ist Gegenstand zahlreicher Untersuchungen der vergangenen Jahre [z. B. Bayoumi/Eichengreen 1993, 1996, Bayoumi/Thomas 1994, Carruth et al. 1994, de Nardis et al. 1996, Boone 1997]. Bemerkenswert ist die geringe Übereinstimmung der Ergebnisse. ${ }^{16}$ Sie variieren zwischen pessimistischen und optimistischen Einschätzungen, wobei auch die pessimistischen Untersuchungen in der Regel einen „Kern” aus EU-Ländern mit hohem Grad an - wie auch immer gemessener - realer Konvergenz identifizieren. In diesem ökonomischen Epizentrum treten keine (national) asymmetrischen Schocks auf, die absorbiert werden müßten. Genannt werden hier meist die E(W)G-Gründerstaaten Deutschland, Frankreich, Belgien, Luxemburg, Niederlande plus Österreich, gelegentlich auch Dänemark, minus Italien.

Vergleich EU-USA. Eine Möglichkeit, die Asymmetrie von Schocks, unabhängig ob sie von der Angebots- oder der Nachfrageseite der Volkswirtschaft ausgehen, zu untersuchen, ist die Ermittlung der Korrelationskoeffizienten $(\rho)$ der Wachstumsraten des regionalen Outputs im Verhältnis zur Kernregion. ${ }^{17}$ Eine hohe positive Korrelation deutet auf eine ausgeprägte Symmetrie hin. Abbildung 2-3 zeigt die Ergebnisse einer IWF-Berechnung für die USA und die EU im Vergleich. Jeweils wurde das wirtschaftsstärkste Gebiet als Referenzpunkt definiert: in den USA der mittlere Osten, in Europa die Bundesrepublik (nur alte Länder) als größtes EU-Land. Betrachtet wird der Zeitraum 1964 bis 1990.

16 Für einen Überblick siehe Schmidt/Straubhaar (1995: 218).

17 Andere Untersuchungen kritisieren diesen Ansatz, denn er impliziert eine statische Welt, in der keine strukturellen Entwicklungen stattfinden. Auch Veränderungen des politischen Regimes, wie die deutsche Einheit oder das Entstehen des EWS, bleiben ausgeblendet. Boone (1997) zum Beispiel kommt in einem „dynamischen Ansatz” zwar in etwa zum üblichen Ergebnis - es gibt einen „Kern” aus Deutschland, Frankreich, Belgien, Österreich und den Niederlanden -, ist aber gleichzeitig in der Lage zu zeigen, daß mit Italien und Spanien zwei große PeripherieLänder gegenüber den Kern-Ländern eine zunehmend symmetrische Wirkung exogener Schocks aufweisen. Sie entwickeln sich somit auf den Kern zu. Für die übrigen PeripherieLänder stellt Boone eine solche Entwicklung nicht fest und kommt daher zu dem Schluß, daß „[...] there is a strong asymmetry in the way European economies are converging" [Boone 1997: 31]. 
Abbildung 2-3: Asymmetrie im Vergleich USA und EU: Korrelationskoeffizienten des regionalen Output-Wachstum (Zeitraum 1964-1990)

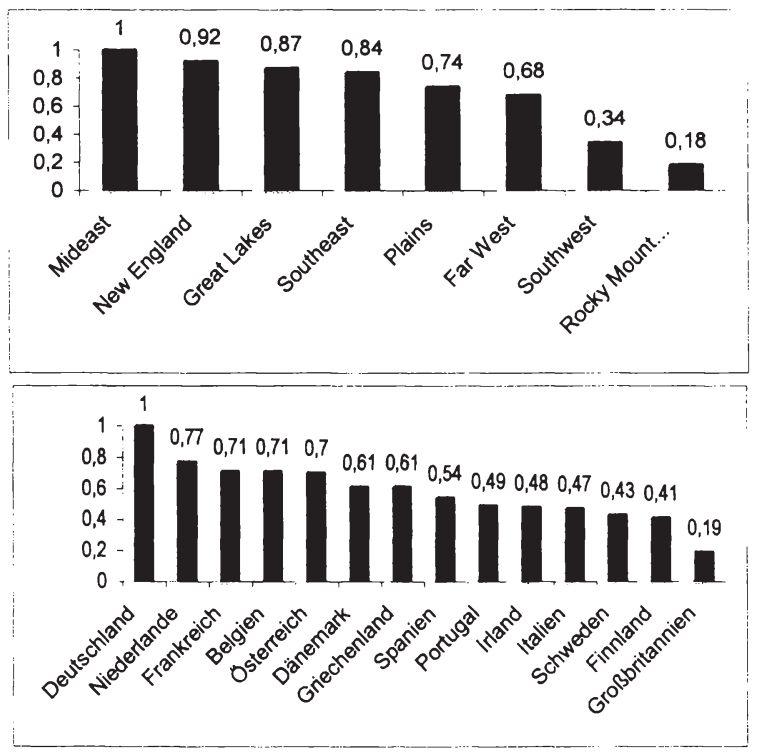

Quelle: IWF 1997

Das IWF-Ergebnis zeigt sowohl für die USA als auch für die EU einen Kern mit relativ hohen Korrelationskoeffizienten $(\rho \geq 0,7)$ : In den USA gehören dazu Mideast, New England, Great Lakes, Southeast und Plains, in der EU Westdeutschland, die Niederlande, Frankreich, Belgien und Österreich. Die übrigen Regionen zählt der IWF zur jeweiligen Peripherie. Bemerkenswert an den Ergebnissen sind zwei Beobachtungen: zum einen, daß die Variationsbreite der Korrelationskoeffizienten zwischen Kern und Peripherie in den USA größer ist als in der EU, auch wenn die Kernregionen hier höhere Werte erreichen, ${ }^{18}$ zum zweiten, daß dies für einen Zeitabschnitt gilt, in dem es weder einen EU-Binnenmarkt noch einen Maastricht-Fahrplan mit Politikkoordinierung gab, ja, bis 1979 gab es nicht einmal ein Europäisches Währungssystem (EWS), an dem allerdings auch später längst nicht alle Länder teilnahmen. Die USA hingegen betreiben bereits seit mehr als 80 Jahren eine einheitliche Geldpolitik. ${ }^{19}$ Eine EU-Entwicklung hin zu mehr

18 Der ungewichtete Durchschnittswert des Korrelationskoeffizienten für die Kernregionen $(\rho \geq$ $0,7)$ der USA liegt bei 0,87 , für die der EU bei 0,78 .

191913 gingen die USA endgültig zur einer einheitlichen Geldpolitik über und gründeten das Federal Reserve System [von Hagen 1996: 48]. 
Konvergenz, inbesondere wenn politisch induzierte Schocks ausbleiben, ist deshalb durchaus naheliegend.

Pro-Kopf-Einkommen und Branchenstruktur. Häufig wird unterstellt, asymmetrische Schocks seien bei Gebieten unterschiedlich hoher Pro-Kopf-BIP wahrscheinlicher. Der Grund: Die Branchenstruktur variiert mit unterschiedlichem Entwicklungsstand, so daß branchenspezifische Schocks sich regional bzw. national konzentriert auswirken. Somit wäre eine rasche Annäherung der ProKopf-Einkommen, ein Hinweis auf eine zunehmende wirtschaftliche Symmetrie. Doch trotz Förderprogrammen geht dieser Prozeß der realen Konvergenz recht schleppend vonstatten: Nach Berechnungen des Instituts der deutschen Wirtschaft beträgt die „Aufholgeschwindigkeit” der einkommensschwachen Regionen gerade 1,6 Prozent jährlich und verläuft folglich im „Schneckentempo” [IW 1997].

Abbildung 2-4: Regionale Unterschiede in der EU: BIP pro Kopf (in \% des EUDurchschnitts)

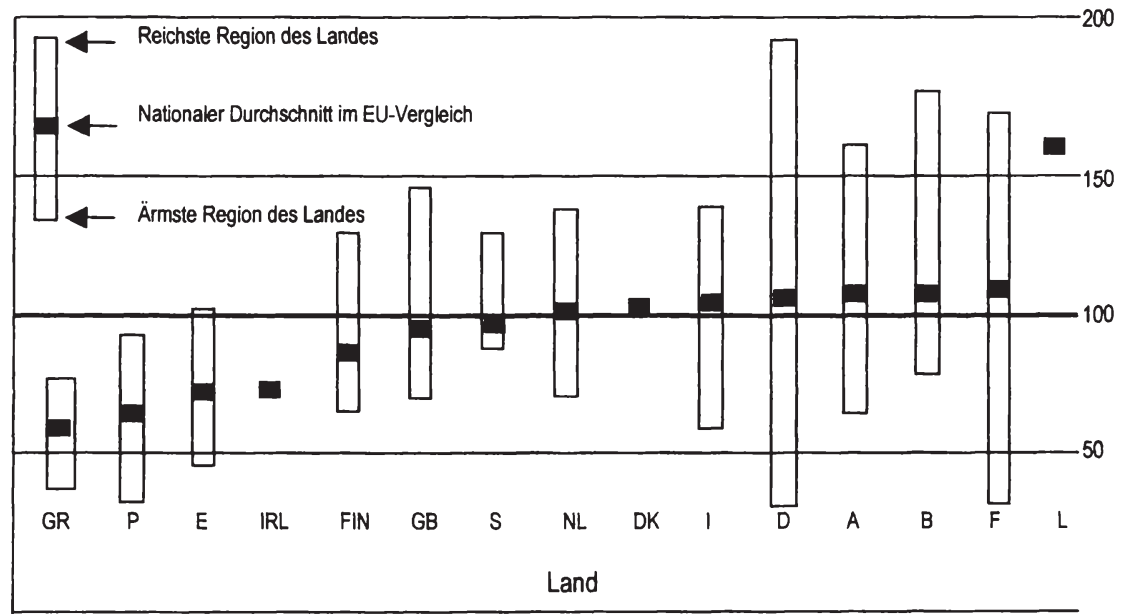

Quelle: EU-Kommission, Stand: 1992

Abbildung 2-4 zeigt die regionalen Unterschiede in der EU. Dabei ergibt sich, daß gerade in großen EU-Länder wie Deutschland, Frankreich, Italien und Großbritannien die Streuungen des BIP-pro-Kopf über die Regionen gravierend sind gravierender als die Streuung der nationalen Durchschnitte. Es wird zudem deutlich, daß gerade die einkommensstarken Staaten, deren Durchschnittseinkommen über dem EU-Durchschnitt liegt, jene sind, die in empirischen Studien stets als „Kern” bezeichnet werden, der kaum von asymmetrischen Schocks betroffen ist. 
Einzig Italien bildet hier eine Ausnahme - es gehört zwar zur Gruppe der Wohlhabenden, nicht aber zum Kern. Der Grund dafür mag in der jahrelang betriebenen Makropolitik liegen, die gekennzeichnet war von hohen Budgetdefiziten und Inflationsraten sowie ständigen nominalen Abwertungen.

Nicht nur die Anfälligkeit für asymmetrische Schocks läßt die EU-Länder als nicht eben optimalen Währungsraum erscheinen. Auch, so lautet ein Standardargument, die potentiellen Anpassungsmechanismen an plötzliche exogene Veränderungen sind wenig entwickelt - die Löhne sind starr [z. B. Fröhlich et al. 1997], ${ }^{20}$ die Menschen immobil [Straubhaar/Wolter 1996, Kiehl/Werner 1998], und auch ein ausgebauter Mechanismus fiskalischer Transfers (siehe unten) ist nicht existent.

\section{1. 4 Politische Erwägungen und die Ratio des EWU-Designs}

Bei der Auswahl der EWU-Teilnehmerländer spielten reale Konvergenzkriterien keine Rolle. Statt dessen formulierte der Maastricht-Vertrag drei nominale und zwei budgetäre Richtgrößen. ${ }^{21}$ Beim EWU-Design stand folgender Grundgedanke im Vordergrund: Aus politischen Gründen sollte die EWU allen Mitgliedsländern offenstehen. Dafür waren Konvergenzkriterien à la TOW untauglich, denn sie hätten auf lange Zeit einen Großteil der EU-Länder ausgeschlossen und damit den Binnenmarkt noch tiefer gespalten, als es der Verzicht auf eine Währungsunion zur Folge gehabt hätte. Gleichzeitig wollten gerade die traditionellen „Hartwährungsländer” sicherstellen, daß die EWU nicht zur „Inflationsgemeinschaft” degeneriert. Die Kriterien sollten gewährleisten, daß sich der Übergang zur Währungsunion, allmählich und möglichst spannungsfrei vollziehen konnte. Daneben sollten die politischen Risiken der EWU begrenzt werden.

20 Für eine etwas optimistischere Sicht auf die Arbeitsmarktflexibilität vgl. Muet (1996).

21 Die drei nominalen Kriterien beziehen sich auf die Inflationsraten, die langfristigen Zinssätze und die Wechselkurse. Der Maastricht-Vertrag formuliert als „Konvergenzkriterien“ (EGV Art. 109 j Abs. 1 sowie das „Protokoll über die Konvergenzkriterien nach Artikel 109j des Vertrags zur Gründung der Europäischen Gemeinschaft“ und das „Protokoll über das Verfahren bei einem übermäßigen Defizit"): Die Inflationsrate darf um höchstens 1,5 Prozentpunkte über derjenigen der (höchstens) drei Länder mit den niedrigsten Inflationsraten liegen; der Zinssatz für langfristige Staatsanleihen darf die Zinssätze in diesen (höchstens) drei Ländern maximal um zwei Prozentpunkte übersteigen. Die Währung darf im Europäischen Währungssystem die normalen Schwankungsbreiten mindestens zwei Jahre vor der Prüfung nicht überschritten haben. Dazu kommen die beiden budgetären Richtgrößen: Das Defizit der öffentlichen Haushalte soll drei Prozent des BIP nicht überschreiten; es darf die Drei-Prozent-Marke allerdings geringfügig überschreiten (,in der Nähe des Referenzwertes“), wenn dies nur „ausnahmsweise und vorübergehend“ geschieht oder die Defizitquote „erheblich und laufend“" gesunken ist (EGV Art. 104c Abs. 2a). Der öffentliche Schuldenstand soll 60 Prozent des BIP nicht überschreiten; die Schuldenquote darf allerdings über diesem Wert liegen, sofern sie ,hinreichend rückläufig ist und sich rasch genug dem Referenzwert nähert" (EGV Art. 104c Abs. 2b). 
Polit-ökonomische Risiken. Geldpolitik kann ohne Unterstützung durch die übrigen wirtschaftspolitischen Bereiche nicht erfolgreich sein. Sie sollte sich harmonisch in die gesamte staatliche bzw. intergouvernmentale Ordnung einfügen. Historische Vorläufer der EWU zeigen, daß ein solcher (wirtschafts-)politischer Rahmen insbesondere nötig ist, um gemeinsam flexibel auf Veränderungen des ökonomischen, politischen oder gesellschaftlichen Umfelds reagieren zu können. Ohne einen solchen Rahmen waren Währungsunionen stets dazu verurteilt auseinanderzubrechen. So hat Theul (1996) bei einer Analyse der Skandinavischen und der Lateinischen Münzunionen des 19. Jahrhunderts festgestellt: Immer wenn es „(...) im Zuge eines dauerhaften Wandels von Rahmenbedingungen oder durch kurzzeitige Störungen” zu einem Konflikt gekommen sei, der zu einer Zielantinomie zwischen nationalem Interesse und unionsgerechtem Verhalten führte, „(...) dann wurde - von einzelnen oder allen Mitgliedsländern - konsequent gegen das Unionsinteresse gehandelt" [Theul 1996: 31]. Folglich scheiterten die Währungsverbünde am Ende. Zwar agiert die EU im Vergleich zu diesen historischen Vorbildern unter weitgehend veränderten ökonomischen und politischen Rahmenbedingungen. Daß auch hier im Zeitablauf multiple Konflikte zwischer nationalem und Gemeinschaftsinteresse auftreten, ist jedoch überaus wahrscheinlich, so daß es eines Mechanismus bedarf, sie zu lösen.

Durch den Übergang zu einer Währungsunion werden öffentliche Güter geschaffen, die allen teilnehmenden Staaten zur Verfügung stehen und von denen sie nicht mehr ausgeschlossen werden können, sobald sie Mitglied der Währungsunion sind. Entsprechend schwierig ist es, effektive Sanktionsmechanismen zu entwerfen, die ein dauerhaftes Funktionieren der Währungsunion gewährleisten.

So läßt sich Geldwertstabilität als ein öffentliches Gut ansehen, an dessen Produktion sich alle EWU-Staaten beteiligen müssen. Es ergeben sich „Freeriding"-Probleme, sofern ein Land seine Fiskal- oder Lohnpolitik, die in nationaler Hoheit bleiben, in einer Weise ausrichtet, die dem Ziel der Geldwertstabilität zuwiderläuft. Während die betreffende Regierung kurzfristige Vorteile erhoffen kann, bürdet sie die damit verbundenen Kosten der Inflationsbekämpfung (insbesondere höhere Zinsen) auch den Partnerländern auf - sie verursacht somit negative externe Effekte.

Ähnliches gilt für das Verhältnis der nationalen Fisci untereinander. Sie gehen eine Art impliziten Versicherungsvertrag ein. Denn es ist wahrscheinlich, daß im Falle der Zahlungsunfähigkeit eines Staates ${ }^{22}$ die übrigen Regierungen einen

22 Die Gefahr der Zahlungsunfähigkeit ist in einer Währungsunion eher gegeben als im nationalstaatlichen Kontext, sofern die Staaten sich nicht mehr bei der Notenbank verschulden können. Zudem entfällt angesichts offener Kapitalmärkte auch die Möglichkeit, via Kapitalverkehrsbeschränkungen die eigene Bevölkerung zum Kauf von Staatsanleihen zu zwingen [z. B. Bishop 1996: 206ff]. 
Teil der Verbindlichkeiten übernehmen. ${ }^{23}$ Der Anreiz hierfür ist selbst bei einem formalen Verbot groß, weil andernfalls alle mit einem erhöhten Risikoaufschlag auf die von den Anlegern geforderte Rendite für Staatspapiere rechnen müssen. Diese Erwartung der Versicherungsleistung durch die Partnerländer schafft für jedes Land individuell Anreize, ungenügende Vorkehrungen gegen Zahlungsunfähigkeit zu treffen („Moral hazard”). Der institutionelle Rahmen muß diese Anreize nach Möglichkeit vollständig eliminieren.

Konvergenz der makroökonomischen Politiken und Philosophien. Das Maastricht-Programm sah vor, den Prozeß der Desinflation vor Beginn der dritten Stufe graduell zu vollziehen statt eine abrupte „Cold-Turkey”-Strategie zu verfolgen. Die Vorteile liegen vor allem in einer Anpassung der Institutionen (insbesondere Entlassung der Zentralbanken in die Unabhängigkeit), einer Konvergenz der Erwartungen der Akteure (insbesondere der Tarifparteien und der Aufbau von Glaubwürdigkeit gegenüber den Finanzmärkte) und einer allmählichen Synchronisierung der Konjunkturzyklen via Geldpolitik, unterstützt durch eine stabilitätsorientierte Fiskalpolitik.

Dieser Prozeß der Annährung von Inflationsraten und Zinsen auf niedrigem Niveau, die Stabilisierung der Wechselkurse im Rahmen des EWS und die Konsolidierung der öffentlichen Haushalte war eingebettet in einen institutionellen Lernprozeß: Mit Beginn der zweiten Stufe zum Jahresbeginn 1994 bereiteten sich die (bis zum Beginn der dritten Stufe in die Unabhängigkeit zu entlassenden) Zentralbanken im EWI darauf vor, eine gemeinsame Geldpolitik zu betreiben, und die nationalen Regierungen unterwarfen sich einer Haushaltskontrolle durch die Europäische Kommission und die übrigen Länder gemäß EGV Art. 104c.

Am Ende des Integrationsprogramms stand ein politischer Auswahlprozeß, in dem die Staats- und Regierungschefs im Frühjahr 1998 mit qualifzierter Mehrheit über jedes Land einzeln abstimmten. Es war frühzeitig ersichtlich, daß keine im Sinne der TOW homogene Ländergruppe eine Chance hatte, eine Mehrheit zu bekommen, und daß in einem „Log-rolling”-Prozeß auch andere Fragen eine Rolle spielen würden, die mit der EWU allenfalls am Rande etwas zu tun haben [Müller 1997b]. Viele Analysen des Maastricht-Programms resümieren deshalb, „(...) daß die Währungsunion in erster Linie ein politisches Projekt ist" [Meister 1997: 1].

Grundprinzipien der EWU. Die oben skizzierte graduelle, möglichst spannungsfreie Anpassung der Politiken, Institutionen und Erwartungen erachte-

23 Die Palette an Beispielen ist reichhaltig. Prominente Fälle der vergangenen Jahre sind der von den USA erzwungene und teilweise bezahlte IWF-Kredit an Mexiko, als das lateinamerikanische Land Ende 1994 von einer massiven Kapitalflucht betroffen war („PesoKrise") - zu beachten ist, daß die USA mit Mexiko nicht durch eine Währungsunion, sondern nur durch die Freihandelszone NAFTA verbunden sind -, sowie Ende 1997 die Hilfen für Südkorea, Indonesien und andere südostasiatische Länder. 
ten die europäischen Akteure insbesondere für nötig, weil der EWU ein staatlicher Rahmen, eine wirkliche Politische Union, fehlt. Es gibt keine starke Zentralebene, die, analog der deutschen Bundesorgane, etwaiges Fehlverhalten einzelner Regierungen oder Tarifparteien ohne weiteres sanktionieren könnte.

In Abwesenheit eines kohärenten politischen Rahmens funktioniert die EWU nach zwei grundlegenden Prinzipien: Erstens soll das Regelwerk verhindern, daß einzelne Regierungen die Solidarität der übrigen Mitgliedsstaaten ausnutzen („Moral hazard”, „Free riding”). Zweitens soll die EZB ungestört von politischem Druck das Ziel der Geldwertstabilität verfolgen können.

Getragen von den beiden Grundprinzipien - Geldwertstabilität und Abschreckung von „Free-Riding”- und „Moral-Hazard”-Verhalten - ergibt sich der Rahmen für die Europäische Währungsunion als heterogenes Setting. Es herrscht ein Nebeneinander von supranationalen und intergouvernementalen Elementen. Indem die teilnehmenden Staaten zur dritten Stufe der Währungsunion übergingen, traten sie die Zuständigkeit für die Geldpolitik vollständig an die Gemeinschaftsebene $a b$. Nach den in Maastricht vereinbarten Regelungen ist für diesen Politikbereich allein die EZB bzw. das ESZB zuständig. Das „vorrangige Ziel” dieser neuen Institutionen ist es, „die Preisstabilität zu gewährleisten” [EGV Art. 105 Abs. 1]. Die übrige Wirtschaftspolitik (sofern sie nicht, wie die Subventionen für einzelne Wirtschaftszweige und Regionen, den Binnenmarktregeln unterliegt) verbleibt prinzipiell in nationaler Hoheit und wird lediglich in abgestufter Form koordiniert und überwacht. Hierbei ist je nach Teilgebiet ,,(..) eine unterschiedliche Entscheidungsstruktur und Beteiligungsdichte der Gemeinschaftsorgane erkennbar" [Weidenfeld/Jung 1994: 22]. Der Vertrag von Maastricht samt beigefügten Protokollen konstitutiert somit eine "wirtschaftspolitische Asymmetrie" [Hasse 1997: 16]. Die Funktionsweise der wichtigsten Bereiche sei im folgenden kurz erörtert.

\section{2 Geldpolitik im institutionellen Rahmen der EWU}

Definitionsgemäß ist die gemeinsame Geldpolitik der Kern einer Währungsunion. Die Gestalt der EWU hängt deshalb entscheidend von ihrem institutionellen Rahmen ab, der sich eng an die Regelungen für die Deutsche Bundesbank anlehnt.

\section{2. 1 Ziele}

Der Maastricht-Vertrag verpflichtet das ESZB auf das Ziel der Preisstabilität, dem er damit vor den anderen Zielen der Gemeinschaft unbedingten Vorrang einräumt. Allerdings soll das ESZB ,die allgemeine Wirtschaftspolitik” unterstützen, ,soweit dies ohne Beeinträchtigung des Zieles der Preisstabilität möglich ist” (EGV Art. 105 Abs. 1). Nach EGV Art. 2 lauten die sonstigen Ziele der Union, ,eine harmonische und ausgewogene Entwicklung des Wirtschaftslebens”, ein „beständiges, nicht-inflationäres Wachstum”, einen „hohen Grad an Konvergenz der 
Wirtschaftsleistungen”, ein „hohes Beschäftigungsniveau”, ein „hohes Maß an sozialem Schutz, die Hebung der Lebenshaltung und Lebensqualität", die Förderung des ,wirtschaftlichen und sozialen Zusammenhalt(s)" und der "Solidarität zwischen den Mitgliedstaaten" zu erreichen. Zudem sollen nach Art. 3a Abs. 2 sämtliche wirtschaftpolitische Teilbereiche inklusive der Geld- und Währungspolitik den Grundsatz einer „offenen Marktwirtschaft mit freiem Wettbewerb” unterstützen.

\section{2. 2 Zuständigkeit}

Die Verantwortung für die Geldpolitik liegt eindeutig bei einem Gemeinschaftsorgan, dem ESZB. Dessen Machtzentrum ist der EZB-Rat, in dem das EZB-Direktorium sowie die Präsidenten der nationalen Zentralbanken zusammensitzen. ${ }^{24}$ Er formuliert autonom die geldpolitischen Ziele und Strategien, entscheidet über geldpolitische Zwischenziele, Änderungen der Leitzinssätze und die Bereitstellung von Zentralbankgeld. ${ }^{25}$ Für die Ausführung der Beschlüsse des Rates ist die EZB zuständig, die dafür den nationalen Zentralbanken die Weisungen erteilt. Neben der Formulierung der Geldpolitik ist das ESZB dafür zuständig, Devisengeschäfte auszufuihren, die offiziellen Währungsreserven der Mitgliedstaaten $\mathrm{zu}$ halten und zu verwalten und einen reibungslosen Zahlungsverkehr zu gewährleisten (EGV Art. 105 Abs. 2).

\section{2. 3 Beurteilung}

Die starke Stellung des ESZB und der EZB im Setting der EWU resultiert vor allem aus zwei Prinzipien:

- der Unabhängigkeit gegenüber den politischen Instanzen,

- der uneingeschränkten Festlegung auf das Ziel der Preisstabilität.

Der Maastricht-Vertrag verbietet die Gewährung von Krediten an öffentliche Haushalte und Unternehmen durch die EZB oder die nationalen Zentralbanken (EGV Art. 104). Dadurch soll verhindert werden, daß die Mitgliedstaaten mit ihren Haushaltsdefiziten direkt die Inflation anheizen, indem eine Monetisierung der Staatsdefizite stattfindet. Die EZB ist also Herrin über die geldpolitischen Instrumente (,instrumentelle Unabhängigkeit”). Zudem ist die EZB unabhängig von politischen Weisungen jedweder politischen Instanz (,funktionelle Unabhängigkeit"). ${ }^{26}$ Dies gilt jedoch nur bedingt für die Außenwährungspolitik. Dieser Bereich wird im folgenden Abschnitt näher beleuchtet.

24 Art. 10 des Protokolls über die Satzung des Europäischen Systems der Zentralbanken und der Europäischen Zentralbank

25 Art. 12. 1. des Protokolls über die Satzung des Europäischen Systems der Zentralbanken und der Europäischen Zentralbank

26 EGV Art. 107 
Eine lange geführte Diskussion beschäftigt sich damit, ob diese juristische Unabhängigkeit der europäischen Zentralbanken ausreicht, auch faktisch unabhängig sein zu können [z. B. Willms 1992: 218ff, de Grauwe 1997a: 117ff]. Diese Überlegungen beziehen sich vor allem auf die personelle Unabhängigkeit der EZBRatsmitglieder. Thnen steht ein relativ großer Ermessensspielraum offen: Der Vertrag selbst setzt lediglich das Ziel der Preisstabilität, ohne es jedoch zu quantifizieren, so daß der EZB-Rat womöglich auch eine Inflationsrate von vier oder fünf Prozent für damit vereinbar halten könnte, insbesondere sofern zum Beispiel große Ungleichgewichte auf den Arbeitsmärkten zu verzeichnen wären. ${ }^{27}$

Es ist denkbar, daß einzelne EZB-Ratsmitglieder in einen Konflikt zwischen kurzfristigen eigenen und langfristigen volkswirtschaftlichen Interessen kommen. ${ }^{28}$ Denn die Mitglieder des EZB-Direktoriums werden auf acht Jahre gewählt, eine Wiederwahl ist ausgeschlossen; ${ }^{29}$ für die übrigen EZB-Ratsangehörigen, die nationalen Zentralbankpräsidenten, gibt es nur die Anforderung, sie sollten auf mindestens fünf Jahre ernannt werden. ${ }^{30}$ Sofern der Präsident einer nationalen Zentralbank an einer Wiederernennung durch eine Regierung mit geringer Inflationsaversion interessiert ist oder ein EZB-Direktoriumsmitglied an einer anderen begehrten Positionen, ist es möglich, daß diese Person nicht so „hard nosed" gegenüber Forderungen nach einer laxeren Geldpolitik ist. Ebenso könnte es sein, daß Ratsmitglieder aus Ländern mit zweifelhaftem „Track record” eine weniger ausgeprägte (kulturell bedingte) Inflationsaversion mitbringen. Die personelle Unabhängigkeit des EZB-Rates würde also nicht ausreichen, um den bekannten „Inflationary bias” zugunsten kurzfristiger Beschäftigungseffekte zu vermeiden. ${ }^{31}$

Der Internationale Währungsfonds (IWF) legt besonderes Gewicht auf die öffentliche Unterstützung der multinationalen Institution ESZB, die, anders als nationale Institutionen, direkt in keiner nationalen Öffentlichkeit verankert sei. Um Konflikte über den geldpolitischen Kurs zu verhindern, müsse deshalb das ESZB und insbesondere die EZB ihre „[...] mechanisms to ensure public under-

27 Das Europäische Währungsinstitut, als Vorgängerin des ESZB, hat allerdings festgestellt, daß es einen breiten Konsens zwischen den Zentralbanken gebe, daß ,[...] a range of 0-2 percent inflation per annum would be appropriate" [Europäisches Währungsinstitut 1997a: 12]. Die Europäische Zentralbank hat dieses Ziel im Herbst 1998 bestätigt. Wegen der Zeitverzögerung in der Wirkung der Geldpolitik verfolgt die EZB eine mittelfristige Strategie [EZB 1998].

28 Entsprechend Phillipskurven-Ansatz besteht regelmäßig die Möglichkeit, durch eine erhöhte Versorgung der Volkswirtschaft mit Zentralbankgeld kurzfristige Output- und Beschäftigungseffekte zu erzielen. Für einen entsprechenden formalen Ansatz siehe Kapitel 4.

29 Art. 11. 2. Protokoll über die Errichtung des ESZB und der EZB

30 Art. 14. 2. Protokoll über die Errichtung des ESZB und der EZB

31 Ein umfassender Überblick über Theorie und Empirie dieses „Bias” findet sich bei Romer 1996: $388 \mathrm{ff}$. 
standig of the ESCB`s policy decisions" über die im Maastricht-Vertrag niedergelegten Veröffentlichungspflichten hinaus ausbauen. Denn, so der IWF, ,the long-run success of the ESCB in delivering low inflation will to some extent, as with any monetary authority, depend on the public's support for that objective" [IWF 1997: 53]. ${ }^{32}$

\section{3 Institutioneller Rahmen der Außenwährungs- und Wechselkurspolitik}

Engverbunden mit der oben beschriebenen Geld- bzw. Zinspolitik ist die nach außen gerichtete Währungspolitik. Allerdings sind hier die Zuständigkeiten anders verteilt.

\subsection{Ziele}

Wie bei der Geldpolitik, so steht auch die Währungs- bzw. Wechselkurspolitik unter dem Primat der Geldwertstabilität. Ansonsten gilt: Sofern keine Gefahr für die Preisstabilität besteht, kann die Wechselkurspolitik in den Dienst der übrigen Ziele der EU gestellt werden.

\section{3. 2 Zuständigkeit}

In der Ausgangslage zu Beginn der Währungsunion liegt die Zuständigkeit für diesen Bereich beim ESZB. Der Ministerrat kann die Zuständigkeit dafür allerdings an sich ziehen, so er dies wünscht (EGV Art. 109). EZB und nationale Notenbanken haben dann im Auftrag die entsprechenden Beschlüsse umzusetzen, insbesondere indem sie Devisengeschäfte auf den Finanzmärkten abwickeln (EGV Art. 105 Abs. 2 zweiter Spiegelstrich).

Der Ministerrat wird dabei stets auf Initiative der Europäischen Kommission oder der EZB aktiv; sofern der Anstoß von der Kommission ausgeht, wird die EZB gehört. Allerdings kann auch der Ministerrat die Kommission oder die EZB auffordern, Vorschläge für die Währungs- und Wechselkurspolitik unterbreiten. Die Entscheidungsbefugnisse liegen in jedem Fall beim Ministerrat.

Das Verfahren bei alternativen Wechselkursregimen. Drei Fälle, in denen jeweils eigene Regeln gelten, sind zu unterscheiden: a) formelle Wechselkurssysteme, b) das Währungssystems (EWS II) zwischen der Eurozone und den nichtteilnehmenden EU-Ländern (,Pre-Ins“), c) es existiert kein formelles Wechselkurssystem.

Implementierung und Management formeller Wechselkurssysteme. Gemäß EGV Art. 109 Abs. 1 kann der Rat der Europäischen Union „förmliche Vereinbarungen über ein Wechselkurssystem" gegenüber Drittländern treffen. Die grund-

32 Auch die Bundesbank fordert für das ESZB, daß es nach den Grundsätzen „Glaubwürdigkeit, Transparenz und Kontinuität” arbeiten möge [Deutsche Bundesbank 1997c: 5]. 
sätzliche Entscheidung, ob ein solches System eingeführt wird, fällt der Rat einstimmig unter der Gruppe der Euro-Staaten („Ins”). Die Minister der „Pre-Ins“ dürfen zwar an den Beratungen teilnehmen, sind aber nicht stimmberechtigt. Die Festlegung der Leitkurse innerhalb eines Wechselkurssystems erfordert die qualifizierte Mehrheit der „Ins”. Die Modalitäten der Verhandlungen auf internationaler Ebene über ein solches System werden vom Rat ebenfalls mit qualifizierter Mehrheit beschlossen.

Wechselkursmechanismus zwischen dem Euroland und den "Pre-Ins" (EWS II). Eine deutlich stärkere Position hat die EZB im Rahmen des Wechselkurssystems zwischen den Euro- und den am neuen Wechselkursmechanismus teilnehmenden übrigen EU-Ländern (EWS II); zum Zeitpunkt des Beginns der Währungsunion sind dies lediglich Dänemark und Griechenland. Änderungen der Leitkurse und der Schwankungsbreiten gegenüber dem Euro werden „im gegenseitigen Einvernehmen" [Europäischer Rat 1997c: 24] zwischen Europäischer Kommission, der EZB sowie den zuständigen Ministern der „Ins”, den Ministern der am Wechselkursmechanismus teilnehmenden „Pre-Ins” sowie deren Zentralbankpräsidenten getroffen. Nicht am EWS II teilnehmende EU-Staaten können ebenfalls Minister und Zentralbankpräsidenten entsenden, diese sind aber nicht stimmberechtigt.

Innerhalb des EWS II haben die EZB und die übrigen beteiligten Zentralbanken die Möglichkeit, Interventionen - die ,grundsätzlich automatisch und in unbegrenzter Höhe erfolgen" sollen - nach eigenem Ermessen auszusetzen, sofern sie dem Ziel der Geldwertstabilität zuwiderlaufen, und ein Realignment der Wechselkurse auf die Tagesordnung zu setzen. ${ }^{33}$

Wechselkurspolitik ohne Einbindung in ein Wechselkurssystem. Sofern kein formelles Wechselkurssystem gegenüber Drittländern besteht, kann der Rat ebenfalls Einfluß auf die Wechselkurspolitik nehmen. In diesem Fall hat er die Möglichkeit, mit qualifizierter Mehrheit der „Ins” „allgemeine Orientierungen für die Wechselkurspolitik" aufzustellen (EGV Art. 109 Abs. 2). EZB und nationale Notenbanken sind dann gehalten, die entsprechenden Beschlüsse umzusetzen. Der Rat fällt seine Entscheidungen auf Empfehlung der EZB oder auf Empfehlung der Kommission, wobei im letzteren Fall die EZB gehört wird. Abbildung 2-5 illustriert das Entscheidungsverfahren für die Wechselkurspolitik, die Besonderheiten des EWS II bleiben unberücksichtigt.

Da der Euro - mit Ausnahme der beiden EWS II-Staaten - zum Zeitpunkt der EWU-Gründung nicht in ein formelles Wechselkurssystem eingebunden ist, haben sich die Regierungen der 15 EU-Länder im Vorfeld des Beginns der dritten Stufe der EWU bemüht, potentielle Spannungen zwischen Ministerrat und EZB abzubauen. So beschloß der Europäische Rat, lediglich ,in exceptional circumstances" zum Instrument wechselkurspolitischer Orientierungen zu greifen

33 Zum EWS II siehe detailliert Deutsche Bundesbank (1998d) sowie de Grauwe (1997b). 
und ansonsten den Außenwert des Euro ,as the outcome of all other economic policies" ansehen zu wollen [Europäischer Rat 1997c]. Bindend ist diese Selbstverpflichtung nicht.

Abbildung 2-5: EU-Wechselkurspolitik bei alternativen Wechselkursregimen

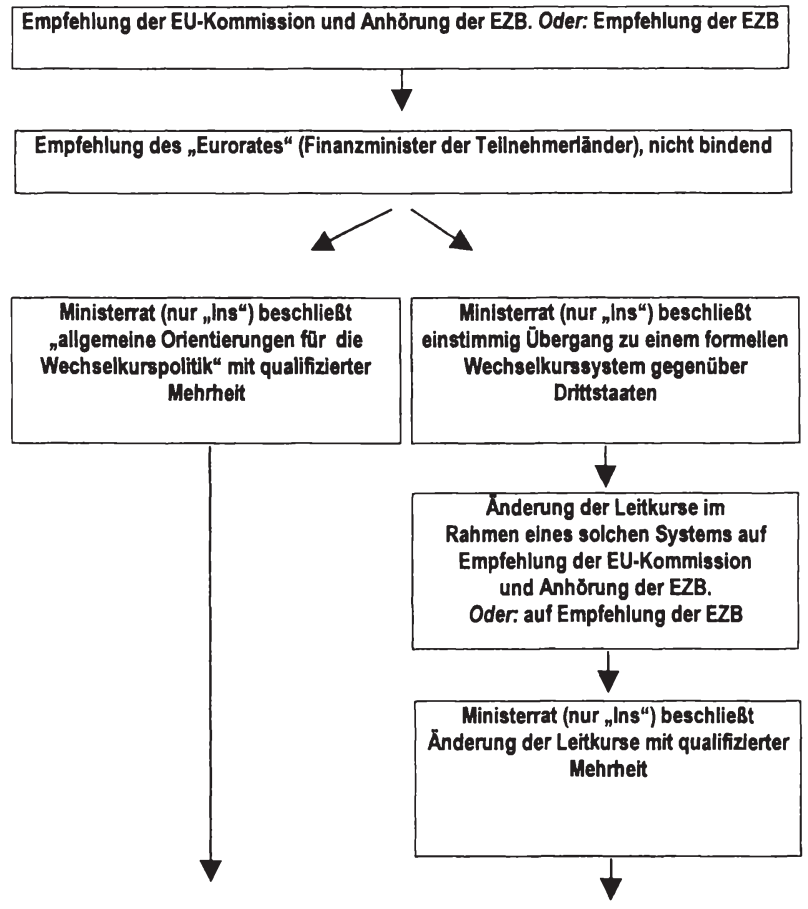

EZB führt aus.

Oder Konfilkt fall: EZB sieht Geldwertstabilităt gefahrdet und weigert sich

Quelle: eigene Darstellung

Abstimmung im Ministerrat. Solange einige EU-Staaten nicht EWU-Mitglieder sind, entscheiden die "Ins“ allein über Fragen, die für die Währungsunion von Belang sind. Sofern einstimmige Entscheidungen vorgeschrieben sind, bedeutet dies stets Einstimmigkeit unter den Teilnehmerstaaten. Bei Abstimmungen mit qualifizierter Mehrheit ist eine Zweidrittelmehrheit der „Ins” notwendig, die „PreIns" sind nicht stimmberechtigt (EGV Art. 109k Abs. 5). Wenn alle EU-Staaten an der Währungsunion teilnehmen, fallen Mehrheitsentscheidungen nach der üblichen qualifizierten Mehrheit nach EGV Art. 148 Abs. 2 sowie Art. K.6 Abs. 3 des 
Vertrag von Amsterdam: 62 Stimmen sowie zehn Staaten müssen für eine Vorlage stimmen, damit sie als angenommen gelten kann. Die Stimmgewichte sind grob nach der jeweiligen Bevölkerungsgröße verteilt (Übersicht 2-1).

Übersicht 2-1: Stimmgewichte im Ministerrat

\begin{tabular}{|c|c|}
\hline Land & Anzahl der Stimmen \\
\hline \multicolumn{2}{|l|}{ Euro-Staaten (,Ins") } \\
\hline Frankreich & 10 \\
\hline Deutschland & 10 \\
\hline Italien & 10 \\
\hline Spanien & 8 \\
\hline Niederlande & 5 \\
\hline Belgien & 5 \\
\hline Portugal & 5 \\
\hline Österreich & 4 \\
\hline Irland & 3 \\
\hline Finnland & 3 \\
\hline Luxemburg & 2 \\
\hline Stimmen der "Ins" insgesamt & 65 Stimmen \\
\hline Zweidrittelmehrheit der "Ins" & 43 Stimmen \\
\hline Qualifizierte Mehrheit & 62 Stimmen \\
\hline \multicolumn{2}{|l|}{ Nicht-Euro-Staaten (, Pre-Ins") } \\
\hline Großbritannien & 10 \\
\hline Griechenland & 5 \\
\hline Schweden & 4 \\
\hline Dänemark & 3 \\
\hline Stimmen der „Pre-Ins" insgesamt & 22 \\
\hline Stimmen EU-15 insgesamt & 87 \\
\hline
\end{tabular}

Zum Zeitpunkt des EWU-Starts genügt in wechselkurspolitischen Fragen, für die Mehrheitsentscheidungen vorgeschrieben sind, die Zahl von 43 Stimmen. Sie liegt um 22 Stimmen unter der gesamten Stimmenzahl der „Ins“. Zudem ist die Regel ausgesetzt, daß nicht nur 71 Prozent der Stimmen zusammenkommen müssen (62 von 87), sondern zudem zwei Drittel der EU-Staaten (10 von 15) zustimmen müssen. Folglich ist die Schwelle, um Mehrheiten in der Wechselkurspolitik zu erreichen, deutlich unter die ursprünglich intendierte Schwelle gesunken. So könnten fünf Staaten die erforderliche Zweidrittelmehrheit zusammenbringen, nämlich Deutschland, Frankreich, Italien, Spanien sowie entweder die Niederlande oder Belgien oder Portugal. Selbst wenn die heutigen „Pre-Ins” in den kommenden Jahren der EWU beitreten sollten, so dürfte dieser Zustand der herabgesetzten Mehrheit in Fragen der Außenwährungs- und Wechselkurspolitik dauerhaft anhalten: Im Zuge der EU-Osterweiterung wird es stets Staaten geben, die zwar EU- 
jedoch nicht EWU-Mitglieder sind. Schon ein Mitgliedstaat mit „Pre-In”-Status genügt, die Übergangsregelung nach EGV Art. 109k anzuwenden.

Rolle des „Euro-11-Rates”. Innerhalb der EU ist neben den Ministerrat als Entscheidungszentrum für währungspolitische Fragen ein weiteres Gremium getreten: der sogenannte Euro-11-Rat, in dem sich die Wirtschafts- und Finanzminister der "Ins" vor den Sitzungen des eigentlichen Ministerrates abstimmen. Insbesondere über die Wechselkurspolitik tauschen sich die EWUMitglieder hier aus, ohne daß die Minister der „Pre-Ins“ beteiligt wären.

Das Gremium ist informeller Art, in den EU-Verträgen ist es nicht vorgesehen. Entscheidungen kann der Euro-11-Rat nicht fällen. Seine Bedeutung liegt vor allem darin, daß die Regierungen der Euro-Staaten stets aufs Neue versuchen, eine gemeinsame Position zu formulieren, mit der sie in die Verhandlungen mit den „Pre-Ins“ gehen, wobei letztere, wie erwähnt, ohnehin nicht stimmberechtigt sind. Bei der Schaffung von Mehrheiten dürte der Euro-11-Rat daher im Zeitablauf eine gewichtige Rolle spielen, dies umso mehr als sich die EWU im Zuge der Osterweiterung zum „Club der Reichen” innerhalb der EU entwickeln dürfte.

Vertretung in internationalen Organisationen. Mitglieder in internationalen Organisationen sind weiterhin die einzelnen EU-Staaten. Entsprechende Rechte und Pflichten werden von ihren nationalen Organen ausgeübt. Sie dürfen dort auch individuelle Vereinbarungen für ihre Länder schließen (EGV Art. 109 Abs. 5).

Allerdings sollen die Vertreter der EWU-Staaten in Fragen, die für die Währungsunion ,von besonderer Bedeutung” sind, in internationalen Organisationen, insbesondere im Internationalen Währungsfonds (IWF), einen gemeinsamen Standpunkt beziehen. Die europäische Position wird auf Vorschlag der Kommission vom Ministerrat mit qualifizierter Mehrheit der EU-Länder bzw. der Zweidrittelmehrheit der „Ins” festgelegt. Die EZB wird vor der Entscheidung gehört (EGV Art. 109 Abs. 4). ${ }^{34}$

Der Europäische Rat von Wien hat für die Vertretung des Eurolandes in internationalen Organisationen folgende Regelungen gefordert [Europäischer Rat 1998: Ziff. 14 sowie Anlage II]:

An den G 7-Tagungen (Finanzminister und Zentralbankpräsidenten) soll das Euroland künftig mit zusätzlichen Vertretern teilnehmen. Bisher war die Europäische Union mit vier Staaten anwesend, nämlich Deutschland, Frankreich, Italien und Großbritannien. Nun soll auf jeden Fall der jeweilige Präsident des Euro-11-

34 EGV Art. 109 Abs. 3. Siehe auch Europäische Kommission (1997a.) Daneben verändert die EWU die Rolle im operativen Gebaren zum Beispiel des IWF. So gewinnt bei der wirtschaftspolitischen Überwachung der Blick auf die EU als Region an Bedeutung. Die Zahlenwerke über die Zahlungsbilanzen und Währungsreserven müssen neuinterpretiert werden, die Zusammensetzung und Bewertung der Sonderziehungsrechte ändert sich [IWF 1997: 75, Pollak 1997, Thygesen 1997]. 
Rates teilnehmen. Kommt dieser nicht aus einem der drei „Ins” unter den G 7 Deutschland, Frankreich, Italien -, sondern aus einem kleineren Mitgliedstaat, ist die EU mit fünf Staaten vertreten. Daneben soll auch noch ein Vertreter der Kommission teilnehmen, was die US-Regierung allerdings beim ersten $G$ 7-Treffen der Euro-Ära, im Februar 1999 in Bonn, ablehnte. Vor den G 7-Treffen soll eine Vorbereitungssitzung im Euro-11-Rat stattfinden, um gemeinsame Positionen zu entwickeln [Europäischer Rat 1998: Anhang II, Ziff. 10].

Im Internationalen Währungsfonds ist die Eurozone durch die EZB vertreten, die einen „Beobachterstatus“ im IWF-Direktorium einnimmt. Den gemeinsamen Standpunkt in Fragen der Währungspolitik, die die Eurozone betreffen, soll der jeweilige Euro-11-Vorsitzende im Exekutivdirektorium vorbringen, wiederum „unterstützt“" von einem Vertreter der Kommission [Europäischer Rat 1998: Anhang II, Ziff. 13].

\subsection{Beurteilung}

Die Regelungen für die externe Währungspolitik sind in mehrfacher Hinsicht ungenügend. Sie bergen eine potentielle Quelle von Konflikten zwischen den Mitgliedstaaten, zwischen den Institutionen der EU sowie zwischen der EU einerseits und Drittstaaten andererseits. Insbesondere folgende Punkte sind problematisch:

Wechselkurspolitik und Inflation. Ein politisch beeinflußter Außenwert dürfte Rückwirkungen auf die binnenwirtschaftliche Preisstabilität im Euroland zeitigen. Es ist möglich, daß wechselkurspolitische Entscheidungen des Ministerrats die Inflation schüren. Denn mittelfristig spiegelt der Außenwert den Binnenwert einer Währung wider. Wünscht der Ministerrat eine Abwertung des Euro, so ist dies dauerhaft nur möglich, wenn die EZB eine expansive Geldpolitik betreibt. Dies schürt aber inflationäre Spannungen im Euroraum und wäre im übrigen ein Angriff auf die instrumentelle Unabhängigkeit der Zentralbank.

Verhindern läßt sich ein solcher inflationärer Impuls, wenn die EZB das Instrument sterilisierter Interventionen am Devisenmarkt einsetzt. In diesem Fall kommt es nicht zu einer Ausweitung der Zentralbankgeldmenge. Allerdings zeitigen sterilisierte Interventionen allein erfahrungsgemäß keine dauerhaften Wechselkurseffekte. Nur wenn die Notenbank damit ein bewußtes Signal an die Finanzmärkte über den künftigen geldpolitischen Kurs sendet, also letztlich zinspolitische Schritte ankündigt (,Signalling"), sind sterilisierte Interventionen längerfristig wirksam [z. B. Catte et al 1994, Weber 1996].

Kurz- bis mittelfristig können die Wechselkurse mittels sterilisierter Interventionen sehr wohl beeinflußt werden. Auch dies wirkt sich möglicherweise auf den Geldwert im Euroraum aus: Im Falle einer Abwertung steigen die Importpreise, zugleich nimmt die Exportnachfrage zu. Beides schürt die Inflation.

Diese kurzfristig exansiven Wirkungen sind insbesondere bedeutsam, als gewählte Regierungen erfahrungsgemäß dazu neigen, den Zeithorizont ihres Handelns an Wahlzyklen zu orientieren. Wären sie für die Geldpolitik zuständig, 
unterlägen sie stets der Versuchung, durch eine übermäßig expansive Versorgung der Volkswirtschaft mit Zentralbankgeld kurzfristige Output- und Beschäftigungseffekte zu erzielen. Auf mittlere Sicht hingegen ist eine solche Politik real wirkungslos. Die Folgen sind regelmäßig steigende Inflationsraten.

Bedenklicherweise kann im Maastricht-Design eine Koalition aus nationalen Regierungen über den Wechsekurshebel Einfluß auf die Geldpolitik gewinnen. Zwar verpflichtet der Maastricht-Vertrag den Ministerrat, bei seinen wechselkurspolitischen Entscheidungen das Ziel der Preisstabilität zu berücksichtigen (EGV Art. 109 Abs. 1 und 2). Quantifiziert wird dieses Ziel jedoch nicht. Es ist daher durchaus denkbar, daß der Ministerrat sich nicht der Definition der Notenbanken anschließt und höhere Inflationsraten, vielleicht drei oder fünf Prozent, für vertragskonform hält.

Kommt es zum Konflikt zwischen Ministerrat und EZB, so bietet der Maastricht-Vertrag keinen Lösungsweg an. Im Extremfall, das heißt bei einer signifikanten Verletzung des Ziels der Preisstabilität, bliebe der EZB als ultima ratio die Möglichkeit, vor dem Europäischen Gerichtshof zu klagen.

Inflation und Wechselkurssysteme. Dabei erscheinen die Regelungen des EWS II am wenigsten konfliktträchtig. Hier verfügen die EZB und die übrigen beteiligten Notenbanken über eine starke Position, da sie nach eigener Entscheidung Interventionen aussetzen und Verhandlungen über ein Realignment initiieren können. Hingegen schränkt ein internationales System fixierter Wechselkurse bzw. Wechselkurszielzonen die Autonomie der EZB gravierend ein. ${ }^{35}$ Je nach Ausgestaltung eines solchen Regimes wäre sie möglicherweise verpflichtet, ein Wechselkursziel zu verfolgen, das ihrem obersten Ziel, der Wahrung der Preisstabilität, zuwiderläuft. Insofern ergibt sich in diesem Fall ein erhebliches Konfliktpotential.

Unilaterale Wechselkurspolitik. Was die Möglichkeit angeht, ,allgemeine Orientierungen für die Wechselkurspolitik“ zu formulieren, so ist auch hier Vorsicht angebracht. Zum Beispiel ist denkbar, daß der Ministerrat unilateral einen Zielkurs gegenüber dem US-Dollar festlegt. Dies kann mit verschiedenen Intentionen erfolgen. Zum einen besteht die Versuchung, auf diesem Wege Einfluß auf die Geldpolitik zu nehmen. Zum anderen kann es sein, daß es sich um eine monetäre Spielart der Handelspolitik handelt. ${ }^{36}$ Eine solche Strategie kann nicht nur zum Konflikt zwischen Rat und EZB führen, sondern auch zwischen der Eurozone und anderen Ländern, insbesondere den größten außereuropäischen Handelspartnern USA und Japan. ${ }^{37}$

35 Zur Problematik internationaler Fixkurs- bzw. Zielzonensysteme siehe die ausführliche Diskussion in Kapitel 5.

36 Siehe hierzu Abschnitt 3. 2.

37 Dies wird in den Kapiteln 3 und 4 näher diskutiert. 
Relativ kleine Mehrheit. Im Gegensatz zur erforderlichen Einstimmigkeit bei der Implementierung eines Fixkurssystems genügt für solche „allgemeinen Orientierungen" eine Mehrheit von derzeit 43 Stimmen. Mit nicht einmal der Hälfte der Stimmen aller EU-Staaten kann eine Gruppe von „Ins“-Regierungen Einfluß auf die Wechselkurspolitik gewinnen. Die Auswirkungen werden nicht nur auf die Teilnehmerländer begrenzt bleiben, sondern in der gesamten EU spürbar sein. Denn auch die übrigen Volkswirtschaften und Währungen orientieren sich eng am Euro, entweder durch einen expliziten Zielkorridor innerhalb des EWS II oder durch eine am Wechselkurs vis-à-vis dem Euro orientierte Geldpolitik.

Schwerfällige Außenvertretung. Regelmäßig wirken drei Institutionen bei der Außenvertretung des Eurolandes zusammen: die EZB, die Kommission, der Ministerrat, daneben noch der Rat der Euro-11-Gruppe. Eine herausgehobene Position haben zudem die drei „Ins“, die ständige Mitglieder der G 7 sind. Zwischen diesen Institutionen besteht ein erheblicher Abstimmungsbedarf. Dies verschärft sich noch durch die hälbjährlichen Wechsel in der Präsidentschaft der Euro-11Gruppe. Sich auf eine gemeinsame Position zu einigen dürfte daher nicht immer leicht sein. So forderte bereits der Europäische Rat von Wien ,die Kommission, den Rat und die Mitgliedstaaten auf, die notwendigen Maßnahmen zu ergreifen, um eine rechtzeitige und wirksame Vorbereitung gemeinsamer Standpunkte und gemeinsamer Ausrichtungen sicherzustellen, die gegenüber Dritten in internationalen Foren vertreten werden können" [Europäischer Rat 1998: Ziff. 15]. Ob sich die derzeitige unübersichtliche Lösung dauerhaft aufrecht erhalten läßt, ist fraglich.

\section{4 Haushaltskontrolle und die Vermeidung übermäßiger Defizite}

Die Haushaltskontrolle und die Prozeduren zur Vermeidung übermäßiger Defizite stellen einen Spezialbereich der allgemeinen Wirtschaftspolitik dar. Die Ausgestaltung unterscheidet sich jedoch in vielerlei Hinsicht von den übrigen Feldern der Wirtschaftspolitik, weshalb sie zunächst für sich genommen analysiert werden soll.

Um die oben diskutierten Unwägbarkeiten bezüglich der Unabhängigkeit der neuen Währungsbehörde zu lindern, sieht der Vertrag zur Hauskontrolle ein detailliertes Verfahren vor, das über die allgemeinen wirtschaftspolitischen Spielregeln in der EU hinausgeht. Diese Regelungen haben die Regierungen der Teilnehmerstaaten später im Rahmen des „Stabilitäts- und Wachstumspakts” (StWP) weiter verschärft. Es handelt sich hierbei um ein recht striktes Überwachungsverfahren, an dessen Ende finanzielle Sanktionen bei Verstößen gegen die Gemeinschaftsregeln stehen. 


\section{4. 1 Ziele}

EGV Art. 104c und der StWP verfolgen vor allem ein Ziel: In Abwesenheit einer zentralen europäischen Regierung sollen sie verhindern, daß die EZB in Bedrängnis gerät, die defizitäre Haushaltspolitik der Mitgliedstaaten durch eine zügellose Geldpolitik zu alimentieren. Ein solcher Interessenkonflikt zwischen Fiskal- und Geldpolitik kann insbesondere in zwei Situationen entstehen:

- Ein Mitgliedsland versucht, mit einer „Deficit-spending”-Politik die Nachfrage übermäßig anzuheizen. Falls die EZB dem resultierenden inflationären Druck mit einer Anhebung der Leitzinsen entgegentritt, wirken Geld- und Fiskalpolitik in unterschiedliche Richtungen - eine expansive Fiskalpolitik wird durch eine restriktive Geldpolitik konterkariert. Entsprechend groß ist der Druck auf die EZB, von einer Leitzinserhöhung abzusehen. Solcherlei Einflußnahme kommt in dieser Situation nicht nur aus dem Verursacherland, sondern womöglich auch aus den übrigen Staaten, die ohne eigenes Verschulden ebenfalls die Kosten der erhöhten Zinsen zu tragen hätten und folglich versuchen könnten, eine Zinsanhebung abzuwenden.

- Hohe aufgelaufene Staatsschulden engen den Haushaltsspielraum der Mitgliedsländer ein. Da der Schuldendienst umso teurer ist, je höher die nominalen Zinsen sind, liegt die Befürchtung nahe, daß Staaten mit einer hohen und steigenden aufgelaufenen Staatsverschuldung Druck auf die Zentralbank ausüben werden, die Zinsen niedrig zu halten, selbst wenn dies dem Ziel der Geldwertstabilität zuwiderliefe.

Die finanzpolitischen Regeln der EWU sind auch eine Sicherungsmaßnahme der nationalen Fisci untereinander. Denn eine über längere Zeiträume stark defizitäre Haushaltspolitik ist nicht dauerhaft tragbar. Sie führt in eine Schuldenfalle, in der die Differenz zwischen Staatseinnahmen und Staatsausgaben vor Zinsausgaben („Primärüberschuß”) nicht ausreicht, um die aufgelaufenen Schulden zu bedienen. ${ }^{38}$ Ein Staat wird umso eher in eine solche Situation geraten, je wahrscheinlicher eine Haftungsübernahme („Bailing out”) durch die Partnerländer ist. Es existieren also veritable Anreize, die durch die „No-Bail-out”-Regel des MaastrichtVertrags (EGV Art. 104a) nicht vollständig beseitigt werden, so daß eine Verschärfung mittels StWP geboten erschien.

38 Gemessen wird dies anhand des Konzepts der Primärübeschußquote (pü). Sie ist definiert als Primärüberschuß im Verhältnis zum Bruttoinlandsprodukt und drückt den Anteil am BIP aus, den eine Volkswirtschaft im langfristig Mittel aufbringen muß, um die aufgelaufenen Staatsschulden $z u$ bedienen. Sofern $p \ddot{u}=(i-\gamma) s$ gilt, mit $i$ als Nominalzins, $\gamma$ als Wachstumsrate des nominalen BIP und $s$ als Schuldenquote, reichen die Einnahmen des Staats aus, um langfristig die Schuldenquote konstant zu halten [Klodt/Stehn et al. 1994: 254ff]. Zur Problematik versteckter versteckter Schuldenlasten in den Sozialsystemen der EU-Staaten mit der Währungsunion vgl. Kopits 1997. 


\section{4. 2 Zuständigkeit}

Mit Beginn der zweiten Stufe der EWU unterwarfen sich die EU-Staaten dem Procedere der Überwachung der Haushaltslage gemäß EGV Art. 104c. Mit Beginn der dritten Stufe trat der StWP inkraft. Danach sind die Mitgliedstaaten ,(...) weiterhin für ihre Haushaltspolitik verantwortlich”, allerdings „,vorbehaltlich der Bestimmungen des Vertrags" [Europäischer Rat 1997a: 16]. Thr finanzpolitisches Gebahren unterliegt der permanenten Kontrolle durch die Europäische Kommission und die im Ministerrat versammelten Regierungen der übrigen Mitgliedsländer. Die Überwachung der Haushaltspolitik trägt damit „deutlich zwischenstaatliche Züge" [Weidenfeld/Jung 1994: 22ff].

Eskalationsleiter. Prinzipiell handelt es sich um ein „Frühwarnsystem” [Europäischer Rat 1996: 11], das Fehlentwicklungen bereits vor Überschreiten der Grenzwerte offenlegen soll. Stellt die Kommission ,schwerwiegende Fehler” fest, insbesondere wenn das Haushaltsdifizit drei Prozent des jeweiligen BIP überschreitet, ${ }^{39}$ setzt sie das Verfahren des StWP in Gang..$^{40}$

Der StWP legt eine Eskalationsleiter für einen haushaltspolitischen Konflikt zwischen einem Mitgliedsland und dem Rest der EU fest, wobei die Initiative stets von der Kommission ausgeht, die Entscheidung auf jeder Stufe jedoch im Rat der Wirtschafts- und Finanzminister (ECOFIN) mit qualifizierter Mehrheit fällt. Kommission und Rat agieren also Zug um Zug.

Bedeutsam sind insbesondere die Fälle, in denen nach StWP Bußgelder verhängt werden können. Sie sind die Ultima ratio der Haushaltsüberwachung und stellen das eigentliche Abschreckungspotential gegen übermäßige Defizite dar.

Verhängung von Sanktionen. Bußgelder können erhoben werden, sofern die Defizitquote 3,0 Prozent des BIP überschreitet und die betreffende Regierung diesen Zustand nicht im Rahmen der zuvor vom Rat gesetzten Frist korrigiert. Zur Verhängung eines Bußgeldes ist wiederum eine Mehrheitsentscheidung des Rates erforderlich. Er prüft, ob eine Ausnahmesituation vorliegt, eine Rezession, in der es aus konjunkturpolitischen Gründen sinnvoll erscheint, die automatischen Stabilisatoren weiter wirken zu lassen. Sofern in dem betreffenden Land eine „schwere Rezession” herrscht, gilt auch eine Defizitquote von mehr als 3,0 Prozent des BIP nicht als übermäßiges Defizit. Befindet der Rat, daß dies der Fall ist, entfallen die Sanktionen.

Der Rat verfügt allerdings nur über einen eingeschränkten Entscheidungsspielraum. In jedem Fall gilt ein realer BIP-Rückgang von zwei Prozent oder mehr als „schwere Rezession”. Politischer Spielraum über Sanktionen besteht für den Ministerrat insbesondere bei einem realen BIP-Rückgang zwischen 0,75 und zwei Prozent. Die Mitgliedstaaten haben sich verpflichtet, einen leichteren Rückgang

39 Art. 2 des Protokolls über das Verfahren bei einem übermäßigen Defizit.

40 Im einzelnen siehe Europäischer Rat (1996: 9ff). 
als 0,75 Prozent oder gar eine BIP-Zunahme ,in der Regel” nicht als Ausnahmesituation gelten $\mathrm{zu}$ lassen und entsprechend Sanktionen zu verhängen [Europäischer Rat 1997a: 17].

Höhe der Sanktionen. Die Bußgelder setzen sich zusammen aus einer festen Komponente von 0,2 Prozent des BIP des jeweiligen Landes sowie einer veränderlichen Komponente, die „(...) ein[em] Zehntel des Betrages entspricht, um den das Defizit den Referenzwert von 3\% des BIP übersteigt" [Europäischer Rat 1996: 14]. Diese Summe ist bei der EZB als unverzinsliche Einlage zu halten. Sofern das Defizit binnen zwei Jahren nicht auf oder unter die 3,0-Prozent-Marke zurückgekehrt ist, verwandelt sie sich in eine Geldbuße.

\section{4. 3 Beurteilung}

Bei den haushaltspolitischen Regeln handelt es sich um einen Minimalkonsens. Einerseits soll die Haushaltspolitik in nationaler Hoheit bleiben, andererseits sollen Anreize zu „Free riding” und „Moral hazard” beseitigt werden, die wiederum zwischenstaatliche oder supranationale Eingriffe in die nationale Haushaltspolitik nötig machen. Es besteht also ein fundamentaler Konflikt, den es auszubalancieren gilt.

Einschränkung parlamentarischer Rechte. Der StWP ist mit erheblichen Einschränkungen der Rechte der nationalen Parlamente verbunden [Hasse 1997: 18]. Dies gilt nicht nur für die Verhängung von Bußgeldern und die Beschränkung der Nettoneuverschuldung auf drei Prozent des BIP. Die nationale Finanzpolitik wird insbesondere auch dadurch eingeschränkt, daß sich die EWU-Länder verpflichtet haben, ihre Staatshaushalte bei normaler Konjunkturlage möglichst ausgeglichen zu halten, damit in rezessionären Situationen genug Spielraum für die Wirksamkeit der automatischen Stabilisatoren besteht, ohne daß die Grenzwerte überschritten werden. Im Endeffekt ist die Finanzpolitik zwar nicht zentralisiert, sie läßt die Ausgabenseite bislang weitgehend unberührt. ${ }^{41}$ Die Einnahmenseite der öffentlichen Budgets ist jedoch in ihrer Struktur teilweise festgelegt.

Effektive Abschreckung? Gleichzeitig ist keineswegs gewiß, ob der StWP eine glaubwürdige Abschreckung gegen übermäßige Defizite bietet. Mit dieser Frage hat sich gerade der deutsche wissenschaftliche Diskurs eingehend beschäftigt. Die Kritik entzündet sich vor allem am Entscheidungslag bis die Sanktionen greifen, am weiterhin bestehenden politischen Entscheidungsspielraum des Rates in allen Entscheidungsstufen des StWP [Siebert 1997] sowie an der festgelegten maximalen Obergrenze der Sanktionen von 0,5 Prozent des BIP, die sogar einen Anreiz zu noch weiteren Überziehungen des Grenzwertes schaffe [Vaubel 1997]. Weiterhin läßt sich bezweifeln, daß die Grenzwerte tatsächlich überzeugen, da sie ökonomisch nicht begründbar sind, sondern von den Unterzeichnern des Maastricht-Vertrags letztlich willkürlich festgelegt wurden. Fraglich ist auch, ob

41 Eingriffe der EU-Ebene gibt es hier insbesondere bei der Subventionskontrolle. 
Geldbußen gegen Länder greifen, die ohnehin schon eine unsolide Finanzpolitik betreiben. Denn die Zahlung erschwert ihnen die Haushaltskonsolidierung zusätzlich.

Alternativen zum StWP. Um die Probleme des StWP zu vermeiden, wurden in den vergangenen Jahren immer wieder Alternativen diskutiert. So schlagen zum Beispiel Eichengreen/von Hagen (1995) vor, jedes EWU-Land solle einen „nationalen Stabilitätsrat” erhalten: ein mit Fachleuten besetztes Gremium analog dem EZB-Rat, das jährlich entsprechend der konjunkturellen Lage das maximal zulässige, mit einer Stabilitätspolitik vereinbare staatliche Haushaltsdefizt bestimmt. Damit ließe sich sowohl die Problematik der willkürlichen Grenzwerte als auch der Eingriffe in nationale Haushaltshoheit vermeiden..$^{42}$ Gros (1995) schlägt eine andere institutionelle Neuerung vor: Danach sollen Vertreter von Ländern, bei denen der Ministerrat ein exzessives Defizit festgestellt hat, bis zur Beseitigung des Mißstandes ihr Wahlrecht im EZB-Rat verlieren. ${ }^{43}$

Herstellung von Öffentlichtkeit. Insgesamt erscheint es wahrscheinlich, daß es in der EWU zu Konflikten zwischen der Fiskalpolitik einzelner Mitgliedstaaten und der Geldpolitik der Europäischen Zentralbank kommt. Ähnliche Konflikte hat es in der Vergangenheit auch immer wieder mit den nationalen Zentralbanken gegeben. Entscheidend für den Ausgang solcher Konflikte ist die relative Machtposition der Kontrahenten. Hierbei hat die EZB eine relativ starke Stellung. Nicht nur ihre verbriefte Unabhängigkeit spielt eine Rolle, sondern auch die Schwächung der Positionen potentieller Kontrahenten via StWP.

Selbst wenn es nie zur Verhängung finanzieller Sanktion kommen sollte: Der Eskalationsprozeß des StWP macht die Verfehlungen einzelner Staaten frühzeitig öffentlich. Diese Rückendeckung dürfte dazu führen, daß die EZB im Licht der Öffentlichkeit nicht als bürgerferne Institution erscheint, die der Bevölkerung rücksichtslos die sozialen Kosten einer monetären Stabilisierung aufbürdet. Aufgrund dieses Überwachungsmechanismus wird die EZB in den allermeisten Fällen die Mehrheit der Ratsmitglieder auf ihrer Seite haben. Somit dürfte es der StWP den EZB-Ratsmitgliedern erleichtern, eine konsequent stabilitätsorientierte Geldpolitik zu verfolgen.

42 Die teilweise Entmachtung der nationalen Parlamente wäre allerdings auch hier gegeben.

Allerdings dürften solche Strafen kontraproduktiv wirken. Letztlich schwächen sie die Unabhängigkeit der EZB und der nationalen Zentralbanken, weil deren Repräsentanten für Verfehlung ihrer Regierungen haftbar gemacht werden. Mithin unterstellt diese Form der Sanktion implizit, daß die jeweilige nationale Zentralbank ihre nationale Regierung in einer Art imperativem Mandat vertritt. Diese Sichtweise steht der formalen und höchst erwünschten Unabhängigkeit dieser Gremien diametral gegenüber. Insofern wäre auch die abschreckende Wirkung gering. Allenfalls ein drohender Prestigeverlust der Regierung bei der nationalen Öffentlichkeit stellt in diesem Zusammenhang ein Abschreckungspotential gegen übermäßige Defizite dar. 


\section{5 Sonstige Wirtschaftspolitik im EWU-Design}

Die Koordinierung der Wirtschaftspolitiken der Mitgliedstaaten soll das ordnungsgemäße Funktionieren der EWU sicherstellen.

\section{5. 1 Ziele}

Insbesondere angesichts der Heterogenität der Volkswirtschaften des EWURaums bedarf es einer Verpflichtung, politische Maßnahmen zu unterlassen, die von sich aus zu divergenten Entwicklungen führen können. Deshalb legt der Maastricht-Vertrag den Mitgliedstaten die Verpflichtung auf, eine dauerhafte ökonomische Konvergenz zu fördern (EGV Art. 103 Abs.3). Grundlage und somit Oberziel ist ein effizienter Einsatz der Ressourcen in einer offenen Marktwirtschaft mit freiem Wettbewerb (EGV Art. 102a). Seit der Unterzeichnung des Vertrags von Amsterdam 1997 gilt der Beschäftigungspolitik ein besonderes Augenmerk.

\section{5. 2 Zuständigkeit}

Die Wirtschaftspolitik liegt - mit Ausnahme einiger unmittelbar binnenmarktrelevanter Bereiche wie der Wettbewerbs- (EGV Art. 85) oder der Beihilfenkontrolle (EGV Art. 92), für die direkt die Europäische Kommission zuständig ist - weiterhin in den Händen der nationalen Regierungen. Der Maastricht-Vertrag verpflichtet sie allerdings darauf, ,(...) ihre Wirtschaftspolitik als eine Angelegenheit von gemeinsamem Interesse" [EGV Art. 103 Abs. 1] anzusehen und sie so auszurichten, daß sie ,(...) zur Verwirklichung der Ziele der Gemeinschaft” [EGV Art. 102a] beitragen. Um dies zu erreichen, koordinieren sie ihre nationalen Politiken. Zuständig sind der Rat und die Kommission, wobei ersterer die Entscheidungsbefugnis hat, der Kommission obliegt die Überwachung und das Vorschlagsrecht für Ratsentscheidungen.

Formulierung von Zielen. Den Katalog der wirtschaftspolitischen Ziele („Grundzüge der Wirtschaftspolitik”) formuliert die Kommission vor. Nachdem der Rat mit qualifizierter Mehrheit zugestimmt hat, folgt ein Diskussionprozeß mit dem Europäischen Parlament und den Mitgliedstaaten über diesen „Entwurf”. Im Anschluß daran zieht der Europäische Rat „Schlußfolgerungen”, woraus wiederum der Ministerrat mit qualifizierter Mehrheit eine „Empfehlung” an die Mitgliedstaaten richtet, wie diese ihre Wirtschaftspolitik prinzipiell ausrichten sollten (EGV Art. 103 Abs. 2).

Überwachung der Implementierung. In der Folge überwacht der Rat auf Grundlage von Berichten der Kommission die Wirtschaftspolitik der Mitgliedstaaten. Da es sich bei solchen Empfehlungen nicht um einklagbare oder verbindliche Beschlüsse handelt, fehlen jedoch Sanktionsmöglichkeiten bei Verstößen [Weidenfeld/Jung 1994: 22f]. Sofern ein Staat die gemeinsamen Grundzüge ignoriert oder , ,...) das ordentliche Funkionieren der Wirtschafts- und Währungsunion 
zu gefährden droht" (EGV Art. 103 Abs. 4), hat der Rat die Möglichkeit, an den betreffenden Staat - wiederum auf Vorschlag der Kommission und mit qualifizierter Mehrheit - eine Empfehlung zu richten. Als Ultima ratio kann er diese Empfehlung veröffentlichen lassen.

Beistand in Notsituationen. Neben dieser Verpflichtung zu gemeinschaftsverträglichem Verhalten haben sich die EU-Staaten auch dazu verpflichtet, sich gegenseitig finanziellen Beistand in Notlagen zu gewähren. Dies gilt, falls ein Mitgliedstaat ,(...) aufgrund außergewöhnlicher Ereignisse, die sich seiner Kontrolle entziehen", in Schwierigkeiten geraten ist oder zu geraten droht (EGV Art. 103a Abs. 2). Auf Vorschlag der Kommission kann der Rat in solchen Fällen einstimmig Hilfsmaßnahmen beschließen. Sind Naturkatastrophen die Ursache der Schwierigkeiten, genügt eine qualifizierte Mehrheit.

Sonderbereich Arbeitsmarktpolitik. Eine Sonderstellung im Bereich der Wirtschaftspolitik nimmt die Arbeitsmarktpolitik ein [Europäischer Rat 1997b]. Seit der Unterzeichnung des Vertrags von Amsterdam, der ein beschäftigungspolitisches Kapitel enthält und dessen Unterzeichnung ein erster außerordentlicher EU-Beschäftigungsgipfel am 20./21. November 1997 in Luxemburg folgte, bemüht sich die EU um eine Arbeitsmarktpolitik, die sich an der Funktionsweise der Haushaltsüberwachung nach EGV Art. 104c orientiert. Die Verschärfung gegenüber dem Verfahren für die allgemeine Wirtschaftspolitik ergibt sich insbesondere durch die Festsetzung ,spezifischer Zielwerte" in den beschäftigungspolitischen Empfehlungen des Ministerrats. Eine numerische Festlegung erhebt ihren Status über die sonstigen eher unverbindlichen wirtschaftspolitischen Ziele hinaus. Um die von der Gemeinschaft gesetzten Marken zu erreichen, müssen die Mitgliedstaaten ausgehend von den Empfehlungen ,nationale Aktionspläne” für mehr Beschäftigung erarbeiten. Sie sollen sich dabei konkrete Zielwerte und Zeitrahmen setzen, wo immer dies möglich ist.

Die ersten beschäftigungspolitischen Empfehlungen sehen insbesondere eine Stärkung der aktiven Arbeitsmarktpolitik vor. Danach sollen arbeitslose Jugendliche binnen sechs Monaten seit Beginn ihrer Arbeitslosigkeit eine Ausbildung, Umschulung, eine Stelle, ein Praktikum oder andere Maßnahmen der aktiven Arbeitsmarktpolitik angeboten bekommen. Arbeitslose Erwachsene sollen spätestens nach zwölf Monaten ein derartiges Angebot erhalten. Außerdem sollen die Staaten sich Ziele setzen, bis wann sie ihre aktiven Arbeitsmarktprogramme ausgebaut haben wollen. Als Ziel wird ihnen der Durchschnitt der drei „erfolgreichsten Mitgliedsländer" vorgegeben, mindestens aber sollen 20 Prozent der Arbeitslosen in Maßnahmen der aktiven Beschäftigungspolitik unterkommen. Außerdem verpflichten sich die EU-Mitgliedstaaten, berufliche Selbständigkeit sowie kleine und mittlere Unternehmen zu fördern. Darüberhinaus sollen sie die Steuer- und Abgabenlast abbauen, insbesondere auf geringqualifizierte Beschäftigung [Europäischer Rat 1997b]. 


\section{5. 3 Beurteilung}

Obwohl vom Ansatz her so angelegt, begründet das EWU-Design keinen föderalen staatlichen oder quasi-staatlichen Aufbau. Der vollständigen Integration im Bereich der Geldpolitik fehlt eine Entsprechung auf anderen Feldern der Politik. ${ }^{44}$ Die Frage ist: Genügt der bestehende Grad an Integration möglicherweise dennoch?

Das föderale Assignment-Problem. Einen Anhaltspunkt liefert die finanzwissenschaftliche Theorie, die in marktwirtschaftlichen Systemen drei prinzipielle Gründe für staatliche Interventionen unterscheidet [Musgrave 1959]: Der Staat sollte erstens die Allokation der Güter und Produktionsfaktoren verbessern, sofern privatwirtschaftliche Mechanismen versagen. Dies betrifft zum Beispiel die Bereitstellung von öffentlichen Gütern, die Internalisierung von externen Effekten, die Wettbewerbskontrolle oder die Beseitigung von Informationsasymmetrien unter den Marktteilnehmern. Zweitens verfolgt der Staat das Ziel der makroökonomischen Stabilisierung, indem er plötzliche Einbrüche der privaten Nachfrage auszugleichen versucht. Drittens gehört zu den Staatsaufgaben die Verteilungspolitik, also der Eingriff in die marktmäßige personelle, funktionielle oder regionale Verteilung der Einkommen oder Vermögen entsprechend der gesamtgesellschaftlichen Gerechtigkeitsvorstellungen.

Die Frage, welcher Politikbereich bei welcher staatlichen Ebene angesiedelt werden sollte, stellt das bekannte Assignment-Problem föderaler Systeme dar. Die Theorie des fiskalischen Föderalismus formuliert dazu zwei widerstreitende Prinzipien: Dezentralisierung, wo immer möglich - Zentralisierung, wo nötig [z. B. Boadway et al., 1994, Kilper/Lhotta 1996: 56ff].

$\mathrm{Da}$ staatliche Interventionen möglichst auf der niedrigsten Ebene stattfinden sollten, ist politökonomisch und informationstheoretisch begründet: Je niedriger die Entscheidungsebene, desto eher erkennen die politischen Entscheidungsträger die Präferenzen der Bürger, d. h. desto „besser” fallen politische Entscheidungen aus. Darüber hinaus lassen sich durch Dezentralisierung Verwaltungskosten (insbesondere Informations- und Überwachungskosten) einsparen. Und es kommt zu einem institutionellen Wettbewerb staatlicher Einheiten der gleichen Ebene, der potentiell effizienzsteigernd und innovationsfördernd wirkt.

Eingeschränkt wird dieses Prinzip durch die Kosten der Dezentralisierung. So erfordert zum Beispiel das Allokationsziel in einem Binnenmarkt eine gewisse Harmonisierung staatlicher Vorschriften (z. B. Produktstandards), um die Transaktionskosten niedrig zu halten und damit die Effizienz privater Märkte zu erhöhen. Auch ist es vorteilhaft, ein öffentliches Gut auf einer höheren staatlichen Ebene zur Verfügung zu stellen, wenn seine Produktion mit steigenden Skalener-

44 Ein Umstand veranlaßte das Bundesverfassungsgericht in seinem Maastricht-Urteil von 1993 zu der Warnung, die EWU könne wieder auseinanderbrechen. Eine „Lösung aus der Gemeinschaft" sei durchaus denkbar und rechtlich möglich [Weber 1994: 58]. 
trägen („Economies of scale”) verbunden ist. Staatliche Leistungen sollten möglichst frei von externen Effekten (,Spillovers”) sein, so daß im institutionellen Wettbewerb der staatlichen Einheiten einer Ebene keine „Moral-hazard”- oder „Free-riding”-Anreize auftreten, die zu Verzerrungen in der Produktion von staatlichen Leistungen führen. Der institutionelle Wettbewerb kann darüber hinaus zu „Adverse-selection”-Wirkungen führen, sofern die mobilen Faktoren sich den staatlichen Abgaben entziehen und von staatlichen Leistungen angezogen werden. Inwieweit orientiert sich das EWU-Design an diesen Vorstellungen?

Allokationspolitik. Das Binnenmarktprogramm der EU stellt das Ziel einer besseren Allokation von Gütern und Faktoren in den Vordergrund. Insbesondere die Öffnung der Güter- und Kapitalmärkte wurde in den vergangenen Jahren erreicht. Das Oberthema dieser Politik lautet, Verzerrungen und Diskrimminierungen zu vermeiden. Einheitliche Produktstandards wurden etabliert, ansonsten gilt das Prinzip der universellen Geltung einer nationalen Zulassung im gesamten Binnenmarkt, wie es das „Cassis-de-Dijon”-Urteil des Europäischen Gerichtshofs festgestellt hat. Nationale Subventionen unterliegen der Beihilfenkontrolle der Europäischen Kommission. Ehemals nationale Monopole, etwa bei Post, Telekommunikation und Bahn, werden zusehends aufgebrochen und dem Wettbewerb ausgesetzt. Kapitalverkehrsbeschränkungen wurden bis 1990 beseitigt. In diesem Kontext ist auch die Schaffung der Währungsunion zu sehen, die als Vollendung des Binnenmarktes für eine weitere Senkung der Transaktionskosten sorgen soll. Die Regelung und Durchführung dieses Programms einschließlich der Geldpolitik ist auf Gemeinschaftsebene angesiedelt und supranational organisiert.

Stabilisierungspolitik. Bei den übrigen Zielen ist das EWU-Design weniger stringent. In einem Binnenmarkt mit gemeinsamer Währung treten unter den Mitgliedsländern an vielen Stellen „Spillover”-Effekte auf. Dies gilt zum Beispiel für die Konjunkturpolitik: Im Fall eines allgemeinen Nachfrageeinbruchs (,symmetrischer Schock") besteht die Gefahr, daß die EWU-Staaten zuwenig antizyklische Maßnahmen ergreifen, weil sich jeder einzelne auf entsprechende ,überschwappende" Maßnahmen aus dem Partnerländern verläßt bzw. eigene Anstrengungen nicht nur innerhalb nationalstaatlicher Grenzen wirken, sondern auch in den Partnerstaaten. Der spätere Schuldendienst, der „Deficit-spending”-Programmen unweigerlich folgt, obliegt jedoch ganz allein dem jeweiligen nationalen Fiskus. Eine rational handelnde Regierung mit langem Zeithorizont wird deshalb weniger Konjunkturpolitik betreiben als den optimalen Level [Cangiano/Mottu 1998]. Es erscheint fraglich, ob der relativ unverbindliche Koordinierungsmechanismus nach EGV Art. 103 ausreicht, um diese Anreize zu kompensieren. Sie werden sogar noch verstärkt durch den StWP, der gerade den entgegengesetzten Fall betont: daß nämlich die nationalen Regierungen in Zeiten guter Konjunktur eine Politik zu hoher (defizitfinanzierter) Staatsausgaben betreiben und damit 
sukzessive einen unhaltbaren Schuldenberg anhäufen. Welcher Effekt in der Praxis überwiegt, ist offen. ${ }^{45}$

Das Fehlen eines großen, stabilisierenden Zentralbudgets wirkt sich auch bei ,asymmetrischen Schocks” aus, die auf einzelne EWU-Staaten wirken. Gemeinsame staatliche Haushalte haben die Eigenschaft, asymmetrische Entwicklungen abzufedern. So gibt es in den USA zum Beispiel eine zentralstaatliche Einkommensteuer, deren Einnahmen unter anderem über eine ebenfalls zentrale Arbeitslosenversicherung zurückverteilt werden. Somit kommt es zu einem Transfer von Mitteln aus Regionen mit einer konjunkturell günstigen Situationen hin zu Regionen, die unter einem Nachfrageeinbruch leiden. Dies führt zu einem potentiell wohlfahrtssteigernden Zusammenfassen („Pooling”) von konjunkturellen Risiken [Inman/Rubinfeld 1991, Sala-i-Martin/Sachs 1992].

Verteilungspolitik. Die Erreichung personeller und funktionaler Verteilungsziele ist generell Sache der Mitgliedstaaten. Es gibt keine supranationalen Steuer- oder Sozialversicherungssysteme, was aufgrund der geringen grenzüberschreitenden Mobilität der Europäer prinzipiell eine vorteilhafte Organisationsform sein dürfte. Daneben findet regionale Umverteilung auch auf EU-Ebene statt, insbesondere über die Gemeinsame Agrarpolitik [z. B. Henrichsmeyer/Witzke 1994: 545ff] sowie über die Struktur- und Sozialfonds [Peffekoven 1992]; beide Politikbereiche werden zentral von der EU-Kommission verwaltet. Dazu kommen noch die Kohäsionsfonds, der Geld an Länder ausschüttet, die ein Pro-Kopf-BIP von weniger als 90 Prozent des Gemeinschaftsdurchschnitts aufweisen [Häde 1996: 156ff]. Damit verfügt die EU über ein Instrument in der „Nähe eines bundesstaatlichen Finanzausgleichs" [Häde 1996: 157]. Auch die Agrarfonds enthalten massive regionale Umverteilungselemente, da sie zuvörderst den strukturschwächeren EU-Staaten mit relativ großen Agrarsektoren zugute kommen. Agrar- und Strukturfonds zusammen machen etwa Dreiviertel des EUBudgets aus.

Nationale Programme zur Regionalförderung (in der Bundesrepublik insbesondere die "Gemeinschaftsaufgabe Verbesserung der regionalen Wirtschaftsstruktur") unterliegen der Aufsicht durch die EU-Kommission. Im Gegensatz zum deutschen Fiskalsystem, das geprägt ist von ungebundenen Transfers zwischen Bund und Ländern („Bundesergänzungszuweisungen”) sowie zwischen den Ländern („Länderfinanzausgleich”), gibt es in der EU nur gebundene Transfers für

45 Auch der IWF teilt die Befürchtung, es könne zu zu geringen antizyklischen konjunkturpolitischen Maßnahmen kommen. Die Washingtoner Organisation folgert, daß ,[...] external leakages of fiscal stabilization, which can be quite large, especially from the smaller, more open EU economies" dazu führen könnten, daß ,[...] in the absence of policy coordination the amount of fiscal stabilization done in aggregate might be suboptimal" [IWF 1997: 61]. De Silguy (1999) fordert einen Konjunkturfonds auf EU-Ebene. 
bestimmte Aufgaben, an denen sich auch der jeweilige Mitgliedstaat beteiligen muß (,Prinzip der Additionalität”). ${ }^{46}$

Steuerpolitik. Ein Problemfeld innerhalb der EU, das sowohl das Verteilungs- als auch das Allokationsziel berührt, ist die Steuerpolitik, insbesondere wo sie die direkte Besteuerung betrifft. Auch sie ist weiterhin national organisiert und wird EU-weit koordiniert, wobei allerdings einstimmige Voten des Ministerrates erforderlich sind. Eine gewisse Harmonisierung findet bei den Verbrauchssteuern statt bzw. wurde bereits vollzogen. ${ }^{47}$ Bei den direkten Steuern gibt es bislang keine vergleichbaren Schritte [Hoeller et al. 1996: 20ff]. Der Bericht des RudingKomitees im Auftrag der Europäischen Kommission, vorgelegt 1992, kam zu dem - umstrittenen - Urteil, daß a) die derzeitige Vielfalt der Einkommen- und Körperschaftsteuersysteme, Steuersätze und Bemessungsgrundlagen zu Verzerrungen auf den europäischen Kapitalmärkten führe und daß b) insbesondere bei Steuern auf Portfoliokapital eine Erosion der Steuerbasis aufgrund des Steuerwettbewerbs zwischen den EU-Staaten zu befürchten sei.48 Das Ruding-Komitee schlug deshalb vor, bis zum Beginn der dritten Stufe der Währungsunion ein einheitliches Körperschaftsteuersystem zu errichten mit einheitlicher Steuerbasis und Steuersätzen innerhalb eines Korridors von 30 bis 40 Prozent sowie die Zins- und Dividendenbesteuerung zu harmonisieren [Committee of Independent Experts 1992] ${ }^{49}$

Bislang konnten solche Vorschläge in der europäischen Politik nicht verfangen. Die EU-Staaten verfolgten statt dessen den Ansatz, einen Verhaltenskodex für den Steuerwettbewerb um hochmobile Faktoren, insbesondere PortfolioKapital, zu entwickeln. Damit wollen sie Steueroasen 50 innerhalb der EU austrocknen, um einen „schädlichen Steuerwettbewerb” zu verhindern. Im Vordergrund stehen also rein fiskalische Erwägungen. Zudem ist dieser Kodex rechtlich

46 Eine umfassende Analyse und Kritik der EU-Regionalpolitik findet sich bei Arnold (1995).

47 EGV Art. 99. Allerdings läßt beim Mehrwertsteuersystem bislang ein Übergang zum Ursprungsland- bzw. Binnenmarktprinzip auf sich warten.

48 Sinn (1990) kommt in einem Tibout-Setting zu einer weit pessimistischeren Prognose. Seine Schlußfolgerung für den Standortwettbewerb innerhalb Europas lautet: „Even if all Europeans were equally risk averse and would prefer government redistribution to laissez-faire, competitive and decentralized gonvernments would not be able to satisfy their needs. Any country that tries to establish an insurance state would be driven into bankrupcy because it would face emigration of the lucky who are supposed to give and immigration of the unlucky who are supposed to receive" [Sinn 1990: 502].

49 Eine Diskussion der Vorschläge des Ruding-Komitees findet sich bei Chown (1992), Devereux (1992), Genser et al. (1992), zur generellen Problematik der Unternehmensbesteuerung bei offenen Kapitalmärkten siehe die Beiträge in Siebert (1990).

50 Dies ist insbesondere der Fall, wenn in einem Land Gebietsfremde (z. B. sogenannte Off-shoreUnternehmen) günstigere steuerliche Bedingungen vorfinden als als Einheimische [Europäische Kommission 1997d: 12]. 
nicht bindend. Hauptsächliches Instrument ist der Informationsaustausch zwischen den Mitgliedsländern [Europäische Kommission 1997d]. ${ }^{51}$

Beschäftigungspolitik. Einen erheblich weitergehenden Ansatz verfolgt die gemeinsame Beschäftigungspolitik à la Amsterdam. Zwar liegt auch ihre Ausgestaltung weiterhin in Händen der Regierungen der Mitgliedstaaten. Deren Spielraum wird jedoch eingeschränkt, indem ihnen von der EU-Ebene konkrete Ziele vorgegeben werden. Dieses Vorgehen ist insbesondere in Deutschland umstritten. Die Gegner betonen, daß erfolgreiche Beschäftigungspolitik nur auf der Ebene der Mitgliedstaaten möglich sei. Nach einer solchen Sichtweise eignet sich eine Leviathan-EU-Ebene, repräsentiert insbesondere durch die EU-Kommission, Befugnisse an, die ihr gemäß Subsidiaritätsprinzip eigentlich nicht zustehen [z. B. Berthold 1996].

Tatsächlich erscheint fraglich, ob die ersten beschäftigungspolitischen Empfehlungen für das Jahr 1998 den richtigen Weg weisen. Sie legen einen starken Akzent auf die aktive Arbeitsmarktpolitik. Die drei numerisch festgelegten Ziele Dauer der Arbeitslosigkeit von Jugendlichen und Erwachsenen bis zum Angebot einer Maßnahme, Umfang der aktiven Arbeitsmarktpolitik insgesamt - konzentrieren sich auf dieses Feld. Andere Maßnahmen, die auf eine dauerhafte privatwirtschaftliche Beseitigung der Ungleichgewichte auf dem Arbeitsmarkt gerichtet sind, spielen nur eine Nebenrolle. So sollen die EU-Staaten Selbständigkeit, Klein- und Mittelbetriebe fördern sowie die Steuer- und Abgabenlast senken, was allerdings nur unverbindlich in den Empfehlungen erwähnt wird und daher nicht einklagbar ist.

Unabhängig von der Bewertung der Ausgestaltung der beschäftigungspolitischen Empfehlungen, ist die Koordinierung dieses Politikfeldes doch für die Währungsunion prinzipiell von Vorteil, solange dadurch das Augenmerk auf die mikroökonomischen Bedingungen auf den Arbeitsmärkten gelenkt wird. Somit entlastet sie potentiell die EZB von dem öffentlichen Druck, ihre Geldpolitik bei hoher Arbeitslosigkeit auch an beschäftigungspolitischen Zielen auszurichten. Sie unterstreicht das Assignment des Maastricht-Vertrags, nach dem die EZB allein für die Geldwertstabilität zuständig ist, die nationalen Regierungen und Tarifparteien hingegen für die Konjunktur- und die Beschäftigungspolitik verantwortlich sind. Möglicherweise gelingt es dem Rat der Europäischen Union in künftigen Jahren, beschäftigungspolitische Empfehlungen zu verabschieden, die auf eine stärkere Flexibilisierung der Arbeitsmärkte und einen Abbau von beschäftigungshemmenden Regulierungen abzielen. Dies würde dazu beitragen, die Absorptionsfähigkeit bei externen Schocks zu verbessern [IWF 1999, OECD 1999].

51 Tanzi/ Zee (1998) bezweifeln, daß eine Harmonisierung der Steuern überhaupt nötig ist, und verweisen auf das Beispiel USA. 
Übersicht 2-2: Assignment ausgewählter wirtschaftspolitischer Bereiche

\begin{tabular}{|c|c|c|c|c|c|c|c|}
\hline & Geldpolitik & $\begin{array}{l}\text { Wechsel- } \\
\text { kurspolitik }\end{array}$ & $\begin{array}{l}\text { Haushalts- } \\
\text { politik }\end{array}$ & $\begin{array}{l}\text { Arbeits- } \\
\text { markt- } \\
\text { politik }\end{array}$ & $\begin{array}{l}\text { Steuer- } \\
\text { politik }\end{array}$ & $\begin{array}{l}\text { Fiskal- } \\
\text { politik }\end{array}$ & $\begin{array}{l}\text { Regional- } \\
\text { politik }\end{array}$ \\
\hline Ziele & $\begin{array}{l}\text { Primär: } \\
\text { Geldwert- } \\
\text { stabilität } \\
\text { Sekundär: } \\
\text { Unterstütz- } \\
\text { ung allgem. } \\
\text { Wirtschafts } \\
\text {-politik }\end{array}$ & $\begin{array}{l}\text { Primär: } \\
\text { Geldwert- } \\
\text { stabilität } \\
\text { Sekundär: } \\
\text { Unterstütz- } \\
\text { ung allgem. } \\
\text { Wirtschafts } \\
\text { politik }\end{array}$ & \begin{tabular}{|l|} 
Primär: \\
Unabhäng- \\
ige EZB, \\
Ver- \\
meidung \\
von „Moral \\
Hazard”- \\
Verhalten \\
Sekundär: \\
Konsoli- \\
dierte öff. \\
Haushalte
\end{tabular} & $\begin{array}{l}\text { Primär: } \\
\text { Hoher Grad } \\
\text { an } \\
\text { Beschäfti- } \\
\text { gung } \\
\text { Sekundär: } \\
\text { Unabhäng- } \\
\text { ige EZB, } \\
\text { allgemeine } \\
\text { politische } \\
\text { Stabilität }\end{array}$ & \begin{tabular}{|l|} 
Primär: \\
Sicherung \\
der \\
Staatsein- \\
nahmen \\
Sekundär: \\
Störungs- \\
freier \\
Binnen- \\
markt
\end{tabular} & \begin{tabular}{|l|} 
Primär: \\
Konjunktur \\
-politische \\
Stabilisie- \\
rung \\
Sekundär: \\
Absicher- \\
ung der \\
EWU
\end{tabular} & $\begin{array}{l}\text { Primär: } \\
\text { Konvergenz } \\
\text { der EU- } \\
\text { Ökonomien } \\
\text { Sekundär: } \\
\text { Störungs- } \\
\text { freier Bin- } \\
\text { nenmarkt }\end{array}$ \\
\hline $\begin{array}{l}\text { Zustän- } \\
\text { digkeit }\end{array}$ & $\begin{array}{l}\text { ESZB, EZB } \\
\text { (exklusiv) }\end{array}$ & \begin{tabular}{|l|} 
Primär: \\
Ministerrat \\
Sekundär: \\
EZB
\end{tabular} & \begin{tabular}{|l|} 
Primär: \\
EU-Staaten \\
Sekundär: \\
Ministerrat
\end{tabular} & $\begin{array}{l}\text { Primär: } \\
\text { EU-Staaten } \\
\text { Sekundär: } \\
\text { Ministerrat }\end{array}$ & $\begin{array}{l}\text { Primär: } \\
\text { EU-Staaten } \\
\text { Sekundär: } \\
\text { Ministerrat }\end{array}$ & \begin{tabular}{|l|} 
Primär: \\
EU-Staaten \\
Sekundär: \\
Ministerrat
\end{tabular} & $\begin{array}{l}\text { Primär: } \\
\text { EU- } \\
\text { Kommis- } \\
\text { sion } \\
\text { Sekundär: } \\
\text { Ministerrat }\end{array}$ \\
\hline \begin{tabular}{|l} 
Instru- \\
mente \\
der EU- \\
Politik
\end{tabular} & $\begin{array}{l}\text { Zinspol., } \\
\text { Devisen- } \\
\text { markt- } \\
\text { interven* }\end{array}$ & $\begin{array}{l}\text { Orientierun } \\
\text { gen an EZB }\end{array}$ & $\begin{array}{l}\text { Gem. Haus- } \\
\text { haltsüberwa } \\
\text { chung nach } \\
\text { StWP }\end{array}$ & $\begin{array}{l}\text { Beschäfti- } \\
\text { gungspol. } \\
\text { Leitlinien }\end{array}$ & \begin{tabular}{|l|} 
Steuer- \\
kodex \\
(Moral Sua- \\
sion)
\end{tabular} & $\begin{array}{l}\text { Wirtschafts } \\
\text {-politische } \\
\text { Leitlinien }\end{array}$ & $\begin{array}{l}\text { Regional-, } \\
\text { Struktur-, } \\
\text { Kohäsions- } \\
\text { fonds, GAP }\end{array}$ \\
\hline
\end{tabular}

*Weitere Instrumente stehen der EZB nach eigenem Ermessen zur Verfügung, insbesondere die Mindestreservepolitik. Das Hauptgewicht der geldpolitischen Steuerung liegt auf wöchentlichen Wertpapierpensionsgeschäften [Europäisches Währungsinstitut 1997b, Europäische Zentralnbank 1999a]. Quelle: eigene Darstellung

Wie Übersicht 2-2 zeigt, ist die europäische Wirtschaftspolitik insgesamt eher von dem Bemühen geprägt, eine verstärkte Koordinierung nationalstaatlicher Politiken zu erreichen als weitere Kompetenzen auf der Gemeinschaftsebene zu zentralisieren. Dies ist prinzipiell zu begrüßen, insbesondere da bislang keine wirkliche demokratische Kontrolle der EU-Institutionen existiert. ${ }^{52}$ Die europäische Integration ist jedoch als ergebnisoffener Prozeß angelegt, eine Vergemeinschaftung weiterer Politikbereiche ist somit durchaus möglich. Dies ist insbesondere wahr-

52 Der IWF hält insbesondere folgende Punkte für unabdingbar: eine Flexibilisierung der Arbeitsmärkte und eine Konsolidierung der öffentlichen Finanzen in den Mitgliedsländern, um auch unter dem Regime des StWP asymmetrische Schocks abfedern zu können. ,[...] If EMU is not accompanied by further progress with structural reforms and fiscal consolidation, there are likely to bei serious consequences for Europe" [IWF 1997: 77]. 
scheinlich, wenn gravierende ökonomische oder politische Spannungen auftreten. 53

Allerdings ist dieses Vorgehen, wie eingangs erwähnt, mit dem erheblichen Risiko verbunden, daß sich die EU-Regierungen womöglich zum entscheidenden Zeitpunkt nicht einigen können, etwa weil es die innenpolitischen Konstellationen in einigen Ländern nicht zulassen. Dies gilt insbesondere bei Fragen, die einstimmige Voten erfordern, etwa die Steuerpolitik. Treten solche, durch die derzeitigen Koordinierungsmechanismen der EU nicht lösbaren Spannungen auf, werden sie sich Ventile suchen. ${ }^{54}$

\section{6 Genügt der institutionelle Rahmen den Herausforderungen der Zukunft?}

Da die Gestalt des Euro-Raums nicht den von der TOW postulierten Kriterien folgt und das EWU-Design vor allem bei der Stabilisierungspolitik erhebliche Mängel aufweist, ist durchaus zu erwarten, daß auftretende ökonomische Spannungen zu entsprechend ernsten politischen Konflikten innerhalb der Europäischen Union führen. Denn die EU dürfte damit wirtschaftlichen Ungleichgewichten ausgesetzt sein, die sich nach Beginn der EWU nicht mehr mit den Instrumenten Geld- und Wechselkurspolitik abbauen lassen. Insbesondere mangelt es an der Flexiblität der Arbeitsmärkte, aber auch der nationalen Fisci. Wie sich unter diesen Bedingungen ein asymmetrischer Schock auswirken kann, sei am Beispiel eines mittelfristig bevorstehenden Großereignisses erläutert: dem EU-Beitritt der Mittel- und Osteuropäischen Länder (MOEL).

Die EU-Osterweiterung als politik-induzierter Schock. Mit dem Beitritt der MOEL steht der Europäischen Union nach der EWU ein weiterer struktureller Einschnitt von großer Tragweite bevor. Ab dem Jahr 2002 ist mit der Mitgliedschaft der ersten Staaten zu rechnen. Beitrittsverhandlungen hat die EU $1998 \mathrm{zu}-$ nächst mit fünf Ländern aufgenommen: mit Polen, Ungarn, der Tschechischen Republik, Slowenien und Estland. ${ }^{55}$ Dabei wird deutlich, daß bei der Osterweiterung, wie zuvor bei der Währungsunion, politische Erwägungen dominieren. Insbesondere der Beitritt Polens dürfte wegen der Größe und des wirtschaftlichen Entwicklungsrückstands des Landes für Verwerfungen innerhalb der EU sorgen (Abbildung 2-6).

53 So weist von Hagen (1996) darauf hin, daß die wirtschaftspolitische Integration der USA entscheidend durch Wirtschaftskrisen vorangetrieben wurde, insbesondere durch den ,New Deal" als Reaktion auf die Weltwirtschaftskrise der dreißiger Jahre.

54 Berthold (1996: 61) spricht gar vom „Pulverfaß einer Währungsunion”.

55 Daneben wurden auch Verhandlungen mit Zypern aufgenommen, 1999 auch mit Malta. 


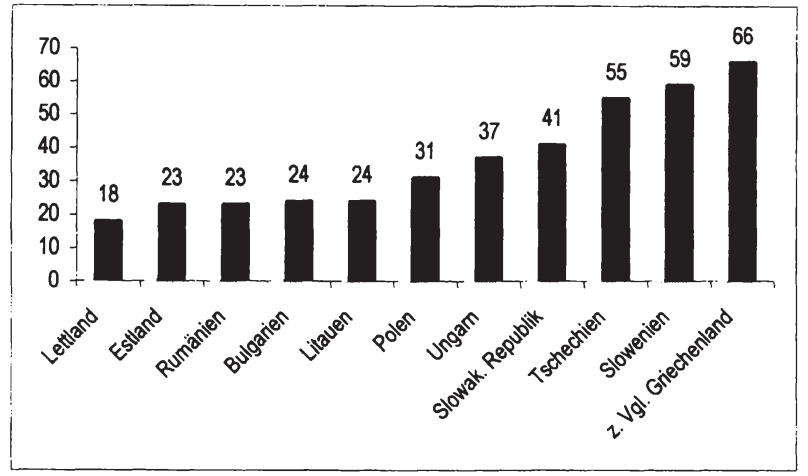

BIP in ECU zu Kaufkraftstandards in Prozent des EU-15-Durchschnitts, Stand: 1995. Quelle: EU-Kommission (1997e)

Anpassunglasten im Westen. Insgesamt wird die Integration derart heterogener Volkswirtschaften wie diejenigen der heutigen EU und der MOEL mit erheblichen Anpassungskosten verbunden sein. So weist die Europäische Kommission (1997e: 19) darauf hin, daß die positiven Effekte der Integration - eine bessere Ressourcenallokation und die Ausnutzung von Größenvorteilen in einem Binnenmarkt mit letztlich einer halben Milliarden Menschen - sich , ,[...] nicht alle von heute auf morgen einstellen und auch nicht gleichmäßig verteilt sein" werden. Vielmehr sei „[...] noch lange Zeit nach der Erweiterung” ein „substanzieller Anpassungdruck auf sektoraler und regionaler Ebene unvermeidlich. Dies könnte wirtschaftliche, soziale und politische Spannungen verursachen". 56

Die Integration der osteuropäischen Länder in den EU-Binnenmarkt impliziert zwei grundlegende Effekte: Zum einen entfallen auf den Güternmärkten die noch bestehenden Handelshemnisse (Zölle, Quoten). Zum anderen öffnen die EUStaaten wie die MOEL ihre Faktormärkte, indem sie rechtliche Regelungen abschaffen, die bislang noch Ausländer diskrimminieren.

Handelstheoretische Analyse. Die daraus erwachsenden Effekte lassen sich in einem traditionellen neoklassischen Heckscher-Ohlin-Setting veranschaulichen: Die EU als ganzes ist relativ reichlich mit Kapital ausgestattet, die MOEL relativ reichlich mit dem Faktor Arbeit. Die Transformationskurven der EU (TT')

56 Aus ökonomischer Sicht dürfte die rasche Aufnahme in den europäischen Binnenmarkt nicht die optimale Lösung sein. Vorzuziehen wäre eine allmähliche Annäherung an den westeuropäischen Entwicklungsstand in einem „Stufenplan” [Bruha/Straubhaar 1997]. Doch hat diese Option kaum Chancen auf Realisierung. Für eine Analyse der Konvergenzgeschwindigkeit zwischen Ost- und Westeuropa vgl. Fischer et al (1998), für eine Analyse der Reformen in den MOEL vgl. Europäische Kommission (1998b), für eine Analyse der EU-Strukturpolitik im Lichte der Osterweiterung vgl. Hallet (1997). 
und der MOEL ( $\left.\mathrm{T}^{*} \mathrm{~T}^{*}\right)$ in Abbildung 2-7 sind entsprechend unterschiedlich geformt. Bei einer Intensivierung des Handels ergibt sich somit, gemäß HeckscherOhlin (H-O), ein komparativer Vorteil der EU bei kapitalintensiven Gütern $\left(Q_{1}\right)$, während die MOEL bei arbeitsintensiven Gütern $\left(Q_{2}\right)$ einen komparativen Vorteil besitzen. Folglich verschiebt sich das Spezialisierungsmuster: Die EU produziert mehr desjenigen Gutes, das den reichlichen Faktor Kapital intensiv nutzt $\left(Q_{1}\right)$, und weniger des arbeitsintensiv produzierten Gutes $\left(Q_{2}\right)$. Spiegelbildlich produzieren die MOEL weniger $Q_{1}^{*}$, sondern importieren eine größere Menge davon aus der EU. Sie produzieren mehr $Q_{2}{ }^{*}$ und exportieren dies ihrerseits in die EU. Es stellt sich ein einheitlicher Relativpreis $\left(p^{\prime}\right)$ ein. ${ }^{57}$

Gewinner und Verlierer. Anhand von Abbildung 2-7 lassen sich die Verlierer des Freihandels identifizieren: Es sind die Faktoren im jeweiligen Importsubstitionssektor. Sie werden weniger nachgefragt, ergo sinkt der Faktorpreis und damit ihr reales Einkommen (,Stolper-Samuelson-Theorem”). Sofern die Reallokation der Faktoren nicht friktionslos möglich ist oder die Faktorpreise nicht flexibel sind - was in der Realität meist der Fall sein dürfte -, kommt es zu einem Absinken der Beschäftigungsmenge von sektorspezifischen Faktoren.

\section{Abbildung 2-7: Allokationseffekte der Osterweiterung im H-O-Setting}

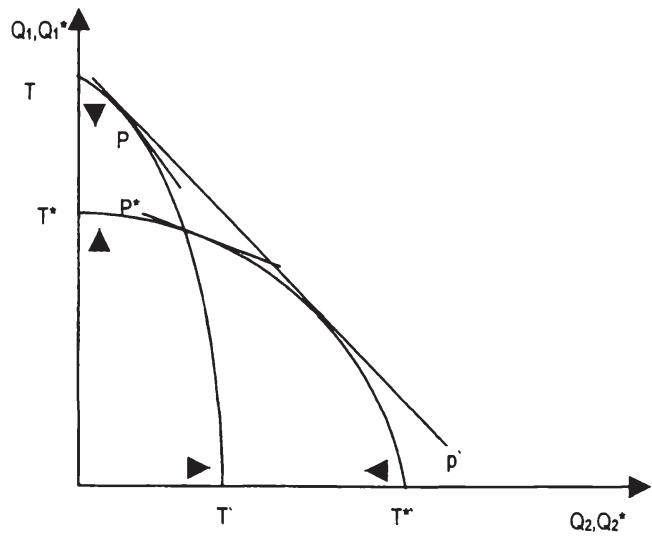

Da die Integration in den Binnenmarkt zugleich die Öffnung der Faktormärkte beinhaltet, kommt es zudem tendenziell zu Faktorwanderungen, wobei allerdings gerade beim Faktor Arbeit die Mobilitätshemmnisse erheblich sind. Kapital wandert aus der EU in die damit schwach ausgestatteten MOEL, weil es dort, wie im neoklassischen Kontext unterstellt, höhere Grenzerträge (reale Renditen) abwirft,

$57 p$ und $p^{*}$ in Abbildung 2-7 bezeichnen die Relativpreise auf dem jeweiligen Markt vor dem Wegfall der Handelsbarrieren. 
während die Grenzerträge in der reichlich mit Kapital ausgestatteten EU relativ niedrig sind. Arbeit wandert von den MOEL nach der EU, wo die Löhne real höher sind. Beide Wanderungsbewegungen führen dazu, daß sich die Transformationskurven von der Form her annähern, wie die Pfeile in Abbildung 2-7 andeuten.

Die Folgerung lautet: Durch die Osterweiterung bekommen tendenziell die arbeitsintensiven Branchen in den EU-Ländern den Konkurrenzdruck aus den MOEL zu spüren. Dies dürfte insbesondere die Textil-, die Bekleidungsindustrie und die Lebensmittelverarbeitung betreffen, aber auch die Landwirtschaft sowie die Kohle- und Bergbauindustrie [Europäische Kommission 1997e: $21 \mathrm{f}$ ]. ${ }^{58}$

Diese Branchen sind regional in der EU unterschiedlich verteilt. So sind die arbeitsintensiven Industrien aus Hochlohnländern wie der Bundesrepublik längst weitestgehend verschwunden. Nur nichthandelbare arbeitsintensive Produkte (insbesondere lokal oder regional begrenzte Dienstleistungen) werden weiterhin hergestellt. ${ }^{59}$ Arbeitsintensive Branchen konzentrieren sich in der EU in denjenigen Ländern, die niedrigere Durchschnittseinkommen und eine schlechtere Ausstattung an physischem und Humankapital aufweisen. Gerade sie werden deshalb die Konkurrenz aus den MOEL zu spüren bekommen.

Andererseits sind technologisch hochwertige, (human-)kapitalintensive Branchen praktisch ohne Konkurrenz aus den MOEL. Im Gegenteil: Diese Güter werden im beschleunigten Entwicklungsprozeß von den osteuropäischen Ländern verstärkt nachgefragt. Regionen, in denen sich ihre Produktion konzentriert, gehören somit innerhalb der EU tendenziell zu den Gewinnern der Osterweiterung, zumal sie von den günstigeren arbeitsintensiven Importen zusätzlich profitieren.

Die Osterweiterung der EU läßt sich somit auffassen als ein politischinduzierter asymmetrischer Schock: Während die höher entwickelten EU-Länder davon tendenziell profitieren, verlieren die weniger entwickelten Länder. Sofern die realen „Stoßdämpfer” - flexible Löhne und Preise sowie die Mobilität von Faktoren - nicht hinreichend funktionstüchtig sind, müssen andere Mechanismen zur Abfederung hinzukommen.

Schockverarbeitung. Unter den Bedingungen der EWU steht eine national abgestufte Zins- und Wechselkurspolitik nicht mehr zur Verfügung. Gewinner und Verlierer sind unter dem Dach des Euro vereint. Folglich haben die Verlierer in dieser Situation tendenziell mit einer zu hoch bewerteten Währung und möglicherweise zu hohen Zinsen zu kämpfen, denn die MOEL werden zunächst nicht Mitglied der Währungsunion sein. Zwar dürften im Falle einer erfolgreichen Her-

$58 \mathrm{Zu}$ beachten ist hierbei, daß bei Landwirtschaft, Kohle und Bergbau nicht nur die Ausstattung mit Kapital und Arbeit eine wichtige Rolle spielt, sondern auch die natürlichen Ressourcen. Es handelt sich somit eher um ,Ricardo-Güter”.

59 Nur wenige Bereiche lassen sich entgegen den marktmäßigen Handelsmustern mit hohen Subventionen am Leben erhalten, in Deutschland gilt das vorwiegend für den Bergbau und die Landwirtschaft. 
anführung der MOEL deren Währungen auf mittlere Sicht gegenüber dem Euro stärker werden, doch handelt es sich bei diesen Wechselkursen um einen Durchschnittswert, der weder den Bedürfnissen der Erweiterungsgewinner noch der verlierer gerecht wird: Die Verlierer benötigen als ,Shock absorber” eine Abwertung und eine reichliche Versorgung mit Zentralbankgeld. Für die Gewinner wären zur Dämpfung der Nachfrage und eines möglicherweise auftretenden inflationären Drucks eine Aufwertung und eine knappe Versorgung mit Zentralbankgeld von Vorteil. Die EZB gerät in dieser Situation in schwieriges Fahrwasser: Aus Sicht der Gewinner steuert sie einen zu laxen Kurs, aus Sicht der Verlierer einen zu harten Kurs. Falls eine reale Anpassung versagt und die monetäre Anpassung in der EWU nicht mehr möglich ist, bleibt eine Schockabfederung mittels staatlicher Budgets übrig. Doch dies wird schwierig: Erstens fehlt ein großes Zentralbudget, durch das eine automatische interregionale Umverteilung stattfindet. Zweitens sind die öffentlichen Haushalte insbesondere der wohlhabenden Mitgliedsländer durch höhere Beiträge für die neuen Mitgliedsländer belastet. ${ }^{60}$ Drittens sind ihre Haushalte durch den Stabilitäts- und Wachstumspakt in ihrer Nettokreditaufnahme beschränkt, so daß die Rivalität zwischen Ausgaben zugunsten der jeweiligen nationalen Bevölkerung und zugunsten anderer EU-Länder wächst.

Abbildung 2-8 zeigt die Eskalationsleiter des Szenarios nach Beitritt der MOEL: Wenn alle übrigen „Shock absorbers” funktionsunfähig sind, bietet sich den politischen Akteuren der Versuch einer Abwertung des Euro gegenüber anderen wichtigen Währungen, insbesondere gegenüber dem Dollar.

Zwar ist die Formulierung der externen Währungspolitik traditionell Sache der Regierungen. Doch im EWU-Design ist dies ein deutlicher Mangel: Der EZB steht keine Zentralregierung gegenüber, sondern eine relativ große und heterogene Zahl von Nationalstaaten. Sich in anderen Bereichen der Wirtschaftspolitik zu einigen ist regelmäßig schwierig, zumal häufig einstimmig abgestimmt werden muß, etwa in der Steuerpolitik. Die Wechselkurspolitik könnte sich daher zum Ventil entwickeln, gewissermaßen als kleinster gemeinsamer Nenner in einer institutionell unterentwickelten Währungsunion. Denn in keinem anderen Politikbereich genügt eine derart kleine Mehrheit - derzeit lediglich 43 Stimmen, die bereit fünf Staaten zusammenbringen können. Zudem ergibt sich ein Kontrollproblem. Nicht eine einzige Regierung kann für Fehlentscheidungen von der Öffentlichkeit oder dem Gericht haftbar gemacht werden, sondern ein ganze Gruppe von Regierungen. Deren Politik auf europäischer Ebene unterliegt aber nur einer relativ schwachen Kontrolle durch die Bürger in den Nationalstaaten. Die externe

60 Die Europäische Kommission rechnet mit zusätzlichen Beiträgen von 53,8 Milliarden ECU (in Preisen von 1997), die die EU-15 bis einschließlich 2006 zugunsten der Aufnahmekandidaten aufbringen müssen. Sie geht hierbei von einem Beitritt von fünf Mitgliedsländern im Jahr 2002 aus [Europäische Kommission 1997e: 102ff]. 
Währungspolitik ist damit extrem abhängig von der jeweiligen politischen Konstellation und somit kaum prognostizierbar.

Abbildung 2-8: Die Osterweiterung als asymmetrischer Schock

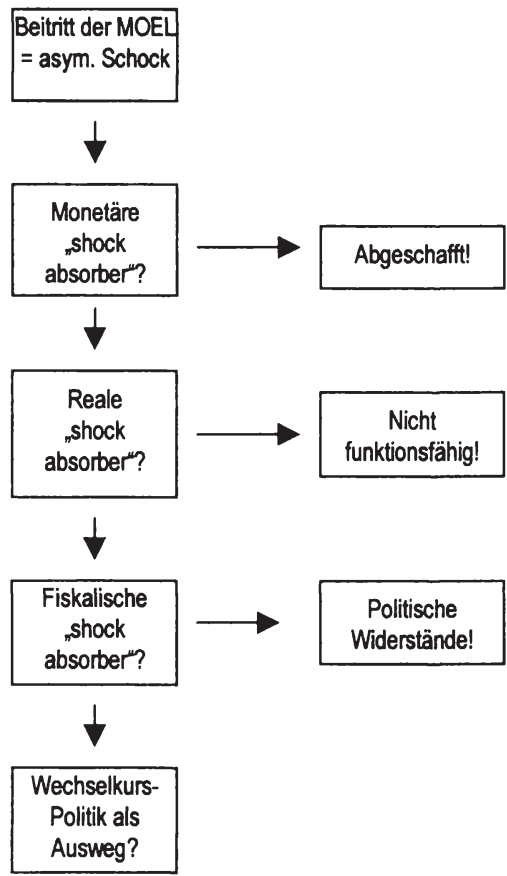

Inwieweit der Euro als international bedeutsame Währung die Möglichkeit bietet, eine solche handels- bzw. konjunkturpolitisch motivierte Wechselkurspolitik zu betreiben, untersuchen die Kapitel 3 und 4. 


\section{Die EWU-Landschaft: Neue ökonomische Rahmenbedingungen für die Regierungen im Euroland}

Warum sollten die Regierungen des Eurolandes den Wechselkurs als wirtschaftspolitisches Instrument nutzen? Wieso sollten sie dem Außenwert des Euro besondere Aufmerksamkeit widerfahren lassen? Schließlich sind die Mitgliedstaaten durch ihren Beitritt zur Eurozone weit geschlossenere Volkswirtschaften geworden. Entsprechend weniger sind sie für außenwirtschaftliche Störungen anfällig, etwa für importierte Inflation, so daß die Notenbanken dem Außenwert kein herausragendes Gewicht beimessen sollten [Scheide/Solveen 1997]. Außerdem haben die Euroland-Staaten im Rahmen des Maastricht-Prozesses während der zweiten Stufe der EWU nach und nach den Wechselkurs als wirtschaftspolitisches Instrument aufgegeben: Innerhalb der EWS sollten die Währungen die normalen Schwankungsbreiten nicht verlassen. Länder wie Italien, Spanien oder Portugal gingen zu einem neuen Policy mix über, dessen positive Effekte sie in Form von historisch niedrigen Zinsen erfuhren. Es gibt also gute Gründe anzunehmen, daß die Wechselkurspolitik nicht zum Instrumentarium der Euroland-Regierungen zählen sollte.

Hingegen hat die öffentliche wirtschaftspolitische Diskussion in den Teilnehmerstaaten kurz vor und erst recht nach dem Beginn der Währungsunion dem Außenwert des Euro einen hohen Stellenwert zugewiesen. Der Wechselkurs ist auf die wirtschaftspolitische Agenda zurückgekehrt, bis hin zur Forderung, den Euro in ein Systems von Wechselkurszielzonen einzubinden. ${ }^{61}$ Und bereits im Januar 1999 erklärten die damaligen Finanzminister Frankreichs und Deutschlands, wie sie sich die Wechselkurspolitik für den Fall vorstellen, daß ein solches internationales System gemanageter Paritäten nicht existiert:

\footnotetext{
„Wir müssen innerhalb der Euro-11-Gruppe die Wechselkursentwicklungen überwachen und eine kohärente Haltung formulieren. Wir sollten auch in der Lage sein, diese Haltung den Märkten gegenüber gemeinsam zu vertreten, und erforderlichenfalls von den vertraglichen Bestimmungen Gebrauch machen, die die Möglichkeit vorsehen, allgemeine Leitlinien für die Wechselkurse herauszugeben. Dies ist im Rahmen der Einführung des Euro von besonderer Bedeutung: Marktteilnehmer sollten wissen, daß wir eine übermäßige Aufwertung des Euro nicht begrüßen“ [Lafontaine/Strauss-Kahn 1999].
}

Die Gründe für diese Entwicklung liegen in der neuen polit-ökonomischen Landschaft, die sich den wirtschaftspolitischen Entscheidungsträgern im Euroland präsentiert. Bislang hatten die EU-Staaten einen starken Anreiz, eine Hartwährungs-

61 Siehe dazu näher Kapitel 5. 
politik zu betreiben, dies vor allem aus zwei Gründen: Zum einen bedeutete entsprechend der Maastricht-Kriterien ein Abweichen vom Stabilitätspfad, von der EWU-Teilnahme ausgeschlossen zu werden. ${ }^{62}$ Zum anderen drohte den relativ kleinen, sehr offenen europäischen Staaten ein Vertrauensschwund seitens des Finanzmarktpublikums, wodurch Risikoprämien und mit ihnen Nominalzinsen rasch in die Höhe geschnellt wären, entsprechend hätten sich private Investitionen wie auch der Schuldendienst der Staaten verteuert. Eine glaubwürdige Geld- und Fiskalpolitik hingegen wurde mit niedrigen Zinsen belohnt. In der Währungsunion kann sich diese disziplinierende Wirkung der Märkte abmildern. Aus Sicht europäischer Wirtschaftspolitiker mag sich daher ihre Bewegungsfreiheit erhöhen.

Dieses Kapitel untersucht, in welcher Weise die Schaffung einer gemeinsamen Währung den ökonomischen Handlungsrahmen für die Regierungen der Euroland-Staaten verändert, mathematisch gesprochen, wie sich die Nebenbedingungen im Optimierungskalkül verändern. Dazu wird die Internationalisierung des Euro untersucht, die Entwicklung auf den Finanzmärkten, die Position des Eurolandes im Welthandel und die daraus resultierenden polit-ökonomischen Effekte.

\section{1 Der Euro als internationale Währung}

Indem die elf EWU-Gründerstaaten ihre nationalen Währungen im Euro aufgehen lassen haben, ist der zweitgrößte Währungsraum der Erde entstanden, übertroffen allein von den USA. Sowohl am globalen Bruttosozialprodukt als auch am Weltexport liegt die EWU-11 dicht hinter den USA. Auch der Grad der Offenheit, gemessen als Durchschnitt der Ex- und Importe in Prozent des jeweiligen BIP, ist ähnlich (Abbildung 3-1). Diese Annäherung der EWU an die Größe der USA wird mit dem erwarteten Beitritt weiterer EU-Staaten, insbesondere Großbritanniens, noch zunehmen. Japan hingegen verliert im weltwirtschaftlichen Gefüge an Gewicht.

Diese Kerndaten des EWU-Gebietes werden - mit Ausnahme des Offenheitsgrades - durch den Übergang zur gemeinsamen Währung nicht unmittelbar berührt. Bereits vor Beginn der dritten Stufe war die EU der größte Binnenmarkt der Welt, wenn auch noch teilweise segmentiert durch die Transaktionskosten, die mit der Existenz unterschiedlicher Währungen verbundenen sind. Keine dieser kleineren Währungen reichte auch nur annähernd an die Bedeutung des US-Dollar heran. Weder allein die international zweitwichtigste Währung, die D-Mark, noch die Währungen aller 15 EU-Staaten zusammengenommen konnten die überragende Bedeutung des US-Dollar gefährden.

62 Siehe Abschnitt 2. 1 
Abbildung 3-1: Kerndaten des Eurolandes im internationalen Vergleich

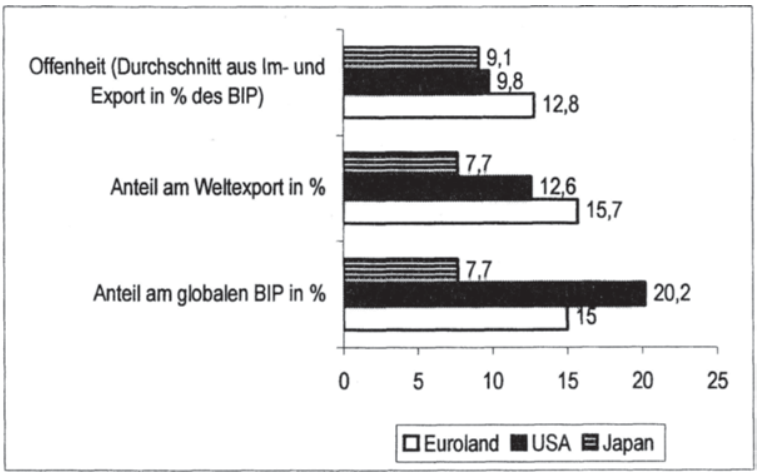

Stand: Ende 1998. Quelle: EZB (1999a), eigene Berechnungen

Die Bedeutung der amerikanischen Währung übertrifft bei weitem die Bedeutung der amerikanischen Volkswirtschaft. Im Welthandel zum Beispiel liegt das Volumen, das in Dollar abgewickelt wird, viermal höher als der tatsächliche Anteil der USA am Welthandel, Unternehmen außerhalb der USA bedienen sich also des Dollar für ihren Außenhandel [Hartmann 1996: 10ff]. Die Reservehaltung der Notenbanken, die Bedeutung der Finanzmärkte für die Kreditaufnahme der Entwicklungsländer - in all diesen Punkten liegt der Dollar klar vorn. Allein bei der Denominierung von Anleihen reicht die Summe der EU-Staaten annähernd an die US-Währung heran (Abbildung 3-2).

Diese andauernde Dominanz des Dollar wirft die Frage auf, inwiefern der Euro in der Lage sein wird, in Konkurenz zur US-Währung zu treten. Ob bzw. auf welchen Feldern kann es für die Akteure außerhalb des Eurolandes vorteilhaft sein, den Euro zu verwenden?

\section{1. 1 Internationale Handels- und Vehikelwährungen ${ }^{63}$}

Wenn Wirtschaftssubjekte Außenhandelstransaktionen tätigen, haben sie grundsätzlich die Wahl, in welcher Währung sie das jeweilige Geschäft abschließen wollen. Es stellt sich somit die Frage, was Im- und Exporteure dazu veranlaßt, eine bestimmte Währung zu wählen. Häufig wird die Heimatwährung eines der beteiligten Geschäftspartner verwendet. Daneben gibt es aber auch Fälle, in denen die Währung eines Drittlandes als „Vehikelwährung” verwendet wird.

Fakturierungstrends. Folgende Muster haben sich in den vergangenen Jahrzehnten im Welthandel herausgebildet: Zwischen den Industrieländern wird Handel in Industriegütern meist in der Heimatwährung des Exporteurs fakturiert,

63 Dieser und der folgende Abschnitt orientieren sich stark an Hartmann (1996) und der dort angegebenen Literatur sowie an Ranki (1993). 
seltener in der Währung des Importeurs, noch seltener in einer Drittlandswährung. Währungen werden umso eher verwendet, je niedriger die Inflationsrate ist und je weniger der Umtausch gesetzlichen Regulierungen unterliegt. Sofern ein Handelspartner aus einem Industrieland kommt, der andere aus einem Entwicklungsland, wird meist die Währung des Industrielandes gewählt oder eine Drittlandswährung als Vehikel. Handel in Rohstoffen wird überwiegend in Dollar abgewikkelt. Für diese Trends werden üblicherweise zwei Erklärungslinien angegeben: zum einen die Form des jeweiligen Gütermarktes, zum anderen die Interessenbzw. Machtverhältnisse auf Seiten der Handelspartner.

\section{Abbildung 3-2: Internationale Bedeutung der Währungen vor Beginn der Währungsunion}

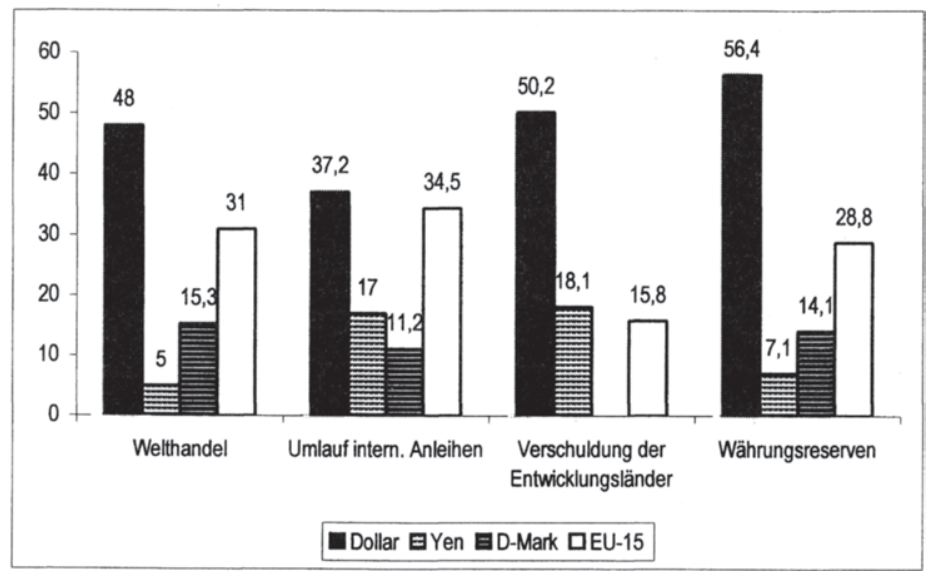

Angaben in Prozent. EU-15: Euroland plus Großbritannien, Schweden, Dänemark, Griechenland. Quellen: IWF (1997), Deutsche Bundesbank (1997b)

Bedeutung der Marktform. Kommt die Marktform für das jeweils gehandelte Gut dem theoretischen Ideal der vollständigen Konkurrenz nahe, wird meist eine Vehikelwährung benutzt. Dies ist bei Rohstoffen der Fall, die homogene Güter darstellen. Winzige Preisunterschiede geben hier den Ausschlag für Transaktionsentscheidungen. Entsprechend werden sie an wenigen zentralisierten Börsen (zuvörderst in Chicago und London) gehandelt. Die Währung ist in der Regel der US-Dollar, weil dadurch die Preise unmittelbar vergleichbar und zudem die Transaktionskosten minimiert werden (der folgende Abschnitt erläutert dies näher). Hingegen spielen kleine Transaktionskostenvorteile beim Handel mit differenzierten Produkten, also Industriegütern und Dienstleistungen, keine Rolle. Hier herrscht die Marktform des monopolistischen Wettbewerbs oder des Oligopols. Die Verwendung einer Drittlandswährung ist daher in den meisten Fällen überflüssig. Ausnahmen sind vor allem Fälle, da die Heimatwährungen des Ex- wie 
auch des Importeurs hohen Inflationsraten und/oder Transaktionsrestriktionen unterliegt. In diesem Fall wird eine Vehikelwährung attraktiv.

Verhandlungen zwischen Ex- und Importeure. Prinzipiell ist es sowohl für Ex- wie für Importeure von Vorteil, in eigener Währung zu fakturieren. Für die Laufzeit eines Vertrages können sie damit das Wechselkursrisiko ausschalten, zusätzliche Transaktionskosten für Kurssicherungsgeschäfte entfallen. Warum gibt es aber eine eindeutige Präferenz für die Währung des Exportlandes? Erstens kann es auch für Importeure von Vorteil sein, die Währung des Exportlandes zu akzeptieren. Dies ist der Fall, wenn er aus einem Entwicklungsland kommt, dessen Währung nicht frei konvertibel ist und daher hohe Transaktionskosten anfallen. Im Handel zwischen Industrieländern spielt auch die Variabilität des Wechselkurses und der Inflationsrate eine Rolle: Ist die Währung des Importlandes mit größeren Schwankungen behaftet als die Währung des Exportlandes, ist es auch für einen risikoaversen Importeur rational, einer Fakturierung in fremder Währung zuzustimmen. Zweitens spielt auch die Machtverteilung zwischen Im- und Exporteur eine Rolle. Weil exportierende Unternehmen häufig größer sind als importierende, haben sie mehr Durchsetzungsmacht in Verhandlungen. Hierfür sind technologische Faktoren ausschlaggebend: International werden vorwiegend Industrieprodukte gehandelt, überwiegend in der Marktform der monopolitischen Konkurrenz. „Economies of scale“ in den Produktionsfunktionen der Firmen führen zu sinkenden Durchschnittskosten. Es gibt also eine Tendenz zu großen Unternehmenseinheiten, die auf seiten der Importeure weniger stark ausgeprägt ist.

Netzwerkeffekte. Offensichtlich sind bei der Verwendung von Währungen „Network externalities“ am Werk. Die Nutzer profitieren von positiven externen Effekten, wenn weitere Nutzer hinzukommen. Diese Netzwerkeffekte sind aus der Informationstechnologie bekannt [z. B. Shapiro/Varian 1999: 13ff], treffen aber auch auf die Nutzung von Geld zu. Dessen Funktionen als Tauschmittel, als Recheneinheit und als Wertaufbewahrungsmittel kommen nur zum Tragen, wenn es allgemein anerkannt ist, also eine genügend große Zahl von Nutzern vorhanden ist. Dies gilt für nationales wie für internationales Geld. Eine Weltwährung setzt einen allgemein akzeptierten pekuniären Standard. Verglichen mit anderen Währungen bietet sie den Vorteil niedrigerer Transaktionskosten. Diese positiven externen Effekte spielen vor allem auf den Devisenmärkten eine Rolle. ${ }^{64}$

Aus diesen Gründen erfreuen sich Währungen großer Währungsgebiete vergleichsweise großer Beliebtheit. Zugleich aber führen die Netzwerkeffekte bei der Verwendung von Weltwährungen zu erheblichem Beharrungsvermögen. Ein Wechsel zu einer neuen Währung findet nur statt, wenn das „Konkurrenzprodukt“ gegenüber dem herrschenden Standard für die Nutzer deutliche Vorteile aufweist.

Perspektiven für den Euro als Handelswährung. Auf Rohstoffmärkten wird der Dollar auf Grund von Netzwerkeffekten auch weiterhin dominieren. Für

64 Siehe den folgenden Abschnitt. 
die Fakturierung im internationalen Handel mit Industriegütern (und Dienstleistungen) hat der Euro gute Chancen, dem Dollar Konkurrenz zu machen. Dieser Befund ergibt sich vor allem aus dem relativen Gewicht des Eurolandes im internationalen Vergleich, wie eingangs beschrieben - Größe zählt. Insbesondere da das Euroland das weltweit wichtigste Exportland ist, dürfte der Euro aufgrund der bisherigen Erfahrungen eine rasche Verbreitung erfahren: Die USA, auch hier unangefochten an der Spitze, konnten vor Beginn der Währungsunion 92 Prozent ihrer Exporte in Dollar fakturieren, die Bundesrepublik immerhin noch 77 Prozent ihrer Exporte in D-Mark, Frankreich 55 Prozent in Francs.

Da die Gemeinschaftswährung in den (noch) nicht an der EWU teilnehmenden europäischen Ländern als eine Art Parallelwährung fungieren dürfte, wird vermutlich auch mit ihnen einen sehr hoher Anteil des Außenhandels in Euro ablaufen [Duisenberg 1998]. Über die EU hinaus dürfte der Euro im Handel mit den europäischen Emerging Markets, also den mittel- und osteuropäischen Ländern (MOEL), dem südlichen und östlichen Mittelmeerraum sowie den Ländern der früheren afrikanischen Francs-Zone (AKP-Staaten) eine dominierende Rolle spielen: Der Euro ist den Währungen dieser Länder deutlich überlegen in puncto Stabilität und Konvertibilität. Abbildung 3-3 zeigt, wie stark die Länder dieser Region mit dem Euroland verflochten sind:

\section{Abbildung 3-3: Die Bedeutung des Eurolandes als Handelspartner für} ausgewählte Drittländer*

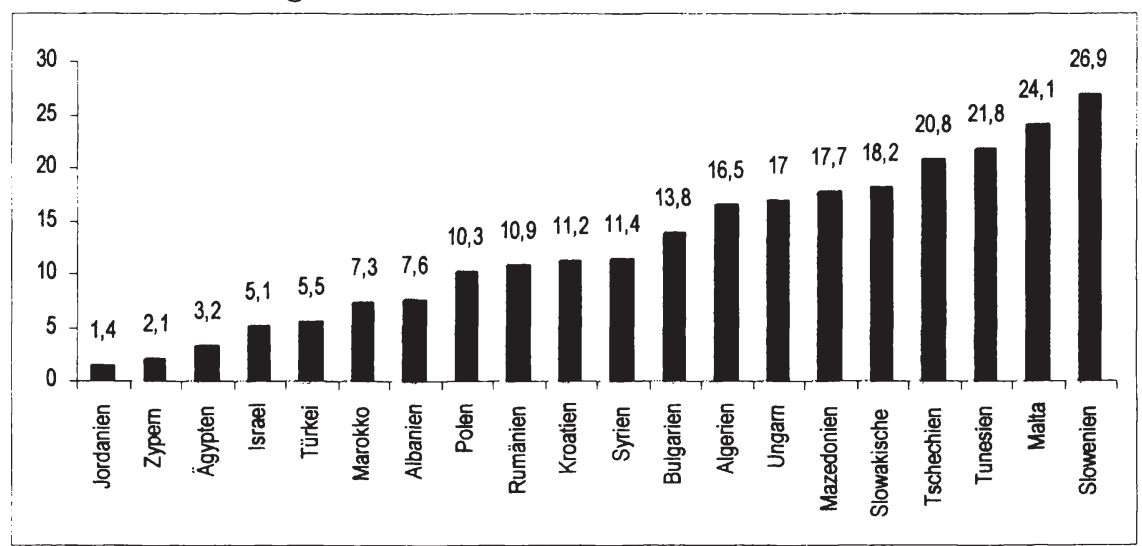

*Anteil der Exporte in die EWU-Staaten in \% des jeweiligen BIP (1996) Quelle: IWF (1998b), eigene Berechnungen

Daneben dürfte die europäische Währung auch im EU-Export nach Asien und Lateinamerika eine wichtige Rolle spielen. Inwieweit auch Importe in die EU aus diesen Ländern in Euro fakturiert werden können, ist offen. Dies hängt nicht 
zuletzt von der Währungspolitik ab: Hält der Trend zur „Dollarisierung” in Lateinamerika und Asien an, dürfte es der Euro hier schwer haben.

Als Vehikelwährung im Welthandel dürfte der Euro allenfalls ganz allmählich Boden gewinnen. Dies liegt insbesondere an den genannten Netzwerkeffekten, die den Dollar als einmal etablierte Währung bevorteilen. Wie die D-Mark früher innerhalb der Europäischen Gemeinschaft eine gewisse Rolle als Vehikel spielte, so dürfte der Euro zuerst im Handel zwischen Nachbarländern des Eurolandes als Vehikelwährung Verwendung finden: zwischen den übrigen westeuropäischen Ländern, den MOEL, den Mittelmeeranrainern und den AKP-Staaten. Auch hier spielt die Ausrichtung der Währungspolitik eine wichtige Rolle: Bestehen enge währungspolitische Bindungen an die europäische Gemeinschaftswährung, wird der Euro für diese Länder attraktiver [Funke/Kennedy 1997: 9]. Einen wichtigen Einfluß auf die Verwendung als Vehikelwährung im Handel hat auch die Entwicklung der Euro-Finanzmärkte, insbesondere der Terminmärkte, auf denen sich Währungsrisiken absichern lassen.

\section{1. 2 Vehikelwährungen auf den Devisenmärkten}

Transaktionen auf Devisenmärkten basieren nur zu einem Bruchteil auf Handelstransaktionen oder auf Kapitalverkehr. Von den Geschäften im Wert von 1500 Milliarden US-Dollar täglich ${ }^{65}$ geht ein Teil auf die Nutzung von Vehikelwährungen zurück. Das heißt: Beim Tausch von Währung A in Währung B wird eine weitere Währung dazwischen geschaltet. In der Regel ist dies bislang der USDollar. Innerhalb Europas liefen Transaktionen bis zur Gründung der EWU häufig über die D-Mark ab. Wie stark die US-Währung die Devisenmärkte dominiert, verdeutlicht Abbildung 3-4. Dieser Vorsprung des US-Dollar ist durch den Übergang zur Währungsunion noch gewachsen, da nun der Devisenhandel zwischen den EWU-Staaten fortgefallen ist.

Bedeutung von Transaktionskosten. Wer die Frage beantworten will, wie die Chancen des Euro als Devisenhandelswährung stehen, muß zunächst die Motive für die Verwendung einer Vehikelwährung untersuchen. Auch hier liegt der Schlüssel in den Transaktionskosten, die die Wirtschaftssubjekte zu minimieren suchen. Die Transaktionskosten auf den Devisenmärkten äußern sich in den Differenzen zwischen Kauf- und Verkaufspreis („Bid-ask spread”). Die Privaten wählen den Umweg über eine Vehikelwährung, der ja zwei Transaktionen statt nur einer einzigen umfaßt - Tausch von Währung $\mathrm{A}$ in die Vehikelwährung, Tausch der Vehikelwährung in Währung B -, wenn dabei niedrigere Transaktionskosten anfallen als beim direkten Tausch. Ist also der Spread zwischen A und B größer als die Summe der Spreads von A und B gegenüber der Verhikelwährung, so ist dieser Umweg rational.

65 Diese Zahl umfaßt nur die „traditionellen” Devisenmarkttransaktionen, nämlich Kassa-, Outright-Forward- und Devisen-Swap-Geschäfte [BIZ 1998c: 5]. 


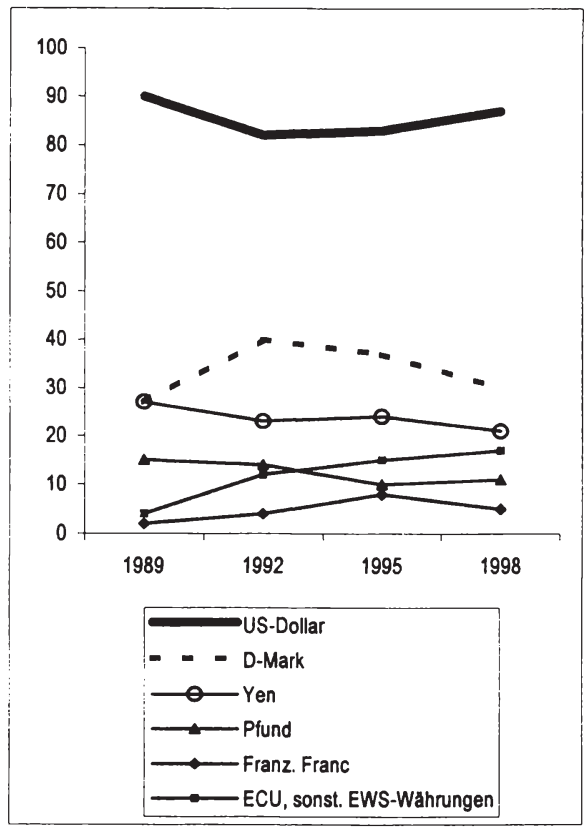

Angaben in Prozent. Insgesamt summieren sich die Anteile im Devisenhandel zu $200 \%$, da stets die ge- und die verkaufte Währung an einer Transaktion beteiligt sind. An 200 fehlende \%: sonstige Währungen. Quelle: BIZ (1998c)

Marktgröße und Netzwerkeffekte. Die Größe der Kaufs-Verkaufs-Preisdifferenz hängt entscheidend $a b$ vom Risiko der Transaktion. Für dieses Risiko sind wiederum vor allem zwei Faktoren verantwortlich: erstens die Möglichkeit, zum gewünschten Zeitpunkt keinen Tauschpartner zu finden, zweitens die Volatilität der Wechselkurse. Beide Größen werden entscheidend von der Größe der Volkswirtschaft beeinflußt: Je tiefer und breiter ein Devisenmarkt ist, desto geringer ist das Tauschrisiko. Auch weisen die Wechselkurse großer, hochentwickelter Ökonomien tendenziell eine geringere Volatilität auf, da sie über eine diversifizierte Wirtschaftsstruktur verfügen, so daß sich exogene Schocks tendenziell schwächer in Wechselkursschwankungen zeigen; für die Volatilität spielen allerdings auch politische Entscheidungen, insbesondere die Währungspolitik, eine große Rolle.

Die Größe der zugrundeliegenden Volkswirtschaften ist zwar eine notwendige Bedingung dafür, daß sich eine Währung zum Vehikel auf den Devisenmärkten entwickelt, eine hinreichende Bedingung ist sie jedoch nicht. Denn noch stärker als im Güterhandel, kommen hier „Network externalities“ zum Tragen. 
Sind einmal große, liquide Devisenmärkte etabliert, haben es Konkurrenzwährungen schwer. Das Netzwerk, auf dem der Dollar basiert, existiert seit langem. Es ist ein Ergebnis des Bretton-Woods-Systems: In den ersten Nachkriegsjahrzehnten liefen Devisentransaktionen stets über den Dollar ab, wie auch die Paritäten vis-àvis dem Dollar festgelegt waren. 66

Perspektiven für den Euro. Daß die Größe der Devisenmärkte einen entscheidenden Einfluß auf die Verwendung einer Vehikelwährung hat, ist zweifellos ein Nachteil für den Euro. Das Beispiel der D-Mark, die sich in den achtziger Jahren zu einer regional bedeutenden Vehikelwährung in Europa entwickelte, zeigt jedoch, daß daneben auch andere Währungen eine Chance haben. Wie beim Dollar auch, wuchs die D-Mark auf dem Boden ihrer Funktion als Leitwährung in einem Fixkurssystem. Diese Rolle konnte sie aus den gleichen Gründen einnehmen, die auch eine Vehikelwährung attraktiv machen: Für die D-Mark sprachen eine glaubwürdige Geld- und Währungspolitik sowie, als Währung einer vergleichsweise großen Volkswirtschaft, liquide Märkte. ${ }^{67}$

Für den Euro läßt sich daraus folgern: Als Vehikelwährung dürfte er zuvörderst zwischen den Währungen der übrigen europäischen und der afrikanischen Staaten dienen, insbesondere jenen, die ihre Währungen direkt an den Euro gebunden haben. Für Wirtschaftssubjekte aus diesen Staaten drängt sich die Gemeinschaftswährung als einheitlicher Tauschstandard geradezu auf, wenn sie einen gemeinsamen monetären Anker darstellt. Im Rest der Welt jedoch wird es der Euro erheblich schwerer haben. Hierfür wird wichtig sein, welchen Kurs das Euroland und die USA in der Geld- und Währungspolitik einschlagen. Im Zweifelsfall wird die härtere Währung als Vehikel im Vorteil sein.

\section{1. 3 Internationale Anlagewährungen}

$\mathrm{Zu}$ Beginn der EWU verfügt das Euroland im internationalen Vergleich über unterentwickelte Finanzmärkte. Wie Abbildung 3-5 zeigt, sind sowohl die Anleihe- als auch die Aktienmärkte im Vergleich zu den USA erheblich geringer kapitalisiert. Sie ähneln eher der Größe der japanischen Märkte. Ein BIP-Vergleich würde hingegen eher die Vermutung nahelegen, daß die Euroland-Märkte an die der USA heranreichen sollten. In der Ausgangssituation kommt statt dessen Bankkrediten eine weit größere Bedeutung für die Finanzierung des privaten Sektors zu. Spiegelbildlich sind Bankeinlagen verhältnismäßig verbreitetes als Instrument der Geldanlage.

Bisherige Segmentierung der Finanzmärkte. Der Grund für dieses Bild liegt vor allem in der bisherigen Segmentierung der Finanzmärkte. Durch die Existenz unterschiedlicher Währungen blieben unsichtbare Grenzen auf den Kapital-

66 Zum Bretton-Woods-System siehe näher Kapitel 5. 2. 1.

67 Zur Entwicklung des EWS siehe Kapitel 5. 2. 3. 
märkten bestehen, auch nachdem 1990 sämtliche Kapitalverkehrskontrollen weggefallen waren. Hierfür war vor allem das Wechselkursrisiko verantwortlich, wodurch Aktiva unterschiedlicher Denomination mit unterschiedlichen Währungsrisiken behaftet waren. Auf Seiten der Anleger bestand ein beträchtlicher „Home bias", insbesondere institutionelle Anleger halten den weitaus größten Teil ihrer Assets in heimischer Währung [Prati/Schinasi 1997: 15]. Diese Tendenz beruhte nicht nur auf risikoaversem Verhalten, sondern vor allem auf staatlichen Regulierungen, die Investmentfonds und Versicherungen zur Bevorzugung der heimischen Währung verpflichtete, um das Wechselkursrisiko für ihre Gläubiger gering zu halten.

\section{Abbildung 3-5: Finanzmärkte im internationalen Vergleich}

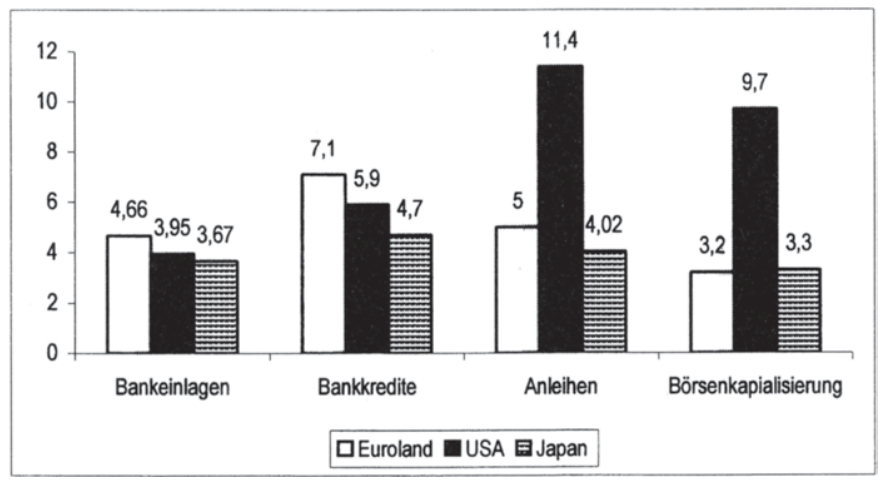

Angaben in Billionen Euro. Stand: 1998. Quelle: EZB (1999a)

Tendenzen nach dem EWU-Start. Mit Beginn der dritten Stufe der EWU wurden die Wechselkursrisiken zwischen den Teilnehmerländern eliminiert. Gesetzliche Verpflichtungen, die Anlagen in nationaler Währung bevorzugten, sind daher gegenstandslos und dürften, selbst wo sie formal noch weiterbestehen, im Binnenmarkt auf Dauer keinen Bestand haben. Dank der gemeinsamen Währung reduzieren sich die direkten Kosten von Kassatransaktionen, Wechselkursrisiken und die damit verbundenen Kurssicherungskosten fallen weg. Statt dessen rücken innerhalb des Eurolandes andere Risiken stärker ins Blickfeld der Anleger, bei Anleihen insbesondere das Bonitätsrisiko. Durch den Wegfall der Währungsgrenzen intensiviert sich der Wettbewerb der Emittenten um die Anleger: Für die Emittenten fällt ihr angestammter Heimatmarkt weg, indem der „Home bias” sich zunehmend auflöst. [Prati/Schinasi 1997: 13ff]. Dies ist gerade in Deutschland spürbar, dessen Emittenten bisher von der Benchmark-Rolle des deutschen Marktes profitierten. Sie stehen nun unmittelbar im Wettbewerb mit anderen Emittenten aus dem gesamten Euroland. Dieser Wettbewerb betrifft auch die Fi- 
nanzplätze, der zu einer Angleichung der Marktpraktiken führt [Deutsche Bundesbank 1998e: 62ff].

Auf den Anleihemärkten dominierten bislang die Staaten als Emittenten. Der Markt für Industrieobligationen hingegen ist sehr schwach ausgebildet, lediglich 76 Milliarden Euro betrug das aussehende Volumen 1997 in den elf EWUStaaten, verglichen mit 1547 Milliarden Euro in den USA [Deutsche Bundesbank 1998e: 65f]. Durch den Wegfall von risikoreicheren Staatsanleihen aus Weichwährungsländern innerhalb des heutigen Eurolandes dürfte das Marktsegment der Industrieobligationen wachsen: Durch den Maastricht-Prozeß und den Wegfall des Wechselkursrisikos haben sich die Ertrags-Risiko-Profile von Staatsanleihen stark angenähert. Dies eröffnet Raum für eine verstärkte Schuldenaufnahme von Unternehmen auf den Finanzmärkten („Securisation”), da Anleger nun auf der Suche nach neuen risikoreicheren Bonds sind.

Insgesamt dürfte sich das Spektrum vergrößern, sowohl was die Laufzeiten angeht, als auch was die Möglichkeit zur Absicherung auf den Terminmärkten angeht. Eine einheitliche Zinsstrukturkurve dürfte sich herausbilden mit liquiden Kassa- und Terminmärkten entlang des gesamten Laufzeitenspektrums [McCauley 1997: 33ff]. Wie schnell dieser Prozeß abläuft, hängt nicht nur von der Lernund Anpassungsfähigkeit der Akteure ab, sondern auch von staatlichen Marktregulierungen und der Basis an institutionellen Investoren [Prati/Schinasi 1997: 32f]. Die schwache Rolle institutioneller Investoren ist vor allem auf die im Euroland nach wie vor dominierenden staatlichen umlagefinanzierten Alterssicherungssystemen zurückzuführen, die einen großen Teil der potentiellen gesamtwirtschaftlichen Ersparnis absorbieren.

Portfoliotheoretische Überlegungen. Insgesamt steigt die Attraktivität der Euro-denominierten Märkte, dies vor allem deshalb, weil sie an Breite, Tiefe und Liquidität gewinnen. Gerade aus Sicht großer institutioneller Anleger ist das Tauschrisiko ein großes Hindernis für das Engagement in kleineren Märkten. Sie können größere Mengen an Assets möglicherweise zum gewünschten Zeitpunkt nicht abstoßen, weil sie keinen Tauschpartner finden. Zudem müssen sie damit rechnen, die Preise zu beeinflussen, was die Handlungsmöglichkeiten von Portfoliomanagern und von Emittenten deutlich beschränkt. Zudem fallen bei jeder Transaktion vergleichsweise hohe Kosten an. Große Anleger und große Emittenten von Anleihen und Aktien hatten daher bislang kaum eine Alternative zum USMarkt.

Nun entsteht allmählich in Europa eine Alternative, die über ähnliche Risiko- und Transaktionskostenstrukturen verfügen wird. Tiefere, liquidere Finanzmärkte im Euroland dürften internationale Anleger anziehen, aber auch staatliche und private Schuldner [McCauley/White 1997: 4]. Beiderseits des Atlantiks wird es künftig eine große Zahl von Anleihen, Aktien und darauf basierenden Derivaten geben, die jeweils dem gleichen Währungsrisiko unterliegen. Da nun eine Alternative zum US-Markt existiert, sprechen portfoliotheoretische Überlegungen 
für eine Diversifizierung: Indem sie einen Teil ihrer Assets ins Euroland umschichten, können sie ihr Portfoliorisiko insgesamt vermindern. Dieser Effekt dürfte umso stärker auftreten, je schwächer bzw. negativer die Korrelation der gesamtwirtschaftlichen Entwicklung und der Kursverläufe zwischen dem Euroland und den USA ist.

Konsequenzen für den internationalen Kursverbund. Bislang ist die Korrelation der europäischen Finanzmärkte mit dem US-Markt hoch. Insbesondere in Phasen der Unsicherheiten orientieren sich die Anleger an den New Yorker Weltleitbörsen [Deutsche Bundesbank 1998e: 68f]. Möglicherweise ändert sich das künftig, so daß Europa sich wenigstens teil- und zeitweise vom weltweiten Kurs- und Zinsverbund abkoppeln könnte. Der Grund hierfür liegt nicht nur in der schieren Größe, sondern auch in unterschiedlichen Branchengewichten an den Börsen, unterschiedlichen Konjunkturverläufen, unterschiedlichen Policy mixes, unterschiedlichen Großunternehmen, die die Entwicklung der Börsen beeinflussen. All dies könnte dem europäischen Markt im positiven Sinne „Ballast” verschaffen, der ihn gegenüber Anstößen aus den USA träger macht [McCauley/White 1997: 18f]. Auch dies ist ein wechselseitiger Prozeß, der sich erst allmählich im Zeitablauf entwickeln wird. Je mehr Investoren diese Diversifizierungsmöglichkeiten entdecken, desto größer wird der Abkopplungsspielraum - je größer wiederum der Abkopplungsspielraum, desto mehr Investoren werden die Diversifizierungsmöglichkeiten nutzen.

\section{1. 4 Zusammensetzung offizieller Währungsreserven}

Bei Beginn der Europäischen Währungsunion spielte der US-Dollar nach wie vor eine überragende Rolle bei der Reservehaltung der Notenbanken. Fast zwei Drittel der weltweiten Devisenreserven lauteten auf Dollar, auf die D-Mark als zweitwichtigste Reservewährung entfielen 14 Prozent, zusammen mit Französischem Franc und ECU-Reserven erreichten die Vorläufer des Euro einen Anteil von 17,5 Prozent. Der Yen hingegen blieb mit sieben Prozent Anteil sehr schwach repräsentiert, gemessen am Gewicht der japanischen Volkswirtschaft ${ }^{68}$ (Abbildung 3-6).

Neben dem raschen Aufbau von Währungsreserven gibt es einen Trend in der Form der Reservehaltung. Verstärkt nehmen Notenbanken ihre Reserven in Form zinstragender Wertpapiere in ihre Portfolios, größtenteils als kurzlaufende Staatsanleihen. Im Fall der D-Mark beobachtete die Deutsche Bundesbank, daß Ende 1990 noch die Hälfte der Notenbankreserven als Einlagen bei der Bundesbank, bei inländischen Kreditinstituten oder am Eurogeldmarkt gehalten wurde.

68 Die Gründe für diese Unterrepräsentation des Yen liegen vor allem in gesetzlichen Regulierungen in Japan. So wird unter anderem beim Kauf von Staatsanleihen eine Umsatzsteuer erhoben, die die Transaktionskosten von ,verbrieften” Yen-Reserven erhöht. Zur Rolle des Yen als internationale Reservewährung vgl. Garber (1996). 
Dieser Anteil sank bis Ende 1996 auf ein Drittel. Notenbanken verfolgen offenbar zunehmend ein Ertrags-Risiko-Kalkül, das in gewisser Weise dem Verhalten privater Portfoliomanager ähnelt [Deutsche Bundesbank 1997b: 29f].

Abbildung 3-6: Zusammensetzung offizieller Währungsreserven

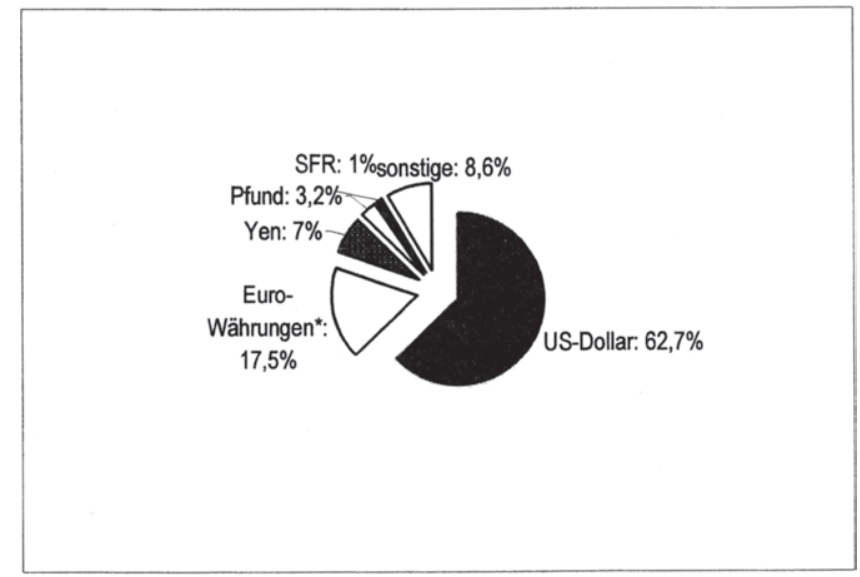

Angaben in Prozent. *Euro-Währungen: D-Mark, Franz. Franc, ECU.

Quelle: Deutsche Bundesbank (1997b), eigene Berechnungen

Funktion von offiziellen Devisenreserven. Notenbanken halten Devisenreserven aus zwei Gründen: Zum einen dient dieser Vorrat dazu, jederzeit inländische gegen ausländische Währung tauschen zu können, damit staatliche Stellen und Private ihre Zahlungsverpflichtungen begleichen können. Zum anderen dienen die Reserven zur Intervention an den Devisenmärkten, um den Wechselkurs vis-à-vis anderen Währungen zu beeinflussen [z. B. Garber 1996: 5f].

Ausgehend von diesen beiden Funktionen, richtet sich die Höhe der Bestände nach folgenden Determinanten: Je größer und je offener eine Volkswirtschaft ist, desto mehr Devisenreserven wird sie vorhalten wollen. Gemessen wird dies in der Regel als Volumen der Fremdwährungstransaktionen, der Importe oder des Bruttoinlandsprodukts. In der Praxis werden häufig grobe Indikatoren bemüht, wenn beurteilt werden soll, ob die Notenbank eines Landes Reserven in genügendem Umfang hält: zum Beispiel wieviele Wochen lang aus den Reserven die Importe eines Landes bezahlt werden könnten [Leahy 1996: 376f].

Die zweite wichtige Determinante für die Höhe der Rerservehaltung ist die währungspolitische Strategie. Verfolgt die Notenbank ein Wechselkursziel, sei es unilateral oder im Rahmen eines internationalen Wechselkurssystems, benötigt sie größere Mengen an Devisenreserven, als wenn sie den Kurs frei floaten läßt und allenfalls gelegentlich interveniert, um den Devisenmärkten Signale zu geben. 
Angesichts eines rasch wachsenden internationalen Devisenmarktes versuchen die Notenbanken mit dieser Entwicklung Schritt zu halten. Dies erklärt den raschen Aufbau in der ersten Hälfte der neunziger Jahre: Einerseits nahm das Handelsvolumen rapide $\mathrm{zu}$, andererseits verfolgten gerade die Notenbanken Asiens und Lateinamerikas eine Politik der einseitigen Anbindung an den US-Dollar, für dessen Verteidigung sie eine gut gefüllte „Kriegskasse” verfügen mußten. Die Wahl der Reservewährung steht also in engem Zusammenhang mit der Wahl einer Ankerwährung, die im folgenden Abschnitt erörtert wird.

Die Wahl der Reservewährung. Welche Währung wählen Notenbanken für die Reservehaltung? Wie für private Portfoliomanager, so gilt auch für Notenbanken, daß sie ein Reservemedium wünschen, das in größtmöglichem Maß liquide ist, das sich also auf einen großen, tiefen, liquiden Finanzmarkt stützt. Insofern hängt die offizielle Reservehaltung stark von der Existenz privater Kapitalmärkte ab. Sofern unvorhergesehene Zahlungen in fremder Währung auf sie zukommen oder sie sich gezwungen sieht, am Devisenmarkt zu intervenieren, um den Wechselkurs zu stabilisieren, muß eine Notenbank ihre Reserven rasch mobilisieren können. Dies kann entweder über die Gewährung von Krediten bei ausländischen Geschäftsbanken geschehen oder besser noch durch die Haltung von Wertpapieren in der betreffenden Reservewährung. Analog privaten Portfoliomanagern wünschen auch Notenbanken eine diversifizierte Struktur der Laufzeiten und Risiken [Garber 1996: 6].

Wegen der genannten Funktionen der Rerserven, wird eine Notenbank stets die Währungen der wichtigsten Partnerländer für den Güter- und Kapitalverkehr halten wollen. Ist dies nicht oder nur in sehr begrenztem Umfang möglich, weil deren Währungen sich nicht auf große, liquide Kapitalmärkte stützen, bedarf es einer Vehikelwährung. Hält eine Notenbank US-Dollar, so kann sie Reserven in dieser Währung in jede andere Währung tauschen, denn der Dollar verfügt, wie oben beschrieben, über liquide Devisenmärkte gegenüber nahezu allen sonstigen Währungen der Erde.

Perspektiven für den Euro als Reservewährung. Vieles spricht dafür, daß der Euro gegenüber dem Dollar Marktanteile gewinnen kann und einen größeren Stellenwert haben wird als die Summe seiner Vorgängerwährungen. Wie an mehreren Stellen erwähnt, ist die Funktion des Euro als Reservewährung eng verschränkt mit anderen Funktionen eines internationalen Geldes: als Transaktions-, Anlage- und Ankerwährung. Wie bei allen anderen Funktionen auch, so wird dieser Übergang nicht abrupt, sondern graduell über eine längere Zeitspanne vonstatten gehen.

Die ersten Kandidaten für eine verstärkte Nutzung des Euro als Reservewährung sind Länder, die enge Handels- und Kapitalverkehrsverbindungen zum Euroland pflegen und die zugleich ihre Währung an den Euro gebunden haben. Sie benötigen den Euro sowohl zur Begleichung von Zahlungsverpflichtungen als auch zur Intervention auf den Devisenmärkten. Dies trifft zuvörderst auf die Län- 
der Mittel- und Osteuropas sowie auf die Mittelmeeranrainer [Funke/Kennedy 1997: 9] und die übrigen afrikanischen AKP-Staaten zu.

Neben einem solchen direkten Bedarf könnten auch andere Notenbanken einen Teil ihrer Währungsreserven aus einem Diversifizierungskalkül heraus in Euro umschichten. Diese Möglichkeit bietet sich nun, da eine zweite große Währung zur Verfügung steht. Einige Notenbanken mögen dies als eine willkommene Gelegenheit verstehen, zu einer ausgeglicheneren Portfoliostruktur zu gelangen. Denkbar ist dies vor allem in Asien, wie sich am Beispiel der taiwanesischen Notenbank zeigt, die schon seit längerem einen solchen Kurs verfolgt und graduell den Anteil ihrer D-Mark-Bestände aufgestockt hat [McCauley 1997: 35]. In Lateinamerika hingegen wird der Euro wahrscheinlich nur wenige Anhänger finden, Anlaß zu dieser Vermutung geben die engen Bindungen dieser Region an den Dollarraum.

\section{1. 5 Internationale Ankerwährungen}

Mit Beginn der Währungsunion hat der Euro die Rolle seiner Vorgängerwährungen als Ankerwährung übernommen. Im Jahr 1998 folgten insgesamt 23 Staaten einem fixierten Wechselkurs gegenüber einer der Währungen, die mittlerweile im Euro aufgegangen sind: 15 afrikanische Staaten (AKP-Staaten) hatten ihre Währungen an den Französischen Francs gebunden, drei mittel-osteuropäische Staaten die ihren an die D-Mark. Je ein weiteres Land orientierte sich entweder an der Lira, am Escudo oder an der ECU. Dazu kamen noch Dänemark und Griechenland, die am EWS teilnahmen und nun seinem Nachfolger, dem EWS II, angehören. Hingegen hatten 20 Staaten ihre Währungen an den Dollar gebunden, vier weitere verfolgten eine flexiblere Bindung an die US-Währung. Neben dieser Ausrichtung auf eine einzige Währung gab es eine ganze Reihe weiterer Arrangements, bei denen die betreffende Notenbank einem Währungskorb folgte, sei es gegenüber den Sonderziehungsrechten (SZR), sei es gegenüber einem individuell zusammengesetzten Mix, oder bei denen sie ihre Währung inoffiziell an eine größere gepeggt hatte [IWF 1998c: 140f].

Funktion einer Ankerwährung. Staaten, die ihre Währung an eine andere binden, verfolgen damit zuvörderst das Ziel, einen Glaubwürdigkeitstransfer von einer größeren, international akzeptierten Währung zu ihrer eigenen zu schaffen. Implizit geben sie damit das Versprechen ab, dem Kurs der weithin respektierten Notenbank der Ankerwährung zu folgen. Ziel ist es, dem Publikum auf den Finanzmärkten, aber auch den heimischen Investoren, Konsumenten und Tarifparteien Vertrauen in die Währungspolitik zu vermitteln. Dadurch soll zum einen die Inflation niedrig gehalten, zum anderen soll die Volatilität des Wechselkurses gegenüber den Währungen der wichtigsten Partnerländer eingedämmt werden, um Handel und Kapitalverkehr eine stabile Kalkulationsgrundlage zu verschaffen.

Dies ist nicht immer unproblematisch: Sofern Wechselkursanpassungen nicht möglich sind, kann es zu dauerhaften Ungleichgewichten kommen; dies ist 
insbesondere bei „Currency boards" der Fall, die massive negative realwirtschaftliche Effekte haben können. Auch bei fixierten „Pegs“ gibt es die Tendenz, notwendige Anpassungen zu lange hinauszuschieben. Sich rasch entwickelnde Staaten, die große Mengen an Kapital importieren, erliegen oft dieser Versuchung: Eine Überbewertung verschafft ihnen günstige Konditionen für den Kapitalimport. Im Fall einer Abwertung hingegen befürchten sie einen drastischen Zinsanstieg. Da sich dies nicht nur auf die privatwirtschaftlichen Investitionsentscheidungen auswirkt, sondern auch auf den öffentlichen Haushalt, der durch einen erhöhten Schuldendienst belastet wird, dürften gerade hochverschuldete Staaten der Versuchung einer Überbewertung erliegen. Eine Anpassung des Wechselkurses wird aber unausweichlich, wenn die Anker- und die Peg-Notenbank einen divergenten geldpolitischen Kurs verfolgen, wenn also das Inflationsdiffential zwischen beiden Ländern wächst - die gepeggte Währung wertet dann real auf und verschafft der heimischen Wirtschaft einen möglicherweise gravierenden Wettbewerbsnachteil. Wird dies offensichtlich, kann es zu einer massiven Kapitalflucht kommen, wie 1995 in Mexiko, 1997 in Südasien und 1999 in Brasilien. ${ }^{69}$ Eine Möglichkeit, solche massiven, dauerhaften Ungleichgewichte zu vermeiden, ist ein „Crawling peg“, bei dem entsprechend der erwarteten Inflationsdifferenz kontinuierlich und kontrolliert gegenüber der Ankerwährung abgewertet wird. Insofern kann dies ein glaubwürdigeres und daher stabileres Verfahren sein als eine einfache, feste Wechselkursbindung. ${ }^{70}$

Euro und Dollar als Ankerwährungen. Wie Abbildung 3-3 erwarten läßt, folgen vor allem Länder dem Euro bzw. folgten seinen Vorgängerwährungen, für die der Handel mit den Euroland-Staaten einen großen Stellenwert hat [z. B. McCauley 1997: 21ff]. Dies gilt insbesondere für die MOEL und für die Länder des Mittelmeerraumes. Hingegen binden Rohstoffexporteure, deren Exporte in aller Regel in Dollar fakturiert sind, ${ }^{71}$ ihre Währungen an die US-Währung. Dies zeigt sich auch in der ,Nachbarschaft” des Eurolandes, im übrigen Europa, Nordafrika und dem Nahen und Mittleren Osten (Übersicht 3-1):

69 Eine sich auftürmende Auslandsverschuldung ist aus Sicht der Regierung ein Substitut für weit schwieriger umsetzbare strukturelle Reformen.Dies war auch bei der asiatischen und bei der russischen Währungskrise von 1997/98 der Fall. Vgl. BIZ (1998), insbesondere Kap. 3, sowie IMF (1998).

70 Für eine umfassende Analyse der Wechselkursstabilisierung in Entwicklungsländern vgl. Diehl/Schweickert (1997). Dornbusch (1999) empfiehlt den Ländern an der Peripherie entschieden, „Currency Boards” einzurichten und ihre Währungen an Euro oder Dollar zu binden.

71 Siehe 3. 1. 1 . 
Übersicht 3-1: Wechselkursarrangements im geographischen Umfeld der EWU

\begin{tabular}{|c|c|c|}
\hline Land & Wechselkursregime & Währung / Währungskorb \\
\hline Albanien & Freies Floating & - \\
\hline Bosnien-Herzegowina & Currency Board & Euro* \\
\hline Bulgarien & Currency Board & Euro* \\
\hline Kroatien & Managed Floating & Euro* \\
\hline Tschechien & Managed Floating & - \\
\hline Estland & Currency Board & Euro* \\
\hline Ungam & Crawling Peg & $70 \%$ Euro* / $30 \%$ US-Dollar \\
\hline Lettland & Peg & Sonderziehungsrechte \\
\hline Litauen & Currency Board & Euro* \\
\hline Mazedonien & Managed Floating & De facto Peg an Euro* \\
\hline Polen & Crawling Peg & $\begin{array}{l}45 \% \text { US-Dollar } / 40 \% \text { Euro } / 10 \% \text { Brit. Pfund } 5 \\
\% \text { S.Fanken }\end{array}$ \\
\hline Rumänien & Freies Floating & F \\
\hline Slowakische Republik & Peg & $60 \%$ Euro* / $40 \%$ US-Dollar \\
\hline Slowenien & Managed Floating & De-Facto-Bindung an Euro* \\
\hline Zypern & Peg & Euro $^{+}$ \\
\hline Israel & Crawling Peg & $\begin{array}{l}54 \% \text { US-Dollar / } 32 \% \text { Euro }^{8} / 8 \% \text { Brit. Pfund / } \\
7 \% \text { Yen }\end{array}$ \\
\hline Malta & Peg & $67 \%$ Euro $^{+} / 21 \%$ US-Dollar / $12 \%$ Pfund \\
\hline Türkei & Managed Floating & US-Dollar \\
\hline Algerien & Managed Floating & US-Dollar \\
\hline Iran & Peg & US-Dollar \\
\hline Jordanien & Peg & US-Dollar \\
\hline Libanon & Managend Floating & US-Dollar \\
\hline Marokko & Peg & Währungskorb \\
\hline Saudi Arabien & Peg & US-Dollar \\
\hline Syrien & Peg & US-Dollar \\
\hline Tunesien & Managed Floating & Währungskorb \\
\hline AKP-Staaten & Peg & Euro $^{\circ}$ \\
\hline
\end{tabular}

${ }^{\circ}$ bisher Franz. Francs ${ }^{+}$bisher ECU *bisher D-Mark " bisher $35 \%$ D-Mark, $5 \%$ Franz. Francs bisher 26 \% D-Mark, 6 \% Franz. Francs. Stand: 1998, Quelle: IWF (1998b)

Der Grund, warum der Dollar bislang auch in vielen Ländern Mittel- und Osteuropas eine große Rolle spielt, liegt vor allem in der Bedeutung der US-Finanzmärkte. Für ihre Auslandsverschuldung haben sie bislang auf den US-Markt zurückgegriffen, in den meisten Staaten macht die Verschuldungen in europäischen Währungen nur einen relativ kleinen Teil aus. Daraus ergibt sich ein Mismatch: Der Außenhandel ist in fast allen Ländern an der EWU-Peripherie stark auf das Euroland ausgerichtet, die Auslandsverschuldung hingegen ist größtenteils in Dollar (oder Yen) denominiert. Einzige Ausnahme ist Jordanien (Abbildung 37. 
Abbildung 3-7: Denominierungs-Mismatch bei Außenhandel und Auslandsverschuldung*

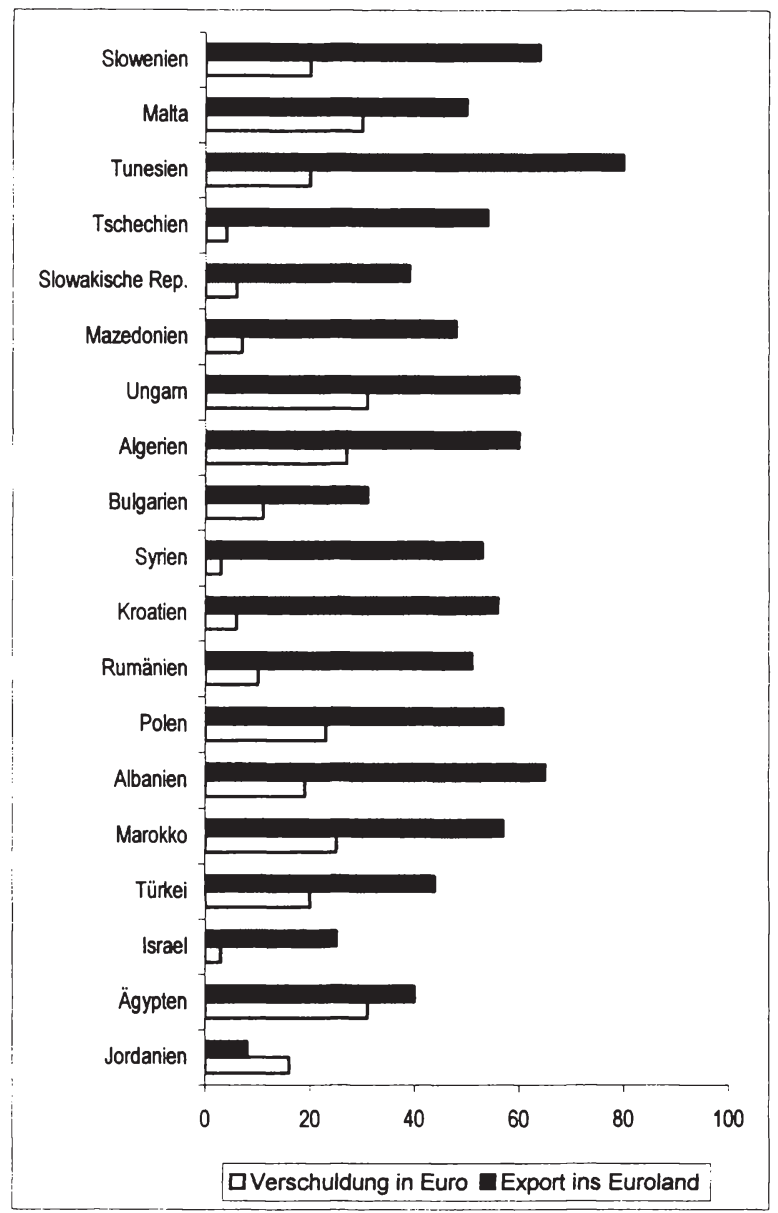

*Exporte ins Euroland in \% der gesamten Exporte des jeweiligen Landes, in Euro denominierte Verschuldung in \% der jeweiligen gesamten Auslandsverschuldung. Stand: 1996. Quelle: IWF (1998b)

Die Notenbanken dieser Staaten stehen somit vor einem Problem, wenn sie auf der Suche nach einem monetären Anker sind: Die wichtige Rolle des Außenhandels mit dem Euroland spricht für eine Bindung an den Euro, die Verschuldung in Dollar hingegen für eine Bindung an die US-Währung. Ein Land wie Bulgarien zum Beispiel, das sich per „Currency board“ an den Euro gebunden hat, kann Probleme bekommen, wenn es zu großen Bewegungen im Außenwert des 
Euro kommt. Das hochverschuldete Land (Auslandsverschuldung: 90 Prozent des BIP) hat nur elf Prozent seiner Auslandsschulden in Euro, zusammen aber 76 Prozent in Dollar und Yen denominiert. Es wickelt jedoch 45 Prozent seiner Exporte mit dem Euroland ab. Kommt es zu einer Abwertung des Euro gegenüber Dollar und Yen, vollzieht die bulgarische Währung Lew diesen Schritt mit. Dadurch verbessert sich zwar tendenziell die Konkurrenzfähigkeit bulgarischer Unternehmen auf den Weltmärkten, zugleich steigen aber die Auslandsschulden im Wert, entsprechend teurer wird die Tilgung - angesichts der hohen Auslandsverschuldung eine möglicherweise dramatische Entwicklung. Dennoch erscheinen der bulgarischen Regierung die Vorteile durch den Glaubwürdigkeitstransfer von der Europäischen Zentralbank an die nationale Zentralbank so groß, daß sie dieses Risiko in Kauf nimmt.

Die Gefahr, in einen solchen Spagat zu geraten, ist der Grund, warum einige Staaten ihre Währungen an einen Korb gebunden haben, in den Dollar und Euro das größte Gewicht einbringen. Darunter waren 1998 sogar Ungarn, Polen und Malta, die zur Runde der ersten EU-Beitrittskandidaten zählen und die daher ein großes Interesse an einer währungspolitischen Zusammenarbeit mit der Eurozone haben sollten.

Der Dollar fungiert in vielen erdöl- und anderen rohstoffexportierenden Ländern als Ankerwährung, aber auch in den Emerging Markets Lateinamerikas und Asiens sowie bis 1998 in Rußland. Allerdings hat er in dieser Hinsicht an Bedeutung eingebüßt, da viele der einseitigen Wechselkursbindungen nicht aufrechtzuerhalten waren und in den schon erwähnten Währungskrisen mündeten, so 1997 in Thailand, Indonesien, Malaysia, Südkorea, 1998 in Rußland, 1999 in Brasilien. Es ist denkbar, daß auch diese Länder in fernerer Zukunft ihre Währungen an einen Korb binden, in dem auch dem Euro ein gewisses Gewicht zukommt, dies in dem Maße, wie Auslandsverschuldung und Handel mit Europa zunehmen.

Perspektiven für den Euro als Ankerwährung. Indem im Euroland große, liquide Finanzmärkte entstehen, eröffnet sich anderen Ländern die Möglichkeit, ihre Kreditaufnahme in den Euroraum zu verlagern. Vor allem die Staaten an der EWU-Peripherie dürften diese Option ergreifen, um den Mismatch zwischen AuBenhandel und Schuldendenominierung zu beseitigen und damit das Fundament zu legen für die währungspolitische Annährung an die Währungsunion. Auch Länder in anderen Weltregionen dürften zunehmend das Euroland für ihre Verschuldung nutzen, um, wie unter 3. 1.3 erläutert, zu einer ausgewogeneren Portfoliostruktur zu gelangen. Jedoch dürften sie den Euro nicht als Ankerwährung, sondern allenfalls als Teil eines Währungskorbes verwenden. Wie schnell dieser Prozeß der Umschuldung in den Euroraum abläuft, ist schwer vorherzusagen. Entscheidend hierfür ist vor allem die Entwicklung der europäischen Finanzmärkte, aber auch der währungspolitische Kurs im Euroland und in den USA. 


\section{1. 6 Verschafft die Weltwährung Euro den EWU-Mitgliedsländern neue wirtschaftspolitische Freiheitsgrade?}

Die Ausgangsfragen dieses Abschnitts lauteten: Verschafft der Euro den Regierungen der EWU-Staaten größere Freiheiten in der Wirtschaftspolitik? Können sie Abwertungen inszenieren, ohne schmerzhafte Sanktionen der Finanzmärkte befürchten zu müssen? Versetzt die Weltwährung Euro die Europäer in die Lage, eine an reinen EU-Interessen ausgerichtete Währungspolitik zu betreiben? Einige Antworten sind bereits nach der bisherigen Erörterungen möglich:

Die frühen Jahre. Der Euro ist zwar vom Start weg die zweitwichtigste Währung der Welt, aber noch keineswegs eine Weltwährung. In den vorhergehenden Abschnitten wurde aufgezeigt, daß die Internationalisierung des Euro einige Jahre, wenn nicht Jahrzehnte dauern wird. Diese Entwicklung hängt vor allem von folgenden Faktoren ab: erstens dauerhaft niedrigen Inflationsraten, die die Glaubwürdigkeit der Europäischen Zentralbank unter Beweis stellen, zweitens der Freiheit von Kapitalverkehrskontrollen, so daß Kapital frei und zu möglichst niedrigen Kosten ins Euroland und wieder heraus transferiert werden kann, drittens liberalen Finanzmarktregulierungen, die ein rasches Zusammenwachsen der Finanzmärkte begünstigen. Für den dritten Punkt ist weiterhin interessant, ob bzw. wie schnell Großbritannien EWU-Mitglied wird und damit London, der nach New York zweitwichtigste Finanzplatz der Welt, in die Eurozone kommt.

Solange die EZB noch nicht über einen ausreichenden „Track record" verfügt, wird eine Wechselkurspolitik, die ihre Glaubwürdigkeit in Frage stellt, von den Märkten sanktioniert. Die Folge sind steigende Risikoprämien. Eine handelspolitisch motivierte Wechselkurspolitik, die eine dauerhafte Schwächung des Euro zum Ziel hat, ist daher mit relativ hohen Kosten verbunden. Inwieweit dies die wirtschaftspolitischen Entscheidungsträger davor zurückschrecken läßt, den Wechselkurs als wirtschaftspolitisches Instrument zu benutzen, ist allerdings fraglich. Denn die meisten EWU-Staaten waren lange Zeit weit höhere Risikoprämien gewöhnt als sie zu Beginn der Euro-Ära herrschen. Ein gemäßigter Anstieg über dieses historisch niedrige Niveau hinaus kann ihnen daher durchaus tolerierbar erscheinen. ${ }^{72}$

Die reiferen Jahre. Ist der Euro erst als internationale Währung mit halbwegs respektablem „Track record” etabliert, schrumpfen die Anreize für eine Hartwährungspolitik weiter. ${ }^{73}$ Diese Schlußfolgerung stützt sich insbesondere auf die Erwartung, daß große einheitliche Finanzmärkte entstehen, die für Anleger allein aus Gründen der Diversifizierung attraktiv sind. Auch das Einsetzen einer Netzwerkdynamik zugunsten des Euro spricht für eine größere Toleranz seitens der Anleger gegenüber der europäischen Währungspolitik - verfolgen die EWU-

72 Eine Formalisierung der Aussage dieses Absatzes findet sich in Abschnitt 4. 4.

73 Formal gesprochen, sinkt der Wert des rechten Terms in Gleichung (4-38) in Abschnitt 4. 4. 
Regierungen eine Politik der gelegentlichen Abwertungsversuche, wird der Anstieg der Risikoprämien deutlich geringer ausfallen als zuvor.

Die Güte des Dollar. Nicht nur die Vorgänge im Euroland beeinflussen die Entscheidungen der europäischen Regierungen, sondern auch die Währungspolitik der USA. Sollte der Dollar erneut Schwächephasen erleiden wie zuletzt 1995, dürfte dies die Verbreitung des Euro als Weltwährung beschleunigen. Die Privaten wie auch die Notenbanken werden dann ihre Portfolios umzuschichten versuchen. Falls sich der Euro als härter erweist als der US-Dollar, so dürfte er weit über seine direkte Peripherie hinaus als Transaktions-, Anlage-, Anker- und Reservewährung interessant werden. Umgekehrt wird es die europäische Währung schwer haben, sofern sie deutlich weicher als der Dollar werden sollte, also höheren Inflationsraten unterliegt.

Ein schwacher Dollar würde auch den Euroland-Regierungen mehr Freiheitsgrade bei der Währungspolitik verleihen. Umgekehrt beschränkt ein starker, attraktiver Dollar, der auf einer strikten Geldpolitik basiert, den Spielraum der Euroland-Regierungen. Der Ausgang des Währungswettbewerbs - ob es zu einem Härtungs- oder zu einem Abwertungswettlauf kommt -, hängt daher auch von der wirtschaftspolitischen Philosophie, also dem vorherrschenden ökonomischen $\mathrm{Pa}$ radigma, ab. ${ }^{74}$

\section{2 Die EWU-Länder als Handelsnationen}

Bisher ging es darum zu zeigen, wie die Entwicklung des Euro zur Weltwährung die Disziplinierung der Politik durch die Finanzmärkte beeinflußt. Dieser Abschnitt beschäftigt sich nun mit der handelspolitischen Dimension des Übergangs zur EWU. Die Betrachtung ist dabei überwiegend eine länderweise, denn es sind ja die Regierungen im Ministerrat, die über die Währungspolitik entscheiden. ${ }^{75}$

\section{2. 1 Auswirkungen des EWU-Beitritts auf die Exponiertheit im Außenhandel}

Zunächst bedeutet die Einführung des Euro, daß die Teilnehmerstaaten weit geschlossenere Volkswirtschaften geworden sind: Thr Außenhandel mit den übrigen EWU-Ländern ist zu Binnenhandel geworden. Damit sinkt der wechselkursabhängige Teil des Außenbeitrags. Dies sei kurz anhand der traditionellen keynesianischen Gleichung für den Gütermarkt in der offenen Volkswirtschaft verdeutlicht. Sofern von Reaktionen der Güterpreise in der kurzen Frist abstrahiert wird, ergibt sich folgendes Bild:

$$
y=n(y, i)+g+a_{E W U}\left(y, y_{E W U}^{*}, e_{E W U}\right)+a_{R O W}\left(y, y_{R O W}^{*}, e_{R O W}\right)
$$

74 Zur Rolle der Paradigmen in der internationalen Währungspolitik siehe 5. 1. 2.

75 Siehe Abschnitt 2. 3. 
Die gesamtwirtschaftliche Nachfrage und damit das gesamtwirtschaftliche Einkommen $y$ setzt sich zusammen aus der inländischen Absorbtion $n$ - privater Konsum und Investionen -, die bekanntlich bei steigendem inländischen Einkommen und bei sinkendem Zins $i$ steigt, und der exogenen Staatsnachfrage $g$. Weiterhin ist das Inlandseinkommen abhängig vom Außenbeitrag $a$, für den eine Normalreaktion unterstellt wird, nämlich daß er bei steigendem Inlandseinkommen sinkt (Importnachfrage steigt), bei steigendem Auslandseinkommen $y^{*}$ sowie bei einer Abwertung, also bei steigendem Wechselkurs in Preisnotierung $e$, zunimmt (Exportnachfrage nimmt zu). In Gleichung (3-1) ist der Außenbeitrag geteilt dargestellt: einmal für die übrigen EWU-Länder, zum anderen gegenüber dem Rest der Welt (Rest of the World = ROW). Durch den Beginn der Währungsunion ist $e_{E W U}$ für alle Zeiten festgelegt, der Außenbeitrag gegenüber den EWU-Staaten, $a_{E W U}$, unterliegt keinen Wechselkursschwankungen mehr.

Eine Vorstellung darüber, wie groß dieser Effekt in den Ländern der Europäischen Union ${ }^{76}$ ist, vermittelt Abbildung 3-8. Vor Beginn der Währungsunion waren sie offene, teils sehr offene Volkswirtschaften, mit der Gründung der gemeinsamen Währung wurden sie relativ geschlossene. Der Grund liegt darin, daß die EU-Staaten einander die besten Handelspartner sind, den weitaus größten Teil ihrer Im- und Exporte wickeln sie untereinander ab. ${ }^{77}$ Nur im Außenhandel mit den Staaten außerhalb der Union existieren noch Wechselkursrisiken. Irland, das Land mit dem größten Öffnungsgrad, ist nur noch so offen wie der „Pre-In” Griechenland. Besonders niedrig ist die Außenhandelsabhängigkeit nun in den schwächer entwickelten Südländern der EU.

Auswirkungen auf währungspolitische Interessen. Diese Veränderungen haben Auswirkungen auf die Interessenlagen, denen sich die Regierungen in ihren Ländern gegenübersehen. Früher schlugen gerade in den kleineren Ländern Währungsschwankungen stark auf inländische makroökonomische Größen durch: auf das Preisniveau, auf die gesamtwirtschaftliche Nachfrage, auf die Beschäftigung. Wenn, wie einst in Irland oder Belgien, mehr als die Hälfte des Sozialprodukts im Außenhandel verdient wurde, hatte eine Veränderung des Wechselkurses möglicherweise gravierende Folgen: Im Fall einer Abwertung explodieren die Importpreise, im Fall einer Aufwertung leidet die Wettbewerbsfähigkeit der heimischen

76 Hier wie auch im folgenden Teil des Abschnitts werden alle 15 EU-Staaten betrachtet, da die Datenbasis für das Euroland zum Zeitpunkt des Schreibens noch nicht breit genug war. Im übrigen erscheint dieses Vorgehen gerechtfertigt, da auch die bisherigen „Pre-Ins” vermutlich in wenigen Jahren der Währungsunion angehören werden.

77 Als ganzes betrachtet, ist die EU-15 ein ebenso geschlossener Wirtschaftsraum wie die USA oder Japan: In jedem dieser drei Blöcke trägt der Durchschnitt aus Im- und Exporten rund zehn Prozent zum BIP bei. Da das Euroland bei seiner Gründung noch nicht alle 15 Staaten umfaßt, ist es etwas offener als die anderen beiden, der Außenhandelsanteil liegt derzeit noch bei gut zwölf Prozent des BIP (Abbildung 3-1 oben). 
Exportindustrie. Entsprechend groß war das Interesse an einer Koordinierung der Wirtschaftspolitik, um die Wechselkurse stabil zu halten. Gerade die Regierungen der kleinen, sehr offenen Volkswirtschaften - Niederlande, Belgien, Luxemburg, Österreich, Dänemark - haben daher früh auf einen stabilen Wechselkurs gegenüber der Leitwährung D-Mark geachtet und ihre gesamte Geldpolitik auf dieses Ziel hin ausgerichtet. Andere ähnlich offene Staaten, die erst später zur EU stießen oder die einen Entwicklungsrückstand aufholen mußten - Irland, Finnland, Portugal -, schwenkten ebenfalls in den neunziger Jahren recht entschlossen auf diesen Kurs ein. ${ }^{78}$

Abbildung 3-8: Offenheit* der EU-Staaten vor und nach dem Beitritt zur Währungsunion

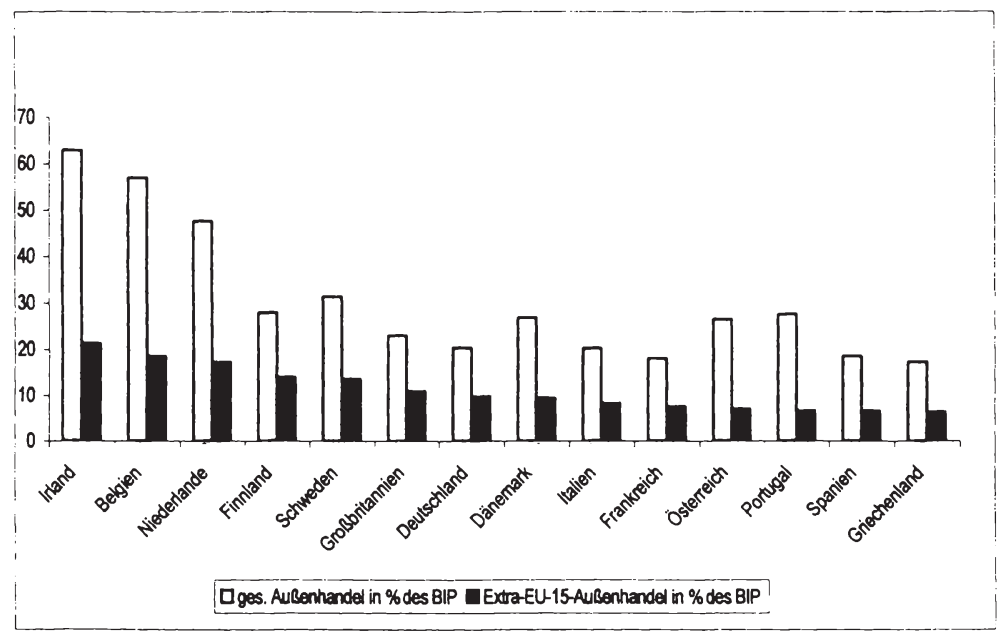

*Durchschnitt aus Ex- und Importen in \% des jeweiligen BIP, Stand 1997.

Quelle: Europäische Kommission (1998), Funke/Kennedy (1997), eigene Berechnungen

Im Umkehrschluß läßt sich schließen, daß die heute geschlosseneren Volkswirtschaften künftig weniger Interesse an einer internationalen Koordinierung der Währungspolitik haben werden. In den kommenden Jahren dürften sich daher die Akzente in der Außenwährungspolitik der Regierungen der Euroland-Staaten deutlich verschieben. Sie werden weniger Interesse an internationaler Koordinierung der Wirtschafts- und Währungspolitik aufbringen, weil sie davon nun in wesentlich geringerem Maße profitieren als zuvor. Hingegen dürften sie nationalen und europäischen Zielen Priorität einräumen. Diese Tendenz wird besonders stark

78 Hierzu näher Abschnitt 5. 2. 2. 
in den Ländern zutage treten, die relativ gering mit dem Rest der Welt verflochten sind, die also in Abbildung 3-8 weit rechts im Spektrum liegen.

Eine andere Frage ist, inwieweit das Interesse in den EWU-Staaten steigen könnte, den Wechselkurs als handelspolitisches Instrument zu nutzen. Bis zum Beginn der Währungsunion wirkten der Verlust an währungspolitischer Glaubwürdigkeit und die damit einhergehenden Kosten abschreckend. Nun könnte sich die Konstellation ändern.

\section{2. 2 Struktur der Exporte der EWU-Länder}

Die potentiellen „Nachfrager" nach einer solchen wechselkurspolitischen Protektion sind zuvörderst die Branchen, die auf den Weltmarkt exportieren. Sie wären die größten Gewinner dieser Politik. Eine Abwertung gegenüber Dollar und/oder Yen würde den entsprechenden europäischen Firmen Wettbewerbsvorteile bringen: Sie könnten zu niedrigeren Preisen anbieten als ihre ausländischen Wettbewerber und/oder ihre Gewinne steigern. ${ }^{79}$

Abbildung 3-9: Struktur der Extra-EU-Exporte (in Mio. Euro)

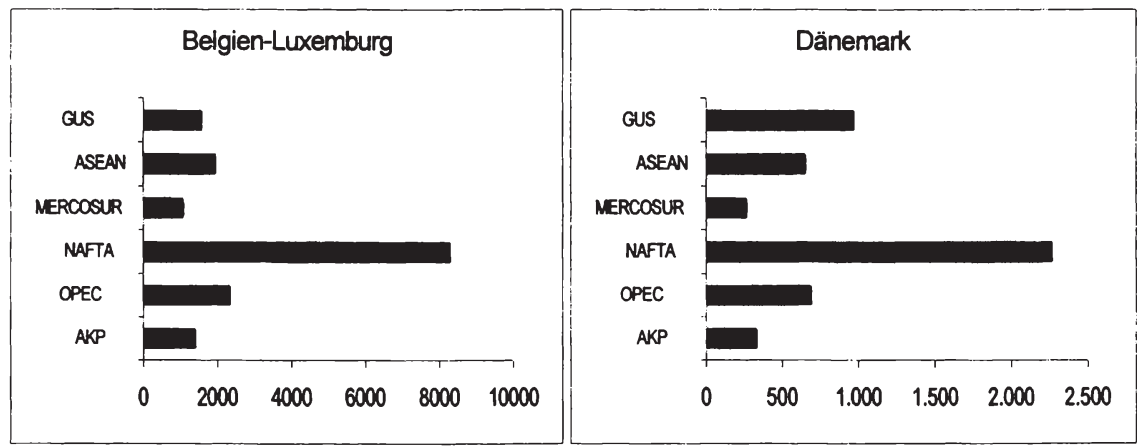

79 In der Regel kommt es zu einer Mischung aus beidem: Sowohl der Preis als auch der Erlös reagiert auf den Wechselkurs. Ob es zu einem völligen Überwälzen der Wechselkursänderung auf die Preise kommt (,Exchange rate pass-through”) oder im anderen Extrem die Preise konstant bleiben und lediglich die Erlöse reagieren („Pricing-to-market”), hängt von der Wettbewerbsintensität auf dem betreffenden Markt sowie von der Zielsetzung des Unternehmens kurzfristige Gewinnmaximierung oder langfristige Behauptung der Position auf einem Markt ab [Deutsche Bundesbank 1997a]. Für eine Analyse des „Pass-through” in der US-Industrie vgl. Antzoulatos/Yang (1996). Häufig werden Persistenzeffekte mit einer Aufwertung verbunden, die daraus resultieren, daß Märkte unwiederbringlich verloren gehen, so daß auch bei einer folgenden Abwertung keine Erholung stattfindet. Dies wurde in den USA vielfach in den achtziger Jahren diskutiert. Für eine Analyse aus europäischer Sicht vgl. Tatom (1995). 
Abbildung 3-9 (Forts.): Struktur der Extra-EU-Exporte (in Mio. Euro)
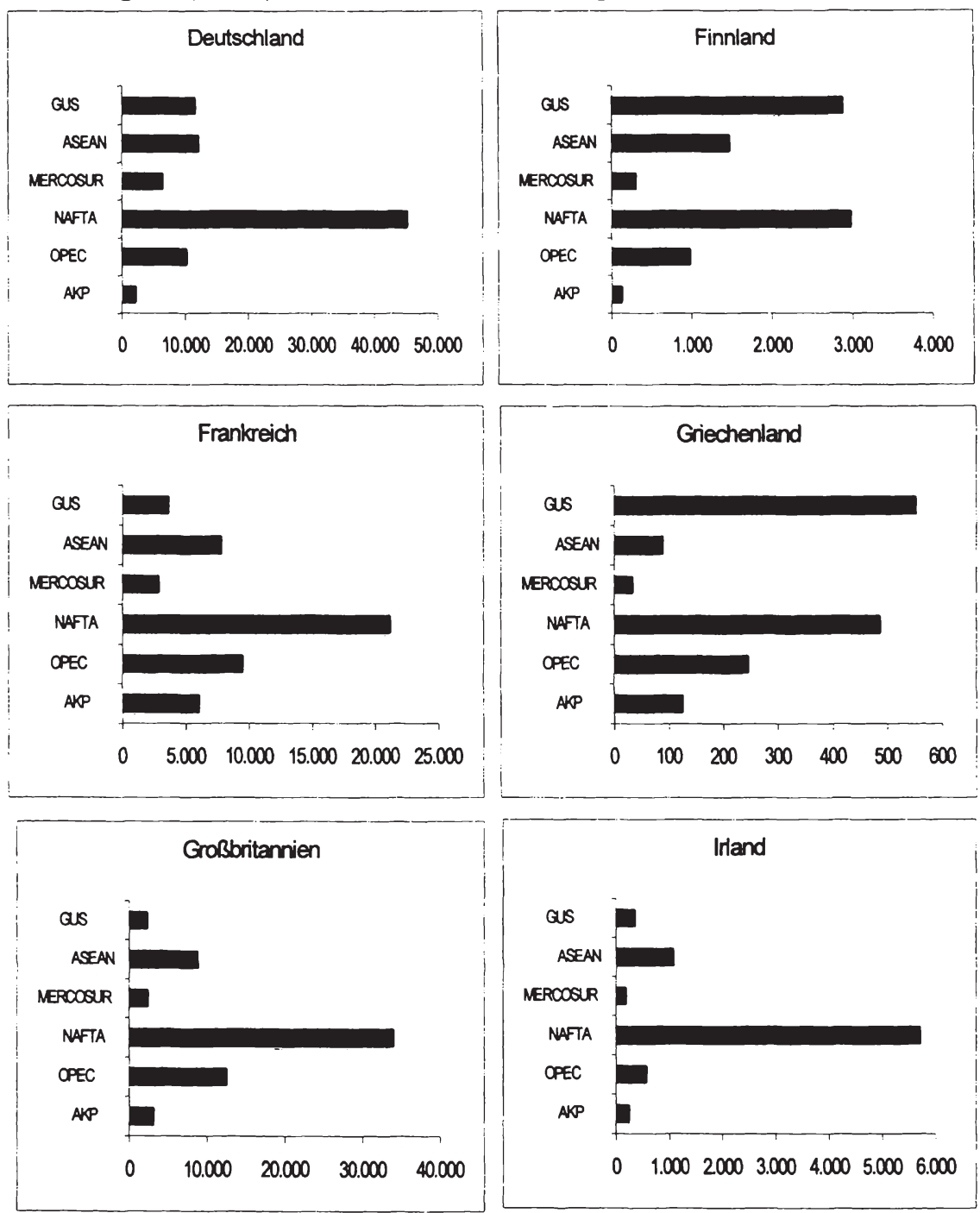
Abbildung 3-9 (Fortsetzung): Struktur der Extra-EU-Exporte (in Mio. Euro)
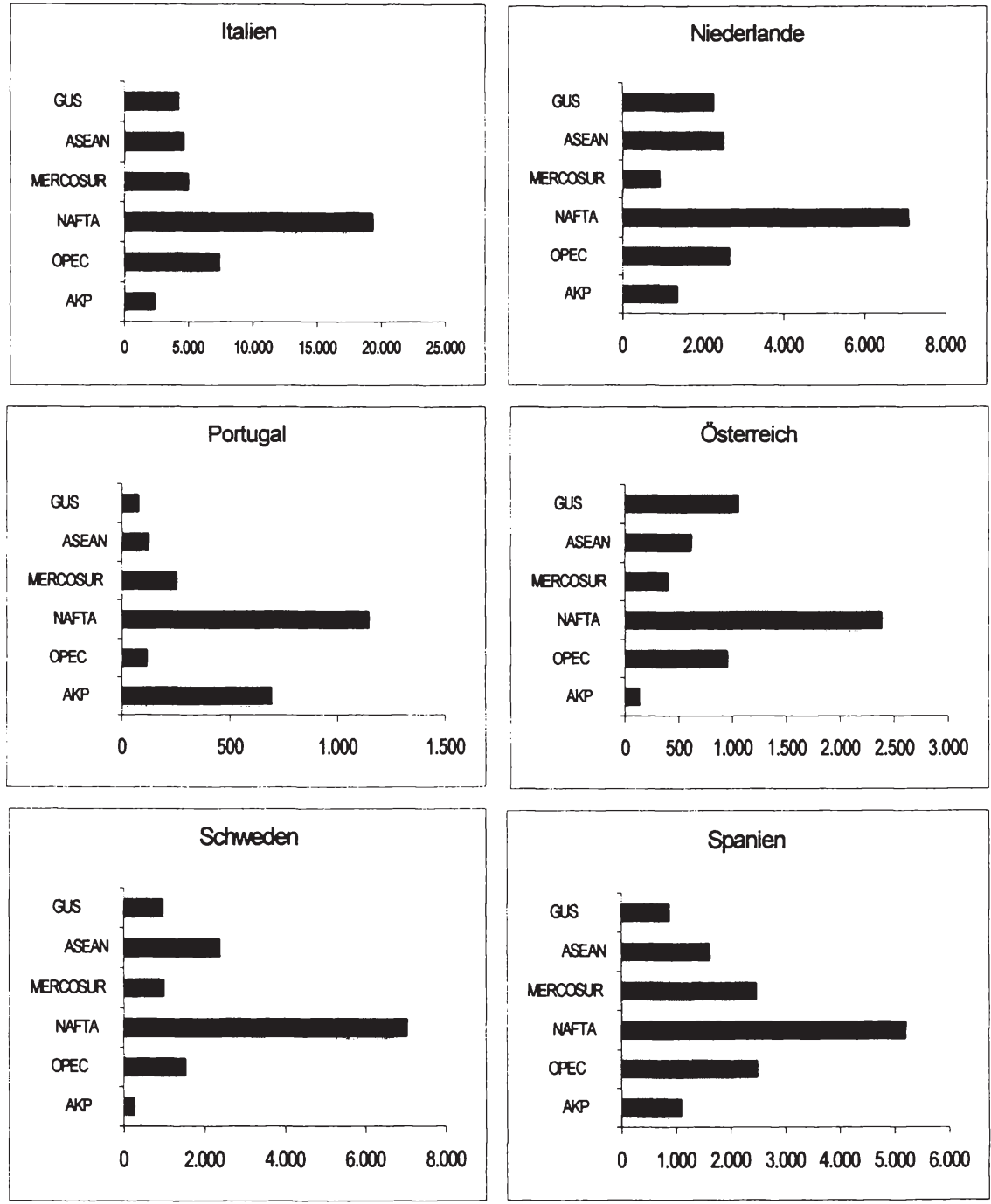

Quelle: EUROSTAT Extra-Euroäische-Union-Statistik (97-98), Stand: Ende 1997

Regionale Struktur der EU-Exporte. Einen Hinweis darauf, welchen handelspolitischen Interessen sich die Regierungen in den EU-Ländern gegenübersehen, gibt ein Blick auf die regionale Struktur der Extra-EU-Exporte der 
einzelnen Länder. Wie die Abbildung 3-980 zeigt, divergieren die Ausrichtungen der EU-Exporte je nach Land ganz erheblich. Gerade für die kleineren Staaten am Rand der EU ist oft der regionale Handel mit den Nachbarn - den MOEL, den Ländern der Euroäischen Freihandelszone (EFTA), den GUS-Staaten - wichtiger als das transkontinentale Geschäft mit den Ländern der NAFTA, der ASEAN oder der OPEC. Für Österreich zum Beispiel sind die MOEL die Abstand wichtigsten Handelspartner, für Dänemark und Schweden spielen die EFTA-Staaten eine herausragende Rolle, insbesondere wegen der Verbindungen zu den skandinavischen EFTA-Mitgliedern Norwegen und Island. Finnland exportiert ebenso viel in die GUS-Staaten, insbesondere zum großen Nachbarn Rußland, wie in die NAFTA.

Diese regionalen Unterschiede in der Exportintensität lassen auf unterschiedliche Interessenlagen in der Wechselkurspolitik schließen. In 3. 1 wurde dargelegt, daß die Nachbarstaaten des Eurolandes den Euro als Transaktionswährung und als monetären Anker nutzen werden. Es gibt daher gute Gründe zu erwarten, daß die EU-Staaten, mindestens aber die „Ins”, ihren Handel mit den MOEL sowie den EFTA- und AKP-Staaten in Euro abwickeln können und daß die Notenbanken dieser Länder versuchen werden, den Kurs zum Euro halbwegs konstant zu halten. Abbildung 3-10 zeigt, wie unterschiedlich die Bedeutung der Exporte in den Dollarraum für die Volkswirschaften der EU-Staaten ist:

Abbildung 3-10: Relevanz des Dollar-Exports* aus Sicht der EU-Staaten

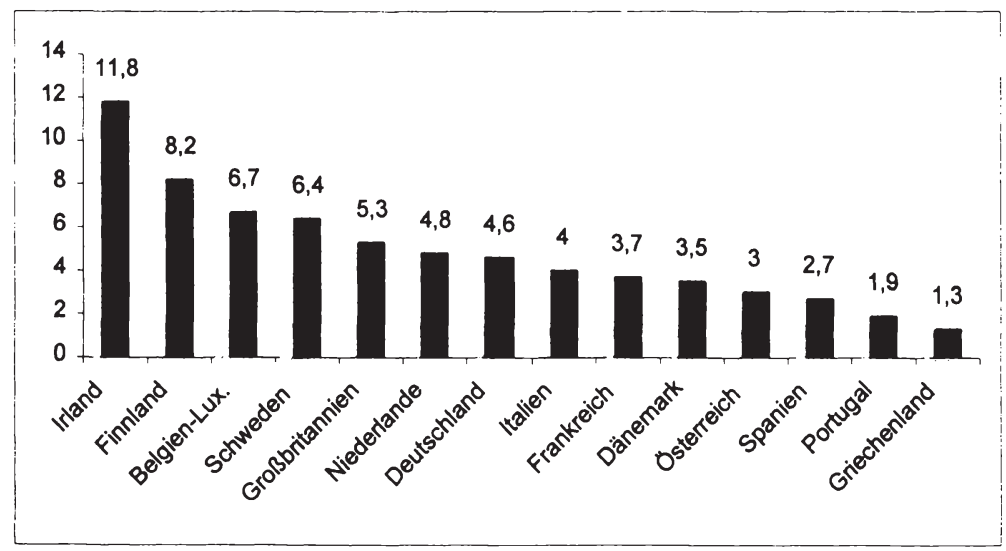

*Exporte in die Länder der NAFTA, MERCOSUR, OPEC, ASEAN, GUS in \% des jeweiligen BIP, Stand: Ende 1997

Quelle: EUROSTAT Extra-Euroäische-Union-Statistik (97-98), eigene Berechnungen

80 Die Teilung der Graphik wurde aus Gründen der Übersichtlichkeit vorgenommen. 
Kommt es zu einer Abwertung des Euro gegenüber dem Dollar, so sind die größten Gewinner jene Unternehmen, die in den Dollarraum exportieren. ${ }^{81}$ Deren regionale Verteilung innerhalb der EU ist höchst ungleich. Während die Südstaaten (rechts in der Graphik) nur schwach exponiert sind, nimmt die Bedeutung dieser Exportströme in der Graphik von rechts nach links deutlich zu. Entsprechend ist ein größeres Interesse an einer handelspolitisch motivierten Wechselkurspolitik zu vermuten.

Branchenstruktur. Die Exporte des Eurolandes sind stark industriell geprägt. Maschinen- und Fahrzeugbau sowie Chemie tragen zusammen weit mehr als zur Ausfuhr bei. Werden sonstige Industrieprodukte in die Überlegung einbezogen, so ergibt sich ein Industrieanteil von rund 87 Prozent an den Exporten [z. B. EZB 1999b: $25 * \mathrm{ff}$ ]. Neben diesen exportorientierten Gewinnern einer Abwertung gibt es weitere Branchen, die ebenfalls von einem schwachen Euro profitieren werden. Dies sind insbesondere die Importsubstitutionsbranchen in den EWUStaaten, z. B. Landwirtschaft und die Montanindustrie.

Eine mittels schwach bewerteter Währung erhöhte Wettbewerbsfähigkeit dieser Branchen zeitigt zudem Sekundäreffekte. Diese können sich in den nationalen und EU-weiten Fisci bemerkbar machen. Sofern die exportorientierten Branchen höhere Gewinne erzielen und möglicherweise auch die Beschäftigung erhöhen, wirkt sich dies c. p. entlastend auf die Staatshaushalte aus, die nun höhere Steuereinnahmen erzielen können, während zugleich die Sozialausgaben abnehmen. Ähnlich sind auch die Effekte bei den Importsubstitutionsbranchen: $\mathrm{Da}$ es sich hierbei um hochsubventionierte Wirtschaftszweige handelt, sinken möglicherweise die entsprechenden Finanzhilfen.

\section{3 Aspekte der Politischen Ökonomie}

Bei einer Abwertung des Euro gibt es freilich nicht nur Gewinner, sondern auch Verlierer. Und es gibt keinen Grund anzunehmen, daß die Zahl der Verlierer kleiner sein sollte als die der Gewinner. Im Gegenteil, vermutlich ist die Zahl der zweiten Gruppe deutlich höher, denn eine Schwächung des Euro verursacht hohe Kosten: Die Importpreise steigen, insbesondere in Dollar fakturierte Rohstoffe wie Erdöl werden teurer. Die große Schar der Konsumenten im Euroland zählt zu den Verlierern, ebenso Branchen, die von importierten Inputs abhängig sind. Daß sich Kosten und Nutzen bestenfalls die Waage halten dürften, diesen Schluß legt Abbildung 3-11 nahe: Die Länderstruktur der gesamten Im- und Exporte der EU ist sehr ähnlich. Mittelfristig dürften die Kosten den Nutzen freilich weit übersteigen, z. B. weil die Risikoprämien auf den Zins steigen.

81 In der kurzen Frist können sie allerdings zu den Verlierern zählen: Sofern Lieferverträge in Dollar abgeschlossen wurden, sinken die Erlöse aus laufenden Geschäften im Falle einer Abwertung. Bei Neuabschlüssen verfügen sie jedoch über einen Preisvorteil (,J-Kurven-Effekt”). 
Abbildung 3-11: Regionale Struktur des Außenhandels der Europäischen Union nach Staatengruppen
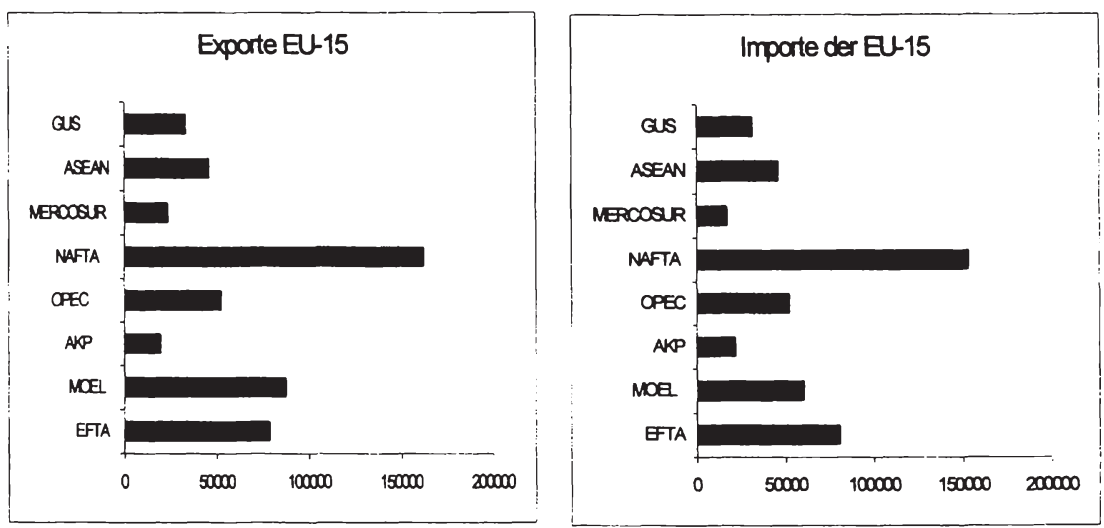

Stand: Ende 1997

Quelle: EUROSTAT Extra-Euroäische-Union-Statistik (97-98), eigene Berechnungen

\section{3. 1 "Nachfrage" nach Protektion}

Gruppeninteressen und Free-riding-Verhalten. Die bloßen Zahlen der Gewinner und Verlierer sagen über das Ergebnis des politischen Prozesses wenig aus. Wie groß eine Gruppe ist, wie groß der Anteil einer Branche am Sozialprodukt ist, all das gibt wenig Aufschluß über ihr tatsächliches Gewicht in der politischen Auseinandersetzung. Die neuere Theorie der Politischen Ökonomie zeigt gerade die umgekehrte Wirkung: Je kleiner eine Gruppe ist, desto besser läßt sie sich organisieren und desto besser ist ihre politische Durchsetzungkraft. Der Grund liegt darin, daß bei großen Gruppen für jedes einzelne Mitglied ein großer Anreiz zum „Free riding“ besteht - also auf die Teilnahme zu verzichten in der Hoffnung, daß sich genügend andere finden, von deren Erfolgen auch der „Schwarzfahrer” profitieren kann. Da sich viele Individuen so verhalten, bleibt die „Pressure group" schwach. Am besten lassen sich Interessen organisieren, bei denen a) die Kosten für die Beteiligung niedrig sind, b) die erwarteten Erträge aus der Unterstützung hoch und c) Zahl der Beteiligten möglichst niedrig, um „Freeriding"-Anreize möglichst gering zu halten [z. B. Caporaso/Levine 1992: 139ff].

In dieser Argumentationslinie steht auch die übliche Erklärung dafür, warum es überhaupt zu Protektion kommt: Die Gesellschaft insgesamt verliert zwar gemäß neoklassischer Außenhandelstheorie, indem sie „Dead-weighed losses" tragen muß - Schutzzölle oder Importquoten machen Effizienzgewinne der internationalen Spezialisierung teilweise rückgängig. Dennoch gewinnen immer wieder protektionistische Tendenzen die Oberhand. Der Grund liegt in einer ungleichmäßigen Verteilung von Kosten und Nutzen: Eine relativ kleine, politisch 
durchsetzungsfähige Gruppe aus Protektionsgewinnern gewinnt - große, politisch impotente Kreise wie die Konsumenten verlieren [z. B. Hillman 1989: 9 ff].

Was für die „reine” Protektion, die mit Zöllen, Quoten und „Freiwilligen Exportbeschränkungen" ausgetragen wird, gilt, läßt sich ebenso auf die monetäre Spielart übertragen: den Wechselkursprotektionismus. Indem das Euroland zu einer weit geschlosseneren Volkswirtschaft geworden ist, verengt sich der Kreis der Begünstigten einer solchen Maßnahme, was apriori für eine Stärkung der politischen Pro-Protektionismus-Position spricht.

Auswirkungen der Technologie. Für die These, daß die Währungsunion protektionistische Tendenzen stärken könnte, sprechen noch weitere Punkte: Bei den unmittelbaren Gewinnern einer Abwertung (Weltmarktexporteuren und Importsubstitutionsbranchen) handelt es sich um etablierte Industrien, die mit relativ großen Unternehmen besetzt sind. Beide Faktoren - Alter der Branche und Unternehmensgröße - begünstigen ihre politische Durchsetzungsfähigkeit. Es handelt sich um Unternehmen, die meist im monopolitischen Wettbewerb stehen, das heißt, die Produkte fertigen, deren Produktion Economies of Scale unterliegen. Wo große Anfangsinvestitionen in Forschung und Entwicklung nötig sind - wie in der Auto- oder der Pharmaindustrie - oder wo es des Aufbaus eines großen Netzwerks bedarf - wie im Telefonmarkt -, ermöglichen erst große Volumina profitables Wirtschaften. Hier gibt es also eine Verbindung zwischen Technologie und politischem Einfluß: Die Existenz sinkender Durchschnittskosten läßt große Unternehmenseinheiten entstehen, die wiederum bereits allein über eine relativ starke Verhandlungsposition gegenüber staatlichen Instanzen verfügen, erst recht aber im Verbund mit anderen Unternehmen der gleichen Branche.

Netzwerkeffekte und „Sunk costs”. Daneben tritt noch ein weiterer Effekt zutage: „Pressure groups“ benötigen ein politisches Netzwerk. Solche Verbindungen zu etablieren - zwischen den Unternehmen einer Branche, zu den politischen Parteien, zu den entscheidenden Stellen in der Exekutive - ist teuer und zeitaufwendig. Es sind also nicht wiederbringbare Anfangsinvestitionen (,Sunk costs") nötig, die den Zutritt zum politischen Markt erschweren. Daher hinkt die politische Auseinandersetzung teilweise mit erheblicher Zeitverzögerung hinter dem ökonomischen Strukturwandel her: Jene Branchen dominieren die politische Debatte und üben Einfluß auf die Gesetzgebung aus, die längst ein reifes Entwicklungsstadium erreicht haben. Neue Branchen formieren sich nur langsam als Interessngruppen, sie benötigen eine ganze Weile, bis sie politischen Einfluß erlangen.

All diese Gründe - die verminderte Zahl, die Größe und die Etabliertheit der Gewinner der Protektion - legen den Schluß nahe, daß in der Europäischen Währungsunion die „Nachfrage” nach Wechselkursprotektion aus strukturellen Gründen zunimmt.

Multinationale Unternehmen. Eine dämpfende Rolle könnten multinationale Unternehmen spielen. Sofern „Economies of Scale“ dafür sorgen, daß Firmen 
mit globalen Interessen entstehen, die weltweit produzieren, forschen, entwickeln und verkaufen, bilden diese tendenziell ein Gegengewicht $\mathrm{zu}$ den Protektionismusbefürwortern. Denn in der Regel werden sie von einer Änderung des DollarEuro-Kurses weder stark profitieren noch in erheblichem Umfang negativ betroffen sein. Bei international verflochtenen Produktionsstrukturen und grenzüberschreitenden konzerninternen Zulieferverhältnissen dürften weniger kurzfristige Wechselkurseffekte im Interesse der Firmen liegen als dauerhaft stabile Kursverhältnisse. Ihre Lobbyarbeit folgt vor allem dem Leitbild eines „ebenen Spielfelds” zwischen den Industriestaaten. Sie wünschen sich Investitionsschutz, international einheitliche Standards bei der Rechnungslegung, Vermeidung von internationaler Doppelbesteuerung, offene Güter- und Kapitalmärkte und so weiter. Wiederkehrende bzw. anhaltende Fehlbewertungen der wichtigsten Währungen der Welt dürften den Multis ein Graus sein, zum Beispiel weil sie die Ermittlung korrekter interner Verrechnungspreise ,at arm`s length” erschweren. Schwerer dürfte noch wiegen, daß der Wechselkursprotektionismus weitere Formen des Protektionismus nach sich ziehen und damit die internationale Arbeitsteilung innerhalb des Konzerns stören kann.

\section{3. 2 ,Angebot" an Protektion}

Was das „Angebot“ an Protektion seitens der Regierungen der EWU-Staaten angeht, so bezog sich die Argumentation unter 3. 1 einzig auf die vermutlich abgeschwächte Disziplinierung der Regierungen seitens der Finanzmärkte. Hinzuzufügen ist weiterhin, daß die Wechselkurspolitik der Hebel ist, der sich den Regierungen der EWU-Staaten bietet, um Einfluß auf die Geldpolitik zu nehmen. Die Hoffnung auf kurzfristige reale Effekte infolge einer expansiv ausgerichteten Geldpolitik kann gerade im Vorfeld von Wahlen verlockend sein. Kapitel 4 untersucht den Zusammenhang zwischen Wechselkurs- und Beschäftigungspolitik sowie die internationalen Rückwirkungen einer solchen „Beggar-thy-neighbour”Politik näher. Die Neigung zu protektionistischer Wechselkurspolitik dürfte auch deshalb steigen, weil die Regierungen einzelner Mitgliedstaaten hoffen können, daß sie zwar Hauptnutznießer einer solchen Strategie sein werden, die Kosten jedoch anderswo im Euroland anfallen.

Auch das institutionelle Design der EWU spricht für eine Nutzung des Wechselkurses als wirtschaftspolitischem Instrument. Wie Kapitel 2 darlegt, mangelt es dem Euroland nach der endgültigen Fixierung vormals anpassungsfähiger Wechselkurse zwischen den Mitgliedsländern an "Shock absorbers": Die institutionellen Regelungen auf den Arbeitsmärkten fördern die Inflexibilität, die Arbeitnehmer sind zu immobil, die nationalen fiskalpolitischen Reaktionsmöglichkeiten angesichts hoher Staatsverschuldung und hoher Staatsquoten zu gering, zwischenstaatliche Transfers schließlich zu unflexibel, um als automatische Stabilisatoren funktionsfähig sein zu können. Wirkt ein asymmetrischer Schock auf 
das Euroland ein, so ist es denkbar, daß sich eine Mehrheit im Ministerrat findet, die einen schwachen Euro wünscht.

Auch die nachhaltig hohe Arbeitslosigkeit in vielen kontinentaleuropäischen Staaten lastet als Hypothek auf der Währungsunion. Sofern die Regierungen sich nicht in der Lage sehen, strukturelle Reformen anzugehen, die nur gegen erhebliche Widerstände durchsetzbar sind, dürfte es immer wieder Druck in Richtung einer expansiven Geldpolitik gegeben, um kurzfristig Beschäftigungseffekte zu erzielen. Das Mittel, mit dem die Regierungen auf die Geldpolitik Einfluß nehmen können, ist die Wechselkurspolitik. Damit wenden sich innere strukturelle Probleme des Eurolandes bzw. einer Mehrheit seiner Mitgliedstaaten unmittelbar nach außen. Internationale Rückwirkungen sind daher programmiert.

\section{3. 3 Stärkere Wechselkursschwankungen?}

Häufig wird die Erwartung geäußert, die bloße Existenz des Euro werde die Wechselkursschwankungen vermindern. Folglich werde auch ins internationale Währungssystem mehr Ruhe einkehren [z. B. Europäische Kommission 1997a: 14]. Begründet wird dies zum einen damit, daß Anlegern nun neben dem USDollar ein zweiter großer Währungsraum zur Verfügung steht. Anders als in den bisherigen kleinen, weil segmentierten Finanzmärkten können sie in beiden Währungsräumen auf eine große Zahl von Aktiva zurückgreifen. Innerhalb dieser beiden Währungsgebiete können Anleger nun kaufen und verkaufen, ohne die Währung wechseln zu müssen, was wiederum die Schwankungen der Wechselkurse begrenzen soll. Die zweite Begründung für einen solchen positiven externen Effekt der EWU liegt darin, daß nicht mehr 15 EU-Regierungen und -Notenbanken weitgehend unabhängig von einander ihre Politiken formulieren, sondern daß sie sich um eine verstärkte Abstimmung bemühen. Vor allem eine einheitliche Geldpolitik im Rahmen des ESZB fördert einen gleichmäßigeren Konjunkturverlauf innerhalb des Eurolands, was sich dämpfend auf die Schwankungen von Preisen, Zinsen und Wechselkursen auswirken sollte [Masson/Turtleboom 1997].

Für eine ruhigere Entwicklung der Kurse spricht noch ein weiterer Punkt: In Schwächephasen des US-Dollar profitierte stets die D-Mark. Anleger transferierten Kapital in die deutsche Währung. Davon waren regelmäßig auch die übrigen EWS-Währungen betroffen, die gegenüber dem Dollar aufwerteten, aber gegenüber der D-Mark ihrerseits unter Abwertungsdruck gerieten. Diese Volkswirtschaften hatten daher zeitgleich mit zwei dämpfenden Effekten zu kämpfen: Einerseits verminderte sich ihre Wettbewerbsfähigkeit aufgrund einer höher bewerteten Währung. Andererseits waren sie wegen des Abwertungsdrucks innerhalb des EWS gezwungen, mit einer restriktiveren Geldpolitik zu reagieren [Kenen 1998: 11]. Solche Spannungen, die häufig überschießende Kursschwankungen auf den Finanzmärkten auslösen, wird es im Euroland nicht mehr geben. Allerdings kann es zu einem volatileren handelsgewichteten Außenwert des US-Dollar kommen, da nun der dämpfende Effekt der gegenläufigen Entwicklung der EWS- 
Währungen - Dollar-Abwertung gegenüber der Mark, Dollar-Aufwertung gegenüber den übrigen Währungen - fortfällt [McCauley 1997: 39ff].

Gegen ein harmonisches Zusammenspiel der Weltwährungen spricht allerdings, daß die Regierungen im Euroland versucht sein könnten, durch einseitige Beeinflussung des Wechselkurses interne wirtschaftspolitische Ziele zu erreichen [Bénassy-Quéré et al. 1997: 187f]. Bisher waren nur die USA in der Lage, diese Strategie zu verfolgen. Nun könnten auch die Euroland-Regierungen einen solchen Kurs einschlagen. Stehen sich nun im Weltwährungssystem zwei große Blöcke gegenüber, die beide „Benign neglect“ betreiben, so könnte das Ergebnis leicht eine höhere Volatilität der Wechselkurse sein [Bergsten 1997b].

Eine erhöhte Volatilität muß nicht mit einer inneren Schwäche des Euro einhergehen. Kurz- bis mittelfristig sind durchaus politisch induzierte Abweichungen vom langfristigen Gleichgewichtskurs möglich, ohne daß sie die Inflationsrate erhöhen. Dafür spricht auch, daß das Euroland eine weit geschlossenere Volkswirtschaft ist, als es die einzelnen Staaten zuvor waren, somit die direkten Inflationseffekte einer Abwertung deutlich geringer ausfallen dürften.

Größere Kursauschläge könnten sogar die Verwendung des Euro als internationale Währung steigern. Aus Sicht der Anleger und Schuldner wird eine Diversifizierung der Portfolios zwischen den großen Währungsräumen interessanter. Länder, für die das Euroland der wichtigste Handelspartner ist, dürften eine rasche Anbindung an den Euro wünschen und daher ihre Auslandsverschuldung möglichst zügig in Euro umschichten, um den Euro als Ankerwährung verwenden zu können. Allerdings würde dies eine Teilung der Welt in währungspolitische Einflußzonen befördern. Kleinere und sich rasch entwickelnde Länder werden sich für eine engere Bindung an die eine oder die andere der beiden Großwährungen entscheiden müssen. 
Henrik Müller - 978-3-631-75010-0

Downloaded from PubFactory at 01/11/2019 09:16:41AM

via free access 


\section{Ein Konfliktszenario ${ }^{82}$}

Nachdem die vorhergehenden Kapitel den institutionellen und den ökonomischen Rahmen dargestellt haben, in dem sich die Wechselkurspolitik der Eurozone bewegt, schließt sich nun eine theoretische Analyse an; darauf aufbauend zieht Kapitel 5 Schlußfolgerungen für das Weltwährungssystem. Die Vorgehensweise dieses Kapitels sieht wie folgt aus: Zunächst wird ein einfaches Modell entwickelt, das den Zusammenhang der Wechselkurspolitik mit anderen wichtigen makroökonomischen Variablen herstellt. Ausgangspunkt der Überlegungen ist ein vieldiskutiertes Spannungsfeld: nämlich der Konflikt zwischen „Stabilitätspolitik” und „Beschäftigungspolitik”, wie ihn der bekannte Phillipskurven-Zusammenhang abbildet [Phillips 1958, Samuelson/Solow 1960, Phelps 1967, Friedman 1968, Lucas 1972, Sargent/Wallace 1975]. Daran schließt sich eine spieltheoretische Analyse an, die untersucht, unter welchen Bedingungen es zu einer strategischen Wechselkurspolitik zwischen zwei großen Wirtschaftsblöcken (Eurozone, USA) kommen kann. Dabei wird zunächst die Eurozone als homogener Block aufgefaßt. In einem zweiten Schritt wird dann die vorgelagerte Entscheidungsstufe innerhalb der EU betrachtet. Weiterhin untersucht dieses Kapitel die Auswirkungen auf weitere Länder außerhalb eines solchen Währungsduopols.

\section{1 Theoretischer Ansatz: eine modifizierte Phillipskurve}

Den theoretischen Ausgangspunkt für die weiteren Überlegungen bildet das Phillipskurven-Modell unter Berücksichtigung der Präferenzen der wirtschaftspolitischen Entscheidungsträger [Barro/Gordon 1983]. Dieser Ansatz wird für die offene Volkswirtschaft erweitert. Zentraler Gedanke ist dabei, daß es einen kurzfristigen „Trade off” zwischen Beschäftigung und Geldwertstabilität gibt. Die klassische Vorstellung, Geldpolitik sei stets neutral für den realen Sektor („klassische Dichotomie") existiert hier also nicht. Vielmehr gibt es kurzfristig expansive reale Effekte einer Ausdehnung der Geldmenge, die sich allerdings nur so lange einstellen, wie das Preisniveau nicht vollständig reagiert hat. Indem die Wirtschaftssubjekte ihre Erwartungen bzw. ihre über mehrere Perioden laufenden Verträge [Fischer 1977] an die neue Wachstumrate der Geldmenge anpassen, verschwinden die realen Effekte sukzessive. Das System erreicht schließlich ein neues Steadystate-Gleichgewicht, das gekennzeichnet ist durch veränderte nominale Größen: eine gestiegene Inflationsrate, einen gesunkenen Außenwert der heimischen Währung, einen Verlust an wirtschaftspolitischer Glaubwürdigkeit und, damit verbunden, höhere Realzinsen durch einen größeren Risikoaufschlag.

Die wirtschaftspolitischen Entscheidungsträger unterliegen also ständig der Versuchung, kurzfristig expansive Effekte, insbesondere niedrigere Arbeitslosen-

82 Dieses Kapitel basiert zu einem Großteil auf Müller (1998b). 
quoten, zu erkaufen durch langfristige Kosten, die bei einer später notwendigen Politik der Disinflation anfallen. Sofern sie über einen hinreichend kurzen Zeithorizont (kurze Wahlperiode, niedrige Zeitpräferenzrate) und/oder eine schwach ausgeprägte Inflationsaversion verfügen, kommt es folglich zu einem suboptimal hohen Geldmengenwachstum.

In der hier gewählten Betrachtung liegt der Fokus allerdings nicht auf der Geldpolitik im engeren Sinne, sondern auf der Wechselkurspolitik. Denn in der EU obliegt erstere der Europäischen Zentralbank, die gut gerüstet erscheint, keinem kurzfristigen „Inflation bias” zu unterliegen. ${ }^{83}$ Hingegen ist die Rolle offen, die der Ministerrat in der Wechselkurspolitik ${ }^{84}$ einschlagen wird.

\section{1. 1 Das Modell für die heimische Wirtschaft \\ Die Phillipskurven-Gleichung sei spezifiziert als}

$$
U=U_{N}-a\left(p_{1}-p_{1}^{E}\right) \quad \text { mit } a \geq 0
$$

wobei $U$ die Arbeitslosenquote im gesamten Euroraum bezeichnet. Der PhillipsZusammenhang besagt nun, daß $U$ unter die "natürliche Arbeitslosenquote”, $U_{N},{ }^{85}$ sinkt, sofern die tatsächliche Preissteigerungsrate, $p_{l}$, höher ist als die für die betreffende Periode ${ }^{86}$ von den Wirtschaftssubjekten erwartete Preissteigerungsrate, $p_{l}^{E}{ }^{E} p_{l}$ und $p_{l}{ }^{E}$ seien die Zuwachsraten des tatsächlichen bzw. antizipierten Preisniveaus.

83 Siehe Abschnitt 2. 2.

84 Siehe Abschnitt 2. 3.

85 In der neueren Literatur wird sie häufig mit der wertfreien NAIRU (= Non Accelerating Inflation Rate of Unemployment) gleichgesetzt, also der Arbeitslosenrate, die unabhängig von Inflationseffekten existiert. Ohne auf Unterschiede in beiden Konzepten näher einzugehen, verwenden wir im folgenden beide Begriffe synonym.

86 Da es sich hierbei um einen dynamischen Ansatz handelt, müßten strenggenommen sämtliche Variablen mit Zeitindizes versehen sein. Zugunsten der Übersichtlichkeit verzichten wir auf eine solche Indizierung.

87 Dieser Zusammenhang läßt sich auf unterschiedliche Weise plausibel machen. Die monetaristische Variante des Phillipskurven-Ansatzes [Phelps 1967, Friedman 1968] stellt den Arbeitsmarkt in den Vordergrund. Sofern die Inflationserwartungen der Gewerkschaften hinter der tatsächlichen Preisentwicklung zurückbleiben, fordern sie zu geringe Geldlohnsätze, um einen konstanten Reallohn zu erzielen. Somit ergibt sich ein expansiver Effekt über eine Ausweitung der Produktionsmöglichkeiten, da nun aufgrund des faktisch gesunkenen Reallohns Arbeitskräfte in den Produktionsproze $\measuredangle$ eingebunden werden, die andernfalls arbeitslos wären. Fischer (1977) hingegen stellt nicht Erwartungsfehler in den Vordergrund, sondern ortet fixierte Geldlohnsätze durch langfristige Tarif- bzw. Arbeitsverträge als Ursache kurzfristiger Beschäftigungseffekte infolge einer expansiven Geldpolitik. Obwohl die Wirtschaftssubjekte rationale 
In der offenen Volkswirtschaft ergibt sich die Steigerungsrate des Verbraucherpreisindex als

$$
p_{1}=\beta p+(1-\beta)\left(p^{*}+\hat{e}\right), \text { mit } 0<\beta \leq 1 .
$$

Der Anteil inländischer Güter am gesamten Inlandskonsum beträgt $\beta$, der Anteil ausländischer Güter $1-\beta .^{88}$ Die inländische Inflationsrate ergibt sich als gewichtetes Mittel aus den Zuwachsraten des Preisniveaus für im Inland produzierte Güter, $p$, und für Importgüter, $p^{*}$, wobei letztere in inländische Währung umgerechnet werden, mit $\hat{e}$ als Änderungsrate des nominalen Wechselkurses. Eine Abwertung der Inlandswährung $(\hat{e}>0)$ führt somit zu einer Steigerung des inländischen Preisniveaus, $p_{l}$. Dieser Effekt ist umso stärker, je kleiner $\beta$, das heißt je offener die Volkswirtschaft ist.

Für den nominalen Wechselkurs soll

$$
\hat{e}=p-p^{*}+v
$$

gelten: In diesem Modell bestimmt sich der Wechselkurs gemäß Kaufkraftparitätentheorie (KKP) - ein erhöhtes Inflationsdifferential zwischen In- und Ausland $\left(p-p^{*}>0\right)$ führt zu einer Abwertung der Inlandswährung $(\hat{e}>0)$, ein vermindertes Inflationsdifferential $\left(p-p^{*}<0\right)$ zieht eine Aufwertung $(\hat{e}<0)$ nach sich..$^{89} v$ sei ein Parameter, der es den währungspolitischen Entscheidungsträgern ermöglicht, kurzfristige Abweichungen vom KKP-Kurs zu inszenieren. $v$ läßt sich somit interpretieren als Änderungsrate des realen Wechselkurses. Dies kann in der Praxis durch bewußte Beeinflussung der Erwartungen der Marktteilnehmer an den Devisenmärkten („Moral suasion”) oder durch überraschende Interventionen an den Devisenmärkten geschehen. Im Modell handelt sich um nichtsterilisierte Inter-

Inflationserwartungen [Muth 1961] haben, kommt es somit zu realen Effekten. Die Neuklassiker [z. B. Lucas 1972] unterstellen nicht nur rationale Erwartungen, sondern zudem völlig flexible Preise. Sie begründen den Transmissionsmechanismus zwischen geld- und güterwirtschaftlicher Sphäre mit Informationsasymmetrien zwischen geldpolitischen Entscheidungsträgern und den Wirtschaftssubjekten: Unternehmen beobachten gestiegene Preise ihrer Produkte und weiten folglich ihre Produktion und damit auch die Beschäftigung aus („Okun`s Law”), auch wenn es sich um eine Erhöhung des gesamten Preisniveaus handelt. Für eine Übersicht der Diskussion vgl. z. B. Romer 1996: 22ff, Issing 1995: 206ff und 1996a: 168ff).

88 1- $\beta$ läßt sich als Öffnungsgrad der Volkswirtschaft interpretieren. Beim Extremwert $\beta=1$ handelt es sich um eine geschlossene Ökonomie, in diesem Fall ist $p_{l}=p$. Es wird ein im betrachteten Zeitraum invarianter Wert für $\beta$ unterstellt.

89 Von weiteren Verfeinerungen dieses Ansatzes wie der Berücksichtigung von Technischem Fortschritt, nichthandelbaren Gütern oder sich verschiebenden Konsumentenpräferenzen sei der Einfachkeit halber abstrahiert, da die Ergebnisse davon unbeeinflußt bleiben. Für die Berücksichtigung dieser Einflußgrößen vgl. z. B. Willms (1992: 102ff). 
ventionen: Ein Ankauf von Devisen führt zu einer Erhöhung der Inflationsrate $p_{l}$, wobei jedoch unterstellt wird, daß das Preisniveau der im Inland produzierten Güter $(p)$ im betrachteten Zeitraum nicht reagiert. ${ }^{90}$

Aus 4-2 und 4-3 ergibt sich

$$
p_{1}=p+(1-\beta) v \text {. }
$$

Die inländische Inflationsrate ergibt sich somit aus der Preisentwicklung für inländische Güter und der Abweichung des nominalen Wechselkurses vom KKPNiveau. Dabei zeigen sich die außenwirtschaftlichen Einwirkungen umso stärker, je offener die Volkswirtschaft, je kleiner also $\beta$ ist.

Die Marktteilnehmer bilden ihre Erwartungen über die Inflationsrate rational, so daß

$$
p_{1}^{E}=\beta p+(1-\beta)\left(p^{*}+\hat{e}^{E}\right)+\eta, \quad \text { mit } \hat{e}^{E}=p-p^{*}, E(\eta)=0
$$

gilt, mit $\eta$ als Zufallsvariable (,weißes Rauschen") ${ }^{91}$. Auch bezüglich der Entwicklung des nominalen Außenwertes der heimischen Währung bilden die Wirtschaftssubjekte ihre Erwartungen, $\hat{e}^{E}$, rational: Sie rechnen mit einem Kaufkraftparitätenkurs. ${ }^{92}$

Der Erwartungsfehler bezüglich der Inflationsrate ergibt sich somit als

$$
\begin{aligned}
p_{1}-p_{1}^{E} & =\beta p+(1-\beta)\left(p^{*}+\hat{e}\right)-\beta p-(1-\beta)\left(p^{*}+\hat{e}^{E}\right) \\
& =(1-\beta) v
\end{aligned}
$$

90 Kauft die Zentralbank Devisen $(D)$ an, so kommt es in diesem Fall zu einer Erhöhung der monetären Basis $(B)$, die wiederum, über den Geld- und Kreditmarkt, die Geldmenge $(M)$ steigen läßt, wodurch auch letztlich die Inflationsrate zulegt $\left(\Delta D=\Delta B>0 \Rightarrow \Delta M>0 \Rightarrow \Delta p_{l}>0\right)$. Es gilt $B=H+D$, wobei $H$ die heimische Komponente der Geldbasis (Bargeld, Zentralbankreserven der Geschäftsbanken) bezeichnet. Eine sterilisierte Intervention $(\Delta D=-\Delta H)$ läßt $B$ unverändert $(\triangle B=0)$, somit blieben auch $p$ und $p_{l}$ konstant. Die realen Wirkungen sterilisierter Interventionen sind daher in der Praxis begrenzt.

91 Abweichungen sind rein zufällig, auch in einer Zeitreihenbetrachtung unterliegen sie keiner Systematik. Der Erwartungswert beträgt null, in den folgenden Betrachtungen fallt dieser Term daher weg.

92 Von kapitalmarktimmanenten Effekten wie spekulativen Blasen (,Bubbles”) und einem ausgeprägten Gruppenverhalten (,Bandwagon effects”) wird hier abstrahiert. Auch die Erfahrungswerte mit der „Abwertungsgeschichte” der Regierung (,Reputation”) sind hier nicht modelliert. Beides wird weiter unter einbezogen. 
ergo als Erwartungsfehler bezüglich des Wechselkurses, der aus der asymmetrischen Information zwischen Regierung und Privaten über den wirtschaftspolitischen Aktionsparameter $v$ herrührt.

Die Phillipskurven-Gleichung (4-1) läßt sich also unter Berücksichtigung von (4-6) als ${ }^{93}$

$$
U=U_{N}-a(1-\beta) v
$$

schreiben. Wie (4-7) zeigt, hat der Einsatz des wirtschaftspolitischen Aktionsparameters $v$ kurzfristig reale Auswirkungen. Diese Implikation ergibt sich allein aufgrund der Verteilung der Informationen über den tatsächlichen Wechselkurs und aus dem daraus resultierenden Erwartungsfehler seitens der Privaten. Durch eine Abwertung der heimischen Währung $(v>0)$ läßt sich ein Absinken der Arbeitslosenquote unter die natürliche Arbeitslosenquote, $U_{N}$, erreichen. ${ }^{94}$ Umgekehrt führt eine Aufwertung $(v<0)$ zu einem Anstieg über $U_{N}$ hinaus. Diese realen Effekte verschwinden allerdings, sobald die Wirtschaftssubjekte ihren Erwartungsfehler korrigieren. Analog der ursprünglichen Phillipskurve läßt sich diese Beziehung graphisch als Kurve darstellen (Abbildung 4-1).

Wie die Phillipskurve, so eröffnet auch die v-Kurve ${ }^{95}$ in Abbildung 4-1 den wirtschaftspolitischen Instanzen ein Tableau für die kurze Frist. Ausgehend von einem Steady-state-Gleichgewicht bei $U_{N}$ - die v-Kurve schneidet die Achse bei der natürlichen Arbeitslosenrate $U_{N}$ - können sie durch eine Abwertung einen Punkt auf dem Kurvenabschnitt nordwestlich des Achsenschnittpunkts erreichen. Wählen sie zum Beispiel eine Abwertung um $v_{l}$, so erreicht die Volkswirtschaft ein Beschäftigungsniveau von $U_{l}<U_{N}$. Die Anpassung an ein neues Steadysteady-Gleichgewicht ist wieder mit der Arbeitslosenrate $U_{N}$, einem höheren Preisniveau und einer dauerhaften Abwertung der heimischen Währung zum neuen KKP-Kurs verbunden. Mit anderen Worten: Die kurzfristige Phillipskurve verschiebt sich nach oben entlang der vertikalen langfristigen Phillipskurve.

93 Wegen $E(\eta)=0$ bleiben Zufallseinflüsse hier unberücksichtigt.

94 Hierbei wird eine Normalreaktion des Außenbeitrags unterstellt. Das heißt, einer Abwertung folgt ein wertmäßig größerer Anstieg der Exporte als der Importe. Somit ergibt sich ein positiver Effekt auf Volkseinkommen und Beschäftigung. Das bekannteste Maß für diesen Effekt ist die „Marshall-Lerner-Bedingung” (für den „Fall des kleinen Landes”, daher werden unendliche Angebots- und Nachfrageelastizitäten unterstellt [z. B. Jarchow/Rühmann 1988: 58]). Kurzfristig ist hingegen ein „J-Kurven-Effekt” möglich: Das heißt, im Zeitablauf reagiert der Außenbeitrag zunächst anomal, weil Exporteure (Importeure) für bestehende Verträge, die in fremder Währung fakturiert sind, bei Erfüllung weniger erlösen (mehr zahlen müssen). Erst nach einer Anpassungsphase der privaten Kontrakte an den neuen Wechselkurs folgt auf den Rückgang des Außenbeitrags ein Anstieg über den Status quo ante hinaus [z. B. Siebert 1991: 240 ff].

95 Der Einfachkeit halber wurde ein linearer Verlauf angenommen. 
Abbildung 4-1: Die v-Kurve: kurzfristige Beschäftigungseffekte einer Abwertung der heimischen Währung

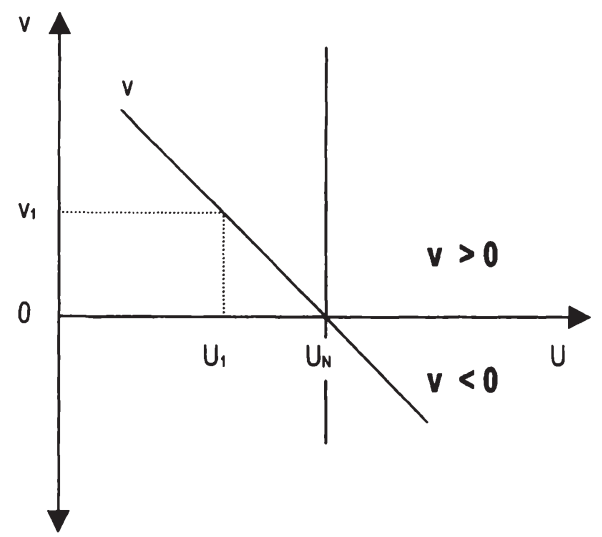

Wirtschaftspolitische Präferenzen. Die Frage, ob die wirtschaftspolitischen Instanzen eine Abwertungsstrategie einschlagen bzw. wie stark diese Abwertungen ausfallen, ist damit noch nicht beantwortet. Dazu bedarf es einer wirtschaftspolitischen Präferenzfunktion, die analog dem Modell von Barro/Gordon (1983) aussieht, nämlich

$$
W=W\left(U, p_{1}\right), \quad \text { mit } \frac{\partial W}{\partial U}<0, \frac{\partial W}{\partial p_{1}}<0 ; \frac{\partial^{2} W}{\partial U^{2}}>0, \frac{\partial^{2} W}{\partial p_{1}^{2}}>0
$$

Sowohl Arbeitslosigkeit als auch Inflation sind aus wirtschaftspolitischer Sicht unerwünscht, beide verursachen soziale Kosten. In (4-8) sind daher die partiellen Ableitungen nach beiden Argumenten der Funktion $W($.) negativ. Bei steigender Arbeitslosigkeit nimmt der damit verbundene entgangene Nutzen $\mathrm{zu}$, die zweite partielle Ableitung nach der $U$ ist daher positiv. Analoges gilt für die Inflationsrate.

Kurzfristig hängt die Inflationsrate vom Ausmaß der Abweichung des nominalen Wechselkurses vom KKP-Kurs, $v$, ab. Nach (4-4) gilt $p_{1}=p+(1-\beta) v$. Wird eine relativ langsame Reaktionszeit der inländischen Güterpreise unterstellt, läßt sich im hier betrachteten kurzfristigen Kontext die Inflationsrate allein als Funktion der Abweichung vom KKP-Kurs darstellen, so daß sich 


$$
p_{1}=p_{1}(v), \text { mit } \frac{d p_{1}}{d v}>0
$$

ergibt. Wie die Ableitung erster Ordnung anzeigt, führt eine Abwertung der heimischen Währung zu einem Anstieg der heimischen Inflationsrate. Somit läßt sich die Präferenzfunktion der wirtschaftspolitischen Akteure schreiben als

$$
W=W(U, v), \text { mit } \frac{\partial W}{\partial U}<0, \frac{\partial W}{\partial \nu}<0
$$

Optimale Abwertungsrate. Die wirtschaftspolitischen Akteure wählen nun $v$ so, daß sie (4-10) maximieren, wobei die v-Kurve (4-7) als Nebenbedingung die Menge der möglichen $U-v$-Kombinationen beschränkt:

Zielfunktion

$$
W=W(U, v) \Rightarrow \max \text { ! }
$$

Nebenbedingung

$$
U-U_{N}+a(1-\beta) v=0
$$

Daraus ergibt sich die Lagrange-Funktion

$$
L(U, v, \lambda)=W(U, v)+\lambda\left\{U-U_{N}+a(1-\beta) v\right\}
$$

mit den Bedingungen erster Ordnung

$$
\begin{aligned}
& \frac{\partial L}{\partial U}=\frac{\partial W}{\partial U}+\lambda=0 \\
& \frac{\partial L}{\partial \nu}=\frac{\partial W}{\partial \nu}+\lambda a(1-\beta)=0 \\
& \frac{\partial L}{\partial \lambda}=U-U_{N}+a(1-\beta) \nu=0
\end{aligned}
$$

Daraus resultiert die Optimalitätsbedingung

$$
a(1-\beta)=\frac{\partial W / \partial v}{\partial W / \partial U}
$$


Die wirtschaftspolitischen Akteure wählen entsprechend (4-15) die aus ihrer Sicht optimalen Werte für $U$ und $v$, so daß die Grenzrate der Substitution der Steigung der v-Kurve entspricht. Graphisch ergibt sich die kurzfristig optimale Abwertung als Tangentialpunkt der Indifferenzkurve der Präferenzfunktion $W($.) mit der vKurve. Das Nutzenniveau, das die Indifferenzkurven repräsentieren, nimmt dabei von links unten nach rechts oben ab, weil höher und rechts liegende Punkte eine höhere Arbeitslosenquote und eine mit der Abwertung verbundene höhere Inflationsrate verbinden. Abbildung 4-2 stellt diesen Optimalpunkt dar:

\section{Abbildung 4-2: Optimale Abwertung aus Sicht der wirtschaftspolitischen Akteure}

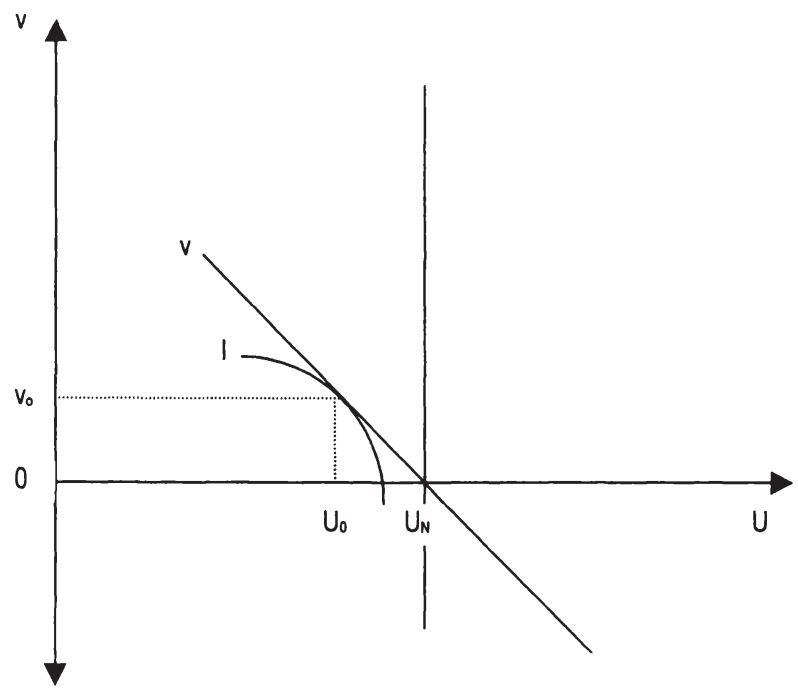

Unterschiedliche wirtschaftspolitische Präferenzen. Je größer die Inflationsaversion der Regierung, desto geringer ist die Versuchung, durch eine Abwertung der Währung kurzfristige Effekte zu erzielen. Graphisch stellt sich dies durch verschiedene Formen der Indifferenzkurven dar, wie in Abbildung 4-3 gezeigt. Die mit $I$ bezeichnete Indifferenzkurve in Abbildung 4-3 entspricht derjenigen in Abbildung 4-2. Hingegen repräsentiert $I$ ' wirtschaftspolitische Akteure, die dem Ziel der Geldwertstabilität mehr Gewicht einräumen und daher deutlich weniger geneigt sind, eine Abwertung zu inszenieren. In Abbildung 4-3 wählen sie $v^{`}\left(<v_{o}\right)$ und $U^{\prime}\left(>U_{o}\right)$. Auch eine Aufwertungsstrategie $(v<0)$ zugunsten einer Stabilisierung des Preisindexes $p_{l}$ ist möglich, so daß kurzfristig sogar höhere Arbeitslosenquoten als die natürliche $U_{N}$ hingenommen werden; in diesem Fall läge der Tangentialpunkt mit der v-Kurve unterhalb der Absisse. Die Indifferenzkurve $I^{\text {" }}$ stellt im Gegensatz dazu eine starke Präferenz zugunsten einer beschäftigungsori- 
entierten Wechselkurspolitik dar. In diesem Fall streben die wirtschaftspolitischen Akteure eine recht starke Abwertung der Währung an $\left(v^{\prime}>v_{o}>v '\right)$, um die Arbeitslosenquote zu drücken $\left(U^{\prime \prime}<U_{o}<U^{\prime}\right)$.

Abbildung 4-3: Auswirkungen unterschiedlicher wirtschaftspolitischer Präferenzen

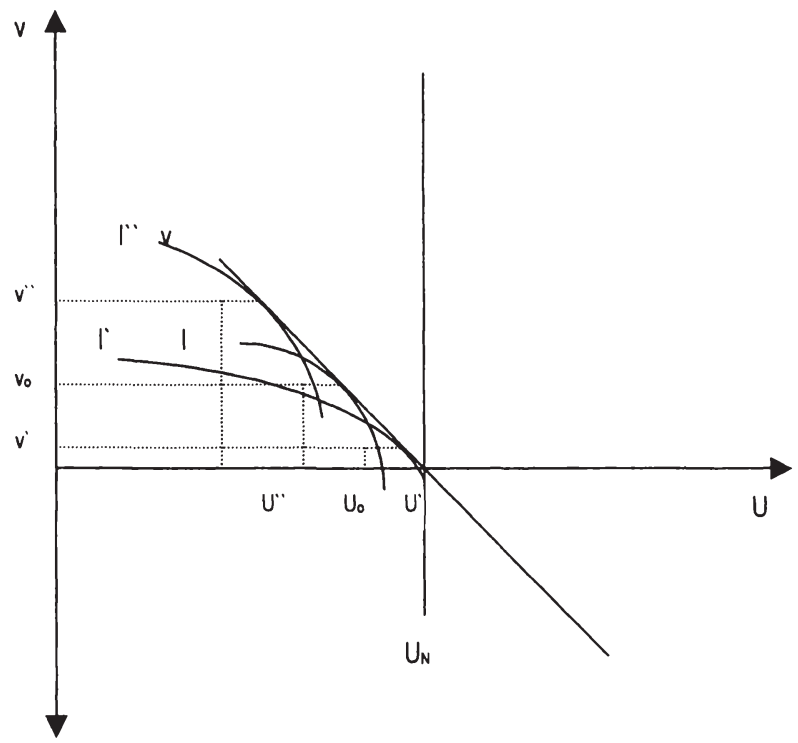

Institutionelle Beschränkungen. Interessant ist in diesem Fall die Auswirkung einer institutionellen Begrenzungen der Geldpolitik auf die Wechselkurspolitik. Sofern es ein glaubwürdiges Inflationsziel bzw. eine Obergrenze für die Entwicklung des Preisindexes $p$, gibt, bindet dies auch die Wechselkurspolitik. Gleichung (4-4) wird also um eine Obergrenze $p_{l \max }$ ergänzt:

$$
\begin{aligned}
p_{1} & =p+(1-\beta) \nu \leq p_{1 \max } \\
\Leftrightarrow \quad v & \leq \frac{p_{1 \max }-p}{1-\beta}
\end{aligned}
$$

Über diesen Zusammenhang ergibt sich auch für die Wechselkurspolitik eine obere Begrenzung. Sobald die maximale Inflationsrate erreicht ist, ist eine Wechselkurspolitik nicht mehr möglich, ohne das Inflationsziel zu verletzen. Die institutionelle Schranke verbietet folglich eine weitere Abwertung über die Schranke 
für $v$ in (4-4) dargestellte Grenze hinweg. Die v-Kurve (4-7) erhält daher mit (44) eine Grenze, die in Abbildung 4-4 dargestellt wird.

Abbildung 4-4: Auswirkungen eines Inflationsziels auf die Wechselkurspolitik

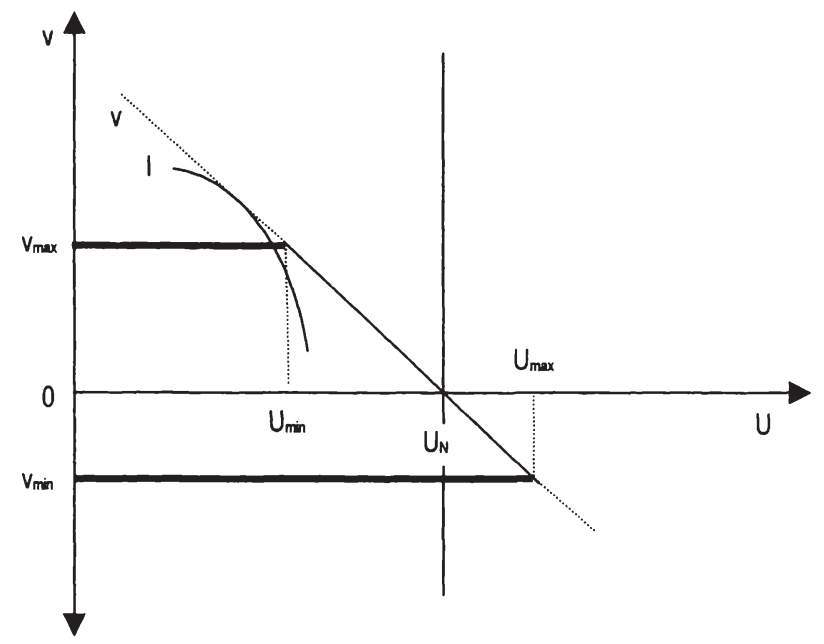

Sofern die wirtschaftspolitischen Instanzen, die für die Wechselkurspolitik zuständig sind, durch eine Inflationsobergrenze gebunden sind, beschränkt sich die Menge ihrer Aktionsmöglichkeiten. Selbst wenn sie, wie die Indifferenzkurve $I$ in Abbildung 4-4 zeigt, eine höhere Abwertungsrate wünschen, können sie doch allenfalls eine Abwertung von $v_{\max }$ verbunden mit einer Arbeitslosenquote von $U_{\min }$ erreichen.

Auch eine untere Grenze für $v$ kann theoretisch existieren, sofern eine ohnehin deflationäre Situation durch allzu stark sinkende Importpreise noch verstärkt wird. In diesem Fall wäre das Ziel der Geldwertstabilität ebenfalls verletzt. Somit gäbe es auch in diesem Fall eine Grenze für $v$, diesmal eine untere, $v_{\min }$, verbunden mit einer maximalen Arbeitslosenquote $U_{\max }$. Für den gesamten Bereich zwischen den Grenzen eröffnet sich den wirtschaftspolitischen Instanzen ein Ermessensspielraum hinsichtlich des kurzfristigen Phillipskurven-Trade-offs.

Alternative Wechselkurserwartungen. Gerade für die kurze Frist erscheint es eine als allzu heroische Annahme, daß der Wechselkurs permanent dem KKP-Niveau entspricht bzw. Abweichungen allein aufgrund politischer Einflußnahme auftreten sollen. In der Realität sind relativ lange Perioden der Abweichung vom KKP-Kurs zu beobachten. Diese beruhen nicht nur auf der Existenz von „realen”, d.h. an den Fundamentalfaktoren orientierten, Kapitalströmen [Branson 1979] oder auf Preisrigiditäten [Dornbusch 1976], sondern insbesondere auf spekulativem Verhalten der Akteure an den Kapitalmärkten [z. B. Dornbusch 
1982]. Hierbei kommt es zu über- oder unterschießenden Reaktionen sowie zu spekulativen „Blasen”, die sich von den Fundamentaldaten entfernen. Insbesondere sind diese Blasen stark von autoregressiven Erwartungen geprägt, so daß ein Trend nach oben oder unten fortgeschrieben wird, bis sich der Tageskurs so weit von einem Niveau, das durch Fundamentaldaten gerechtfertigt wäre, entfernt hat, daß eine große Zahl von Marktteilnehmern zu dem Schluß kommt, das Platzen der Blase stehe kurz bevor - und damit tatsächlich dafür sorgen, daß die Blase platzt. In der Praxis zeigt sich häufig, daß eine Ex-ante-Analyse für den Kursverlauf von Devisenkursen gerade für die kurze Frist unmöglich ist. Der Zeitpunkt, an dem eine spekulative Blase platzt, ist nicht vorhersagbar.

Die einfachste Möglichkeit, solche Effekte im Modell zu berücksichtigen, ist die Einführung eines zusätzlichen Terms in Gleichung (4-3). Sei $k$ ein Parameter, der solche marktimmanenten Abweichungen vom KKP-Kurs darstellt. Somit ergibt sich

$$
\hat{e}=p-p^{*}+k+v
$$

als Bestimmungsgleichung für die Änderungsrate des nominalen Wechselkurses.

Die Marktteilnehmer kennen den wahren Wert von $k$ ex ante nicht. Sie erwarten aber Abweichungen vom gleichgewichtigen Wechselkurs in der aktuellen Periode, wenn sie in der Vorperiode Abweichungen antizipiert haben, ausgedrückt als $k_{t-1}{ }^{96}$ Die Erwartungsbildung erhält damit autoregressive Züge, wie sich in der modifizierten Erwartungsgleichung zeigt:

$$
\begin{aligned}
p_{1}^{E}=\beta p+(1-\beta)\left(p^{*}+\hat{e}^{E}\right)+\eta, \quad \operatorname{mit} \hat{e}^{E} & =p-p^{*}+b k_{t-l}, \\
E(\eta) & =0,0<b<1
\end{aligned}
$$

Der Erwartungsfehler ergibt sich damit als

$$
\begin{aligned}
p_{1}-p_{1}^{E} & =\beta p+(1-\beta)\left(p^{*}+\hat{e}\right)-\beta p-(1-\beta)\left(p^{*}+\hat{e}^{E}\right) \\
& =(1-\beta)\left(k-b k_{t-1}+v\right)
\end{aligned}
$$

Daraus läßt sich schlußfolgern, daß die wirtschaftpolitischen Akteure - zumindest theoretisch - einen kursbereinigenden Einfluß ausüben können. Falls es ihnen gelingt, $v$ so zu setzen, daß die Differenz aus $k$ und $b k_{t-l}$ kompensiert wird, könnte eine raschere Konvergenz zum KKP-Gleichgewichtskurs stattfinden, auch wenn es in der Praxis kaum möglich sein dürfte, exakt gegenzusteuern.

96 Dieser Wert wird mit einem Parameter $b$ multipliziert. Im folgenden werden für $b$ Werte zwischen null und unter eins unterstellt. Somit gibt es gewisse Anpassungträgheiten, aber das System ,explodiert” nicht, wie es zum Beispiel bei einer spekulativen Blase typischerweise der Fall ist. Für $b>1$ müßte der Prozeß der Bildung und des Platzens einer solchen „Bubble” explizit modelliert werden. Für eine Übersicht über derartige Ansätze vgl. z. B. Willms (1992: $124 \mathrm{ff}]$. 
Als modifizierte Phillipskurvengleichung (4-7) folgt daraus unter Berücksichtigung von (4-6)

$$
U=U_{N}-a(1-\beta)\left(k-b k_{t-1}+v\right) .
$$

Sie läßt sich auch als Handlungsanweisung für die Wirtschaftspolitik verstehen, $v$ gerade so zu setzen, daß der rechte Klammerausdruck den Wert null annimmt und somit nach einer Störung das System möglichst rasch zu einem Steady-stateGleichgewicht findet. ${ }^{97}$

Reputation. Nicht nur marktimmanente Einflüsse früherer Perioden dürften das Handeln der Wirtschaftssubjekte in der Gegenwart bestimmen, auch politische Manöver der Vergangenheit schlagen sich nieder. Im einfachsten Fall erinnern sich die Marktteilnehmer an die politisch inszenierte Ab- oder Aufwertung der Vorperiode, $v_{t-l}$, multipliziert mit dem Parameter $c$, der die gleiche Funktion wie der Parameter $b$ ausübt:

$$
\begin{aligned}
p_{1}^{E}=\beta p+(1-\beta)\left(p^{*}+\hat{e}^{E}\right)+\eta, \quad \text { mit } \hat{e}^{E} & =p-p^{*}+c v_{t-1}, \\
E(\eta) & =0,0<c<1 .
\end{aligned}
$$

Der Erwartungsfehler ergibt sich damit als

$$
p_{1}-p_{1}^{E}=(1-\beta)\left(v-c v_{t-1}\right)
$$

und entsprechend die modifizierte Phillipskurvengleichung als

$$
U=U_{N}-a(1-\beta)\left(v-c v_{t-1}\right) .
$$

Für die Wirksamkeit der Wechselkurspolitik läßt sich daraus ein wichtiger Schluß ziehen: Eine Politik, die auf eine immer wiederkehrende Überraschung der Wirtschaftssubjekte zielt, ist nicht mit der Annahme der Rationalität seitens der Privaten vereinbar. Die wirtschaftspolitischen Akteure müssen vielmehr stets „neue Überraschungen" parat halten, um reale Effekt zu erzielen. Dies zeigt sich in Abbildung 4-5:

97 Dabei mag schon die Androhung genügen, zum Mittel der Intervention zu greifen, falls der Markt die Kursabweichung nicht selbst zurücknimmt. Der Parameter $v$ umfaßt in diesem Fall sowohl solche erwartungsbeeinflussenden Aktionen als auch Devisenmarkttransaktionen ab. Zur Rolle der Geldpolitik in von Spekulation getriebenen Finanzmärkten vgl. auch Goodhart (1996). 
Abbildung 4-5: Auswirkungen verminderter Reputation auf die Wechselkurspolitik

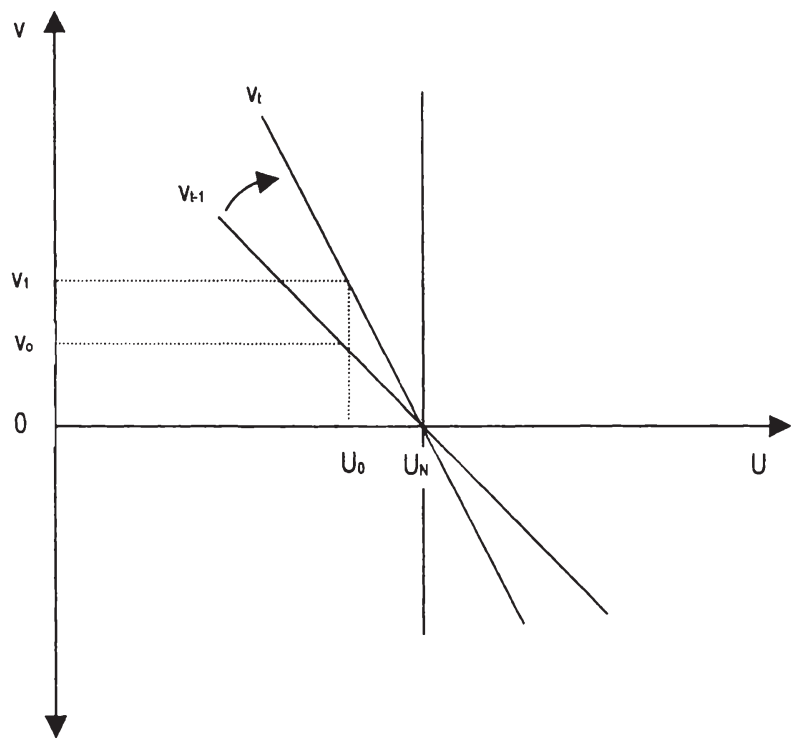

Eine inszenierte Abwertung in Periode $\mathrm{t}-1, v_{t-1}$, antizipieren die Marktteilnehmer in t. Die gleiche Aktion führt nun nur noch zu einem geringeren Beschäftigungseffekt. Um eine Wirkung wie in t-1 zu erzielen - eine Arbeitslosenquote von $U_{0}$-, muß nun ein größerer Impuls auf die Märkte einwirken $\left(v_{l}>v_{0}\right)$. Die v-Kurve, das wechselkurspolitische Menü, aus dem die Wirtschaftspolitik auswählen kann, bleibt im Zeitablauf nicht konstant, sondern dreht sich nach rechts. Diese Politik bringt allerdings weitere Kosten mit sich, die hier im Modell nicht berücksichtigt sind. Insbesondere leidet die Effizienz des Preismechanismus. Auch nimmt die Volatilität des gesamten Systems zu, falls die Wirtschaftspolitik für zusätzliche Unsicherheit sorgt.

Institutionelle Bedingungen auf den Arbeitsmärkten / Finanzierung der öffentlichen Haushalte. Eine Alternative stellt sich den wirtschaftspolitischen Entscheidungsträgern prinzipiell dergestalt, daß sie anstelle einer Abwertung der Währung eine Verbesserung der mikroökonomischen Bedingungen auf dem Arbeitsmarkt anstreben können. Dies gilt insbesondere für institutionelle Regelungen wie den Lohnbildungsproze $ß,{ }^{98}$ den Kündigungsschutz, die Bedingungen, an

98 Je mehr der institutionelle Rahmen des Lohnbildungsprozesses ein „Insider”-Verhalten seitens der Gewerkschaften fördert, desto höher dürfte tendenziell die Arbeitslosigkeit sein. Ein Überblick über „Insider-Outsider-Modelle” findet sich z. B. bei Franz (1994: 288ff). 
welche die Zahlung von Arbeitslosengeld geknüpft ist, ${ }^{99}$ bereitgestellte Informationen über freie Stellen und Arbeitssuchende, Umfang und Qualität öffentlicher Qualifizierungsprogramme. ${ }^{100}$

Eine wichtiges Datum für den Arbeitsmarkt ist die Finanzierung des Staatshaushalts. Indem Steuern und Abgaben am Lohn, einer leicht besteuerbaren Einkommensquelle, anknüpfen, treiben sie einen Keil zwischen realen Netto- und Bruttolohn („Tax wedge”). Dies führt zu effizienzmindernden Verzerrungen, weil Arbeitnehmer und Arbeitgeber nun mit unterschiedlichen Lohnsätzen rechnen: Für die Beschäftigten ist der reale Nettolohn die entscheidende Bezugsgröße, für die Arbeitgeber der reale Bruttolohn zuzüglich Lohnnebenkosten. Ein Abbau dieses Keils - sei es durch einen Abbau der staatlich bereitgestellten Güter und Transferzahlungen, sei es durch eine effizientere Finanzierung der öffentlichen Leistungen $^{101}$ - führt zu einer Verbesserung der Beschäftigungschancen.

Durch solch strukturelle Veränderungen läßt sich mittelfristig eine Senkung der NAIRU erreichen. Graphisch drückt sich dies durch eine Linksverschiebung der v-Kurve aus (Abbildung 4-6). Eine strukturelle Verbesserung der institutionellen Bedingungen auf dem Arbeitsmarkt sorgt für eine Verschiebung der langfristigen Phillipskurve nach links. Die NAIRU sinkt von $U_{N}$ auf $U_{N}$, und zwar ohne daß hierzu der Einsatz der Wechselkurspolitik nötig wäre. Dadurch können die wirtschaftspolitischen Instanzen sogar ein höheres Nutzenniveau erreichen: Eine Wechselkurspolitik, die $\mathrm{zu}$ einer Arbeitslosenrate $U_{0}$ führt, ist mit einem Nutzenniveau $I$ verbunden, eine Arbeitsmarktpolitik, die zur gleichen Arbeitslosenrate führt $\left(U_{0}=U_{N}\right)$ hingegen mit dem höheren Nutzenniveau $I$. Bei der neuen NAIRU eröffnet sich wiederum eine v-Kurve $\left(v^{\prime}\right)$ als wirtschaftspolitisches Tableau, nun allerdings mit dem Achsenschnittpunkt $U_{N}{ }^{\prime}{ }^{102}$

99 Ein hoher Kündigungsschutz wird tendenziell die Einstellungsneigung der Arbeitgeber mindern. Falls eine Beschäftigung unterhalb des vorherigen Qualifikations- und Einkommensniveaus als ,unzumutbar” angesehen wird, mindert dies die Vermittelbarkeit von Arbeitslosen.

${ }^{100}$ Beides spricht dafür, daß die Sucharbeitslosigkeit aufgrund nicht zusammenpassender Qualifikationen und Anforderungen vermindert wird (,Mismatch-Problem"). Zum Matching-Prozeß vgl. Franz (1994: 195ff).

${ }^{101}$ Als eine effizientere Art der Besteuerung werden in der Literatur allgemeine Verbrauchsteuern wie die deutsche Mehrwertsteuer angesehen. Für einen Vergleich der Wirkungen verschiedener Steuerarten vgl. z. B. Musgrave et al. (1993: 117ff).

102 An Gleichung (4-7) ist dies unmittelbar ablesbar. Es ist auch eine Drehung der v-Kurve denkbar. Dies ist der Fall, wenn $a$ als Effizienzparameter des Arbeitsmarktes aufgefaßt wird. Nimmt $a$ sehr große Werte an, läßt sich dies als ein hoher Grad der Informationsverarbeitung auf dem Arbeitsmarkt deuten. Die v-Kurve verläuft dann nahezu senkrecht. Da wechselkursinduzierte Inflationseinflüsse antizipiert werden, sind Beschäftigungseffekte kaum noch zu erzielen. Eine Steigerung der Effizienz des Arbeitsmarktes senkt damit tendenziell die Anreize, die von einer beschäftigungsorientierten Wechselkurspolitik ausgehen. 
Abbildung 4-6: Wirkung struktureller Reformen des Arbeitsmarktes auf die vKurve

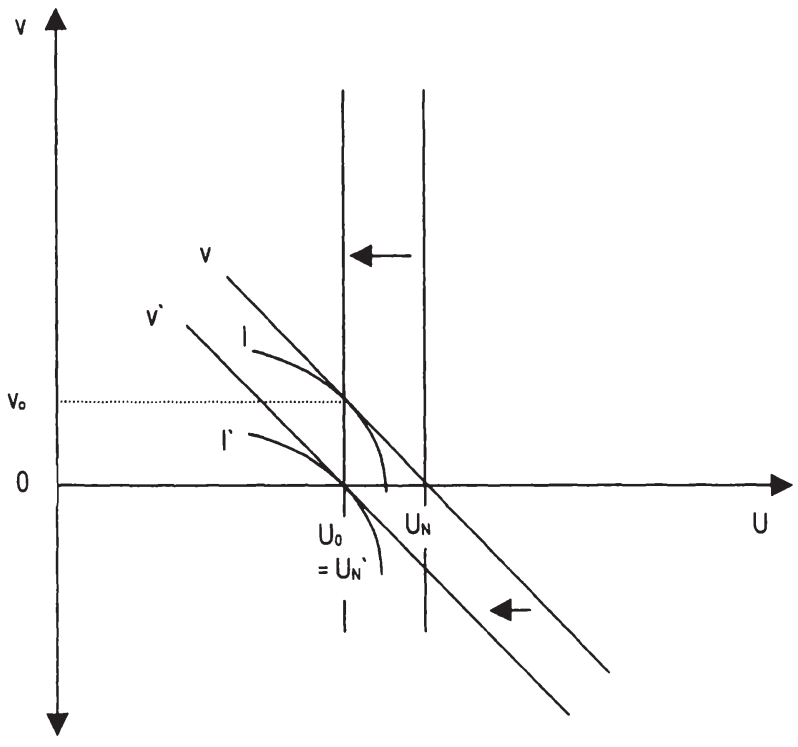

Es gibt also einen substitutiven Zusammenhang zwischen Wechselkurs- und Arbeitsmarktpolitik: Die wirtschaftspolitischen Akteure können $U_{0}$ entweder erreichen, indem sie eine Abwertung $\left(v_{0}\right)$ inszenieren oder indem sie durch strukturelle Maßnahmen die NAIRU auf ein langfristig niedrigeres Niveau drücken. Dennoch unterscheiden sich beide Ansätze in zwei wichtigen Punkten: a) Der Zeitkomponente: Eine Änderung des Wechselkurses ist quasi sofort erreichbar, die Beschäftigungswirkungen stellen sich relativ rasch ein. Strukturelle Veränderungen hingegen brauchen eine lange Zeit, bis sie legislativ und administrativ umgesetzt sind. Und auch die ökonomischen Wirkungen stellen sich erst nach einiger Zeit ein. Aus Sicht der wirtschaftspolitischen Entscheidungsträger sind diese Wirkungslags möglicherweise zu lang, insbesondere im Vorfeld von Wahlen, wenn sie rasch Beschäftigungserfolge vorweisen möchten, um im Amt zu bleiben. b) Die politische Durchsetzbarkeit: Mit dem nominalen Wechselkurs kann eine Koalition aus nationalen Regierungen im EU-Ministerrat eine einzige wirtschaftspolitische Variable beeinflussen. Sofern eine Regierung genug Verbündete findet, ist dies leicht zu erreichen. Reformen der Arbeitsmarktpolitik oder der Struktur der Staatseinnahmen und -ausgaben hingegen sind extrem aufwendig, weil sie mächtige nationale Interessengruppen auf den Plan rufen, nämlich die Begünstigten des Status quo. 
Unter Berücksichtigung des Wahlzyklus bewertet eine nationale Regierung beide Politikansätze zu verschiedenen Zeitpunkten unterschiedlich: Unmittelbar nach der Wahl ist ihr Zeithorizont typischerweise lang. Sie dürfte eher geneigt sein, auf eine strukturelle Arbeitsmarktpolitik zu setzen, da sie darauf hoffen kann, bis zur nächsten Wahl die erwünschten Beschäftigungseffekte zu realisieren. Zugleich wird sie eher eine starke Währung wünschen, um inflationärem Druck entgegen zu wirken, der aus der vorhergehenden Legislaturperiode herüberschwappt. Je weiter die Legislaturperiode fortgeschritten ist, desto weniger attraktiv erscheint die Arbeitsmarkt- und desto interessanter erscheint die Wechselkurspolitik, zumal resultierende Inflationseffekte in die nächste Legislaturperiode fallen. Graphisch drückt sich dies in einer Aufwärtsbewegung der Indifferenzkurven entlang der vKurve aus: Mit zunehmender Dauer der Legislaturperiode bewegen sich die Präferenzen der wirtschaftspolitischen Akteure vom Achsenschnittpunkt weg. Es kann daher zu einer Wellenbewegung kommen, wie sie in Abbildung 4-7 dargestellt ist:

\section{Abbildung 4-7: Ansteigende Welle: Wahltermine und Wechselkurspolitik}

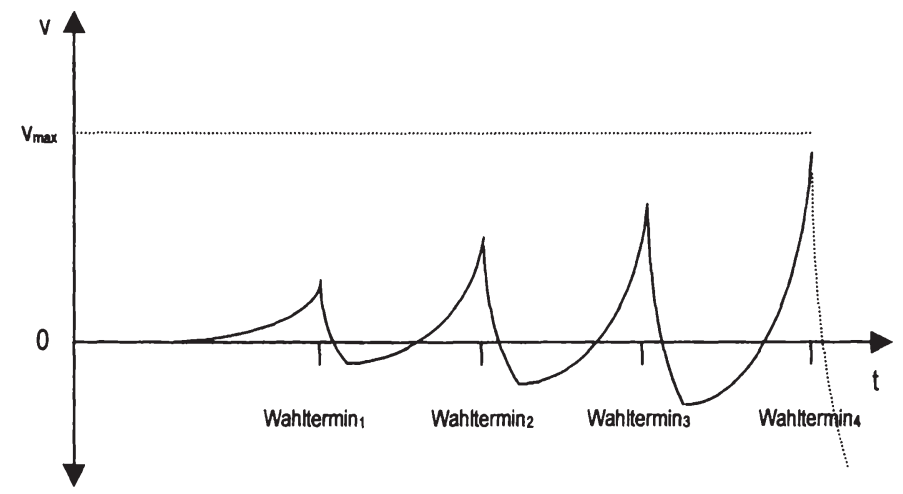

Auf Abwertungsphasen $(v>0)$ folgen unmittelbar nach der Wahl Aufwertungsphasen $\quad(v<0)$, um die Preisentwicklung im Inland zu stabilisieren. Sofern, wie oben beschrieben, die Reputation der wirtschaftspolitischen Instanzen leidet ${ }^{103}$ und es bei den Wählern wie bei den wirtschaftspolitischen Entscheidern nicht zu einer Änderung der Präferenzen kommt, ergibt sich ein Aufschaukeln: Um reale Effekte zu erzielen, müssen die Interventionen immer heftiger ausfallen. Es ist offensichtlich, daß eine solche Politik auf Dauer nicht durchzuhalten ist. Zum einen werden die realen Effekte immer kleiner, zum anderen steigen, wie oben erwähnt, die Wohlfahrtsverluste dieser wechselkurspolitischen Stop-and-Go-Poli-

103 Siehe Gleichung (4-7“') sowie Abbildung 4-5. 
tik aufgrund einer verminderten Markteffizienz. Gibt es, wie im institutionellen Konzept der EWU, eine durch ein Inflationsziel festgelegte Obergrenze für Abwertungen $\left(v_{\max }\right),{ }^{104}$ so ist dem Aufschaukeln eine quasi natürliche Grenze gesetzt.

\section{1. 2 Die Rolle eines zweiten Landes}

Bei der bisherigen Betrachtung ging es ausschließlich um die Perspektive eines Landes, nämlich der EU. Nun soll explizit das Nicht-EU-Ausland in die Analyse einbezogen werden.

Für das zweite Land, die USA, existiert ein analoges Modell wie für die EU. Variablen und Parameter des Auslands sind mit Sternchen versehen. Die Phillipskurve des Auslands ergibt sich somit als

$$
U^{*}=U_{N}^{*}-a^{*}\left(p_{1}^{*}-p_{1}^{E *}\right) \quad \text { mit } a^{*} \geq 0,
$$

die ausländische Inflationsrate analog (4-2) als

$$
p_{1}^{*}=\beta^{*} p^{*}+\left(1-\beta^{*}\right)(p-\hat{e}), \quad \text { mit } 0<\beta^{*} \leq 1 .
$$

Aus Sicht des Auslands bedeutet eine Erhöhung von $\hat{e}$ eine Aufwertung der ausländischen Währung gegenüber der inländischen. ${ }^{105}$ Somit ergibt sich ein dämpfender Effekt für das ausländische Preisniveau. Entsprechend der Gleichungen (43) und (4-4) hat also ein Einsatz der Wechselkurspolitik seitens der EU $(v>0)$ einen preisdämpfenden Effekt auf die USA:

$$
p_{1}^{*}=p^{*}-\left(1-\beta^{*}\right) \nu
$$

Der Erwartungsfehler der Privaten in den USA ergibt sich analog (4-6) als

$$
p_{1}^{*}-p_{1}^{E *}=\left(\beta^{*}-1\right) \nu
$$

Eine Aufwertung des Dollar gegenüber dem Euro qua Wechselkurspolitik antizipieren die Privaten in den USA nicht. Sie überschätzen daher die Inflationsrate ex ante. Dies hat kurzfristig reale Effekte. Die v-Kurve für das Ausland sieht damit wie folgt aus:

$$
U^{*}=U_{N}^{*}-a^{*}\left(\beta^{*}-1\right) \nu
$$

\footnotetext{
104 Siehe Abbildung 4-4.
}

105 Der Wechselkurs wird hier stets in der Preisnotierung aus Sicht der EU verstanden, ergibt sich also als Euro-Dollar-Quotient. 
Ein Einsatz der Wechselkurspolitik seitens der EU, der zu einer Abwertung des Euro gegenüber dem Dollar führt $(v>0)$, führt in den USA zu einem Anstieg der Arbeitslosigkeit über die natürliche Arbeitlosenquote hinaus. Der zweite Term auf der rechten Seite von (4-20) ist negativ, da $0<\beta^{*} \leq 1$. Die v-Kurve aus Sicht des Auslands hat also eine positive Steigung:

Abbildung 4-8: Die v-Kurve des Auslands: reale Außenwirkungen europäischer Wechselkurspolitik

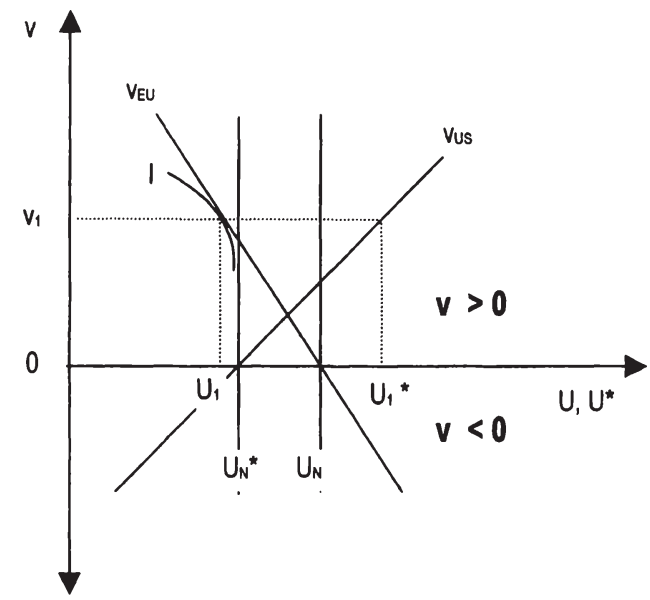

Die v-Kurve des Auslands, in Abbildung 4-8 mit $v_{U S}$ bezeichnet, zeigt die Effekte der Wechselkurspolitik seitens des Inlands. Dabei ist eine Steigerung des Wechselkurses über das KKP-Niveau hinaus mittels Wechselkurspolitik $(v>0)$ aus Sicht des Auslands als Aufwertung zu interpretieren, ein Absinken des Wechselkurses $(v<0)$ als Abwertung. Eine Abwertung des Euro gegenüber dem Dollar um $v_{l}$ beispielsweise, drückt in der EU die Arbeitslosenquote unter die natürliche Quote $\left(U_{N}\right)$ auf $U_{l}$. In den USA hingegen führt dies zu einem Ansteigen der Arbeitlosenquote über die dortige natürliche Quote $\left(U_{N}^{*}\right)$ hinaus auf $U_{I}{ }^{*}$.

Die Indifferenzkurven der ausländischen wirtschaftspolitischen Entscheider verlaufen somit wie in Abbildung 4-9 eingezeichnet $\left(I^{*}\right)$. In nordwestlicher Richtung nimmt das Nutzenniveau zu, da diese Punkte mit einer stärkeren Währung und einer niedrigeren Arbeitslosenquote verbunden sind.

Wirtschaftspolitische Präferenzen. Falls beide Regierungen komplementäre Präferenzen haben, ergibt sich möglicherweise ein harmonisches Zusammenspiel. Dies ist zum einen der Fall, sofern auf seiten der EU eine starke Präferenz für Beschäftigung, auf Seiten der USA zugleich eine starke Präferenz für Preisstabilität herrscht, zum anderen, wenn auf seiten der USA eine starke Präferenz für 
Beschäftigungspolitik herrscht, während in der EU das Ziel der Preisstabilität im Vordergrund steht. Im ersten Fall führt eine Abwertung seitens der EU hier zu mehr Beschäftigung, auf der anderen Seite leistet eine Aufwertung der US-Währung einen Beitrag zur Stabilisierung des dortigen Preisniveaus. Im zweiten Fall führt eine Aufwertung des Euro zu einer Stabilisierung des hiesigen Preisniveaus, zugleich leistet eine Abwertung des Dollar einen Beitrag zur dortigen Beschäftigungssituation.

Abbildung 4-9: Komplementäre wirtschaftspolitische Präferenzen im ZweiLänder-Fall

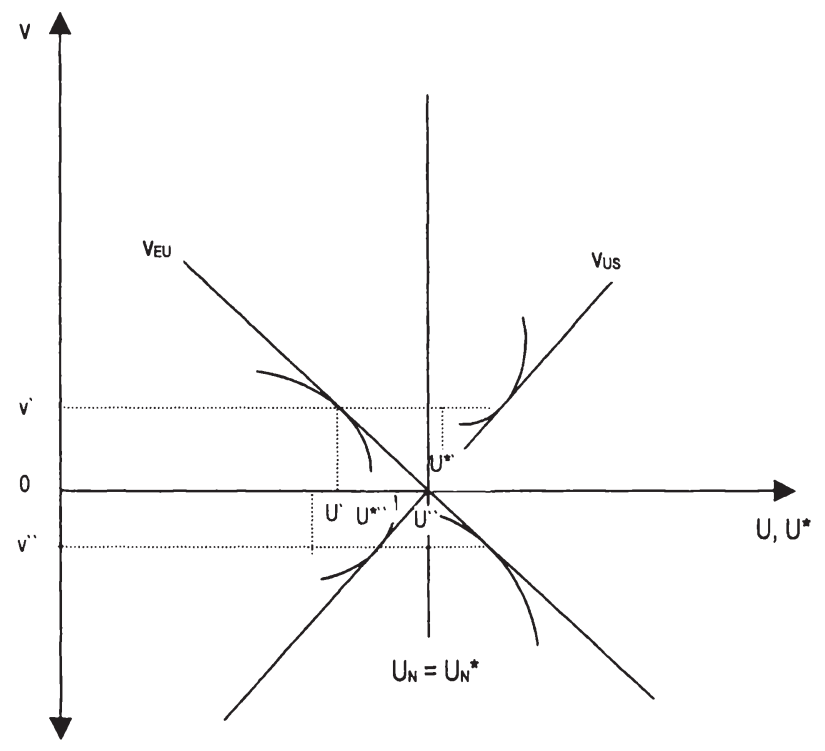

In Abbildung 4-9 wählt das Inland seine optimale Abwertungsrate autonom, das Ausland betreibt selbst keine Wechselkurspolitik, sondern nimmt die Ergebnisse der Aktionen seitens der EU hin, ohne zu reagieren. ${ }^{106}$ Angenommen die EU-Regierung setzt auf eine beschäftigungsorientierte Wechselkurspolitik und wählt eine Abwertungsrate von $v^{\prime}$, verbunden mit einer Arbeitslosenquote von $U^{\prime}$ im Inland und $U^{*}$ im Ausland. Dies kann auch aus US-Sicht eine optimale Strategie sein, sofern die US-Regierung wünscht, die Inflation mittels einer Dollar-Aufwertung zu drücken. Die umgekehrte Situation ergibt sich, falls die wirtschafts-

106 Der Übersichtlichkeit halber sei angenommen, die natürlichen Arbeitslosenquoten seien in beiden Ländern gleich. 
politischen Entscheidungsträger eine Aufwertung des Euro in der Größenordnung $v$ " wählen (große Präferenz für Geldwertstabilität) und dabei eine Steigerung der

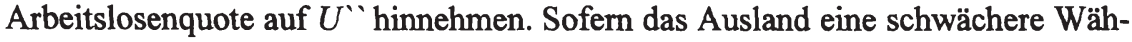
rung zugunsten der Beschäftigung wünscht, ist dies möglicherweise auch aus dessen Sicht optimal. Allerdings ist dies nur zufällig auch aus US-Sicht optimal, schließlich beziehen die wirtschaftspolitischen Akteure in der EU die US-Belange nicht in ihr Kalkül mit ein.

In Abbildung 4-10 liegt eine andere Situation vor: Beide Regierungen wünschen eine Abwertung, etwa weil beide Länder in einer Rezession stecken:

Abbildung 4-10: Konkurrierende wirtschaftspolitische Präferenzen

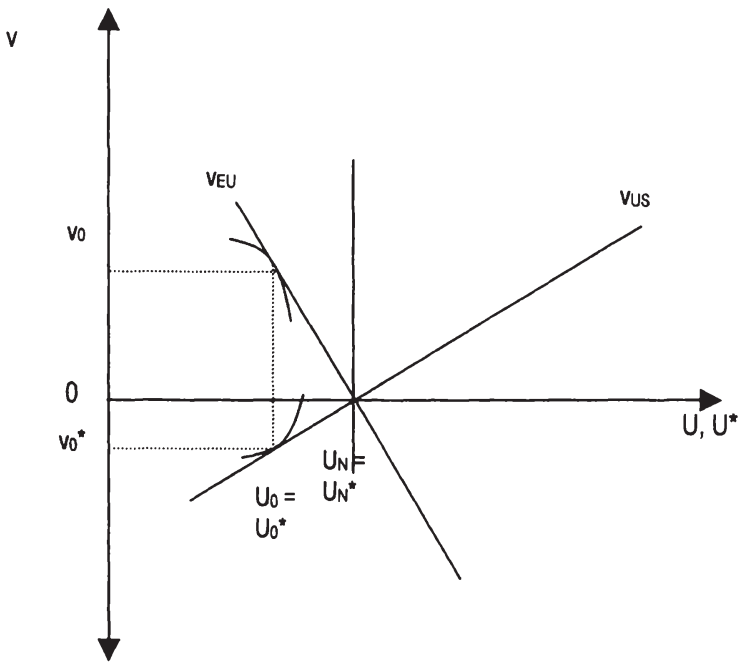

Beide, die US- wie auch die EU-Wirtschaftpolitiker, haben das Ziel, die Arbeitslosenquoten in ihren Ländern auf $U_{0}=U_{0}^{*}$ zu drücken. Dafür wollen die Europäer eine Abwertung des Euro um $v_{0}$, die Amerikaner eine Abwertung des Dollar um $v_{0}{ }^{*}$. Beides ist nicht kompatibel. Es existiert eine klassische strategische Situation, die im folgenden analysiert wird.

\section{2 Strategische Konstellationen}

Die Überlegungen des vorhergehenden Abschnitts unterstellten eine wechselkurspolitische Passivität seitens der US-Regierung - egal mit welcher Politik sie aus der Eurozone konfrontiert ist, sie reagiert unter keinen Umständen. In diesem Abschnitt wird diese Annahme aufgehoben. Nun sei unterstellt, daß die wirt- 
schaftspolitischen Instanzen auf beiden Seiten in einem spieltheoretischen Rahmen interdependent agieren.

Im folgenden werden zwei grundsätzliche Zielsetzungen untersucht: Im ersten Fall handeln beide Seiten aus individuellem handelspolitischen Kalkül, wobei sie sowohl die inflationsbedingten Kosten als auch die Reaktionen der jeweiligen Gegenseite in ihre Entscheidungen einbeziehen. Im zweiten Fall kooperieren beide Seiten, um durch eine gemeinsame Politik den Wechselkurs zwischen Euro und Dollar zu stabilisieren, sofern es zu Über- oder Untertreibungen der Märkte kommt. ${ }^{107}$

\section{2. 1 Theoretischer Ansatz: unkoordiniertes wiederholtes Spiel}

Beide Zielrichtungen - die konjunkturpolitisch motivierte und die stabilisierende Wechselkurspolitik ${ }^{108}$ - werden im Setting eines unkoordinierten wiederholten Spieles analysiert.

Devisenmarktinterventionen des Auslands. In Abschnitt 4.1 hatten die wirtschaftspolitischen Autoritäten des zweiten Landes, „US-Regierung” genannt, annahmegemäß kein wechselkurspolitisches Instrument in der Hand. Das soll sich nun ändern. Analog zu $v$ erhält die US-Regierung die Möglichkeit zur Intervention am Devisenmarkt über den Parameter $v^{*}$. Damit kann sie aus eigenem Antrieb intervenieren, kann aber auch Interventionen der EU neutralisieren und so den Wechselkurs konstant halten. Die Änderungsrate des Wechselkurses ( $\hat{e})$ ergibt sich damit als Differenz der Inflationsraten beider Währungsräume, bereinigt um die Interventionen:

$$
\hat{e}=p+v-p^{*}-v^{*} \text {. }
$$

$\mathrm{Da}$ die Interventionen nichtsterilisiert stattfinden, steigern sie in beiden Ländern die Geldmenge und wirken somit inflationstreibend. Da annahmegemäß aber die Inlandspreise $\left(p, p^{*}\right)$ zunächst nicht reagieren, hängt die Änderungsrate der Inflationsrate im Inland (EU) von der Größe der Interventionsdifferenz $\left(v-v^{*}\right)$ ab:

$$
p_{1}=p+(1-\beta)\left(v-v^{*}\right)
$$

Sofern das Ausland die inländischen Interventionen vollständig neutralisiert $\left(\nu=v^{*}\right)$, bleibt die Inflationsrate konstant. Mittel- bis langfristig allerdings wird auch $p$ bzw. $p^{*}$ reagieren. Kurzfristig jedoch hängt auch die Arbeitslosenquote von der Interventionsdifferenz $a b$ :

107 Siehe unter Abschnitt 4. 1. 1, ,Alternative Wechselkurserwartungen”, insbesondere Gleichung (4-7`).

108 Für die Unterscheidung zwischen handelspolitischer „Beggar-thy-neighbour”- versus stabilisierender Wechselkurspolitik vgl. Claassen (1990: 46f). 
$\left(4-7^{\cdots}\right)$

$$
U=U_{N}-a(1-\beta)\left(v-v^{*}\right) .
$$

Anlog gilt für die Inflationsrate des Auslands:

$$
p_{1}^{*}=p^{*}-\left(1-\beta^{*}\right)\left(v-v^{*}\right)
$$

Interveniert das Ausland, um eine Abwertung des Dollar zu erzielen, und sind diese Interventionen größer als die des Inlands $\left(v<v^{*}\right)$, so kommt es tatsächlich zu einer Abwertung, mit dem Effekt, daß Importgüter sich aus ausländischer Sicht verteuern und die Inflationsrate $\left(p_{1}{ }^{*}\right)$ steigt.

Entsprechend reagiert die Arbeitslosenquote des Auslands auf die Interventionsdifferenz:

$$
U^{*}=U_{N}^{*}-a^{*}\left(\beta^{*}-1\right)\left(v-v^{*}\right) .
$$

Für $v<v^{*}$ verbessert sich die Beschäftigungssituation im Ausland über die Steadystate-Arbeitslosenquote $U_{N}$ hinaus.

Abbildung 4-11: Wechselkurspolitisch induzierte Beggar-thy-neighbour-Politik

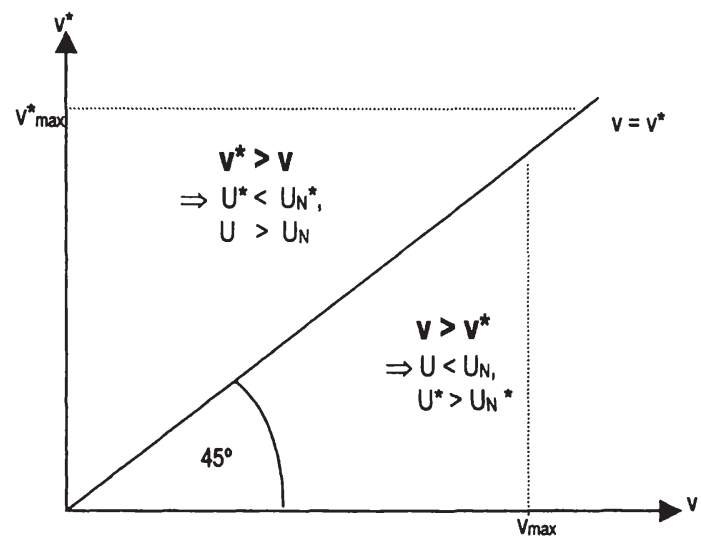

Abbildung 4-11 illustriert das wechselkurspolitische Verteilungsspiel. Die Winkelhalbierende ist der Ort aller sich gegenseitig neutralisierenden $v-v^{*}$-Kombinationen $\left(\nu=v^{*}\right)$. Oberhalb dieser Linie erzielt das Ausland kurzfristige Beschäftigungsgewinne: Hier ist $v^{*}>v$, somit wertet der Dollar gegenüber dem Euro ab, ausgehend von einem steady state-Gleichgewicht sinkt die Arbeitslosenquote des Auslands unter die natürliche $\left(U^{*}<U^{*}{ }_{N}\right)$, das ausländische Preisniveau steigt. Dies geschieht auf Kosten des Inlands: Hier steigt die Arbeitslosenquote bei sin- 
kendem Preisniveau. Unterhalb der Winkelhalbierenden herrscht die spiegelbildliche Situation: Das Inland verbucht wechselkursinduzierte Beschäftigungsgewinne und Inflationseffekte.

Individuelle Optimierung. Im Setting eines wiederholten Spiels streben beide Regierungen an, ihre jeweilige Präferenzfunktion $W($.$) bzw. W^{*}$ (.) über den gesamten Zeithorizont zu maximieren. Das heißt, sie wählen den Parameter $v$ bzw. $v^{*}$ so, daß der Gegenwartswert der künftigen Nettoauszahlungen maximal wird. In der Periode $t$ ergibt sich die Nettoauszahlung einer wechselkurspolitischen Intervention in dieser Periode ${ }^{109}$ als Differenz zwischen den Benefits $G$ einer Abwertung (höheres Beschäftigungsniveau) und den Kosten $C$ (höhere Inflationsrate): 110

$$
W_{t \mid v_{t}, v_{i}^{*}}=G_{t \mid v_{t}, v_{i}^{*}}\left(U_{t}\right)-C_{t \mid v_{t}, v_{i}^{*}}\left(p_{1 t}\right) .
$$

Sowohl Benefits als auch Kosten hängen von den Interventionen beider Länder $\mathrm{ab}$, wobei kurzfristig lediglich die Interventionsdifferenz $\left(v_{t}-v_{t}^{*}\right)$ Auswirkungen hat, langfristig aber weitere Kosten der Abwertung anfallen. Eine analoge Gleichung existiert für das Ausland.

Die währungspolitischen Akteure maximieren ihre aufsummierten, abgezinsten Nettoauszahlungen zum Zeitpunkt $t=0$ :

$$
W_{0 \mid v_{t}, v_{t}^{*}}=\sum_{t=1}^{T} \delta^{t}\left[G_{t \mid v_{t}, v_{t}^{*}}\left(U_{t}\right)-C_{t \mid v_{t}, v_{t}^{*}}\left(p_{1 t}\right)\right] \rightarrow \max !, \text { mit } \delta=\frac{1}{1+i} .
$$

Der Diskontfaktor $\delta$ gibt an, wie stark künftige Entwicklungen ins Kalkül der Entscheidungsträger eingehen. ${ }^{111}$

(4-22) unterstellt eine endliche Spieldauer - das Spiel endet zum Zeitpunkt $T$ -, da Politiker sich zur Wiederwahl stellen müssen und folglich einen begrenzten

109 Im Kontext des Mehr-Perioden-Spiels, in dem im folgenden argumentiert wird, ist es nötig, Zeitindizes zu verwenden.

110 Um die spieltheoretische Analyse möglichst klar zu halten, wird angenommen, daß die währungspolitischen Entscheidungsträger vor der Alternative stehen, zu intervenieren oder dies zu unterlassen. Es handelt sich somit um eine diskrete Entscheidung, $\mathrm{v}>0$ oder $\mathrm{v}=0 \mathrm{zu}$ setzen. Der analytischen Handhabbarkeit halber sei ferner angenommen, alle Kosten und Benefits fielen in der Periode an, in der die Abwertung stattfindet. In der Realität fallen die Benefits quasi sofort an, die Kosten hingegen mit zeitlicher Verzögerung. $B$ und $C$ lassen sich jedoch auch wiederum als abgezinste Gegenwartswerte auffassen.

111 Je größer die Zeitpräferenz der Akteure ist, das heißt, je größer der Zinssatz (i), desto geringer fallen künttige Auszahlungen ins Gewicht. Bei einem Zins von 100 Prozent $(i=1)$ ist $\delta=0,5$. Bei sehr kleinen Werten von $i$ ist die Zeitpräferenz der Akteure gering, ergo ihr Zeithorizont weit. $\delta$ geht folglich mit abnehmender Zeitpräferenz gegen eins. 
Zeithorizont haben. Dies ist jedoch nicht notwendigerweise plausibel: Zum einen bestimmt die Verwaltung zum großen Teil die Politik mit, sie verfügt aber über einen weit längeren, wenn nicht gar unendlichen Zeithorizont. Zum anderen können Politiker wiedergewählt werden, sie werden dann in der folgenden Legislaturperiode mit den Folgen ihrer Handlungen konfrontiert. Mit anderen Worten: Die Spieldauer ist für die Akteure auf beiden Seiten mit Unsicherheit behaftet. Es ist jedoch naheliegend, von einer hohen Zeitpräferenz auszugehen - die nahe Zukunft spielt eine große Rolle, weiter entfernt liegende Perioden finden kaum im Kalkül Niederschlag. Für eine geringe Zeitpräferenz wäre eine dem Phillipskurven-Ansatz folgende Politik nicht rational. ${ }^{112}$

Weiterhin sei angenommen, beide kennten den wahren Wechselkurs, es ist also ein Wert bekannt und allgemein akzeptiert, der den Fundamentaldaten bzw. der KKP folgt $\left(e_{K K P}\right.$ bzw. $\left.\hat{e}_{K K P}\right)$. Beide Seiten kennen zu jedem Zeitpunkt den gesamten bisherigen Spielverlauf („Perfect recall”) sowie die Auszahlungen aller Mitspieler für alle möglichen Optionen („Common knowledge”).

$\mathrm{Zu}$ einer Intervention kommt es, wenn unter Berücksichtigung der erwarteten Intervention des Gegenspielers $\left(v_{t}{ }^{* E}\right)$ der Nettonutzen im Falle einer Abwertung $\left(W_{0 \mid \nu>0, v * E)}\right)$ größer ist als der Nettonutzen bei Stillhalten $\left(W_{0 \mid} v 0, v \cdot E\right)^{113}$ :

$$
W_{0 \mid v>0, v^{* \varepsilon}}>W_{0 \mid v=0, v^{*}} \text {. }
$$

Das Maximum ist dort erreicht, wo unter den jeweils gegebenen Bedingungen die Grenzerträge $(M B)$ den Grenzkosten $(M C)$ entsprechen:

$$
\sum_{t=1}^{T} \delta^{t} M B_{t}=\sum_{t=1}^{T} \delta^{t} M C_{t}
$$

112 Ein Standardergebnis der spieltheoretischen Literatur lautet: Wenn der Endzeitpunkt $T$ eines wiederholten Spiels bekannt ist, ist kooperatives Verhalten nicht rational. Denn kooperatives Verhalten ist nur rational, wenn die Spieler sich darauf verlassen können, daß auch die jeweils anderen kooperativ spielen. Können sie sich nicht sicher sein, daß dies der Fall ist, fahren sie besser, wenn sie unkooperativ spielen. Ist der Endpunkt $T$ aber bekannt, so ist es in der letzten Periode rational, unkooperativ zu spielen. Da alle dies wissen, spielen sie auch in keiner der vorhergehenden kooperativ (,Backward-induction-Argument”). Erst bei einer unendlich häufigen Wiederholung des Spiels oder bei Unsicherheit über das Ende des Zeithorizonts ist es rational, kooperativ zu spielen [Holler/Illing 1996, insbs. Abschnitt 4. 2]. Im folgenden wird Unsicherheit über $T$ unterstellt. Das Ausmaß dieser Unsicherheit hängt dabei vor allem vom Wahlzyklus ab und den Aussichten einer Regierung, wiedergewählt zu werden.

113 Eigentlich müßte der Zeitindex hier auch in den tiefgestellten Symbolen stehen, also $v_{t} b z w$. $\mathrm{v}_{\mathrm{t}}{ }^{*}$. Dies wird allerdings hier aus darstellungstechnischen Gründen unterlassen. 


\section{2. 2 Konjunkturpolitisch motivierte Wechselkurspolitik}

Die Spieler machen zu jedem Zeitpunkt $t$ ihre Spielzüge, ohne zu wissen, wie der jeweils andere handeln wird. Sie kennen aber die Situation, aus der heraus der andere handelt. Wirtschaftsdaten zum Beispiel sind frei verfügbar, es handelt sich um ,gläserne Regierungen”. Daraus folgt: Wegen der Annahme abnehmender Grenznutzen der Inflations- wie der Arbeitslosigkeitsbekämpfung ${ }^{114}$ gehen sie davon aus, daß der jeweils andere umso eher zum Instrument der Abwertung greift, je höher die Arbeitslosigkeit und je niedriger die Inflationsrate sind. Antizipiert die eine Seite eine Intervention am Devisenmarkt seitens ihres Gegenübers, wird sie ebenfalls intervenieren, sofern ihr der Nutzen dafür höher erscheint als die Kosten.

Fall 1: Identische Länder in der Rezession. Sei zunächst angenommen, in den USA wie in der EU herrsche eine typische Rezessionssituation: Die Arbeitslosenquoten sind hoch, die Inflationsraten niedrig. Die Präferenzen der Entscheidungsinstanzen sind identisch. ${ }^{115}$

Das Problem für jede der beiden Regierung sieht nun wie folgt aus: Sofern sie keine Interventionen betreibt, läuft sie Gefahr, eine weitere Verschlechterung der Lage in ihrem Land hinnehmen zu müssen, falls es dem Gegenspieler gelingen sollte, eine Abwertung zu inszenieren. Sofern die Regierung aber selbst zugunsten einer Abwertung aus ihrer Sicht interveniert, hat sie nicht nur die Chance, den Status quo beizubehalten, sondern kann womöglich sogar ihre Lage verbessern: Falls der Widerpart ebenfalls interveniert, kann sie dessen Interventionen neutralisieren; verhält sich die andere Seite passiv, so kann sie sogar eine Verbesserung gegenüber dem Status quo erreichen. Die schlechteste aller Auszahlungen fällt bei Stillhalten und Intervention des Widerparts an $\left(W_{0 \mid} \mid v 0, v>0\right)$, gefolgt von einer sich gegenseitig neutralisierenden Intervention $\left(W_{0 \mid}=W_{0}\right)$, und es besteht sogar die Chance auf eine hohe Auszahlung, sofern der andere Spieler nicht reagiert $\left(W_{0 \mid v>0, v * 0)}\right)$, so daß $W_{0 \mid v 0, v » 0}<W_{0 \mid v v \nu>0}<W_{0 \mid v>0, v=0}$.

Ergo: Sofern beide Länder eine hohe Arbeitslosigkeit und niedrige Inflationsraten aufweisen, kommt es in diesem Setting bei kurzem Zeithorizont zu einem Abwertungswettlauf. Das Nash-Gleichgewicht liegt bei einer beiderseitigen Intervention. Da die Auszahlungen alternativer Politikoptionen allgemein bekannt sind, wissen beide, daß es für den jeweils anderen in jedem Fall vorteilhaft ist, zu intervenieren - wer nicht interveniert, verliert mit Sicherheit, denn $v_{t}{ }^{* E}$ ist stets

114 Siehe Gleichung (4-8) oben.

115 Die Annahme identischer Präferenzen vereinfacht nicht nur die Analyse. Sie sorgt auch dafür, daß unterschiedliche Präferenzordnungen der Entscheidungsträger für die Ergebnisse keine Rolle spielen, sondern sich die Analyse auf objektive Faktoren konzentriert. 
größer null. Es handelt sich somit um eine dominante Strategie. Da beide in dieser Weise handeln, bleiben Beschäftigungseffekte aus. ${ }^{116}$

Begrenzt wird dieser Wettlauf, sofern es institutionelle Regelungen gibt, die eine maximale Inflationsrate und somit auch eine maximale Intervention bindend vorschreiben. ${ }^{117}$ In Abbildung 4-11 sind maximale Interventionsgrenzen eingezeichnet. Sie sind allerdings für beide Länder unterschiedlich, so daß in einer strategischen Situation das Land mit der höheren (oder fehlenden) Obergrenze im wechselkurspolitischen Verteilungskampf die besseren Aussichten hat.

Konjunkturpolitisch motivierte Wechselkurspolitik führt langfristig zu erheblichen Kosten:

- Durch die Interventionen steigen die Weltgeldmenge und somit auch die Inlandspreise.

- Anziehende Preise mindern die gesamtwirtschaftliche Effizienz und sorgen für verschärfte Verteilungskämpfe. Beides führt dazu, daß sich die Wachstumsaussichten eintrüben und die Pro-Kopf-Einkommen langfristig unterhalb ihres möglichen Niveaus bleiben.

- Die Reputation der Regierungen leidet, da eine unbegrenzte Nutzung des Instruments Abwertung nicht möglich ist. Die Regierung beraubt sich damit der Möglichkeit künftiger Abwertungen. ${ }^{118}$

- Kooperation auf anderen Feldern der internationalen Politik wird angesichts einer derartigen Konfrontation schwieriger.

Beim oben unterstellten kurzen Zeithorizont gehen diese Kosten allerdings nur mit geringem Gewicht ins Kalkül ein. Dadurch wird verhindert, daß die langfristig individuell wie kollektiv beste Lösung $v_{t}=v_{t}^{*}=0$ nicht realisiert wird. Die Aussichten für diese kooperative Lösung verbessern sich jedoch, je länger der Zeithorizont der beiden Regierungen ist $(T \rightarrow \infty)$ und je niedriger die Zeitpräferenz $(i \rightarrow 0, \delta \rightarrow 1)$ - dies führt dazu, daß beide Seiten diese langfristigen Kosten einer Abwertung stärker berücksichtigen. Und es wird tendenziell wahrscheinlicher, daß sie von diesem Instrument keinen Gebrauch machen, insbesondere weil es nun möglich wird, Absprachen zu treffen (siehe unten).

Fall 2: Identische Länder in der Hochkonjunktur. Sofern beide Regierungen in einer Situation sind, die gekennzeichnet ist von hohem Beschäftigungs-

116 Dieses Abwertungsspiel ähnelt dem Bertrand-Preis-Wettbewerb in einem Duopol zweier Unternehmen: Beide Akteure konkurrieren um den Preis (hier: den Wechselkurs) und versuchen, sich gegenseitig zu unterbieten. Wie im Bertrand-Wettbewerb, gewinnt am Ende keiner von beiden. Im statischen Duopol-Preiswettbewerb drücken sich beide auf Konkurrenzniveau herunter, am Ende liegt der Preis beim Grenzkostenniveau. Für das Bertrand-Duopol vgl. z. B. Varian (1990: 453f).

117 Siehe oben Abschnitt 4. 1. 1 unter ,Institutionelle Beschränkungen”.

118 Siehe Abschnitt 4. 1. 1 unter ,Reputation”. 
stand und großem Inflationsdruck, gibt es für wechselkurspolitische Interventionen kaum Anlaß: Der Grenznutzen resultierend aus zusätzlichen Beschäftigungsmöglichkeiten ist niedrig, die Grenzkosten aufgrund zusätzlicher Inflation hingegen sind hoch. Keines der Länder hat einen Anreiz zu intervenieren. Im Gegenteil: Eine Höherbewertung der eigenen Währung kann aus stabilitätspolitischen Motiven sogar im Interesse der jeweiligen Regierung liegen, selbst wenn diese lediglich über einen kurzen Zeithorizont verfügt. In diesem Fall ist es unter diesen Bedingungen vorteilhaft stillzuhalten. Jede Regierung erwartet dieses Verhalten auch von der jeweils anderen, $v_{t}{ }^{* E}$ ist gleich null oder sogar negativ. Eine Intervention der Gegenseite bei gleichzeitigem eigenem Stillhalten $\left(W_{0} \mid v=0, v>0\right)$ ist die individuell vorteilhafte Lösung, gefolgt von einer neutralisierden Intervention $\left(W_{0} \mid v \sim r 0\right)$, die schlechteste Option ist die eigene Intervention unter der Bedingung, daß die Gegenseite stillhält $\left(W_{0 \mid v>0, v * 0}\right): W_{0 \mid v>0, v>0}>W_{0 \mid v \vee v>0}>W_{0 \mid v>0, v *=0}$.

Fall 3: Asymmetrische Länder. Trotz ähnlich guter konjunkturelle Lage kann eines der Länder dennoch von hoher Arbeitslosigkeit aufgrund strutureller Starrheiten auf den Arbeitsmärkten geplagt sein. In diesem Fall ist der Anreiz, mit einer Abwertung der eigenen Währung Beschäftigungspolitik zu betreiben, möglicherweise stärker. Allerdings sind die Grenzkosten einer Abwertung nun, anders als in Fall 1, hoch, weil ohnehin schon inflationärer Druck herrscht. Der Anreiz ist aber möglicherweise dennoch groß, weil eine Gegenreaktion der anderen Seite nicht zu erwarten ist $\left(v_{t}{ }^{* E}=0\right)$ - die Regierung des Hochkonjunkturlands mit hohem Beschäftigungsstand kümmert sich vorrangig um die Inflationseindämmung, eine Devisenmarktintervention zugunsten einer Schwächung des Außenwerts der Währung liegt nicht in ihrem Interesse.

Nicht nur strukturell, auch konjunkturell können sich die beiden Länder unterscheiden. Eine konjunkturelle Asymmetrie illustriert Abbildung 4-12. In Hochkonjunkturphasen herrscht typischerweise eine geringe Arbeitslosigkeit und zugleich Inflationsdruck. In einer solchen Situation ist eine Regierung eher bereit, eine Aufwertung der Währung hinzunehmen. Umgekehrt verhält es sich bei schwacher Konjunktur: Die Arbeitslosenquoten sind hoch, der Inflationsdruck gering. Eine Abwertung erscheint den wirtschaftspolitischen Instanzen attraktiv. Sofern also eine Asynchronität der Konjunkturverläufe beider Länder vorherrscht, ist das Konfliktpotential begrenzt. Es kann aber auch hier auftauchen, wie Abbildung 4-12 zeigt.

In Phase I steigt in der EU die Kapazitätsauslastung $(Q)$, in den USA ist es umgekehrt $\left(Q^{*}\right.$ geht zurück); die gestrichelten Linien $Q^{*}$ und $p^{*}$ repräsentieren die US-Wirtschaft. Entsprechend verhalten sich die Inflationsraten $\left(p, p^{*}\right)$ : In der EU steigen die Preise, in den USA geht der Preisanstieg zurück. ${ }^{119}$ Wie in Gleichung (4-3) dargestellt, reagiert der Wechselkurs gemäß KKP-Theorie:

119 Der Einfachkeit halber seien hier Lags bei der Anpassung der Preise, die sonst typischerweise hinter der konjunkturellen Entwicklung herhinken, ausgeschlossen. 
Solange die Inflationsdifferenz zunimmt, wertet der Euro auf, der Wechselkurs $(e)$ sinkt. Kehrt sich in beiden Ländern die Tendenz um, wertet in Phase II der Euro gegenüber dem Dollar ab, bis zu einem Minimum im Zeitpunkt $t=2$. In Phase III kommt es zu einer Wiederbelebung der Konjunktur in der EU und einem Abflauen in den USA, die wiederum zu einer Abwertungsphase führt. Insofern dürfte die wechselkurspolitische Situation über den gesamten Zeitraum relativ entspannt sein.

Abbildung 4-12: Gegenläufige Konjunkturzyklen: idealtypische Konstellationen einiger makroökonomischer Größen

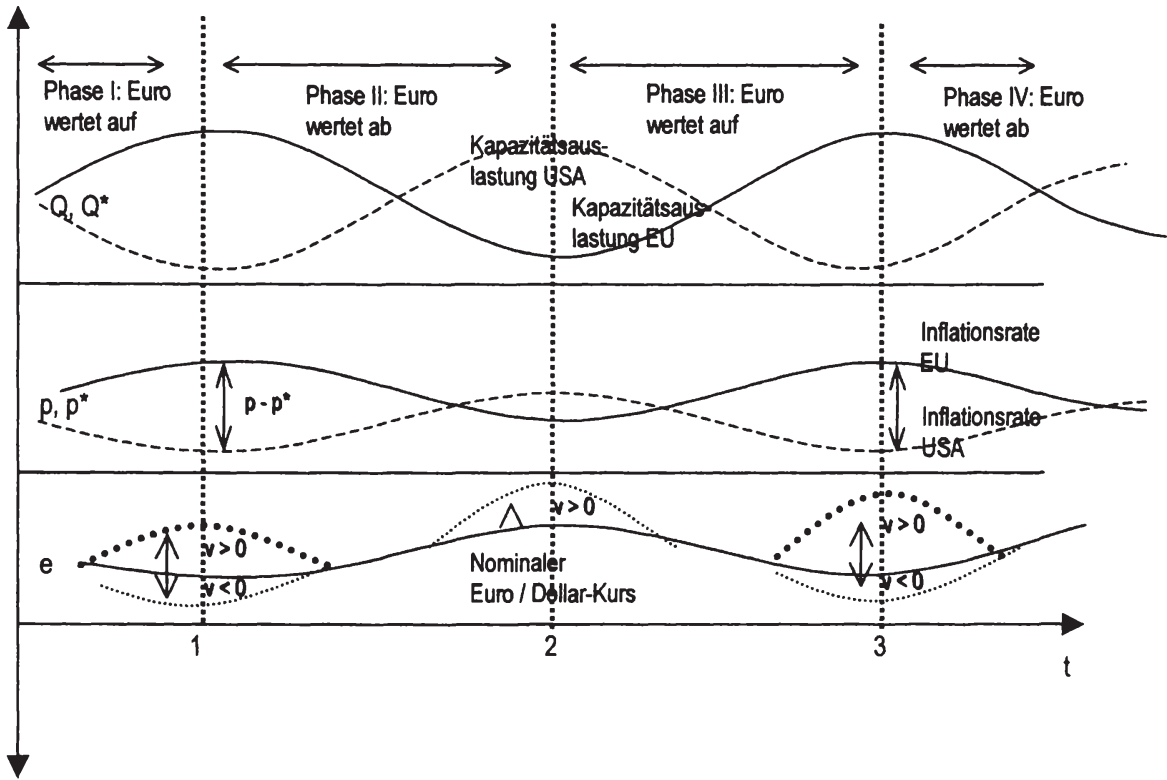

Allerdings ist es durchaus möglich, daß die EU-Instanzen am Tiefpunkt der Rezession in $t=2$ einen noch schwächeren Wechselkurs wünschen, als der Markt von sich aus realisiert, zum Beispiel weil Starrheiten auf den Arbeitsmärkten für einen steilen Anstieg der Arbeitslosigkeit sorgen. Somit können strukturelle Unterschiede zu einem politikinduzierten „Overshooting” des Wechselkurses führen, wie es der gestrichelt gezeichnete Abschnitt rund um $t=2$ zeigt. Ähnlich kann es auch zu einem „Undershooting” wie in $t=1$ und $t=3$ kommen, falls die EU-Regie- 
renden eine starke Präferenz für Stabilisierungsmaßnahmen haben. ${ }^{120}$ Die Kombination aus beidem ist angetan, die Volatilität des Wechselkurses zu erhöhen.

Besonders konfliktträchtig wäre eine Konstellation, in der es zu einem politikinduzierten Overshooting rund um $t=1$ und $t=3$ kommt (fette gestrichelte Passagen). Dies kann der Fall sein, wenn in der EU trotz Hochkonjunktur die Arbeitslosigkeit aufgrund struktureller Gegebenheiten ${ }^{121}$ hoch bliebe und die wirtschaftspolitischen Instanzen sich mit einer „Leaning-against-the-wind”-Politik gegen einen starken Euro stemmten. Die Folgen einer solchen Politik wären nicht nur in den USA spürbar, wo sich die konjunkturelle Erholung verzögert und von wo deshalb Retorsionen erwogen würden, sondern auch in der EU: Ernsthafte Konflikt zwischen den EU-Regierungen und der EZB könnten ausbrechen, denn in einer Boomsituation stellt ein schwacher Euro die größte Gefahr für die Geldwertstabiltität dar.

Fall 4: Wechselkurspolitische Vergeltung. In einem wiederholten Spiel ist es möglich, dem Gegner mit Vergeltungsmaßnahmen in einer der folgenden Perioden zu drohen, sofern dieser eine „Beggar-thy-neighbour”-Wechselkurspolitik betreibt. Eine Intervention seitens des einen Spielers in $t$ würde dann durch eine Gegenintervention in $t+j$ vergolten. Falls also in der EU hohe Arbeitslosigkeit herrscht und die wirtschaftspolitischen Instanzen dies durch eine Abwertung lindern möchten, müssen sie nun eine künftige Reaktion seitens der US-Regierung in Betracht ziehen. Selbst wenn in $t$ die EU-Behörden $v_{t}{ }^{* E}=0$ erwarten, müssen sie nun eine Reaktion in ihr Kalkül einbeziehen. Dadurch versieht die US-Regierung eine Intervention seitens der EU mit zusätzlichen Kosten, eine Intervention wird damit weniger vorteilhaft, dies umso mehr, je länger der Zeithorizont der EUAutoritäten ist.

Allerdings stellt sich die Frage, ob eine solche Drohung glaubwürdig ist. Sofern die Kosten der Vergeltungsmaßnahmen groß sind, dürfte sie die US-Regierung trotz Ankündigung nicht in die Tat umsetzen. Dies ist der Fall, wenn ohnehin ein hoher inflationärer Druck herrscht. In einer Hochkonjunkturphase ist die Drohung daher unglaubwürdig. Sie wird die EU-Entscheidungsträger kaum davon abhalten, die Intervention zu unterlassen.

Fall 5: Ausweitung des Konflikts durch unilaterale Vergeltungsschläge. Bislang wurde die Wechselkurspolitik als alleinige Handlungsoption für die Regierungen betrachtet. Dies ist keineswegs zwingend, denn statt Interventionen des Gegners zu neutralisieren oder spätere eigene Interventionen als Vergeltung anzukündigen, kann der Gegenspieler auch mit Vergeltungsmaßnahmen auf anderen Politikfeldern drohen, die er anwendet, sofern der Gegner die Wechselkurspolitik

120 Die gestrichelten Over- und Undershooting-Passagen können auch anders interpretiert werden: nämlich als ein marktmäßiges Überschießen wie in (4-5'). In diesem Fall gäbe es möglicherweise Bedarf für eine gegensteuernde stabilisierende Wechselkurspolitik (siehe unten 4. 2. 3)

121 Siehe „Institutionelle Bedingungen auf den Arbeitsmärkten” unter 4. 1. 1. 
einsetzt. Falls also in $t$ ein Spieler $v>0$ spielt, kann ihn der andere in einer darauffolgenden Periode $(t+j)$ bestrafen, indem er auf einem anderen Politikfeld ${ }^{122}$ mit Retorsionen $\left(R^{*}{ }_{t+j}\right)$ antwortet. Damit ist es ihm möglich, in Situationen zu reagieren, da Devisenmarktinterventionen nicht in seinem Interesse liegen - also inflationäre Spannungen herrschen -, er aber dennoch ein Abschreckungspotential wünscht.

Der damit bedrohte Spieler bezieht nun diese abdiskontierten Retorsionen in sein Kalkül ein, indem er sie von den abdiskontierten Nettoauszahlungen subtrahiert. Somit ergibt sich der Gegenwartswert des Nettonutzens in $t=0$ als

$$
W_{0 \mid v_{t}, v_{t}^{*}}=\sum_{t=1}^{T} \delta^{t}\left[G_{\left.t\right|_{t}, v_{t}^{*}}\left(U_{t}\right)-C_{t \mid v_{t}, v_{t}^{*}}\left(p_{1 t}\right)\right]-\delta^{t+j} R_{t+j}^{*} \rightarrow \max !
$$

Die Retorsionen drohen ihm mit zusätzlichen Kosten für den Fall, daß er eine Abwertungsstrategie einschlägt. Wenn der Gegenspieler die Abwertung entdeckt hat, kann er mit $R$ reagieren. Er kann dies unmittelbar tun $(j=1)$ oder später $(j>1)$. Spätere Strafen gehen weniger in das Kalkül ein: Weil sie zeitlich weiter entfernt liegen, haben sie von der Gegenwart aus betrachtet ein geringeres Gewicht, sofern $\delta>1$. Falls das Spiel zu einem bekannten Zeitpunkt $T$ beendet ist, kann es sein, daß der Zeitpunkt für die angedrohte Strafe jenseits von $T$ liegt - eine Strafandrohung gegen eine Regierung, die kurz vor einem Wiederwahltermin steht und damit rechnen muß, abgewählt zu werden, ist in ihrer Wirkung recht gering. Mit zunehmendem Zeithorizont $(T \rightarrow \infty)$ und abnehmender Zeitpräferenz $(\delta \rightarrow 1)$ genügen immer geringere Strafen, um abschreckend zu wirken.

Eine Abwertungsstrategie lohnt sich somit für einen Spieler nur, wenn

$$
\sum_{t=1}^{T} \delta^{t} G_{t \mid v_{t}, v_{t}^{*}}>\sum_{t=1}^{T} \delta^{t} C_{t \mid v_{t}, v_{t}^{*}}+\delta^{t+i} R_{t+j}^{*}
$$

gilt. Nur wenn der Gegenwartswert der Benefits größer ist als der Gegenwartswert der Kosten zuzüglich der Vergeltungsschläge, ist es rational eine Abwertungsstrategie zu verfolgen. Um wirksam zu sein, muß daher der Gegenwartswert von $R^{*}$ mindestens so groß sein wie der Nettoertrag der Interventionen:

$$
\sum_{t=1}^{T} \delta^{t+i} R_{t+j}^{*} \geq \sum_{t=1}^{T} \delta^{t}\left[G_{t \mid v_{t}, v_{t}^{*}}-C_{t \mid v_{t}, v_{t}^{*}}\right]
$$

122 Es sind eine ganze Reihe von abgestuften Vergeltungsmaßnahmen denkbar. Sie reichen von diplomatischen Noten über die Weigerung zur Zusammenarbeit in anderen Fragen (etwa der Sicherheitspolitik) bis hin zur Verhängung von Strafzöllen oder Kreditverweigerung. Die Literatur zum Thema Sanktionen ist reichhaltig, vgl. insbesondere Hufbauer et al. $(1990,1996)$ sowie Nossal (1989). 
Somit wäre es möglich, daß eine Regierung die Führungsrolle à la Stackelberg übernimmt und sich verpflichtet, von der Wechselkurspolitik keinen Gebrauch zu machen $\left(v_{t}^{*} * 0\right)$, dafür aber im Gegenzug das gleiche von ihrem Widerpart verlangt $(v=0)$. Andernfalls droht die Regierung mit Vergeltung in anderen Politikbereichen.

Verschiedene Vergeltungsstrategien („Trigger strategies”) sind denkbar. Zum Beispiel kann $R^{*}$ einer Tit-for-tat-Strategie [Axelrod 1984] folgen, so daß der Einsatz der Wechselkurspolitik $\left(v_{t}>0\right)$ in der Folgeperiode sanktioniert wird $\left(R^{*}{ }^{*+1}>0\right)$, ein Verzicht auf Wechselkurspolitik $\left(v_{t}=0\right)$ hingegen belohnt wird $\left(R^{*}{ }^{*}=0\right)$.

$$
R_{t+1}^{*}=\left\{\begin{array}{l}
R_{t+1}^{*}>0 \text { falls } v_{t}>0 \\
R_{t+1}^{*}=0 \text { andernfalls }
\end{array}\right.
$$

Allerdings stellt sich die Frage, ob solche Drohnungen glaubwürdig sind: Ist derjenige, der die Strafe androht, auch bereit, sie anzuwenden? Dies ist nicht der Fall, wenn sie hohe Kosten für ihn verursacht. ${ }^{123}$ Viele Faktoren spielen hierfür eine Rolle. Bei Strafzöllen auf Importe zum Beispiel hängen die Kosten für den Sankionierenden davon ab, wie sehr dessen Volkswirtschaft auf diese Importe angewiesen ist, das heißt, von der Möglichkeit, diese Güter kurzfristig gegen andere zu substituieren.

Insbesondere sind die Kosten hoch, wenn die Regierung, die die Retorsionen verhängt, ihrerseits mit unfreundlichen Akten der anderen Regierung auf anderen Feldern der Politik rechnen muß. Dies zeigt: Unilaterale Vergeltungsmaßnahmen können nicht nur ein Beitrag sein, unkooperatives Verhalten unvorteilhaft erscheinen zu lassen, sondern sie können im Gegenteil sogar zu einer Ausweitung und einem Aufschaukeln des Konflikts fuihren, wenn sie nicht allgemein anerkannten Regeln folgen. Die industrialisierte Welt hat dies im Handelskrieg der dreißiger Jahre dieses Jahrhunderts erlebt. Auch hier war eine Kombination aus „reinen” (Zölle, Quoten) und monetären (Wechselkurse) handelspolitischen Instrumenten im Spiel [Kindleberger 1986].

123 Eine Schätzung der Kosten, die die USA durch Erhebung von Sanktionen aufbringen müssen, präsentieren Hufbauer et al. (1996). Nach dieser Rechnung kosteten die Sanktionen des Jahres 1995 die USA etwa 15 bis 19 Milliarden US-Dollar an entgangenen Exporten. Der Exportsektor hätte seinen Beschäftigten in jenem Jahr 800 Millionen bis zu einer Milliarde US-Dollar mehr zahlen können, wären die Sanktionen nicht in Kraft gewesen. Zu beachten ist hierbei: Die Sanktionen des Jahres 1995 waren in der Hauptsache Exportbeschränkungen, um bestimmte Länder (zumeist Entwicklungsländer wie Irak, Iran, Libyen etc.) aus sicherheitspolitischen Gründen von technologischen Entwicklungen auszuschließen. Sanktionen gegen Euroland, von denen hier die Rede ist, wären ungleich teurer. 
Zusammenfassend läßt sich aus der bisherigen Argumentation folgende These formulieren:

Die wirtschaftspolitischen Instanzen der EU greifen umso eher zu einer Abwertungsstrategie,

- je höher die Arbeitslosenquoten und je geringer der Inflationsdruck in den EU-Ländern (dann besteht ein großer innerer Anreiz, den stabilitätspolitischen Spielraum beschäftigungspolitisch zu nutzen),

- je niedriger die Arbeitslosenquoten und je höher der Inflationsdruck in den USA (eine gegenläufige Intervention wird dann unwahrscheinlicher, weil ein starker Dollar im US-Interesse liegt),

- je kürzer der Zeithorizont und je höher die Zeitpräferenz der „EU-Regierung" (langfristige Kosten der Abwertung fallen weniger ins Gewicht),

- je schwächer die Rolle der EZB innerhalb der EU realiter sein wird (ein autonom vorgegebenens Inflationsziel schafft dann keine bindende Grenze für Devisenmarktinterventionen),

- je weniger glaubwürdig andere, nicht wechselkurzbezogene Vergeltungsstrategien sind.

In der Nachkriegsära haben die USA zunächst die Rolle eines Stackelberg-Führers zugunsten einer stabilen Weltwirtschaftsordnung gespielt: Sie kündigten glaubwürdig an, eine bestimmte Politikstrategie, etwa Freihandel, zu spielen, die übrigen Länder wählten ihre Strategien unter Berücksichtigung dieser Vorgaben. Die US-Regierung stellte unilateral Regeln auf und hatte zudem die Möglichkeit, andere Länder im Falle der Nichteinhaltung zu sanktionieren, insbesondere durch Importbeschränkungen nach den USA. Bis Ende der sechziger Jahre waren sie in der Lage, derart hegemoniale Macht auszuspielen. Da eine große Asymmetrie bestand - die USA waren die mit Abstand größte Volkswirtschaft der Welt -, verursachten die Sanktionen auf seiten der USA zumeist nur geringe Kosten (waren daher glaubwürdig), auf seiten der Bestraften aber hohe Kosten und wirkten somit hochgradig abschreckend [Hufbauer et al. 1990: 99ff]. Insofern war es den USA möglich, aus Eigeninteresse ein internationales öffentliches Gut bereitzustellen: eine internationale (Wirtschafts-)Ordnung.

Durch den wirtschaftlichen Aufstieg anderer Mächte, vor allem der EU, sind die USA dazu nicht mehr in der Lage. Die Situation hat sich fundamental gewandelt: In einer multipolaren Welt mit offenen Güter- und Kapitalmärkten sind unilaterale Sanktionen auch für den Strafenden extrem kostspielig und daher nicht mehr sonderlich erfolgversprechend [Gill/Law 1988: 335ff]. Das Design internationaler Wirtschaftsregime wird dadurch anspruchsvoller: Um überhaupt eine Übereinkunft zu erzielen, müssen sie dauerhaft im Interesse einer Vielzahl von Regierungen sein [Keohane 1989]. Im folgenden wird daher untersucht, welche Chancen sich im Euro-Zeitalter für ein kooperatives Wechselkursregime ergeben. 


\section{2. 3 Stabilisierende Wechselkurspolitik}

Die Abschnitte 4.2. 1 und 4.2. 2 gingen davon aus, am Markt bilde sich ständig ein langfristig gleichgewichtiger Wechselkurs heraus. Allein die Regierungen tragen Volatilität ins System durch konjunkturpolitisch motivierte Devisenmarktinterventionen. Die vergangenen Jahre und Jahrzehnte hingegen prägte eine andere Debatte: Wie bekommt die internationale Gemeinschaft mehr Ruhe ins internationale Währungssystem? Gibt es Möglichkeiten zu vermeiden, daß plötzliche Umschwünge in der marktmäßigen Bewertung von Währungen Krisen ausgelösen, zumindest aber deutlich verschärfen? Und was überhaupt ist der „wahre” Kurs einer Währung? ${ }^{124}$

Stabilisierung der Erwartungen. Die Überlegungen dieses Abschnitts greifen Gleichung (4-7') auf und erweitern sie um die Interventionsmöglichkeiten für das Ausland. Somit ergibt sich

$$
\left(4-7^{\cdots}\right) \quad U=U_{N}-a(1-\beta)\left(k-b k_{t-1}+v-v^{*}\right)
$$

bzw. aus Sicht des zweiten Landes

$$
U^{*}=U_{N}^{*}-a^{*}\left(\beta^{*}-1\right)\left(k-b k_{t-1}+v-v^{*}\right) .
$$

Diese Gleichungen lassen sich als Aufforderung an die beiden Regierungen verstehen: Im Falle einer Abweichungen des Wechselkurses vom Gleichgewichtskurs um $k \neq 0$ sollte mindestens eine Seite intervenieren, so daß der Wechselkurs so

124 In der zweiten Hälfte der achtziger Jahre war das Thema Wechselkursstabilisierung vor allem wegen der dramtischen Berg- und-Tal-Fahrt des Dollarkurses auf der Tagesordnung [Dominguez/Frankel 1993]. In den neunziger Jahren hingegen standen die Entwicklungsländer im Vordergrund, nachdem 1994 Mexiko infolge einer plötzlichen Kapitalflucht und einem resultierenden Absturz des Peso in eine tiefe Krise schlitterte, die andere Emerging Markets mitriß („Tequila-Effekt”) und mittelbar sogar EWS-Währungen wie die Peseta und den Escudo unter Druck setzte. Im Sommer 1997 begann mit der thailändischen Währungskrise eine Abwärtsspirale für den gesamten südostasiatischen Raum, wiederum mit weltweit destabilisierenden Auswirkungen, insbesondere in den Emerging Markets. $\mathrm{Zu}$ diesem Themenkomplex gibt es eine große Vielfalt von Veröffentlichungen, von denen einige exemplarisch herausgegriffen seien: Einen Überblick über die Versuche der Wechselkursstabilisierung in der Post-Bretton-WoodsÄra bietet Claassen (1990). Mit der Entwicklung der Finanzmärkte und den Auswirkungen auf die Volatilität der Märkte beschäftigt sich Goodhart (1996). Einen Überblick über Wechselkursprobleme von Entwicklungsländern und deren Lösungsansätze bieten Dieh1/Schweickert (1997). Für eine generelle Analyse der Asienkrise, ihrer Ursachen und Wirkungen vgl. BIZ (1998: 33ff). Goldfajn/Valdés (1997) beschäftigen sich mit der Frage, ob Wăhrungskrisen prognostizierbar sind und vergleichen dazu die Erfahrungen in Mexiko und Thailand. Cassard/Folkerts-Landau (1997) beleuchten in diesem Zusammenhang, welche Rolle das staatliche Schuldenmanagement bei Entstehen und Vermeiden von Währungskrisen spielen kann. Siehe auch Abschnitt 5. 1. 3 unten. 
schnell wie möglich auf seinen langfristigen Gleichgewichtskurs $\left(e_{K K P}\right)$ zurückkehrt, also die rechte Klammer den Wert Null annimmt. Sie tragen dadurch zu einer Stabilisierung der Erwartungen der Marktakteure bei: Diese erwarten in $t$ eine Abweichung um $b k_{t-l}$ vom KKP-Kurs und richten ihre Pläne daran aus. Tatsächlich sind sie aber mit einer Abweichung von $k$ konfrontiert, so daß reale Effekte auftreten. In der Folgeperiode $t+1$ erwarten sie eine Abweichung um $b k$. Tatsächlich aber ist die Abweichung $k(>b k)$. Die realen Effekte bleiben daher bestehen. Eine Intervention kann im Idealfall die Erwartungen und damit den Wechselkurs stabilisieren, so daß die Volkswirtschaften rasch auf ihren langfristigen Gleichgewichtspfad zurückkehren.

Der grundlegende Ansatzpunkt aller Wechselkursarrangements in der realen Welt ist eine solche Stabilisierung der Erwartungen: Verkünden die beteiligten Regierungen bzw. Notenbanken öffentlich ein nominales Wechselkursziel und machen sie glaubwürdig klar, daß sie bereit sind, dieses Ziel per Intervention und Politikkoordinierung zu verteidigen, so ist eine Intervention tatsächlich selten nötig, weil die Märkte sich an dem Wechselkursziel ausrichten. Erst wenn die währungspolitischen Akteure nicht mehr glaubwürdig vertreten können, daß sie willens und in der Lage sind, das Wechselkursziel unter allen Umständen zu erreichen, kommt es zu spekulativen Attacken, wobei die Marktteilnehmer die Entschlossenheit der Politiker und Notenbanken testen.

Unter welchen Bedingungen erscheint es den währungspolitischen Entscheidungsträgern zweier souveräner Staaten überhaupt vorteilhaft, sich einer bi- oder multilateralen Koordinierung der Wechselkurspolitik zu unterwerfen?

Regimebildung. Im Kontext wiederholter Spiele unter Sicherheit ist eine optimierende Wechselkurspolitik möglich. Dies ist der Fall, wenn der Zeithorizont $(T)$ der Spieler unendlich oder unbekannt ist und zugleich glaubwürdige Sanktionen zur Verfügung stehen. Es lassen sich dann Reaktionsmuster schaffen, die die Summe der Nettoauszahlungen der Spieler maximieren und zugleich keinen schlechter stellen als zuvor. Ein langfristiger Gleichgewichtskurs (bzw. eine entsprechende Änderungsrate) sei bekannt und allgemein akzeptiert, es existiere ein Regime zur Kursstabilisierung.

Die Frage ist allerdings, unter welchen Bedingungen ein solches Regime stabil ist. Da es sich bei den Spielern um Regierungen souveräner Staaten handelt, können sie von keiner übergeordneten Instanz zur Kooperation gezwungen werden. Ein solches Regime ist also nur funktionsfähig, wenn es beiden Seiten vorteilhaft erscheint, und zwar unabhängig von der ökonomischen Konstellation. ${ }^{125}$

Fall 1: Asymmetrische Länder. Beobachten die Akteure in der Periode $t$ eine Abweichung um $k$, sollten sie $v$ bzw. $v^{*}$ so setzen, daß der Wechselkurs auf sein KKP-Niveau zurückkehrt. Das Problem ist indes: Die Abweichung vom

125 Sofern dies nicht möglich ist, muß Kooperation auf weiteren Feldern der Politik hinzutreten, insbesondere der Geld- und der Fiskalpolitik. 
KKP-Kurs kann durchaus im Interesse einer oder beider Regierungen liegen. Sofern beispielsweise die EU hohe Arbeitslosenraten und einen geringen Preisdruck verzeichnet, kann ein schwächer bewerteter Euro $(k>0)$ erwünschte beschäftigungspolitische Effekte induzieren - eine Devisenmarktintervention $(\nu<0)$ läge somit nicht im Interesse der EU-Regierenden. ${ }^{126}$ Herrscht zugleich in den USA inflationärer Druck, so hat die US-Regierung tendenziell ein Interesse an einem starken Dollar, so daß auch eine Intervention der USA zugunsten einer Schwächung des Dollar $\left(v^{*}>0\right)$ nicht sonderlich vorteilhaft erscheinen dürfte. In der spiegelbildlichen konjunkturellen oder strukturellen Situation herrschen ungekehrte Vorzeichen.

Sofern die Lage in beiden Ländern in hohem Maße asymmetrisch ist, besteht für keine der Regierungen ein Anreiz, die zuvor vereinbarten Interventionen in die Tat umzusetzen. Folglich ist ein solches Regime, das explizit ein Wechselkursziel vorgibt, unter diesen Bedingungen instabil. Anders ausgedrückt: In diesem Fall ist Kooperation weder erwünscht noch dringend erforderlich. ${ }^{127}$

Fall 2: Symmetrische Länder. Sofern in beiden Ländern symmetrische Bedingungen herrschen, kommt wechselkurspolitischer Kooperation eine wichtige Rolle zu. Falls beide in einer Rezessionssituation (hohe Arbeitslosigkeit, niedrige Inflationsrate) stecken, liegt eine Abweichung vom Gleichgewichtskurs um $k>0$ (Euro ist gegenüber Dollar unterbewertet) im Interesse der EU-Regierenden, nicht aber im Interesse der US-Regierung. Eine konzertierte Intervention $\left(v<0 \wedge v^{*}>0\right)$ wäre dann erwünscht, jedoch wäre der Anreiz dazu für die EUInstanzen nicht gegeben. Umgekehrt läge eine Abweichung um $k<0$ (Dollar ist gegenüber dem Euro unterbewertet) gerade im Interesse der US-Regierung, die folglich zunächst keinen Anreiz hätte zu intervenieren.

Sanktionen. Im Kontext eines wiederholten Spiels ist eine derartige konzertierte Intervention aber dennoch möglich: nämlich wenn die EU-Regierenden durch eine Intervention entgegen ihrer unmittelbaren, kurzfristigen Interessen Reputation aufbauen können, so daß in einer künftig möglicherweise umgekehrten Situation sie ihrerseits auf Unterstützung der US-Regierung zählen können. Eine Reputation in Sachen kooperativem Verhalten aufzubauen ist für die EU-Regierenden indes nur vorteilhaft, wenn sie mit der glaubwürdigen Drohung seitens der US-Regierung konfrontiert sind, daß sie in kommenden Perioden unkooperativ spielen wird, falls die EU heute nicht zur Kooperation bereit ist.

126 Die EZB würde in diesem Fall Devisenreserven (Dollars) verkaufen $(\triangle D<0)$, so daß die monetäre Basis im Fall einer nicht sterilisierten Intervention sinkt $(\Delta B<0)$. Dadurch kommt es zu einem kontraktiven Effekt.

127 Dies ist in etwa die Situation in der zweiten Hälfte der neunziger Jahren. Die währungspolitische Zusammenarbeit innerhalb der G7 oder des IMF beschäftigt sich nicht etwa mit dramatischen Fehlbewertungen der wichtigsten Währungen, sondern mit Krisen in den Emerging Markets sowie der Rezession in Japan. 
Es ist jedoch auch denkbar, daß der Zeithorizont der Regierungen so kurz bzw. die Zeitpräferenz so hoch ist, daß diese Drohung die Versuchung, unkooperativ zu spielen, nicht eliminiert. In diesem Fall müßte die Sanktion nicht mehrere Perioden später und dann auch noch mit Unsicherheit behaftet auf die EU niedergehen, sondern möglichst sofort. Folglich wären Retorsionen auf anderen Politikfeldern analog der oben beschriebenen ${ }^{128}$ zur Regimestabilisierung nötig.

Regimeerhaltende Interventionen. Retorsionen können bis hin zu einer äußerst massiven Drohung reichen: der Aufkündigung von wechselseitig vorteilhaften Regimen in anderen Feldern der Politik. Eine anhaltende Fehlbewertung einer Währung - sei sie nun von der jeweiligen Regierung inszeniert oder billigend hingenommen - führt zu Verzerrungen auf den Güter- und Kapitalmärkten, dies umso mehr, falls auf diesen ein Freihandelsregime existiert. Die Drohung seitens der Regierung des leidtragenden Landes kann nun lauten, dieses Regime im Falle einer andauernden Fehlbewertung aufzukündigen bzw. Neuverhandlungen anzustreben, mit dem Ziel protektionistische Maßnahmen zu realisieren. $R^{*}$ in (4-25ff) ist dann sehr groß, so daß die Drohnung auch bei hoher Zeitpräferenz effektiv sein dürfte. ${ }^{129}$

Unsicherheit. Bislang war lediglich das Ende des Horizonts $(T)$ nicht genau determiniert, nun tritt ein weiteres fundamentales Unsicherheitsmoment hinzu. Wird die Annahme vollständiger Information aufgegeben, so treten verschiedene Unsicherheitsfaktoren ins Kalkül der Spieler. Sämtliche Größen können nun risikobehaftet sein: die eigenen Nettoauszahlungen und diejenigen des Gegners sowie die Sanktionsbereitschaft des Gegners. Es ist sogar möglich, daß nicht einmal die Wahrscheinlichkeiten bzw. Wahrscheinlichkeitsverteilungen bekannt sind. ${ }^{130}$ Dies dürfte das Verhalten der Spieler fundamental beeinflussen. In der realen Welt gibt es nicht einmal eine allgemein akzeptierte Methode, einen langfristigen gleichgewichtigen Wechselkurs zu bestimmen. Auch der oben stets unterstellte allgemeinverbindlich anzustrebende KKP-Wechselkurs ist daher Gegenstand von Verhandlungen zwischen staatlichen Instanzen.

Diese Unsicherheitsfaktoren führen dazu, daß eine „Policy-optimizing coordination" [Kenen 1998: 4ff] in der Realität nicht zu beobachten ist. Marginale Verbesserungen, die in spieltheoretischen Modellen bei Sicherheit ermittelt und realsiert werden können, sind bei Unsicherheit auf dem Verhandlungswege nicht erreichbar. Was möglich ist, ist die Verhinderung von Krisen und groben Ungleichgewichten. Und eben darauf hat sich die internationale währungspolitische

128 Siehe 4. 2. 1 „Fall 5: Ausweitung des Konflikts”

129 Kenen [1998: 4ff] betont gerade diese regimeerhaltende Funktion der Wechselkursstabilisierung und weist darauf hin, daß zum Beispiel das Plaza-Abkommen von 1985 vor allem deshalb zustande gekommen sei, weil in den USA protektionistische Tendenzen gegen den äußerst starken Dollar laut wurden.

130 Es herrscht dann echte Unsicherheit (im Sinne von Knight 1921) 
Zusammenarbeit in den Jahrzehnten seit dem Ende des Bretton-Woods-Systems konzentriert. Auch in der spieltheoretischen Literatur ist solches Verhalten zu finden: Falls die optimale Lösung nicht bekannt ist, müssen sich die Spieler mit zufriedenstellenden (,satisficing”) Lösungen begnügen [z. B. Holler/llling 1996: $161 \mathrm{ff}]$.

Bei Unsicherheit werden auch Abweichung vom kooperativen Kurs möglicherweise eine Art Vabanquespiel. Nun ist es nämlich möglich, daß eine Regierung die Anreizstrukturen der Gegenseite falsch einschätzt und daher nicht oder nur sehr ungenau vorhersagen kann, mit welchen Gegenmaßnahmen sie rechnen muß - der Preis unkooperativen Verhaltens ist ihr unbekannt. Fehleinschätzungen können zu einer Eskalation führen, insbesondere wenn es zu einem Wettlauf wechselseitiger Retorsionen kommt. Dies aber wirkt systemdestabilisierend. Unter Unsicherheit erscheint somit ein - fallweise kooperativer - systemerhaltender Ansatz am erfolgversprechendsten. ${ }^{131}$

\section{3 Der Entscheidungsprozeß innerhalb der EWU}

Die Überlegungen des vorhergehenden Abschnitts betrachteten die EU als homogenen Block. Wie ein Haushalt, ein Unternehmen oder die Regierung eines traditionellen Staatswesens wurde sie als geschlossen handelnde Einheit behandelt, die auf Basis von makroökonomischen Durchschnittsgrößen (Arbeitslosenquote, Konsumentenpreisindex) Entscheidungen fällt. Allerdings dürfte es auch in puncto Wechselkurspolitik innerhalb der Eurozone Interessengegensätze geben. Dies ist jedoch ein äußerst wichtiger Aspekt, denn sofern die EU kein äußeres Wechselkursarrangement eingegangen ist, kann der Ministerrat ,allgemeine Orientierungen für die Wechselkurspolitik" mit Zweidrittelmehrheit beschließen. ${ }^{132}$ Es stellt sich daher die Frage: Wie wahrscheinlich ist es, daß eine solche Mehrheit zustande kommt?

Inflation und Beschäftigung im Euroland. Im Vordergrund der obigen Argumentation stand der kurzfristige Trade off zwischen Wechselkurs- bzw. Preisstabilität und Beschäftigung. Allerdings unterscheiden sich die EWU-Staaten beträchtlich, insbesondere was die Lage auf den Arbeitsmärkten angeht. Zum Zeitpunkt des EWU-Starts am Jahresende 1998 beispielsweise variierten die Arbeitslosenquoten zwischen 2,2 Prozent in Luxemburg und 18,2 Prozent in Spanien (siehe Übersicht 4-1). ${ }^{133}$ Auch die institutionellen Regelungen auf den Ar-

131 Ein solcher Ansatz wird in Abschnitt 5. 4 entwickelt.

132 Siehe Abschnitt 2. 3.

133 Die Ermittlung der Arbeitslosenzahlen differiert erheblich zwischen den EU-Ländern. In Spanien etwa liegt der Wert nach offizieller nationaler Zählung um 59 Prozent höher als nach international standardisierter Ermittlung [IW 1998]. Am generellen Befund hoher Arbeitslosigkeit ändert dies jedoch nichts. 
beitsmärkten sind höchst unterschiedlich ausgestaltet, etwa was die Finanzierung der gesetzlichen Sozialversicherungen oder den Anspruch auf Arbeitslosengeld betrifft. Verschiedene nationale Gesetzgebungen führen dazu, daß in einigen Ländern die Arbeitsmärkte als flexibel, in anderen als inflexibel zu betrachten sind [OECD 1997, Dohse/Krieger-Boden 1998].

Die dauerhaft hohe Arbeitslosigkeit stellt für die Regierungen der betroffenen Länder permanent einen Anreiz dar, mittels politischer Interventionen den Euro gegenüber anderen wichtigen Währungen zu schwächen. Statt Strukturreformen insbesondere der sozialstaatlichen Sicherungssysteme anzugehen, könnte eine Abwertung des Euro mancher Regierung als schneller Ausweg attraktiv erscheinen. So konstatierte der US-Ökonom Rüdiger Dornbusch bereits im Vorfeld der Währungsunion: „Europe is already desperate about a dollar said to be undervalued. The very last thing they will do is push it down further and lose jobs in the process" [Dornbusch 1996: 2].

Übersicht 4-1: Arbeitslosigkeit und Inflation im Euroland

\begin{tabular}{|c|c|c|c|c|}
\hline & $\begin{array}{c}\text { Arbeits- } \\
\text { losen- } \\
\text { quoten } \\
\text { (harm.) } \\
\text { in } \%\end{array}$ & $\begin{array}{l}\text { Flexibi- } \\
\text { lität der } \\
\text { Arbeits- } \\
\text { märkte }^{+}\end{array}$ & $\begin{array}{l}\text { Infla- } \\
\text { tions- } \\
\text { rate } \\
\text { (harm. } \\
\text { Index } \\
\text { der } \\
\text { Konsu- } \\
\text { menten- } \\
\text { preise) } \\
\text { in \% } \\
\end{array}$ & $\begin{array}{c}\text { Stim- } \\
\text { men im } \\
\text { EU- } \\
\text { Minister } \\
\text {-rat }\end{array}$ \\
\hline Belgien & 8,5 & Gering & 0,6 & 5 \\
\hline Deutschland & 9,4 & Gering & 0,6 & 10 \\
\hline Spanien & 18,2 & Gering & 1,4 & 8 \\
\hline Frankreich & 11,8 & Gering & 0,2 & 10 \\
\hline Irland & 8,5 & Hoch & 2,2 & 3 \\
\hline Italien & $12,1^{*}$ & Gering & 1,7 & 10 \\
\hline Luxemburg & 2,1 & - & 0,5 & 2 \\
\hline Niederlande & $5,2^{*}$ & Hoch & 1,5 & 5 \\
\hline Österreich & 4,4 & Hoch & 0,5 & 4 \\
\hline Portugal & 4,4 & Hoch & 2,6 & 5 \\
\hline Finnland & 10,6 & Gering & 0,9 & 3 \\
\hline Euroland gesamt & 10,8 & - & 0,9 & 65 \\
\hline
\end{tabular}

Stand: 11/1998. *Stand: $1997 .{ }^{+}$Klassifikation nach Dohse/Krieger-Boden.

Quellen: Eurostat, Dohse/Krieger-Boden (1998) 
Gerade in Zeiten, da kaum inflationärer Druck herrscht, bewirkt ein schwächerer Außenwert nicht notwendigerweise, daß die Inflationsrate über den von der EZB gesetzten Maximalwert von zwei Prozent hinausschießt. Eher keynesianisch orientierte Regierungen mögen daher argumentieren, daß ein leichter Anstieg der Inflation hinnehmbar sei, wenn damit die Arbeitslosigkeit gesenkt werden kann. Dies gilt zumal in Situationen, da das Euroland eine Phase annähernder Preisstabilität durchläuft, wie dies Ende 1998 der Fall war. So betrug zum Beispiel im November 1998 im Euroland die Inflationsrate (Jahresrate) lediglich 0,9 Prozent. Nur in Portugal und Irland lag sie über der Zwei-Prozent-Marke (Übersicht 4-1), dies insbesondere weil in diesen ehemaligen Hochzinsländern die Konvergenz der kurzfristigen Zinsen im Euroland dazu führte, daß die Sätze stark sanken - aus Sicht dieser Länder war die Geldpolitik stark expansiv.

In der Konstellation am Jahresende 1998 hätte eine Koalition der Regierungen Belgiens, Deutschlands, Frankreichs, Spaniens und Italiens - alles Länder mit hohen Arbeitslosenquoten bei annähernder Preisstabilität - die erforderliche Zweidrittelmehrheit der Teilnehmerstaaten erreicht, um die EZB mittels ,allgemeiner Orientierungen“ zu einer Politik des schwachen Euro anzuhalten. Bei einer Inflationsrate von 0,9 Prozent im gesamten Euroland hätte die EZB sich dagegen kaum wehren können.

„Abwertungstradition.” Für das Verhalten von Regierungen mag neben den objektiven Faktoren Preisstabilität und Arbeitslosigkeit auch die „Abwertungstradition" des betreffenden Landes eine Rolle spielen. Institutionen entwikkeln Traditionen, sie formen eigene Präferenzordnungen und Prozeduren. ${ }^{134} \mathrm{Ha}-$ ben nationale Regierungen in der Vergangenheit häufig vom Politikinstrument Abwertung Gebrauch gemacht, so spricht dies dafür, daß sie auch in der Zukunft eher dazu neigen werden als Regierungen, die den Wechselkurs überwiegend als Residualgröße ihrer sonstigen Geldpolitik aufgefaßt haben [Müller/Straubhaar 1998: 285f]. Viele Euroland-Staaten blicken auf eine solche Abwertungstradition zurück, insbesondere jene, die bis in die späten achtziger Jahre hohe Inflationsraten zu verzeichnen hatten und daher kontinuierlich abwerten mußten. Dies gilt insbesondere für Italien, Spanien und Portugal. Am wenigsten dürfte dies für die Länder des EWU-Kerns, des ehemaligen D-Mark-Blocks, gelten. ${ }^{135}$

Die Rolle der Exekutive. In der Formulierung der Wechselkurspolitik spielen die Europäische Kommission und die EZB eine starke Rolle. ${ }^{136}$ Zwar entscheiden stets die Regierungen im Ministerrat, die Vorlage für diese Entscheidun-

134 Diese Frage ist vielfach im Hinblick auf Zentralbanken im Rahmen der Neuen Institutionen Ökonomik diskutiert worden.

135 Bis 1987 herrschten im EWS stark differierende Inflationsraten, so daß es regelmäßig zu Realignments kam. Siehe die Analyse des EWS unter 5. 2. 2.

136 Siehe Abschnitt 4. 1. 1. 
gen kommt aber von einer dieser beiden europäischen Institutionen. Entweder empfiehlt die Kommission, in diesem Fall wird die EZB gehört, oder die EZB spricht allein eine Empfehlung aus. Diese Empfehlungen stellen die Diskussiongrundlage dar. Zwar können einzelne nationale Regierungen oder Gruppen von Regierungen die Initiative ergreifen und Kommission und/oder EZB zum Handeln auffordern. Dies hat jedoch keinen bindenden Charakter. Mit Kommission und EZB sind also neben den nationalen Regierungen zwei weitere Akteure an der Formulierung der Wechselkurspolitik beteiligt, deren Zeithorizont möglicherweise länger ist als derjenige der nationalen Regierungen. Dies gilt insbesondere für die EZB. Sie hat zudem die Möglichkeit, für Transparenz im Entscheidungsprozeß zu sorgen, indem sie die langfristigen Kosten einer solchen Politik in die öffentliche Diskussion einbringt.

Nationale Wahlzyklen. Oben wurde argumentiert, daß die Wahlzyklen von großer Wichtigkeit bei der Formulierung nationaler wechselkurspolitischer Ziele sind. ${ }^{137}$ In der EU als ganzer gibt es aber auch im EWU-Zeitalter bis auf weiteres keine harmonisierten Politikzyklen. Somit wird es schwieriger für abwertungswillige Regierungen, gleichgesinnte Partner zu finden. Dies wird in Abbildung 413 deutlich:

Abbildung 4-13: Sich überlagernde Politikzyklen: Wechselkurspolitik bei zwei Ländern mit unterschiedlichen Wahlterminen

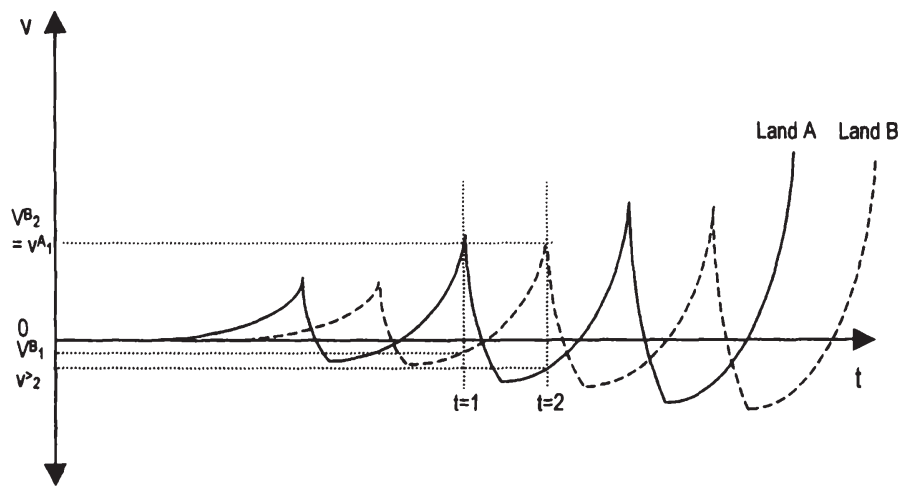

Die durchgezogene Linie entspricht derjenigen in Abbildung 4-7, die gestrichelte Linie repräsentiert die Präferenzen der Regierung eines zweiten EU-Landes B mit einem zeitversetzten Wahlzyklus. Trotz ansonsten gleicher Umstände gibt es keinen Zeitpunkt, bei dem Extremwerte übereinstimmen. $\mathrm{Zu}$ einigen Zeitpunkten

137 Siehe Abbildung 4-7. 
gibt es sogar einen deutlichen Interessengegensatz. Im Zeitpunkt $t=1$ zum Beispiel wünscht die Regierung von Land A eine Abwertung der Größenordnung $v^{A}$, die Regierung von Land $B$ hingegen wünscht eine Aufwertung von $v^{B}$. Zum Zeitpunkt $t=2$ hingegen ist die Situation ungekehrt: Regierung $\mathrm{B}$ wünscht eine $\mathrm{Ab}$ wertung von $v_{2}^{B}$, Regierung A hingegen eine Aufwertung von $v_{2}^{4}$. Bei asynchronen Wahlzyklen kann es somit zu einer gegenseitigen Neutralisierung kommen. Dies verschlechtert die Aussichten deutlich, daß die Abwertungsbefürworter die erforderliche Mehrheit zusammenbringen.

\section{4 Statt eines Abwertungswettlaufs ein Härtungswettbewerb?}

Das oben dargelegte Crash-Szenario geht allein vom Beschäftigungs-AbwertungsTrade-off aus, den die modifzierte Phillipskurve (v-Kurve) unterstellt. Der Fokus ist dabei auf das Zusammenspiel von Geldpolitik und Arbeitsmarkt gerichtet, andere Einflußgrößen und Motivationen wurden weitgehend ausgeblendet. In einem solchen Barro-Gorden-Setting ist das Ergebnis eines Abwertungswettlaufes, der in einen Inflationswettlauf mündet, unausweichlich, falls der Zeithorizont der Regierungen genügend kurz ist, die Arbeitslosigkeit hoch und die Inflation kein drängendes Problem darstellt, also eine klassische Rezessionssituation in beiden Ländern herrscht. Werden jedoch andere Einflüsse und Motive berücksichtigt, ist auch ein komplett gegenläufiges Ergebnis möglich: ein Härtungswettbewerb der beiden Weltwährungen.

In diesem Szenario konkurrieren die Regierungen und Notenbanken des Eurolandes und der USA darum, den Finanzmärkten die attraktivsten Anlagemöglichkeiten bieten zu können. Und das heißt: die niedrigsten Inflationsraten und die glaubwürdigste Währungspolitik. Bislang waren große Anleger und Schuldner auf die US-Finanzmärkte angewiesen, in gewisser Weise konnten die US-Behörden damit eine Monopolstellung ausbeuten. Nun wächst mit dem Euro-Raum ein Konkurrent heran. Diese Konstellation kann zu einem duopolistischen Härtungswettbewerb führen [z. B. Kachelrieß 1999]. Die Argumentation soll hier kurz in einen eigenen formalen Ansatz gegossen werden:

Formaler Ansatz. Wie unter 4. 1, ist der Ausgangspunkt das Modell von Barro/Gordon (1983), allerdings wird es um einen Aspekt erweitert: Neben der Phillipskurven-Gleichung (4-7) haben die wirtschaftspolitischen Entscheidungsträger nun eine zweite Nebenbedingung zu beachten, nämlich die Budgetrestriktion des Staates:

$$
A=F-J(i), \quad \text { mit } \frac{d J}{d i} \geq 0, \frac{d J^{2}}{d^{2} i} \geq 0
$$

wobei $A$ die Nettoausgaben des Staates bezeichnet, die sich aus den Staatseinnahmen $(F)$ abzüglich des Schuldendienstes $(J)$ ergeben. Die Staatseinnahmen - 
Steuern, Abgaben und Kredit - seien exogen. Der Schuldendienst hängt ab vom Nominalzins (i), und zwar mit positiver erster und zweiter Ableitung.

Der Nominalzins wiederum ergibt sich als Summe aus Realzins $\left(i_{R}\right)$ und Inflationsrate $\left(p_{1}\right)$ :

$$
i=i_{R}+p_{1}
$$

Der Realzins hängt ab vom Realzins einer ausländischen Alternativanlage $\left(i_{R}{ }^{*}\right)$ sowie von einer Risikoprämie $(r)$ :

$$
i_{R}=i_{R}^{*}+r\left(p_{t-1}-p_{t-1}^{E}\right)
$$

$i_{R}{ }^{*}$ ist aus Sicht der wirtschaftspolitischen Entscheidungsträger exogen, die Risikoprämie $(r)$ hängt ab vom Erwartungsfehler über die Geldpolitik aus der Vorperiode $\left.p_{t-1}-p_{t-1}^{E}\right)$; der Einfachkeit halber wird hier nur eine Vorperiode betrachtet, nicht eine ganze Zeitreihe. Sofern die Akteure auf den Finanzmärkten in der Vorperiode von einer Devisenmarktintervention $\left(v_{t-l} \neq 0\right)$ überrascht worden sind, fordern sie eine Risikoprämie, der Realzins steigt, die ersten beiden Ableitungen sind daher positiv. Der Erwartungsfehler ergibt sich wie in (4-6), so daß

$$
i_{R}=i_{R}^{*}+r\left(v_{t-1}\right), \quad \operatorname{mit} \frac{d r}{d v_{t-1}}>0, \frac{d r^{2}}{d^{2} v_{t-1}}>0 .
$$

$\mathrm{Da}$ auch $p_{1}$ gemäß (4-4) von $v$ abhängt, ist der Nominalzins in diesem Modell in doppelter Weise von der Wechselkurspolitik abhängig: durch die Erfahrungen des Finanzmarktpublikums an die Politik der Vorperiode und durch die aktuelle Politik. In diesem Modell hängt daher der Schuldendienst des Staates einzig von der Wechselkurspolitik ab, (4-28) läßt sich somit auch als

$$
A=F-J(v), \quad \text { mit } \frac{d J}{d v} \geq 0, \frac{d J^{2}}{d^{2} v} \geq 0
$$

ausdrücken.

Wirtschaftspolitische Präferenzen. Die Nettoausgaben des Staates gehen auch in die Präferenzfunktion der wirtschaftspolitischen Entscheidungsträger ein. Gemäß dem Ansatz der modernen Politischen Ökonomie wird angenommen, daß sie eine Vorliebe für Ausgabenprogramme haben, da sie damit ein Angebot an ihre Wähler machen und hoffen können, wiedergewählt zu werden. $A$ geht daher mit positivem, abnehmendem Grenznutzen in die Präferenzenfunktion ein, die ansonsten wie (4-10) aussieht. 


$$
\begin{aligned}
& W=W(U, v, A), \\
& \text { mit } \frac{\partial W}{\partial U}<0, \frac{\partial W}{\partial v}<0, \frac{\partial W}{\partial A}>0 ; \frac{\partial^{2} W}{\partial U^{2}}>0, \frac{\partial^{2} W}{\partial v^{2}}>0, \frac{\partial^{2} W}{\partial A^{2}}<0
\end{aligned}
$$

Optimale Wechselkurspolitik. Als Optimierungsproblem der wirtschaftspolitischen Entscheidungsträger ergibt sich, daß sie ihren Nutzen gemäß (4-32) maximieren, wobei die Menge ihrer Möglichkeiten nun nicht nur durch die v-Kurve (47) beschränkt wird, sondern zudem durch die Budgetrestriktion der öffentlichen Haushalte (4-28'):

Zielfunktion

1. Nebenbedingung

$$
\begin{aligned}
& W=W(U, v, A) \Rightarrow \max ! \\
& U-U_{N}+a(1-\beta) v=0 \\
& A-F+J(v)=0
\end{aligned}
$$$$
\text { 2. Nebenbedingung }
$$

Daraus ergibt sich die Lagrange-Funktion

$$
L(U, v, A, \lambda, \zeta)=W(U, v, A)+\lambda\left\{U-U_{N}+a(1-\beta) v\right\}+\zeta\{A-F+J(v)\}
$$

mit den Bedingungen erster Ordnung

(4-34) $\frac{\partial L}{\partial U}=\frac{\partial W}{\partial U}+\lambda=0$

(4-35) $\frac{\partial L}{\partial v}=\frac{\partial W}{\partial v}+\lambda a(1-\beta)+\zeta J_{v}=0$

(4-36) $\frac{\partial L}{\partial A}=\frac{\partial W}{\partial A}+\zeta=0$

(4-37) $\frac{\partial L}{\partial \lambda}=U-U_{N}+a(1-\beta) v=0$

(4-38) $\frac{\partial L}{\partial \zeta}=A-F+J(v)=0$

Daraus resultiert als Optimalitätsbedingung

(4-39) $a(1-\beta)=\frac{\partial W / \partial v}{\partial W / \partial U}-\frac{\partial W / \partial A}{\partial W / \partial U} \frac{d J}{d v}$ 
Ein Vergleich mit der ursprünglichen Bedingung (4-15) liefert einige interessante Ergebnisse: Beide Gleichungen sind identisch, mit Ausnahme des rechten Summanden. Die Grenzrate der Substitution zwischen Arbeitslosigkeit und Nettostaatsausgaben verfügt in jedem Fall über ein negatives Vorzeichen (die partielle Ableitung nach $A$ ist positiv, die partielle Ableitung nach $U$ negativ), $d J / d v$ ist positiv oder gleich null. Ist der subtrahierte Term insgesamt negativ, so steigt der Wert der rechten Seite der Gleichung. Graphisch gesprochen rückt der Tangentialpunkt in Abbildung 4-6 entlang der v-Kurve nach rechts. Die Stärke dieses Effekts hängt von zwei Faktoren ab: einerseits der Ausgabenpräferenz der Regierung, andererseits der Reaktion der Finanzmärkte, die sich in der Ableitung $d J / d v$ zeigt.

Wechselkurspolitik und das Niveau der Staatsverschuldung. Die Ausgabenpräferenz einer Regierung richtet sich nicht nur nach der individuellen Nutzenfunktion, sondern auch nach der Höhe der Staatsverschuldung. Je höher die bestehende Verschuldung ist, desto mehr schränkt der Schuldendienst den Budgetspielraum ein, desto größer ist also der Wert der partiellen Ableitung nach $A$. Dies ergibt sich aus der Annahme abnehmenden Grenznutzens in allen Argumenten von (4-32). Bei hoher Staatsverschuldung schränkt eine steigende Risikoprämie den Budgetspielraum umso stärker ein, eine Abwertung ist mit zusätzlichen Kosten verbunden. Wie stark dieser Effekt ist, hängt vor allem von der Reaktion der Finanzmärkte ab.

Wechselkurspolitik und die Reaktion der Finanzmärkte. Nicht nur individuelle Präferenzen der Regierenden und die Höhe der Staatsverschuldung spielen eine Rolle, sondern auch die Reaktion der Finanzmärkte. Fordert das Publikum angesichts einer Abwertung eine erheblich höhere Risikoprämie, ist also der Wert von $d J / d v$ positiv und hoch, verteuert sich der Schuldendienst entsprechend stark. Vor allem in $d J / d v$ tritt mithin die disziplinierende Wirkung der Finanzmärkte zutage. Ist $d J / d v=0$, das heißt reagieren die Finanzmärkte nicht mit einer erhöhten Risikoprämie oder ist die Staatsverschuldung sehr niedrig, entspricht (439) exakt (4-15). Somit ist der oben dargelegte Abwertungswettlauf als Spezialfall in diesem modifizierten Ansatz enthalten.

Da sich mittelfristig mit dem Euroland und den USA zwei Währungsräume mit ähnlich großen, breiten und liquiden Finanzmärkten herausbilden werden, ist davon auszugehen, daß ein solcher Härtungswettbewerb einsetzen könnte. Dies ist eindeutig ein positives Szenario: Die Finanzmärkte disziplineren weiterhin die staatlichen Entscheidungsträger. Ein intensiver Wettbewerb sorgt dafür, daß die Inflationraten niedrig und die Geld-, die Wechselkurs- wie auch die Fiskalpolitik auf möglichst hohe Glaubwürdigkeit ausgerichtet werden. Mittels der Wechselkurspolitik eine Umverteilung der globalen Nachfrage bewerkstelligen zu wollen, wäre mit hohen Kosten verbunden, so daß sie vermutlich nicht zustande käme.

Wechselkurspolitik innerhalb und außerhalb einer Währungsunion. Das Modell dieses Abschnitts läßt sich auch anders interpretieren. Angenommen, 
es repräsentiere nicht das Euroland als ganzes, sondern einen einzigen EU-Mitgliedstaat. In der Ausgangssituation befinde sich das Land außerhalb der Währungsunion, in der zweiten Situation in der Währungsunion. Was ändert sich in Gleichung (4-38)? Zwei Größen: Zum einen steigt $\beta$, also der Anteil der heimischen Güter, die keinem Wechselkursrisiko unterliegen - die Volkswirtschaft wird geschlossener. ${ }^{138}$ Zum anderen sinkt die Wechselkursreagibilität des Staatsbudgets, $d J / d v$, da der EU-Staat nun im größeren Euroland aufgegangen ist, daß gemeinsam über Finanzmärkte verfügt, die mit denen der USA vergleichbar sind.

Das hat gravierende Auswirkungen auf die Haltung der Regierung des betreffenden Landes bezüglich der Wechselkurspolitik: Ein größeres $\beta$ bedeutet, graphisch gesprochen, einen steileren Verlauf der v-Kurve. Um Beschäftigungseffekte zu erzielen, muß die Regierung eine entsprechend drastischere Abwertung des Euro vornehmen. Zugleich nimmt aus Sicht des einzelnen Landes die disziplierende Wirkung der Finanzmärkte $\mathrm{ab}, d J / d v$ sinkt. Somit wird für jedes einzelne Land der Einsatz der Wechselkurspolitik attraktiver, wenn es der Währungsunion beitritt.

Veränderungen für die USA. Repräsentiert obiges Modell hingegen die Situation der USA, so gilt genau das gegenteilige Ergebnis. Mit zunehmender Integration der EWU-Finanzmärkte werden sie ihres Währungsmonopols beraubt. Konnten sie bislang den Außenwert des Dollar vergleichsweise unabhängig von disziplinierenden Einflüssen der Finanzmärkte als wirtschaftspolitisches Instrument nutzen, so dürfte sich dies in der heraufziehenden Duopol-Konstellation ändern: Aufgrund der zunehmenden Diversifizierungsmöglichkeiten im Euroraum nimmt die Disziplinierung durch die Finanzmärkte zu, aus Sicht der US-Administration steigt $d J / d v$.

Verhalten sich die Regierungen entsprechend des obigen Kalküls, so ergibt sich folgende Schlußfolgerung: Die Etablierung des Euro als zweiter Weltwährung fuihrt dazu, daß die USA tendenziell eine dauerhaft striktere Haltung einnehmen, sie bekommen die disziplinierende Wirkung der Märkte stärker zu spüren. Die Euroland-Staaten hingegen befreien sich ein Stückweit aus der Disziplierung. Bis zu welchem Grad diese Effekte auftreten, hängt vor allem davon $a b$, wie das Publikum auf den Finanzmärkten reagieren wird.

\section{5 Auswirkungen auf andere Staaten}

Bislang konzentrierte sich die Argumentation lediglich auf die beiden größten Länder der Welt, das Euroland und die USA. Es liegt jedoch nahe, daß auch Staaten außerhalb des Euro-Dollar-Duopols davon betroffen wären, wenn die beiden Wirtschaftssupermächte eine beschäftigungsorientierte Wechselkurspolitik verfolgen würden. Diese Effekte sollen hier kurz erörtert werden.

138 Siehe Kapitel 3.3 
Destabilisierung. Sollte sich im Euro-Dollar-Duopol die oben beschriebene Rivalität herausbilden, würde dies zunächst ein neues Unsicherheitselement in die Weltwirtschaft hineintragen. Ständig wiederkehrende überraschende Interventionen dürften zu Effizienzverlusten führen, die dramatisch sein können, insbesondere falls es zu einer Destabilisierung des gesamten Finanzsystems käme. Sofern sich, wie oben angenommen, Interventionen nicht sterilisieren lassen, steigt zudem die Weltgeldmenge an - im schlimmsten Fall weitet sich die monetäre Basis sowohl in der EU als auch den USA quasi unkontrolliert aus. Die Folge wäre zwangsläufig ein Anziehen der weltweiten Inflation.

Dabei wären die Kosten für die beiden großen Spieler relativ gering: Sowohl die USA als auch die EU verfügen über große Binnenmärkte, auch über große Binnen-Kapitalmärkte. Sie sind daher, wie in Kapitel 3 dargelegt, relativ unabhängig von erratischen Wechselkursbewegungen. Hingegen sind kleine Volkswirtschaften erfahrungsgemäß von Währungsturbulenzen am stärksten betroffen: Es kommt zu einer möglicherweise raschen Kapitalflucht, Abwertungen schlagen stark und direkt auf die reale Wirtschaft durch. Auch die Folgen einer oben beschriebenen handelspolitischen Eskalation des Konflikts wären tendenziell für andere Länder ebenfalls groß, möglicherweise sogar relativ größer als für die Verusacherländer EU und USA.

Länder mit gepeggten Währungen. Viele Entwicklungs- und Transformationsländer, die nur über geringe geldpolitische Glaubwürdigkeit verfügen, versuchen ihrem geldpolitischen Regime durch die Bindung an einen monetären Anker zu verleihen. ${ }^{139}$ Allerdings taugt eine Währung nur zur Ankerwährung, solange sie selbst stabil ist. Ein Abwertungswettlauf zwischen den USA und Euroland würde daher die Rolle des Dollar und/oder des Euro als internationaler Ankerwährung mindern - die Kosten der Wechselkurspolitik fielen nicht nur in den USA oder in der EU an.

In eine schwierige Lage können insbesondere Länder kommen, bei denen ein Mimatch zwischen Außenhandel und Auslandsverschuldung besteht. Wie unter 3. 1.5 dargelegt, gibt es einen verbreiteten Mismatch in der Bedeutung der EU als Partner für Handel einerseits und für die langfristige Kreditaufnahme andererseits. Kommt es zu einer Abwertung des Euro gegenüber dem Dollar, geraten die währungspolitischen Instanzen in diesen Ländern in eine schwierige Situation: Halten sie die Parität zum Euro, werden Dollar denominierte Güter teurer, wovon ein inflationärer Impuls ausgeht. Da das Publikum an den Finanzmärkten dies antizipiert, dürften unmittelbar die Zinsen steigen. Dies wiederum wiegt umso schwerer, je größer der Anteil der Verschuldung ist, die in Nicht-EU-Währungen denominiert sind. Sofern die Euro-Bindung unverändert bleibt, dürften sich jedoch andererseits die Bedingungen für Exporteure verbessern, da sie vom nun teureren Dollar profitieren. Alternativ haben die nationalen Regierungen die

139 Siehe Abschnitt 3. 1. 5. 
Möglichkeit, die jeweils heimische Währung gegenüber dem Euro aufzuwerten was ebenfalls negative realwirtschaftliche Auswirkungen zeitigen würde.

Allerdings wird den Regierungen der meisten Entwicklungsländer kaum etwas anderes übrigbleiben, als an ihrem jeweiligen Währungsanker festzuhalten. Die mit dem Verlust an Glaubwürdigkeit verbundenen Kosten für Währungsstabilisierung, Disinflation und Kreditsicherung dürften den möglichen kurzfristigen Nutzen einer Änderung der Parität weit übersteigen.

Realiter dürfte sich die Frage nach einer Aufwertung für die Länder an der Peripherie der Eurozone bzw. der Dollarzone gar nicht stellen. Denn es ist zu erwarten, daß gerade sie von Kapitalfluchttendenzen betroffen wären, wenn politikinduzierte Währungsturbulenzen zwischen den USA und der EU Unruhe ins internationale Währungssystem bringen sollten. In solchen Zeiten flüchten sich Anleger gern in sichere Häfen.

Kleinere „Safe-haven”-Währungen. Sollte es zu einem ausgeprägten Dollar-Euro-Abwertungswettlauf kommen, könnten davon beliebte Safe havenWährungen profitieren. Sofern sie einen stabilitätspolitisch einwandfreien „Track record" vorweisen können, dürften sie Anleger anziehen. Dies gilt in Europa für den Schweizer Franken, der allerdings nicht die erforderliche Liquidität und Produktbreite bietet, um mit den Großwährungen konkurrieren zu können. Japan hingegen könnte auf mittlere Sicht von einer Verunsicherung des Publikums auf den internationalen Finanzmärkten sogar profitieren. Bislang spielt der Yen international kaum eine Rolle. Im Falle eines Abwertungswettlaufs könnte er daher $\mathrm{Zu}$ fluchtsort für Anlegergelder sein. ${ }^{140}$

Die Auswirkungen auf die Safe-haven-Volkswirtschaften sind zweischneidig: Einerseits sorgt der Zustrom an Kapital für günstige Finanzierungsbedingungen, insbesondere niedrige Zinsen. Andererseits leiden solche Volkswirtschaften unter einer aus rein güterwirtschaftlicher Sicht überbewerteten Währung, was der Exportwirtschaft Schaden zufügt.

Externe Effekte. Die bisherigen Überlegungen machen deutlich: Eine strategische Wechselkurspolitik seitens der EU und der USA hätte erhebliche externe Effekte für die Weltwirtschaft. Dies sind insbesondere eine erhöhte Volatilität der Wechselkurse, Preise und Zinsen, eine erhöhte Risikoprämie, ergo höhere Realzinsen. Die meisten kleineren Volkswirtschaften, insbesondere die Emerging Markets, würden vermutlich nachhaltig negativ getroffen und hinter ihrem Wachstumspotential zurückbleiben. Nur die kleine Gruppe von Safe-haven-Ländern könnte möglicherweise von Kapitalzuflüssen profitieren.

140 Auf sehr lange Sicht ist es sogar denkbar, daß ein ausgeprägter Dollar-Euro-Antagonismus neue internationale Währungen zu wichtigen Anlagewährungen befördert, zum Beispiel den chinesischen Renminbi. Ein solcher Effekt ist allerdings nur in einem absoluten „Worst-case"Szenario denkbar. 
Die Großen Zwei, EU und USA, könnten allerdings, wie oben skizziert, alternativ auch eine stabilisierende Wechselkurspolitik betreiben, die wiederum positive externe Effekte zeitigen würde. Wenn zwei Großwährungen in ,geordneten Verhältnissen" zueinander stehen, würden gerade kleinere und schwächere Länder davon profitieren. Gerade sie könnten die Benefits in Form einer geringeren Volatilität der Wechselkurse, Preise und Zinsen verbuchen, insbesondere indem sie höhere Wachstumsraten realisieren. EU und USA würden im Idealfall eine - wie auch immer verfaßte - internationale Währungsordnung als ein internationales öffentliches Gut bereitstellen. Wie eine solche internationale Währungsordnung aussehen im Eurozeitalter aussehen kann, wird Kapitel 5 untersuchen. 


\section{Internationale währungspolitische Kooperation in Zeiten des Dollar-Euro-Duopols}

Die vorangehenden Kapitel haben gezeigt, daß die Schaffung der gemeinsamen europäischen Währung für das internationale Währungssystem eine Zäsur bedeutet. Mit der Eurozone entsteht ein zweiter Währungsraum, der dem der USA in vielerlei Hinsicht ähnlich ist: In Bezug auf die Wirtschaftskraft, die Bedeutung des Außenhandels oder den Entwicklungsstand der Kapitalmärkte betritt eine neue - wenn auch noch mit schwachen gemeinsamen Institutionen ausgestattete Kraft die internationale Bühne, die über ein ähnliches Potential verfügt wie die ökonomische Supermacht USA. Zwar haben die Vereinigten Staaten bereits in den vergangenen Jahrzehnten ihre Rolle als Hegemon verloren, die sie in den Jahren nach dem Zweiten Weltkrieg in die Lage versetzte, die internationale Wirtschafts- und Währungsordnung (GATT, Bretton-Woods-System) als eine Art internationales öffentliches Gut bereitzustellen [Gilpin 1987: 72ff]. Dennoch blieben sie die einflußreichste Macht mit dem US-Dollar als mit Abstand wichtigster Währung weltweit.

Auch nach dem endgültigen Zusammenbruch des Wechselkurssystems von Bretton Woods 1973 herrschte Asymmetrie in den internationalen wirtschaftspolitischen Beziehungen: Den USA standen deutlich kleinere Wirtschaftsmächte gegenüber, zuvörderst Japan und die Bundesrepublik Deutschland, aber auch Frankreich, Großbritannien, Kanada und Italien, die zusammen die G 7Gruppe bilden. Diese Asymmetrie eröffnete den USA erhebliche wirtschaftspolitische Spielräume - sie konnten ihre Wirtschaftspolitik nahezu allein an heimischen wirtschaftspolitischen Zielen ausrichten, ohne Rücksicht auf die externen Auswirkungen ihrer Politik nehmen zu müssen („Benign neglect”). Die übrigen Regierungen hatten kaum eine andere Wahl, als sich an den Vorgaben aus den USA zu orientieren.

Traditionell haben die US-Adiminstrationen den Außenwert ihrer Währung weitgehend ignoriert. Ausnahmen bildeten lediglich Phasen massiver Ungleichgewichte wie 1985 (ein sich ausweitendes Leistungsbilanzdefizit sorgte für protektionistische Vorstöße der bedrohten Branchen) oder 1987 (der rasche Fall des Dollar gefährdete in den USA die Geldwertstabilität), in denen die US-Regierung eine ad hoc-Koordinierung mit den übrigen Industrieländern suchte.

Hingegen konnten die übrigen Staaten nicht derart autonom verfahren, da in den kleineren, offeneren Volkswirtschaften der Außenwert der Währungen stets von ungleich größerer Bedeutung war. Thre Handlungsmöglichkeiten waren durch die Vorgaben aus den USA und die Disziplinierung seitens der Märkte begrenzt. Die Europäische Währungsunion faßt nun zunächst drei der G 7-Staaten Deutschland, Frankreich, Italien - mit ihren kleineren Nachbarländern zusammen, 
erweitert sie möglicherweise schon in wenigen Jahren um die restlichen EUStaaten inklusive Großbritannien. In der internationalen Wirtschaftspolitik führt dies zu einer Machtverschiebung: Die Europäer werden allmählich den Amerikanern ebenbürtig, wenigstens auf längere Sicht gesehen und falls sie die gemeinsamen EU-Institutionen weiter stärken, während die Japaner an Einfluß verlieren dürften. Durch die Vergemeinschaftung der Währungspolitik gewinnen die Europäer an Drohpotential hinzu, sie sind nicht mehr gezwungen, sich US-Entscheidungen zu beugen, sondern haben mehr Möglichkeiten, die Politik anderer Nationen zu beeinflussen.

Diese neue Konstellation birgt Konflikte, aber auch die Chance auf eine verbesserte Kooperation. Amerikaner und Europäer können sich in eine Dilemmasituation hineinmanövrieren, wie sie in Abschnitt 4. 2.2 analysiert wurde. Sie können aber zusammenwirken, um gemeinsam monetäre Stabilität als internationales Kollektivgut bereitzustellen (Abschnitt 4. 2. 3). Welches Ergebnis sich in Zukunft tatsächlich einstellen wird, hängt entscheidend vom institutionellen Rahmen ab, in dem sich die handelnden Individuen der beteiligten Administrationen bewegen.

Vorschläge für eine Neuordnung des internationalen Währungssystems, die in die Diskussion geworfen werden, orientieren sich häufig an historischen Wechselkurssystemen oder an früheren Reformvorstößen. Dieses Kapitel klopft diese möglichen Vorbilder auf ihre Tauglichkeit für die Euro-Ära hin ab. Schließlich wird ein eigener Reformvorschlag vorgestellt, die Ergebnisse der Analyse aus Kapitel 4 aufgreift.

\section{1 Regimewechsel im historischen Überblick}

Der institutionelle Rahmen der internationalen Währungsordung hat sich in den Vergangenheit mehrfach geändert. Bevor die Mechanismen ausgewählter Systeme unter 5. 2 detaillierter untersucht werden, erscheint es sinnvoll, sich zunächst den Motor dieses Wandels etwas genauer anzusehen, da sich hieraus wertvolle Einsichten über die zukünftige Entwicklung ableiten lassen.

\section{1. 1 Einige Charakteristika der Regimewechsel}

In der Geschichte des 19. und 20. Jahrhunderts treten zwei Grundformen der internationalen Währungsordnung auf, die sich im Zeitablauf abwechseln: einerseits engen Regeln unterworfene Systeme mit festen Wechselkursen und weitgehender Konvergenz der nationalen makroökonomischen Politiken, andererseits Systeme mit flexiblen, marktbestimmten Wechselkursen, einem hohen Maß 
an nationaler Autonomie bei der Formulierung des Policy Mix und einem geringen $\mathrm{Ma} ß$ an internationaler wirtschaftspolitischer Koordinierung. ${ }^{141}$

Auf den Goldstandard (etwa 1870 bis 1914), ${ }^{142}$ der einen weitgehenden Verzicht der nationalen Behörden auf die Instrumente der Geld- und Wechselkurspolitik implizierte, folgte in den Kriegs- und Zwischenkriegszeiten ein System der „Economic anarchy” (Gilpin), nachdem es nicht möglich gewesen war, den Goldstandard wieder dauerhaft zu installieren. Das System freier Wechselkurse fuihrte letztlich zu einem Abwertungswettlauf. Mangelnde Kooperationsbereitschaft sowie fehlende institutionelle Vorkehrungen trugen zur Eskalation des Wirtschaftskriegs der dreißiger Jahre bei, der die liberale internationale Wirtschaftsordnung nationalstaatlichen Egoismen und Autarkiebestrebungen unterwarf [Kindleberger 1986].

Gegen Ende des Zweiten Weltkrieges etablierten insbesondere die Siegermächte USA und Großbritannien das Bretton-Woods-System (1944-1971) eines Gold-Dollar-Standards, mit dem Ziel, eine Wiederholung des Wirtschaftskriegs der dreißiger Jahre zu verhindern und eine neue internationale ökonomische Ordnung der offenen (Güter)-Märkte zu schaffen. ${ }^{143}$ Dieses System funktionierte über Jahrzehnte erfolgreich und weitgehend spannungsfrei. Es brach schließlich auseinander, letztlich weil die US-Administrationen der sechziger Jahre ihrer Verpflichtung zu geld- und fiskalpolitischer Disziplin nicht nachgekommen waren („Problem des n-ten Landes”). 1971 kündigte die Nixon-Administration die Golddeckung für den Dollar auf, 1973 gingen die wichtigsten Industrieländer endgültig zu floatenden Wechselkursen über. ${ }^{144}$

Die seither marktbestimmten nominalen Wechselkurse haben sich jedoch als weit volatiler erwiesen, als es viele Ökonomen vorhergesagt hatten. Auch gibt es keine dauerhafte internationale Koordinierung der Makropolitiken. Sofern Konflikte

141 Für eine detailliertere Analyse der Geschichte internationaler Währungsordnungen vgl. Gilpin (1987: 118), für einen detaillierten Rückblick auf das Bretton-Woods-System und das folgende System des floatender Kurse vgl. van der Wee (1984: 476ff).

142 Großbritannien praktizierte den Goldstandard bereits seit 1717. Im Laufe des 19. Jahrhunderts schlossen sich nach und nach die wichtigsten Industrieländer dem System an, 1871 auch, nach der Reichsgründung in Versailles, das Deutsche Reich. Damit waren alle ökonomisch wichtigen Staaten vertreten. Die hier und im folgenden stets genannte Periode 1870 1914 kann gewissermaßen als „Blütezeit des klassischen Goldstandards” angesehen werden [Willms 1992: 143ff].

143 Die Briten, wie auch die meisten kontinentaleuropäischen Regierungen, präferierten zunächst eine binnenwirtschaftlich-dirigistisch ausgerichtete Wirtschaftspolitik, deren Hauptziel es war, den Wohlfahrtstaat aufzubauen. Die USA hingegen wollten ein offenes, liberales Handelssystem. Angesichts ihrer ökonomischen Übermacht - insbesondere als größte Gläubigernation - setzten die USA ihre Vorstellungen schließlich durch [van der Wee 1984: 496f].

144 Siehe detailliert unter 5. 2. 1 unten. 
über den wirtschaftspolitischen Kurs auftreten, versuchen die Regierungen und Notenbanken der wichtigsten Industrieländer (G 7, G 10) sie auf dem Wege der ad hoc-Kooperation zu lösen. Immer wieder tauchen Forderungen nach einer fundamentalen Neuordnung des internationalen Finanzsystems auf, insbesondere seitens sozialistischer bzw. sozialdemokratischer Regierungen in Europa. Die Kritik entzündet sich vornehmlich an Währungskrisen (Mexiko-Krise 1994/95, Emerging Markets-Krise 1997ff), die ausgelöst würden von einer „exessiven Spekulation".

\section{Abbildung 5-1: Hegemonie, Dogma und internationale Währungssysteme seit Koordinierungs- grad 1870}

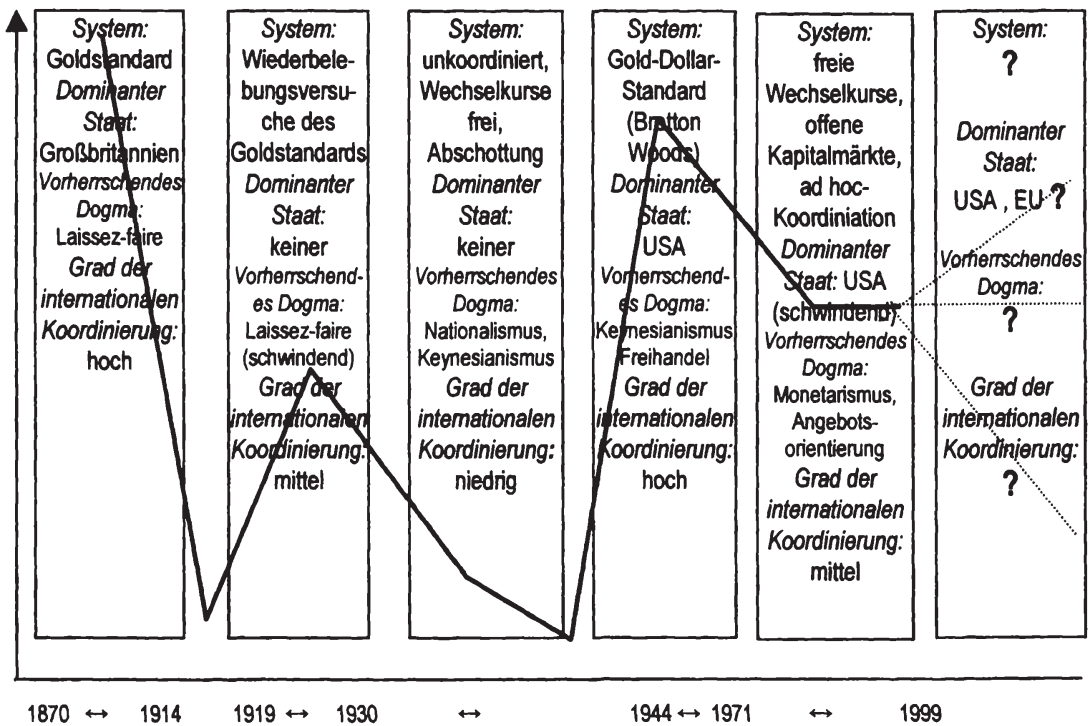

Quelle: Eigene Darstellung. Erläuterungen im Text

Die Europäer ihrerseits haben versucht, mittels einer fortschreitenden währungspolitischen Integration („Schlange”, EWS, Währungsunion) die Wechselkurse in Europa zu stabilisieren, um im Handel untereinander möglichst stabile Wechselkursverhältnisse zu gewährleisten.

In der Geschichte der vergangenen 130 Jahre läßt sich also ein Pendelschlag erkennen (Abbildung 5-1): Festgefuigte Wechselkurssysteme weichen flexiblen Arrangements. Degenerieren diese zu einer wirtschaftspolitischen Anarchie, entschließen sich die Regierungen, sich abermals der Disziplin eines Wechselkurssystems zu unterwerfen. Aus diesem anscheinenden Politikzyklus eine 
Gesetzmäßigkeit herauslesen zu wollen könnte allerdings irreführend sein. Dazu ist der Beobachtungszeitraum zu kurz. Dennoch ist die zunehmende Unzufriedenheit mit dem derzeitigen System flexibler Wechselkurse bei offenen, weitgehend unregulierten Kapitalmärkten deutlich vernehmbar, die sogar profilierte Ökonomen wie Paul Krugman einschließt. ${ }^{145}$ Somit stellen sich die Fragen, a) ob das Pendel abermals zurückschlägt und sich die ökonomischen Großmächte entschließen, ein neues internationales Wechselkurssystem zu installieren und b) wie ein solches System ggf. ausgestaltet sein sollte.

\section{1. 2 Hegemonie, ökonomische Dogmen und Regimebildung}

Eine Anforderung an ein solches System fällt unmittelbar ins Auge: In der derzeitigen historischen Phase gibt es keine singuläre Hegemonialmacht. Der Goldstandard, das Bretton-Woods-System wie auch das EWS waren keine Systeme freiwilliger, wechselseitiger Kooperation. Vielmehr gruppierten sich stets kleinere Länder mit ihren Währungen um eine Leitökonomie, deren Währung den Standard setzte. Hegemonie beschreibt eine asymmetrische Form der Kooperation. Im Goldstandard fungierten Großbritannien und das Pfund Sterling als Fixpunkt, beim Bretton-Woods-System übernahmen die USA und der Dollar diese Rolle, im EWS die Bundesrepublik und die D-Mark. Die jeweilige Leitökonomie war zugleich die (ökonomische) Hegemonialmacht, ihr fiel die natürliche Führungsrolle zu. Das System diente ihren Interessen zuvörderst, sie hatte daher nicht nur die Macht, sondern auch ein fundamentales Interesse, die Einhaltung der Regeln durchzusetzen. Die Hegemonialmacht stellte damit ein internationales (im Falle des EWS ein regionales) öffentliches Gut bereit. ${ }^{146} \mathrm{Da}$ es derzeit keine einzelne überragende ökonomische Macht auf globaler Ebene gibt, müssen internationale Regime in ihrer Struktur multilateral sein und sich auf starke internationale Institutionen stützen [Keohane 1989].

Für das Entstehen und die Stabilität von Regimen sind neben ökonomischen Strukturen auch die gesellschaftlichen Präferenzordnungen der wichtigsten beteiligten Länder und die jeweils vorherrschenden ökonomischen Dogmen relevant

145 Krugman (1998) plädiert für Kapitalverkehrsbeschränkungen. Er sieht in der derzeitigen Situation ein Dilemma der Entwicklungsländer: Sie würden schon bei geringen Verfehlungen ihrer Geld- und Finanzpolitik allzu hart von den Finanzmärkten durch Kapitalflucht bestraft. In der Folge müßten sie ihre Leitzinsen dramatisch anheben und die Staatsausgaben senken, beides verschärfe die Wirtschaftskrise noch, statt sie zu lindern. Die ökonomischen Ratgeber, auch die des IWF, müßten angesichts der Macht der Kapitalmärkte den jahrzehntelang geltenden „Keynesian compact” aufgeben. Die einzige Hoffnung für die betroffenen Länder bestehe darin, das Vertrauen der Investoren wiederzuerlangen. Die Regierungen der Entwicklungsländer seien den Regeln des „Confidence game” ausgeliefert.

146 Dies ist eine in der Theorie der internationalen Wirtschaftsbeziehungen häufig vertretene Sicht der Dinge. Für einen Überblick über die akademische Diskussion zur „Theory of hegemonic stability" vgl. Gilpin (1987: 72ff). 
[Polak 1988, James 1997: 237ff]. Herrscht eine weitgehende Übereinstimmung unter den beteiligten Regierungen, so ist es deutlich leichter, sich auf ein tragfähiges System zu einigen. Bestehen hingegen fundamental unterschiedliche Auffassungen über ökonomische Zusammenhänge, so ist es weit schwieriger, Regierungen souveräner Staaten zu einer Übereinkunft zu bewegen. Anders ausgedrückt: Sofern keine Einigkeit über das „wahre Modell” [Muth 1961] herrscht, erhöhen sich die Transaktionskosten drastisch, möglicherweise soweit, daß sie Kooperation per se verhindern.

In den Jahrzehnten seit dem Ende des Zweiten Krieges läßt sich ein deutlicher Wandel der Präferenzen und der allgemein als „wahr” akzeptierten Modelle erkennen, der wiederum Rückwirkungen auf die Kooperationsbereitschaft zeitigten. ${ }^{147}$ Freilich bietet auch Einigkeit über das „wahre Modell” keine Gewähr für eine weitgehende Kooperation. Denn auch bei ähnlicher Analyse können die wirtschaftspolitischen Ziele und Interessen unter den Regierungen erheblich divergieren.

\section{1. 3 Drei Phasen seit dem Ende des Zweiten Weltkriegs}

Der Keynesianische Konsens - von den fünfziger zu den siebziger Jahren. Von den fünfziger Jahren bis in die späten siebziger Jahren herrschte in den meisten Industrienationen weitgehende Übereinstimmung in der grundlegenden Ausrichtung der Wirtschaftspolitik. In wesentlichen Fragen der wirtschaftspolitischen Agenda bestand Einigkeit - es war die Zeit des keynesianischen Konsens, des Primats der Makropolitik, die durch die Feinsteuerung der gesamtwirschaftlichen Nachfrage für eine stetige Auslastung der Ressourcen und einen durchgängig hohen Beschäftigungsstand sorgen sollte. ${ }^{148}$ Oberstes Ziel war die Beseitigung der Arbeitslosigkeit, der Geldwertstabilität maßen die Regierungen geringe Bedeutung bei, wohl auch deshalb, weil die Inflationsraten während der fünfziger und sechziger Jahre relativ niedrig waren.

Diese herrschende Lehre stieß an ihre Grenzen, als Ende der sechziger, Anfang der siebziger Jahre von der stark expansiven Politik der US-Regierung inflationärer Druck ausging und sich zudem die Ölpreise im Zuge der Ölkrise von 1973 vervierfachten. Dazu kamen heftige Verteilungskämpfe innerhalb des Tarifkartells in den Industrieländern, wodurch die Lohn-Preis-Spirale an Geschwindigkeit zulegte. Folglich stand die Inflationsbekämpfung wieder auf der Tagesordnung, die Geldpolitik bekam erneut eine stärkere eigenständige Rolle zugewiesen. Dies umso mehr, als 1979 die OPEC-Regierungen die Ölpreise noch einmal verdoppelten.

147 Der folgende Teil dieses Abschnitt orientiert sich zu einem großen Teil an Polak (1988).

148 In Deutschland setzte sich dieser Keynesianische Konsens erst mit der Großen Koalition ab 1966 durch, die das Stabilitätsgesetz (,magisches Viereck") schuf. Bis dahin lag in der Bundesrepublik der Schwerpunkt auf der Ordnungspolitik [Polak 1988: 4]. 
Das damals vorherrschende Dogma der interventionistischen Wirtschaftspolitik bezog die internationale Kooperation mit ein. Kooperation konzentrierte sich auf die Fixierung der nominalen Wechselkurse im Bretton-Woods-System. Da die Inflation weder im herrschenden Theoriegebäude einen prominenten Platz einnahm noch ein akutes Problem darstellte, sahen die Regierungen in der Fixierung der Wechselkurse keinen Grund für gravierende Zielkonflikte zwischen Beschäftigungs- und Stabilitätspolitik, selbst wenn die Anpassung der Kurse äußerst träge vonstatten ging.

Zugleich bestand Einigkeit darüber, weitgehend auf den Wechselkurs als wirtschaftspolitisches Instrument zu verzichten. Dies insbesondere deshalb, weil sich so die Geldpolitik gewissermaßen automatisch in den Dienst der Konjunktursteuerung einbinden ließ: Ein kreditfinanzierter expansiver fiskalpolitischer Stimulus fuihrt (im Modellrahmen des keynesianischen Mundell-Flemming-Modells) zu Kapitalimport, wodurch eine Tendenz zur Aufwertung besteht, der die Zentralbank im Fixkurssystem mit dem Ankauf von Devisen entgegenzuwirken verpflichtet ist. Sofern es nicht gelingt, diese Interventionen zu sterilisieren, kommt es zu einer Ausweitung der monetären Basis - ein sekundärer geldpolitischer Impuls unterstützt den primären fiskalpolitischen. Das System fester Wechselkurse verhindert somit, daß die Geldpolitik der Notenbank die Fiskalpolitik der Regierung konterkariert.

Nach dieser Kausalität mindert hingegen ein System flexibler Wechselkurse die Wirksamkeit der Fiskalpolitik. Der Kapitalimport infolge eines expansiven fiskalpolitischen Stimulus führt zu einer Aufwertung der Währung, die zu einer Verschlechterung des Außenbeitrags und somit zu einem kontraktiven Sekundäreffekt führt. Zwar läßt sich dieses „Wechselkurs-Crowding-out” durch eine gleichzeitige Ausweitung der Geldmenge verhindern. Dies geschieht jedoch nicht automatisch, wie im System fester Wechselkurse. Ja, eine unabhängige Notenbank kann sogar den expansiven Primäreffekt der Fiskalpolitik durch eine kontraktive Geldpolitik vollkommen kompensieren (was überdies den Schuldendienst des Staates verteuert und den Budgetspielraum einschränkt). Aus keynesianischer Sicht birgt ein System flexibler Wechselkurse daher ein nationales Koordinierungsproblem zwischen Geld- und Fiskalpolitik.

Mit der Rückkehr der Inflation Anfang der siebziger Jahre brach das Bretton-Woods-System auseinander. Doch auch in den Jahren danach herrschte unter den Regierungen der großen Industrieländer ein prinzipieller Konsens darüber, daß eine enge Abstimmung der Wirtschaftspolitik wünschenswert sei. Diese Grundhaltung fand insbesondere in den Weltwirtschaftsgipfeln ihren Ausdruck. 1975 trafen sich die Regierungschefs der sieben wichtigsten westlichen Länder zum ersten G 7-Gipfel in Rambouillet bei Paris. Die damaligen Staats- und Regierungschefs, voran der deutsche Kanzler Helmut Schmidt und der französische Präsident Valérie Giscard d'Estaing, trieben allerdings nicht nur ökonomische Fragen um, sondern vor allem die politische Stabilität des Westens, die sie damals 
von Linksterrorismus und sowjetischem Expansionsdrang gefährdet sahen. Insofern war aus ihrer Sicht die Schaffung wirtschaftlicher Stabilität ein Instrument zur Sicherung politischer Stabilität [James 1997: 7ff]. Dazu wollten sie ein global koordiniertes Nachfragemanagement installieren. In der Praxis gelang es allerdings häufig nicht, sich auf konkrete Programmpakete zu einigen. ${ }^{149}$ Dennoch kam es in den siebziger Jahren zu relativ häufigen Interventionen am Devisenmarkt.

Angebotspolitik und Inflationsbekämpfung - die achtziger Jahre. Gegen die keynesianische Lehre vom „Fine tuning” erhob sich seit Ende der sechziger Jahre eine machtvolle akademische Opposition. Der Monetarismus und die folgende „Rational expectations revolution” stellten der damals herrschenden Ansicht, daß Marktversagen ein weitverbreitetes Phänomen und die Marktwirtschaft insgesamt ein krisenanfälliges System sei, die These von der inhärenten Stabilität der privatwirtschaftlichen Sphäre gegenüber. Aus dieser Sicht sind es der Staat und das Politikversagen interventionistisch gesinnter Politiker, welche die Stabilität der Märkte beschädigen. Anders als die keynesianische Vorliebe für diskretionäre Intervention setzt der Monetarismus auf Regelbindung. Dies gilt auch für die Koordinierung internationaler Politik, die, wenn überhaupt, vorgegebenen und für die Marktteilnehmer transparenten Regeln unterworfen sein sollte. ${ }^{150}$

Die beiden Ölschocks, die Verteilungskämpfe und die folgende Stagflation der siebziger Jahre brachten unter den Wirtschaftspolitikern und keynesianisch geprägten Ökonomen Ernüchterung bezüglich der Möglichkeiten der makroökonomischen Feinsteuerung. Statt dessen rückte die Geldwertstabilität als Politikziel auf der Prioritätenliste nach oben. Ausdruck dieses Wandels waren Wahlsiege konservativer Regierungen in Großbritannien (Margret Thatcher), den USA (Ronald Reagan), Deutschland (Helmut Kohl) und Frankreich (bürgerliche Regierung unter dem sozialistischen Präsidenten François Mitterant). Sie setzten - wenn auch mit unterschiedlicher Konsequenz - auf angebotsorientierte Strategien, auf Reformen der Einkommen- und Körperschaftsteuern, auf Liberalisierung der Arbeitsmärkte, auf Öffnung der Kapitalmärkte. Eine weitere Öffnung der Gütermärkte rückte ins Zentrum der internationalen wirtschaftspolitischen Agenda, als 1986 die Uruguay-Runde des GATT begann, die auch bis dahin ausgeklammerte Bereiche wie den Handel mit Agrarprodukten und Dienstleistungen sowie die weltweite Wahrung von geistigem Eigentum verhandelte.

Ansonsten sah vor allem die erste Reagan-Administration keinen Anlaß für internationale wirtschaftspolitische Kooperation. Statt dessen verfolgte sie neben der Angebotsorientierung, die sich insbesondere in Steuersenkungen niederschlug,

149 Für eine sehr griffige Analyse der Geschichte der Weltwirtschaftsgipfel vgl. Wagner (1995a: $80 \mathrm{ff})$.

150 So formuliert etwa der Vorschlag Ronald McKinnons (1984) ein komplexes regelgebundenes System einer globalen Geldmengensteuerung (siehe unten). 
eine Strategie der hohen Staatsausgaben, vor allem durch einen rasch wachsenden Rüstungsetat. Dieser Policy Mix („Reagonomics”) führte zu einem Rekorddefizit im US-Staatshaushalt (ca. fünf Prozent des BIP). Die Kapitalnachfrage trieb die Zinsen in die Höhe und führte zu einer dramatischen Aufwertung des Dollar und schließlich zu einer spekulativen Blase, die 1985 platzte. Das Leistungsbilanzdefizit der USA verschlechterte sich, und das bis dato größte Gläubigerland wurde zum größten Kreditnehmer.

Dieser Kurs der USA brachte das Thema Politikkoordinierung zurück auf die Agenda: Zum einen wurden protektionistische Widerstände in den USA als Reaktion auf die verschlechterten Wettbewerbsbedingungen der dortigen Industrie laut, die das freie Welthandelssystem insgesamt bedrohten. Zum anderen zeitigten die Reagonomics erhebliche externe Effekte für den Rest der Welt: Die Mischung aus hohen Zinsen und teurem Dollar führte zu einer Verzerrung der Wirtschaftsstrukturen (Aufblähen des Exportsektors bei gleichzeitigem zinsbedingten Crowding out). Die Schuldenkrise in den Ländern der Dritten Welt, eine Folge steigender Zinsen und gleichzeitig fallender Rohstoffpreise in der induzierten Rezession, bedrohte auch westliche Banken in ihrer Existenz.

Die erste Folge dieser Wiederentdeckung der Koordinierung war das „Plaza-Abkommen” von 1985, bei dem die Regierungen und Notenbanken der fünf größten Industrieländer beschlossen, gemeinsam gegen den Dollar zu intervenieren. Als der Dollar in den folgenden anderthalb Jahren rapide fiel, stiegen in den USA die Inflationsgefahren, während sich in den übrigen Ländern die Exportbedingungen verschlechterten. 1987 vereinbarten die Regierungen mit dem „Louvre-Akkord” wiederum zu intervenieren, diesmal mit dem Ziel, den Fall des Dollar stoppen. Die politikinduzierte Dollar-Achterbahn - zwischen 1981 und 1985 stieg der Dollar von 1,80 Mark auf 3,40 Mark, um dann bis 1987 wieder auf 1,80 Mark zu fallen - brachte das Thema Politikkoordinierung wieder auf die Tagesordnung [Dominguez/Frankel 1993: 7ff].

Der angebotsorientierte, monetaristische Politikentwurf fand auch in den Ländern der Europäischen Gemeinschaft Anhänger, deren Politiken allmählich konvergierten. Dies gilt vor allem für die „Kernländer”, die eine Strategie der Disinflation bei gleichzeitiger Öffnung der Kapitalmärkte verfolgten. Typisch für diesen Paradigmenwechsel war insbesondere die französische Linie des „Franc fort". Die Konvergenz der Makropolitiken rund um das Leitwährungsland Bundesrepublik führte zu einem engeren Zusammenwirken im EWS. Da sich die Inflationsraten auf niedrigem Niveau anglichen, wurden Wechselkursanpassungen zum Ausgleich unterschiedlicher Inflationsraten („Crawling peg”) seltener, ab 1987 verzichten eben jene Kernländer untereinander vollends auf den Wechselkurs als währungspolitischem Instrument.

Haushaltskonsolidierung und Emerging-Markets-Krisen - die neunziger Jahre. Konsequenter noch als in den achtziger Jahren dominierte in den neunziger Jahren das angebotsorientierte, monetaristische Paradigma die Wirt- 
schaftspolitik. Ein Policy Mix aus niedrigen Inflationsraten nahe absoluter Geldwertstabilität und rückläufigen Budgetdefiziten kennzeichnete nicht nur die hochentwickelten Volkswirtschaften, sondern fand auch in asiatischen und lateinamerikanischen Entwicklungsländern immer mehr Gefolgsleute. In den USA strichen die Regierung Bill Clintons und der konservativ dominierte Kongreß Ausgabenprogramme zusammen mit dem Ziel, den Staatshaushalte auszugleichen. In den Ländern der EU ermöglichte der monetaristische Konsens - und der Druck der Regierung des Leitwährungslandes Bundesrepublik - 1992 das Maastricht-Programm zu beschließen, das geld- und fiskalpolitische Disziplin als Eintrittsbedingungen für die Währungsunion vorschrieb. ${ }^{151}$

Zugleich gewann die Politik der Liberalisierung und Marktöffnung an Fahrt. 1994 wurde die Uruguay-Rundes des GATT abgeschlossen. Innerhalb der Europäischen Union bewirkte das ehrgeizige Binnenmarktprogramm eine Welle der Privatisierungen und den Fall nationaler Regulierungen. Nachdem bereits 1990 die Kapitalmärkte völlig geöffnet worden waren, waren nun vor allem bisherige nationale Monopole an der Reihe - insbesondere Telekommunikation, Strom, Bahn, Post. Daß Privatisierungen den Wirtschafts- und Finanzpolitikern zunehmend interessant erschienen, hängt freilich nicht nur mit der Einsicht in die Effizienz des privatwirtschaftlichen Wettbewerbs zusammen, sondern auch mit dem Konsolidierungsdruck auf die Finanzminister, der vom Maastricht-Programm ausging.

Während die EU-Staaten 1994 untereinander zu einer sehr weitgehenden Form der Politikkoordinierung inklusive supranationaler Überwachungsmechanismen übergingen („Stufe 2 der Wirtschafts- und Währungsunion” [z. B. Müller 1997a: 78ff]), setzte sich auf internationaler Ebene die fallweise Koordinierung qua ad hoc-Maßnahmen fort. Anlaß dafür waren vor allem die Finanzmarktturbulenzen: die Mexiko-Krise 1994/95 und die weit dramatischere Emerging MarketsKrise mit dem Ausgangspunkt Thailand in den Jahren 1997ff [IWF 1998a: 23ff, 1998b: 33ff, 1998c: 23ff, BIZ 1998a: 33ff]. In beiden Fällen kam es zu Vertrauenskrisen in Entwicklungsländern, die große weltweite Portfolioumschichtungen zur Folge hatten. Auf die Währungen der Industrieländer hatte vor allem die Mexiko-Krise Auswirkungen, die auch zu einer Vertrauenskrise des Dollar führte die USA sind über die nordamerikanische Freihandelszone NAFTA eng mit Mexiko verbunden -, so daß die US-Devise gegenüber anderen wichtigen Währungen wie Mark und Yen an Wert verlor. Handelsgewichtet kam es vor allem beim Yen, aber auch bei der Mark zu starken realen Aufwertungen (Abbildung 5-2). Aber-

151 Siehe Abschnitt 2. 1. Eine vorübergehendes Abweichen von der europäischen Politikkoordinierung stellt die deutsche Einheit dar. Die starke öffentliche Kreditaufnahme gefolgt von einer kontraktiven Geldpolitik der Bundesbank induzierten Zinssteigerungen, die wiederum zu erheblichen Schwierigkeiten im EWS führten. 
mals intervenierten die Notenbanken dieser G 3-Länder, um den Dollar zu stützen.

Abbildung 5-2: Reale Wechselkurse und der „Tequila-Effekt”

(handelsgewichtete Kurse, Log-Maßstab, 1. Vierteljahr 1987=100

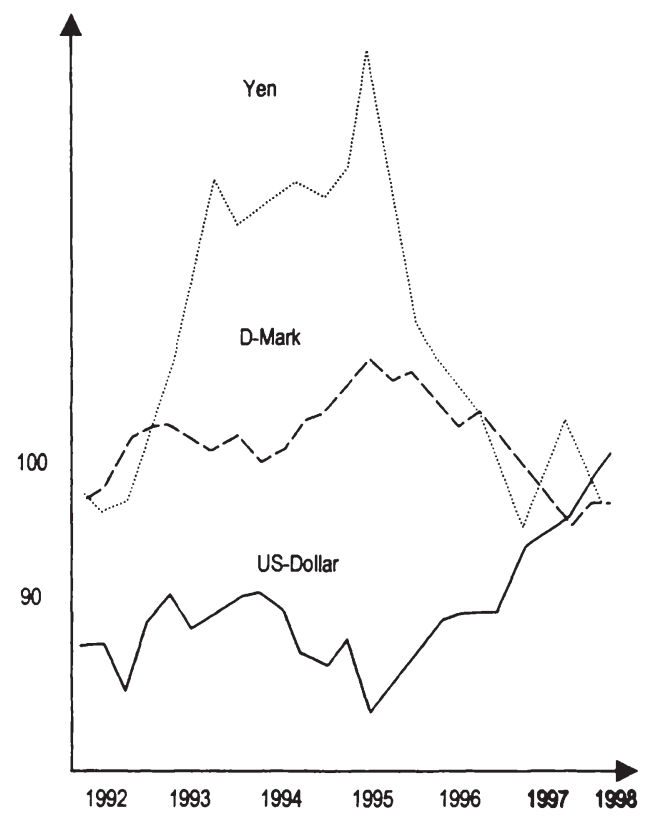

Quelle: Deutsche Bundesbank (1998c)

Auch im Sommer 1998, als der Yen in Folge der Asienkrise massiv unter Druck geriet, kam es wieder zu koordinierten Stützungsmaßnahmen seitens der G 3Notenbanken. Ansonsten gab es in der zweiten Hälfte der neunziger Jahre zwischen den EU-Staaten und den USA kaum Konflikte über die Währungsrelationen. Mit Ausnahme der Entwicklungen des Jahres 1995 im Gefolge der MexikoKrise, bestand ein grundlegender Konsens darüber, daß die Märkte weitgehend fundamental gerechtfertigte Kurse lieferten. Insbesondere in den Jahren 1996 bis 1998 halfen der erstarkende Dollar und die Schwächung von Mark und Yen für eine durchaus erwünschte globale Umverteilung der Nachfrage - weg vom Hochkonjunkturland USA, hin zu den schwächer wachsenden Volkswirtschaften der EU und Japan [BIZ 1998a: 103ff, IWF 1998a: 55ff].

Ein Keynesianisches Rollback? Dennoch entwickelte sich ein wachsendes Unbehagen über die Volatilität der Kurse an den Finanzmärkten und ihre realen 
Folgen. Insgesamt scheint es gegen Ende der neunziger Jahre einen gewissen Keynesianischen Rollback zu geben. Dies gilt insbesondere für die EU: Nach dem Wahlsieg der Sozialdemokraten in der Bundesrepublik im September 1998 gibt es zur Zeit des Schreibens in meisten EU-Staaten sozialistisch oder sozialdemokratisch geführte Regierungen, die - wenn auch in sehr unterschiedlichem Ausmaß interventionistisch gesinnt sind. Diese Regierungen könnten für eine Renaissance der Gesamtsteuerung als dominierendem ökonomischem Leitbild sorgen. Als Instrumente stehen nicht nur eine engere Koordinierung der expansiv ausgerichteten Fiskalpolitik innerhalb der Eurozone zur Debatte, sondern auch eine Rückkehr zu einer aktiven Wechselkurspolitik bzw. einem formalen System fester Wechselkurse. ${ }^{152}$

Schlußfolgerungen für die Euro-Ära? Die Überlegungen der vorhergehenden Abschnitte zeigen, daß das internationale Währungssystem in den vergangenen Eineinviertel Jahrhunderten immer wieder Phasen der Transformation durchlaufen hat: 1870, 1914, 1930, 1944, 1971 - und nun 1999ff? Diese Wechsel waren stets verbunden mit dem „Aufstieg und Fall der großen Mächte”, ${ }^{153}$ also mit der Verschiebung politischer und ökonomischer staatlicher Macht auf der internationalen Ebene. Gab es einen dominierenden Staat und war dieser dazu bereit, ein solches eng koordiniertes internationales System bereitzustellen, so kam es zur Schaffung und Aufrechterhaltung langfristig stabiler Regime. Verlor dieser Hegemon seine relative Überlegenheit, brachen die Regime auseinander. „[... E]rfahrungsgemäß (...) wird dasjenige Geld zum Weltgeld, das vielgebraucht wird und deshalb leicht wieder abgegeben werden kann: das Geld eines besonders großen Wirtschaftsgebietes. (...) Weltgeld und Weltmacht haben insofern etwas miteinander zu tun" [Richter 1994: 49].

Seit dem Ende des Zweiten Weltkriegs hat sich die internationale Machtverteilung immer weiter zuungunsten der USA verschoben. Dies ist das gewissermaßen natürliche Ergebnis des Aufholprozesses in Europa und Asien, dort insbesondere Japans. Mit dem Zusammenschluß der EU-Staaten zur Europäischen Währungsunion verlieren die USA abermals an ökonomischer Überlegenheit. Auf mittlere Sicht entsteht in Europa ein ebenbürtiger Mitspieler, wohingegen Japan,

152 Für einen zeitweise einflußreichen Protagonisten dieser Position vgl. Lafontaine (1998: 31). Der französische Premierminister Lionel Jospin tendierte offenbar eher zu einer diskretionären Wechselkurspolitik. Anläßlich eines Vorschlags des damaligen italienischen Ministerpräsidenten Romano Prodi, die vermeintlich überschüssigen Dollar-Reserven der ESZB-Institute für EU-weite Investitionsvorhaben zu verwenden, wandte er ein, dies könne den Euro gegenüber dem Dollar allzu stark machen. „Die Vermeidung der Überbewertung des Euro” sah Jospin als vordringliches Ziel (Handelsblatt vom 7. Oktober 1998, S. 7).

153 In Anlehung an das vieldiskutierte gleichnamige Buch Paul Kennedys (1987), das freilich einen weit größeren zeitlichen und sachlichen Bogen spannt. 
geschwächt durch seinen instabilen Finanzsektor, ${ }^{154}$ voraussichtlich auf Jahre an Einfluß verlieren dürfte. Das internationale Währungssystem wird sich daher zwischen den beiden Polen USA und EU bewegen. Zur Koordinierung der Politiken dürfte es nur kommen, wenn sich beide davon Vorteile versprechen und sich über eine Aufteilung der Kooperationsgewinne zu einigen vermögen, wenn sich in beiden Ländern bzw. Regionen ein ähnliches wirtschaftspolitisches Dogma durchsetzt, wenn eine oder mehrere internationale Institutionen als unabhängige Schiedsrichter für die Stabilisierung des Regimes sorgen.

Neben der Machtverteilung unter den Staaten der Erde hat sich auch das ökonomische Umfeld, in dem sie agieren, gravierend verändert: Die zur Zeit des Schreibens noch andauernde Phase der Liberalisierung der Güter- und Finanzmärkte hat die Einflußmöglichkeiten der Staaten eingeschränkt. Dies gilt zuvörderst für die Geld- und Währungspolitik, die in einem Umfeld offener Finanzmärkte agiert. Die Kooperation der Behörden kann die Märkte prinzipiell in zweierlei Weise behandeln: Entweder können sich die Staaten den Regeln der Märkte anpassen und als Mitspieler ihr Funktionieren verbessern helfen, und/oder sie können die Liberalisierung rückgängig machen, etwa indem sie, koordiniert oder unkoordiniert, Kapitalverkehrsbeschränkungen einfuihren. Je nach Ausgestaltung kann letztere Option allerdings mit erheblichen Effizienzverlusten verbunden sein.

\section{2 Historische Währungssysteme als Vorbilder für die Zukunft?}

Auf der Suche nach einem Weltwährungssystem für die Gegenwart blicken Ökonomen und Politiker häufig in die Vergangenheit zurück. Welche Lehren lassen sich aus früheren Systemen für das Euro-Zeitalter ziehen?

Der klassische Goldstandard soll hier nicht näher behandelt werden, aus einem einfachen Grund: Eine Rückkehr zum Goldstandard von 1870-1914 kann als allzu unrealistisch angesehen werden. Denn die Bindung der Geldmenge an die Goldreserven führt zu einem faktischen Verzicht auf die Geld- und Wechselkurspolitik. Voraussetzung dafür sind geringe gesellschaftliche Ansprüche an den Staat, und zwar in allen beteiligten Ländern, da im System des Goldstandards nationale wirtschaftspolitische Alleingänge zu „Spillovers” in die Partnerländern führen. Nur in einer , ,[...] era of government noninterventionism and before the rise of the welfare state" [Gilpin 1987: 126] konnte ein solches Währungssystem gedeihen. Auch würden Phasen der Deflation und der Inflation, wie sie unter dem klassischen Goldstandard immer wieder auftauchten, heute nicht mehr akzeptiert. Der Goldstandard widerspricht damit auch monetaristischen Auffassungen von Geldpolitik, da unter diesem Regime eine stetige, nichtinflationäre Geldversorgung der

154 Für eine knappe Analyse der sich zuspitzenden japanischen Finanzkrise in den neunziger Jahren vgl. Economist (1998) sowie IWF (1998b: Kap. IV). 
realen Wirtschaft, die sich am Wachstum des realen BIP orientiert, nicht möglich ist. ${ }^{155}$

Das Hauptaugenmerk liegt daher auf den Währungssystemen der zweiten Hälfte dieses Jahrhunderts: dem System von Bretton Woods, dem EWS sowie dem eher diskretionären Ansatz der G 7-Diplomatie.

\section{2. 1 Das System von Bretton Woods ${ }^{156}$}

Das System von Bretton Woods war, wie bereits erwähnt, eine asymmetrische Form der Politikkoordinierung. Die USA - nach dem Ende des Zweiten Weltkriegs die mit Abstand größte Volkswirtschaft auf dem Globus - stellten den damals noch ans Gold gebundenen Dollar als Leitwährung zur Verfügung und ihren heimischen Binnenmarkt als Absatzmarkt. Die übrigen Teilnehmerländer konnten auf diese Vorzüge zurückgreifen, mußten dafür aber der Politik der USA folgen und ihre Wirtschaftspolitiken entsprechend anpassen. Die USA ihrerseits verfolgten eine Politik der Vernachlässigung des Außenwertes ihrer Währung. Für die übrigen Länder bedeutete die Fixierung der Wechselkurse einen weitgehenden Verzicht auf die Wechselkurspolitik und teilweise auch auf die Geldpolitik. ${ }^{157}$

Ziele. Das Bretton-Woods-System war ein Gegenentwurf zur chaotischen Zwischenkriegsperiode. Damals hatte eine Spirale aus Zollschranken, Abwertungen und Kapitalverkehrskontrollen zu einer langen Wirtschaftskrise in den Industrieländern geführt. Diese Form der unkoordinierten, rücksichtslos auf rein nationale Ziele ausgerichteten „Beggar-thy-neighbour”-Politik sollte die Fixierung der Wechselkurse unterbinden. Gegen nationale Willkür setzte es eine Bindung an internationale Regeln und Institutionen (IWF, GATT), wobei allerdings den nationalen Administrationen größtmögliche Freiheiten gelassen werden sollten eine weitergehende explizite Koordinierung der Makropolitiken unter den Teilnehmerländern fand nicht statt.

Das Bretton-Woods-System war somit ein Pfeiler im größeren multilateralen Handelssystem, das zuvörderst zwei Grundsätzen folgte: freier Austausch von Gütern und Dienstleistungen, daher keine Beschränkung von Leistungsbilanztransaktionen, aber Beschränkung des sonstigem Kapitalverkehrs, um die festen Paritäten ungestört von spekulativen Attacken aufrecht erhalten zu können.

Neben diesen wirtschaftspolitischen Zielen verfolgte das Fixkurs-Freihandels-System zudem ein genuin politisches Ziel: die Eindämmung des sowjetischen

155 Für eine Darstellung des klassischen Goldstandards vgl. Jarchow/Rühmann (1984: 30ff).

156 Für diesen Abschnitt vgl. insbesondere van der Wee (1984: 476ff), Gilpin (1987: 127ff), Willms (1992: 146ff), Wagner (1995a: 123ff), Deutsche Bundesbank (1997d: 12ff), James (1997: 44ff).

157 Sofern sich Interventionen am Devisenmarkt nicht sterilisieren ließen, hatten sie Einfluß auf die heimische Geldmenge und wirkten somit expansiv oder kontraktiv. 
Expansionsdrangs durch ein erfolgreiches, weil effizientes Wirtschaftssystem und seine Überzeugungs- und Anziehungskraft im Wettbewerb der Ideologien. Dabei sollte eine sich herausbildende intensivierte grenzüberschreitende Arbeitsteilung dazu beitragen, die westeuropäischen Staaten sowie Japan in den Westblock zu integrieren.

Institutionelle Aspekte. In Bretton Woods (US-Bundesstaat New Hampshire) hatten 1944 die Regierungsdelegationen aus 45 Ländern die Gründung des Internationalen Währungsfonds und der Weltbank vereinbart, ${ }^{158}$ wobei dem IWF die Rolle zukam, das internationale Währungssystem zu managen, inbesondere durch Kreditvergabe für Länder, die in Zahlungsbilanzschwierigkeiten geraten waren. 159

Im Bretton-Woods-System bestand die Hauptaufgabe dieser Kredite darin, die fixierten Wechselkurse zu verteidigen. Eine Notenbank konnte gegen heimische Währung Devisen (US-Dollars) kaufen, die es zur Intervention an den Devisenmärkten verwendete. Nach Ablauf einer Frist mußte die Notenbank den Kredit in Dollar zurückzahlen. 160

Der Fonds finanziert sich aus den eingezahlten Quoten der mittlerweile 182 Mitgliedsländer (Stand: 1998). Die jeweilige Quote wiederum orientiert sich an Kennzahlen der Wirtschaftskraft des betreffenden Landes (Bruttoinlandsprodukt, Währungsreserven etc.). Die Einzahlungen müssen zu mindestens 25 Prozent in einer konvertiblen Währung oder Gold und dürfen zu höchstens 75 Prozent in

158 Die ebenfalls vorgesehene Gründung einer internationalen Handelsorganisation (,International Trade Organisation", ITO) scheiterte. An seine Stelle trat das GATT, das ein sich fortentwickelndes Vertragsgeflecht darstellte und lediglich über ein „Sekretariat” verfügte. Erst mit Abschluß der Ururguay-Runde ging das GATT in der World Trade Organisation (WTO) auf und erhielt damit einen stringenteren institutionellen Rahmen [Wagner 1995a: 53ff].

159 Nach dem Ende der Bretton-Woods-Ära wandelte sich seine Hauptaufgabe, seither geht es vor allem um Überwachung (,Surveillance”) der Wirtschaftspolitik der Mitgliedsstaaten. Der Fonds bemüht sich, die Stabilität der Weltwirtschaft zu fördern, indem er unsolide, das heißt nicht nachhaltig aufrechtzuerhaltende, nationale Politiken aufzudecken versucht. Im Sinne eines offenen Welthandels will der IWF, den Abbau von Kapitalverkehrskontrollen, insbesondere für Leistungsbilanztransaktionen, sowie wettbewerbskonforme Wechselkurse voranzutreiben. Daneben agiert der Fonds nach wie vor als eine Art Bank für Staaten, die in plötzliche Zahlungsbilanzschwierigkeiten geraten sind.

160 Nach dem Zusammenbruch des Bretton-Woods-Systems haben sich die Ausleihungen des Fonds extrem ausgeweitet, insbesondere in den achtziger und neunziger Jahren, seit Ausbruch der Schuldenkrise in Mexiko 1982 und besonders im Zusammenhang mit der Emerging-Markets-Krise von $1997 \mathrm{ff}$. Anders als im Fixkurssystem versucht der Fonds heute, Entwicklungsbzw. Schwellenländern, die wirtschaftspolitisch unglaubwürdig geworden sind, wieder Zugang zu den internationalen Finanzmärkten zu verschaffen (,Katalysatorfunktion”). Dies geschieht nicht mehr nur über kurzfristige Zahlungsbilanzhilfe, sondern auch durch Kreditgewährung für mittelfristige Strukturanpassungsprogramme („Structural adjustment”). Diese Politik ist gerade in jüngster Zeit heftig umstritten. 
eigener Landeswährung erfolgen. Nach der Höhe der jeweiligen Quote richten sich auch die Stimmrechte der Mitgliedsländer. Somit spiegelte sich vor allem in den Anfangsjahren im Fonds die asymmetrische Machtverteilung des BrettonWoods-Systems.

Entsprechend ihrer Quoten stehen den Mitgliedsländern Kredite zur Verfügung: Auf die 25 Prozent in Gold oder konvertibler Währung kann die Regierung jederzeit zurückgreifen, und zwar ohne Auflagen erfüllen zu müssen. Über diese „Reservetranche” hinausgehende Kredite (,Ziehungen”) unterliegen Bedingungen seitens des Fonds.

Zentrale Merkmale des Systems. Das Bretton-Woods-Modell funktionierte lange Zeit weitgehend reibungslos auf Basis weniger Spielregeln:

Goldkonvertibilität des Dollar. Die US-Regierung garantierte die Goldkonvertibilität des Dollar. Sie verpflichtete sich, auf Wunsch eines jeden Gläubigers, jederzeit Gold zum festgelegten Kurs von 35 Dollar pro Unze herauszugeben.

Fixierte Paritäten gegenüber dem Dollar. Die Regierungen der übrigen Länder legten Paritäten gegenüber dem Dollar fest. Damit war jede Währung indirekt an die Goldbestände der USA gebunden - ein Weg, den die Regierungen eingehen mußten, weil Amerika gegen Ende des Krieges über nahezu den gesamten Goldschatz der Erde verfügte. Zudem waren die Währungen über den Dollar (als Vehikelwährung) tauschbar.

Interventionsverpflichtungen. Die Mitgliedsländer verpflichteten ihre Notenbanken zu intervenieren mit dem Ziel, den Wechselkurs innerhalb einer Bandbreite um den Fixkurs von jeweils einem Prozent nach oben und unten zu halten. Die US-Regierung ging keine entsprechende Verpflichtung ein.

IWF-Kredite bei Zahlungsbilanzschwierigkeiten. Die Aufsicht über das System übernahm der zu diesem Zweck gegründete Internationale Währungsfonds. An dieser Institution waren - und sind bis heute - die teilnehmenden Staaten gemäß ihrer Wirtschaftskraft beteiligt („Quoten”). Dazu zahlten sie Währungsreserven beim IWF ein. Der Fonds seinerseits gewährte auf Basis dieses Kapitals kurzfristige Kredite unter Auflagen an Mitgliedsstaaten, die in temporäre Zahlungsbilanzschwierigkeiten geraten waren.

Anpassung der Wechselkurse. Einmal fixierte Wechselkurse sollten geändert werden, sofern es zu einem „fundamentalen Zahlungsbilanzungleichgewicht" kam. Wollte ein Land eine Änderung der Parität um mehr als zehn Prozent nach oben oder unten, mußte der IWF dem zustimmen. Dadurch sollten unkooperative Abwertungen verhindert werden.

Die geordnete Änderung der Wechselkurse war nur als Ultima ratio möglich. Vorrang hatte die Vergabe von IWF-Krediten, die dazu dienten, „[...] das kooperative Verhalten gegen zeitweilige Zahlungsbilanzstörungen abzuschirmen. Im Verein mit dem sogenannten Paritäten-System haben diese Regelungen mehr als zwei Jahrzehnte gut funktioniert und entscheidend dazu beigetragen, daß 
Welthandel, Produktion und Wohlstand überaus kräftig wuchsen" [Deutsche Bundesbank 1997d: 12f].

Probleme des Systems. Daß das System von Bretton Woods 1971 und endgültig 1973 zusammenbrach, liegt zum Teil in einigen Konstruktionsfehlern begründet, zum Teil aber auch daran, daß die Teilnehmerländer sich nicht an die vereinbarten Spielregeln hielten. Letztlich erwies sich das System nicht als flexibel genug, die auftretenden Probleme und Interessenverschiebungen zu lösen. ${ }^{161}$

Das Problem des $n$-ten Landes. In einem System mit $n$ Währungen mit einer Leitwährung gibt es nur $n-1$ relative Währungspreise (= Wechselkurse), die Leitwährung dient als Numéraire. Während die Regierungen aller übrigen Länder ihre Geld- und Fiskalpolitik am Wechselkurs ausrichten, besteht für die Regierung des $n$-ten Landes keine vergleichbare Verpflichtung. So waren im Bretton-WoodsSystem die Notenbank und die Regierung der USA die einzigen, die volle Souveränität über die Geld- und Fiskalpolitik hatten. Die Versuchung, diese Freiheit für innen- oder außenpolitische Programme zu nutzen, ist für Politiker des $n$-ten Landes groß. Freilich gefährdete sie damit die Stabilität des gesamten Systems. So waren es vor allem die exessiven Ausgabenprogramme der US-Administrationen Johnson und Nixon (sozialpolitisches „Great-Society”-Programm, VietnamKrieg), die dem Bretton-Woods-System den Todesstoß versetzten. Die US-Notenbank war letztlich nicht mehr in der Lage, die Gold-Konvertibilität des Dollar glaubwürdig zu garantieren.

Das Anpassungsproblem. Ein Kernproblem des Systems von Bretton Woods waren die massiven Anreize, die einer regelmäßigen Anpassung der Wechselkurse an Entwicklungsunterschiede in den Teilnehmerländern entgegenstanden. Die Industrie- und Gewerkschaftslobbies in den Überschußländern waren nicht gewillt, auf die Wettbewerbsvorteile zu verzichten, die eine unterbewertete Landeswährung mit sich brachte. In den Defizitländern hingegen - zuvörderst in den USA - waren staatliche und industrielle Schuldner nicht bereit, auf die günstigen Finanzierungsbedingungen zu verzichten, die mit einer überbewerteten Wäh-

161 In den sechziger Jahren stand eine andere Befürchtung im Vordergrund, nämlich daß das Bretton-Woods-System könne in einen Liquiditätsengpaß schlittern („Triffin-Dilemma”). Die Begründung dafür lautete wie folgt: Da Welthandel und grenzüberschreitende Investitionen rasch expandierten, nahmen auch kurzfristige Schwankungen innerhalb der Zahlungsbilanz größere Dimensionen an. Um sie, wie im Fixkurssystem notwendig, auszugleichen, benötigten die Notenbanken der Teilnehmerländer zusätzliche Währungsreserven, mithin US-Dollars. Das System konnte also nur weiter funktionieren, wenn das Leitwährungsland USA ein Leistungsbilanzdefizit hinnahm, Kapital importierte und dafur Dollars herausgab, die dann als Devisenreserven in die Kassen der übrigen Notenbanken wanderten. Dies war langfristig nicht aufrechtzuerhalten. Um einem solchen möglichen Liquiditätsengpaß zuvor zu kommen, wurden 1969 die Sonderziehungsrechte (SZR) als internationale Ersatzreservewährung eingeführt [z. B. Deutsche Bundesbank 1997d: 46ff]. Faktisch erreichten sie aber nie die ihnen zugedachte Bedeutung. 
rung verbunden waren. Zugleich hatte der IWF keine Sanktionsmöglichkeiten, eine Anpassung der Paritäten durchzusetzen. Im Gegenteil, der Fonds förderte dieses Verhalten sogar noch dadurch, daß er über die bis dahin maximalen Kreditlinien hinaus Zahlungsbilanzhilfen vergab.

Die Ungleichgewichte hatten jedoch erhebliche Folgen: In den späten sechziger und frühen siebziger Jahren waren die Notenbanken der übrigen Industrieländer gezwungen, inflationierte US-Dollars zum vorgebenen Kurs zu kaufen, um die vereinbarten Paritäten zu halten. Angesichts der US-Politik tauchte das Problem der importierten Inflation auf. Die USA ihrerseits genossen den Vorteil, sich zu Premiumkonditionen verschulden zu können, da ihre Währung überbewertet war. Jedoch bereitete diese Überbewertung dem güterwirtschaftlichen Sektor gewaltige Probleme. Beides führte letztlich zum Auseinanderbrechen des Systems.

Das Moral-hazard-Problem. Die bereitwillige Kreditvergabe und die unzureichenden Sanktionsmöglichkeiten bei Verstoß gegen die Auflagen des IWF förderte „Moral-hazard”-Verhalten. Eigene Risikovorsorge seitens der Regierungen der Mitgliedsländer wurde unterlassen in der Erwartung, der Fonds stehe im Zweifelsfall bereit. Dies war bereits im Bretton-Woods-System der Fall: IWFKredite ermöglichten erst die mangelnde Anpassung der Wechselkurse und sonstigen Makropolitiken. Verschärft hat sich dieses Problem nach dem Zusammenbruch des Bretton-Woods-Systems.

Vorbild für die Euro-Ära? Ein Währungssystem im Euro-Zeitalter kann nur ein multilaterales sein, mindestens ein bilaterlates zwischen dem Euroland und den USA als ähnlichen starken ökonomischen Kräften. Das Bretton-WoodsSystem hingegen basierte auf der Übermacht der USA und dem US-Dollar als Leitwährung. Den IWF, die internationale Institution, auf der das System basierte, dominierten ebenfalls die USA. Künftig wird das nicht mehr möglich sein: Ein Dollar-Euro-System wird sich entweder auf eine wie auch immer geartete Koordinierung beider Länder stützen, oder es wird vom Konflikt der beiden geprägt sein.

Angenommen, die politischen Führungen beider Länder wären zu einer engen Form der Koordinierung bereit - kann es den Notenbanken überhaupt gelingen, die Wechselkurse zu stabilisieren? Zur Beantwortung dieser Frage gilt es, einen entscheidenden Unterschied $\mathrm{zu}$ beachten: Die dauerhafte Fixierung der Wechselkurse ist bei abgeschotteten Kapitalmärkten wie zu Bretton-Woods-Zeiten relativ einfach möglich. Denn in diesem Fall können die Notenbanken mit vergleichsweise geringem Einsatz von Devisenbeständen entscheidenden Einfluß auf die Marktpreise nehmen. Die grenzüberschreitend gehandelten Devisenmengen sind relativ gering, die Fixierung der Kurse ist daher glaubwürdig.

Bei den heute offenen Kapitalmärkten ist dies nicht ohne weiteres möglich. Angesichts sehr großer gehandelter Mengen sind auch sehr große Mengen an De- 
visenreserven für erfolgreiche Interventionen nötig. ${ }^{162}$ Sofern das Publikum an den Finanzmärkten damit rechnet, daß die Devisenreserven einer Notenbank zur Neige gehen, lädt dies geradezu zur Spekulation ein. Es fließen dann große Vermögenswerte (die Devisenreserven nämlich) aus dem Land ab, die Notenbank kann den Wechselkurs am Ende dennoch nicht halten.

Ergo ist bei offenen internationalen Kapitalmärkten ein Fixkurssystem nur glaubwürdig, wenn zwischen den Vertragsparteien eine gegenseitige Beistandsverpflichtung besteht, den jeweils anderen Partnern Devisenreserven in unbegrenzter Höhe zur Verfügung zu stellen (und möglicherweise nicht auf die Rückzahlung zu bestehen). Nur dann ist das System glaubwürdig [Bofinger 1998].

Unter welchen Umständen werden sich die Regierungen darauf einlassen? Sie werden es nur tun, wenn sie in der Lage sind, ihre Geld-, Wirtschafts- und Finanzpolitik stringent zu koordinieren. Dies aber war im Bretton-Woods-System nicht der Fall. Hier galt der Grundsatz größtmöglicher nationaler Autonomie, lediglich die Wechselkurse waren festgelegt. In einem symmetrischen Setting der Dollar-Euro-Kooperation bei offenen Finanzmärkten genügt das nicht mehr. Denn jede Regierung muß sicher sein können, daß die jeweils andere Seite sich keine einseitigen Vorteile verschafft und dazu noch mit Devisen zur Verteidigung des Kurses versorgt wird. Ein derartiger Beistandspakt basiert also auf nichts anderem als gegenseitigem Vertrauen und ist daher extrem schwierig zu erlangen. Bei unabhängigen Regierungen, die unterschiedlichen nationalen Öffentlichkeiten verantwortlich sind und der nach wie vor herrschenden Heterogenität der wirtschaftspolitischen Zuständigkeiten innerhalb der EU, ist eine derart enge supranationale Koordinierung kaum realisierbar.

Ist ein solcher Beistandspakt aber nicht erreichbar, existiert ein Zielkonflikt: Eine Fixierung der Wechselkurse ist nur bei Beschränkungen des internationalen Kapitalverkehrs glaubwürdig möglich. Die potentiellen Effizienzgewinne, die aus der Stabilisierung der Währungsrelationen resultieren, werden somit erkauft durch Effizienzverluste aufgrund einer teilweisen Abschottung der nationalen Kapitalmärkte. Diese Wohlfahrtsverluste folgen nicht nur aus einer suboptimalen Kapitalallokation, sondern auch aus der damit einhergehenden Beschränkung des institutionellen Wettbewerbs - paretoverbessernde institutionelle Innovationen etwa des Steuer- und Abgabensystems sowie des Angebots an öffentlichen Gütern werden verhindert. Außerdem bleiben prinzipiell die Anreize des Bretton-WoodsSystems bestehen, aus innenpolitischem Opportunismus die Paritäten zu hoch bzw. zu niedrig festzusetzen, was insbesondere bei Beschränkungen des internationalen Kapitalverkehrs überhaupt erst möglich ist.

162 Ein rein intuitiver Vergleich zwischen Devisenumsatz - weltweites Volumen 1998: 1,6 Billionen Dollar täglich [BIZ 1998c] und den offiziellen Weltdevisenreserven - rund 1,4 Billionen US-Dollar [Bundesbank 1997b: 28] - zeigt die stark relativierte Marktmacht der Notenbanken als Spieler. 


\section{2. 2 Das Europäische Währungssystem (EWS) ${ }^{163}$}

Ähnlich wie beim Bretton-Woods-System handelte es sich beim EWS um den Versuch, die Koordinierung der Makropolitiken der Teilnehmerländer über die Fixierung der Wechselkurse innerhalb von relativ engen Wechselkursbändern zu erreichen. Allerdings ging der Integrationsansatz des EWS inhaltlich weiter: Schon in den sechziger Jahren dachten die Europapolitiker über die Schaffung einer Wirtschafts- und Währungsunion nach, und Überlegungen in diese Richtungen spielten auch 1979 bei der Gründung des EWS eine Rolle. Geographisch war dieser Ansatz auf eine vergleichsweise kleine, homogene Gruppe europäischer Länder beschränkt, die relativ ähnliche Vorstellungen über die Ziele der Wirtschaftspolitik verfolgten.

Die Geschichte des EWS läßt sich in vier Phasen unterteilen, die Entwicklung der Leitkurse der ersten drei Phasen ist in Abbildung 5-3 dargestellt. Schon ein erste Blick macht deutlich, daß beim EWS in einigen Zeitabschnitten häufige Anpassungen der Kurse erfolgten, somit von wirklich fixierten Kursen nicht die Rede sein kann.

Phase 1. In der ersten Phase zwischen 1979 und 1987 gab es relativ häufige Anpassungen der Wechselkurse, da nach wie vor große Inflationsdifferentiale bestanden. Insbesondere in den frühen achtziger Jahren ähnelte das EWS eher einem „Crawling-peg-“ als einem Fixkurssystem. Dies änderte sich allmählich, insbesondere mit der stabilitätspolitischen Kehrtwende der französischen Regierung 1983 (Politik des „Francs fort”).

Phase zwei. Die zweite Phase begann mit dem Basel/Nyborg-Abkommen 1987. Sie bedeutete den Versuch eines weitgehenden Verzichts auf die Nutzung der Wechselkursanpassungen. Künftig sollten die sonstigen Wirtschaftspolitiken enger koordiniert werden. Auch hier stand das Ziel eines Übergangs zur vollständigen Währungsunion im Hintergrund. Die Koordinierung gelang allerdings nur teilweise.

Phase drei. Beendet wurde diese Phase der Wechselkursstabilität 1992 mit spekulativen Attacken, die vor allem die „Weichwährungen” trafen: Britisches Pfund und Lira mußten den Wechselkursmechanismus verlassen, Peseta und Escudo wurden abgewertet. Auslöser für die Turbulenzen waren die Ablehnung des Maastricht-Vertrags durch Volksabstimmung in Dänemark sowie die äußerst knappe Mehrheit dafür in Frankreich. Sie öffneten Zweifeln Raum, ob die europäischen Regierungen tatsächlich bereit seien, den Maastricht-Fahrplan ${ }^{164}$ einzuhalten und die bestehenden Überbewertungen einiger Währungen aufgrund divergierender Geld- und Fiskalpolitiken auszuhalten.

$163 \mathrm{Zu}$ diesem Abschnitt vgl. insbesondere Willms (1992: 197ff), de Grauwe (1997a: 87ff), Deutsche Bundesbank (1997e: 110ff), Ambrosius (1996: 123ff).

164 Siehe Abschnitt 2. 1. 


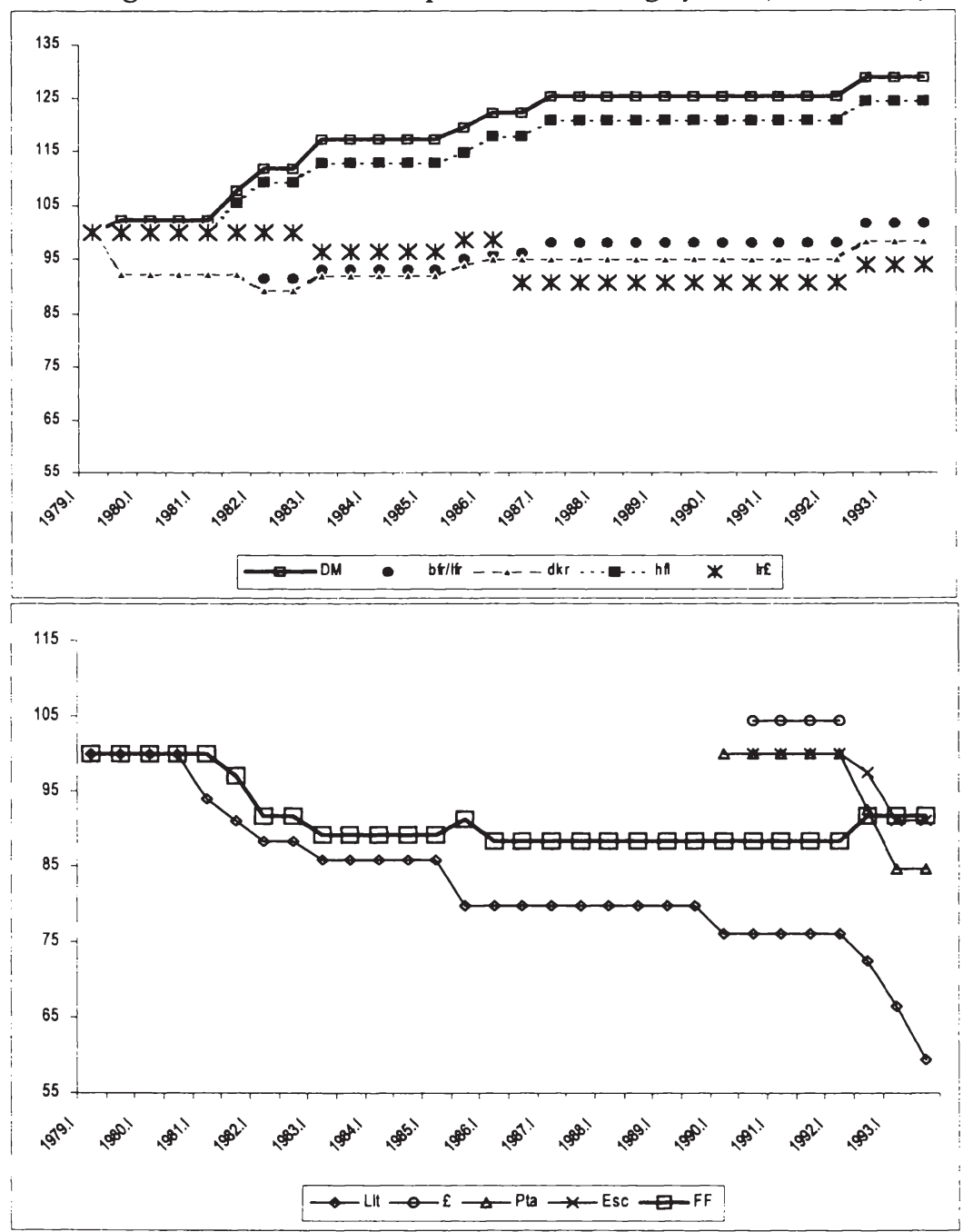

Quelle: Deutsche Bundesbank (1997e)

165 Anmerkungen: Angaben in Prozent des jeweiligen Startkurses $(1979=100)$. Brit. Pfund: Eintrittskurs 1990 bei 104,32 \% aufgrund fiktiver Werte der Vorjahre. Für Pta und und Esc liegen fiktive Werte nicht vor, da sie zuvor nicht im ECU-Korb enthalten waren, daher wurden hier Kurse bei Eintritt (Pta: 1989, Esc. 1990) ins EWS $=100$ gesetzt. Die Lit stieg am 17. September 1992 aus dem Wechselkursmechanismus aus, die danach eingezeichneten Kurse sind fiktive Kurse. 
In diesem Zusammenhang spielte auch der Schock im Gefolge der Deutschen Einheit eine Rolle, der massives „Deficit spending” seitens der Bundesregierung, Inflationsdruck und somit europaweit hohe kurzfristige Zinsen zur Folge hatte. Da die Leitkurse im EWS zu spät angepaßt wurden (erst am 14. September 1992), kamen Zweifel auf, ob die übrigen Länder die Kosten, die mit dem Verzicht auf das Wechselkursinstrument verbunden waren, zu tragen bereit wären. In der dritten Phase des EWS 1992/93 war das System daher von Glaubwürdigkeitskrisen bedroht. ${ }^{166}$ Sie wurde letztlich gelöst durch die drastische Ausweitung der Schwankungsbreiten der Marktkurse um die Leitkurse auf \pm 15 Prozent. Nur niederländischer Gulden und D-Mark blieben mit der engen Schwankungsbreite von $\pm 2,25$ Prozent aneinander gebunden.

Phase 4. Mit Beginn der zweiten Stufe der Wirtschafts- und Währungsunion zum Jahresbeginn 1994 existierte das EWS zwar weiter, es änderte aber seinen Charakter grundlegend: Durch den eigentlichen Beginn des Maastricht-Prozesses stand nun die Teilnahme an der dritten Stufe der Währungsunion für die EU-Regierungen im Vordergrund. Dies führte schließlich zu einer weitgehenden nominalen Konvergenz. ${ }^{167}$ Dennoch kam es auch in dieser Phase nochmals zu spekulativen Verwerfungen im Gefolge der Mexiko-Krise, die insbesondere die „Weichwährungen" Peseta und Escudo trafen. Thre Leitkurse mußten trotz der stark erweiterten Bänder im Frühjahr 1995 abermals abgewertet werden. Gegen Ende des Jahres 1996 trat die Markka erstmals und die Lira wieder in den Wechselkursmechanismus ein, im März 1998 erstmals die Drachme.

Ziele. Das EWS entstand als europäische Reaktion auf den Zusammenbruch des Bretton-Woods-Systems, die erste Ölkrise von 1973 und die darauf folgenden Wechselkursfluktuationen. In Anbetracht der wirtschaftlichen Probleme Mitte der siebziger Jahre fand damals eine Renationalisierung der Wirtschafts- und Währungspolitiken in Europa statt. Als Alarmsignal wurde gewertet, daß die europäischen Regierungen begannen, nichttraiffäre Handelshemmnisse zu errichten, die den Gemeinsamen Markt in der EG segmentierten [Ambrosius 1996: 132].

1975 stellte der „Marjolin-Bericht”, den die Europäische Kommission in Auftrag gegeben hatte, fest:

166 Für eine einfache formale Analyse dieser Glaubwürdigkeitskrisen vgl. de Grauwe (1997a: 87ff).

167 Siehe Abschnitt 2. 1. 4. Die Beitrittskriterien sollten gemäß Maastricht-Vertrag nicht nur unmittelbar vor der Prüfung, sondern "dauerhaft" eingehalten werden. Zudem begann eine Phase der engeren Koordinierung der Wirtschafts- und Währungspolitik mit regelmäßiger Überprüfung seitens der EU-Kommission und dem 1994 neugegründeten Europäischen Währungsinstitut. 
„Das Europa der 60er Jahre stellte ein verhältnismäßig ausgewogenes wirtschaftliches und monetäres Gefüge dar, das in den letzten Jahren auseinandergefallen ist. Die Wirtschafts- und Währungspolitik ist seit 25 Jahren nie so uneinheitlich, ja gegensätzlich gewesen wie heute" [zitiert nach Ambrosius 1996: 126].

Das EWS kann somit als Mittel gewertet werden, diese Einheitlichkeit wiederherzustellen. Es spielten sowohl wirtschaftliche als auch politische Ziele eine Rolle. Durch eine engere Koordinierung der Währungspolitiken sollte ein Auseinanderfallen des Gemeinsamen Marktes verhindert werden. Die Stabilisierung der Wechselkurse sollte den innergemeinschaftlichen Handel anregen. Neben ökonomischen Effizienzüberlegungen wollten die Europapolitiker Ende der siebziger Jahre aber auch dem seit Gründung der EWG verfolgten politischen Ziel einer immer engeren Zusammenarbeit der westeuropäischen Staaten ein Stück näher kommen, dies auch vor dem Hintergrund einer zunehmend schwächer erscheinenden Führungsmacht USA und einer erneuten Zuspitzung des Ost-WestKonflikts.

Zentrale Merkmale des Systems. Das System bestand aus einigen Grundelementen, deren Anwendung sich jedoch im Lauf der Zeit wandelte:

Europäische Währungseinheit (ECU). Anders als das Bretton-Woods-System war das EWS ursprünglich konzipiert als ein Modell ohne Leitwährung. Damit sollte das Problem des $n$-ten Landes vermieden werden. Vielmehr bildete die Korbwährung ECU die Grundlage, ein Gitter aus bilateralen Leitkursen zu fixieren. An der Wertentwicklung der ECU orientierte sich auch der „Abweichgungsindikator", der Wechselkursbewegungen frühzeitig anzeigen sollte, so daß Zentralbanken und Regierungen reagieren konnten. ${ }^{168}$ Der Wechselkursmechanismus hätte allerdings auch ohne die ECU allein auf Basis der bilateralen Kurse funktioniert.

Wechselkursbänder. Im Vergleich zum Bretton-Woods-System wies das EWS eine deutlich höhere Flexibilität auf. So existierten zwei Bandbreiten für die nominalen Wechselkurse: Prinzipiell galt ein Korridor von $\pm 2,25$ Prozent um den Leitkurs, schwächeren Währungen (Lira, später Pfund, Peseta, Escudo) konnte eine erweiterte Bandbreite von \pm 6 Prozent eingeräumt werden. Ab 1993 galten für alle Währungen die stark erweiterten Bänder von \pm 15 Prozent, lediglich Mark und Gulden blieben mit der ursprünglichen engen Bandbreite aneinander gekettet. Gegenüber Dollar und Yen floateten die EWS-Währungen.

Interventionsmechanismus. Sobald der bilaterale Marktkurs zweier Währungen die Grenze des Korridors („Interventionspunkt”) erreichte, waren die beteiligten Notenbanken verpflichtet, in unbegrenzter Höhe zu intervenieren, indem sie die schwache Währung kauften und die starke verkauften. Länder mit starker Währung wurden also regelmäßig gezwungen, ihre Devisenreserven aufzustocken

168 Zur Berechnung und den weiteren Funktionen der ECU vgl. z. B. Willms (1992: 200ff). 
und somit ihre monetäre Basis auszuweiten, während Länder mit schwacher Währung gezwungen waren, ihr Angebot an Zentralbankgeld zu verknappen. Allerdings bot sich Hartwährungsnotenbanken die Möglichkeit, ihre Interventionen zu sterilisieren.

Neben diesen obligatorischen Interventionen am oberen und am unteren Interventionspunkt waren auch intramarginale Interventionen möglich. Notenbanken konnten innerhalb des Bandes eingreifen, um den Markt in die gewünschte Richtung zu beeinflussen. Intramarginale Interventionen in einer Gemeinschaftswährung bedurften der Zustimmung der übrigen Notenbanken. Innerhalb der Bänder konnten die Notenbanken auch in Dollars intervenieren - Notenbanken von Ländern mit starker Währung kauften dann die schwächere gegen Hergabe von Dollar. Dies hatte aus Sicht der intervenierenden Behörde zwei Vorteile: Zum einen bedurften intramarginale Dollar-Interventionen nicht der Zustimmung der übrigen Notenbanken. Zum anderen waren sie geldmengenneutral, da sich lediglich die Zusammensetzung, nicht aber die gesamte Höhe der Devisenreserven änderte (Dollar-Bestand sank, EG-Währungsbestand stieg).

Kreditmechanismus. Um der Wechselkursfixierung Glaubwürdigkeit zu verleihen, war ein ausdehnter Kreditmechanismus nötig. Damit räumten sich die EWS-Notenbanken gegenseitig Währungskredite ein, die zunächst über den Europäischen Fonds für Währungspolitische Zusammenarbeit (EFWZ), seit 1994 über das Europäische Währungsinstitut (EWI) abgewickelt wurden. Dieser Mechanismus bestand aus drei Stufen - sehr kurzfristigen Krediten, kurzfristigen Krediten, mittelfristigen Krediten. Der Mechanismus ähnelt den IWF-Tranchen: Beim IWF werden mit zunehmender Kredithöhe die Auflagen für das betreffende Land strikter, beim EWS mit zunehmender Dauer.

Sehr kurzfristige Kredite mußten sich die Zentralbanken gegenseitig in unbegrenzter Höhe einräumen, um ihren Interventionsverpflichtungen nachzukommen. Rückzahlbar waren diese Beträge binnen 45 Tagen in der Währung, in der sie aufgenommen wurden zuzüglich Zinsen (verzinst mit dem Durchschnitt der Geldmarksätze der EG-Mitgliedsländer). Die Rückzahlung konnte bis zu drei Monaten verlängert werden, allerdings nur bis zur Ausschöpfung der Schuldnerquote (siehe unten).

Kurzfristige Kredite dienten dazu, Zahlungsbilanzdefizite auszugleichen, die zum Beispiel durch plötzliche außenwirtschaftliche Störungen auftraten. Die Schuldnerzentralbank mußte sie binnen drei Monaten zurückzahlen, zwei weitere Verlängerungen um jeweils drei Monate waren möglich. Maximal konnten sie in Höhe der für jedes Land festgelegten Schuldnerquote ausgeschöpft werden. Anders als bei den sehr kurzfristigen Krediten bestand hier keine Pflicht zur Kreditgewährung, sondern sie mußten durch einstimmigen Beschluß der Zentralbankpräsidenten genehmigt werden. Sie waren nicht an Auflagen gebunden.

Das „einheitliche System des mittelfristigen Währungsbeistands” sollte Zahlungsbilanzanpassungen erleichtern. Sie waren binnen zwei bis fünf Jahren 
rückzahlbar. Das Geld stammte aus Einzahlungen der Mitgliedsstaaten in einen EG-Plafonds oder konnte durch Anleiheemission seitens die EG für ein Land erfolgen. Über die Gewährung entschied der EG-Ministerrat mit qualifizierter Mehrheit nach Anhörung des Währungsausschusses auf Antrag der betroffenen Regierung oder der Kommission. Ähnlich wie bei IWF-Krediten waren sie an Auflagen gebunden. Insbesondere mußte die antragstellende Regierung selbst einen Sanierungsplan vorlegen. Auf mittelfristige Kredite griffen insbesondere Italien, Irland, Frankreich und Griechenland zurück.

Anpassung der Kurse. Ziel des ausdehnten Kreditmechanismus war es, vom Instrument der Kursanpassung möglichst keinen Gebrauch machen zu müssen. Die Wiederherstellung des Gleichgewichts sollte über eine Anpassung der sonstigen Wirtschafts- und insbesondere Geldpolitik ablaufen, Kredite sollten dies ermöglichen und glaubwürdig abstützen. Eine Anpassung der Leitkurse war als Ultima ratio vorgesehen und bedurfte einer einstimmigen Entscheidung im Ministerrat. Einstimmigkeit war vor allem deshalb erforderlich, weil die Struktur der ECU implizierte, daß die Abwertung einer Währung eine Aufwertung aller übrigen Währungen (und vice versa) bedeutete.

Institutionelle Ausgestaltung. Im Gegensatz zum Bretton-Woods-System war das EWS eingebunden in den umfassenderen institutionellen Rahmen der Europäischen Gemeinschaften. Das heißt, das Arrangement war durch vergleichsweise starke Gemeinschaftsorgane flankiert. Grob gesprochen sah die Rollenverteilung wie folgt aus: Grundsatzentscheidungen fällte der Europäische Rat (Staats- und Regierungschefs) einstimmig. Der Ministerrat (ECOFIN) war das Gremium für laufende Entscheidungen, für die meisten Fragen war Einstimmigkeit erforderlich. Die Umsetzung der Politik war Sache der nationalen Zentralbanken. Sie kooperierten im 1972 gegründeten Europäischen Fonds für Währungspolitische Zusammenarbeit. Entscheidungen vorzubreiten und ihre Umsetzung zu überwachen war Aufgabe der Europäischen Kommission. Vereinbarungen stellten Recht der Gemeinschaft dar, das vor dem Europäischen Gerichtshof eingeklagt werden kann.

Daneben existierte der Beratende Währungsausschu $\beta$ als Konsultationsund Koordinierungsgremium für Fragen der Wirtschafts- und Finanzpolitik. Hier saßen je ein Notenbanker und ein Regierungsmitglied jedes Mitgliedsstaates sowie zwei leitende Beamte der Kommission zusammen.

In Phase 4 (nach Beginn der zweiten Stufe der Währungsunion ) trat mit dem EWI - Anteilseigner waren die 15 nationalen EU-Notenbanken - ein weiteres beratendes Gremium hinzu, dessen Einfluß vor allem durch seine Überwachungsfunktion (Einhaltung der Konvergenzkriterien) relativ groß war. Auch die Kommission erhielt im Maastricht-Vertrag und 1997 im Vertrag von Amsterdam zu- 
sätzliche Kompetenzen der ständigen Überwachung der Wirtschaftspolitiken der Mitgliedsländer. ${ }^{169}$

Probleme des Systems. Das EWS war ursprünglich als System mit fixen, aber anpassungsfähigen Wechselkursen konzipiert, wobei nationale Kapitalverkehrskontrollen möglich waren. Es sollte symmetrisch funktionieren, das heißt ohne daß eine Währung die Ankerrolle übernahm. Allerdings: So hat es realiter nie funktioniert. In der Anfangsphase ähnelte das EWS eher einem „Crawlingpeg”-System. Im Laufe der Jahre wandelte es sich zu einem über längere Zeit stabilen System, das allerdings asymmetrisch konstruiert war - mit der Mark als Leitwährung. Es löste sich dann faktisch 1993 in den Spekulationskrisen auf. Seine weitere Existenz verdankte es zuvörderst der antizipierten Wohlfahrtsgewinne durch die anpeilte Währungsunion, für die die EWS-Mitgliedschaft Voraussetzung war.

Der Grund für diesen Wandel liegt vor allem in folgenden Problemen:

Das Kooperationsproblem. Die Grundidee des Systems lag in der symmetrischen Intervention jeweils zweier Zentralbanken. Interveniert eine Hartwährungszentralbank zugunsten einer schwachen Währung, ist sie gezwungen, ihre monetäre Basis zu erhöhen, wovon ein expansiver geldpolitischer Impuls ausgeht. Die Weichwährungszentralbank handelt entgegengesetzt: Sie verkauft Hartwährung und verknappt damit ihr Angebot an Zentralbankgeld. Damit induziert sie einen kontraktiver monetären Impuls. Am Ende sind die Inflationsrate und damit der kurzfristige Zins im Hartwährungsland gestiegen. Ein symmetrisches System setzt also die Bereitschaft aller beteiligten Notenbanken voraus, möglicherweise höhere Inflationsraten in Kauf zunehmen und dennoch die Kooperation aufrechtzuerhalten. Eine Stabilisierung des nominalen Wechselkurses wird über eine Anpassung der Inflationsraten erreicht. Sofern zwischen den Teilnehmerländern unterschiedliche Präferenzen bezüglich der Inflation vorliegen, wird dies nicht dauerhaft funktionieren.

So war es auch im EWS. Die Deutsche Bundesbank kam zwar ihren marginalen Interventionsverpflichtungen nach, sterilisierte sie allerdings regelmäßig, um eine Ausweitung der monetären Basis zu verhindern. Nun passierte folgendes: Kam eine Währung unter Druck - in der Regel weil die Inflationsrate höher war als in Deutschland -, war die andere Notenbank gezwungen, ihre monetäre Basis zu verknappen, indem sie Mark-Reserven verkaufte. Die Bundesbank hingegen hielt die Zentralbankgeldmenge (weitgehend) konstant. Aus Deutschland hatte die andere Notenbank also keine Erleichterung ihrer Aufgabe zu erwarten, entsprechend restriktiv mußte sie ihre Geldpolitik gestalten. Die Zinsen lagen höher als in Deutschland, dies umso mehr, je weniger glaubwürdig die Stabilisierungspolitik war, da das Publikum auf den Finanzmärkten sich für das Abwertungsrisiko kompensieren ließ. 
Aus Sicht der übrigen Notenbanken gibt es aber noch eine weitere Option: Sie können ihre Geldpolitik glaubwürdig an die der Ankerwährung koppeln. Sie profitieren damit von der Reputation der Leit-Notenbank und werden mit ähnlich niedrigen Risikoprämien auf den Zins belohnt. Sie bezahlen diese Wechselkursstabilität allerdings mit dem Verzicht auf eine eigenständige Geldpolitik, ein Verlust, der sich insbesondere zeigt, wenn ein asymmetrischer Schock die Volkswirtschaft des angekoppelten Landes trifft. Das „Pegging” einer Währung an einen monetären Anker erscheint somit vor allem vorteilhaft, a) wenn die stabilitätspolitischen Präferenzen denen im Leitwährungsland ähneln, b) wenn die Handelsverflechtungen eng sind und c) die reale Konvergenz so weit vorgeschritten ist, daß ausschließlich symmetrische Schocks auftreten. ${ }^{170}$

Im EWS entstand eine Zwei-Klassen-Gesellschaft: einerseits der D-MarkBlock (später inklusive Frankreich), andererseits die Weichwährungsländer (insbesondere Italien, ab 1990 aber auch die damals neuen EWS-Teilnehmer Großbritannien, Spanien und Portugal). Während die Länder des D-Mark-Blocks auf das Instrument der Wechselkursanpassung untereinander weitgehend verzichten konnten, waren letztere immer wieder gezwungen abzuwerten. Der Hauptgrund lag in den unterschiedlich hohen Inflationsraten.

Das EWS entwickelte sich somit zunehmend zu einem asymmetrischen System. Damit einher gehen sinkende Kosten der Koordinierung: Die Teilnehmerregierungen und -notenbanken brauchen sich nicht auf geldpolitische Ziele zu einigen, statt dessen fällt die Leit-Notenbank ihre Entscheidungen autonom, die übrigen folgen. Ohne diese Entwicklung hin zur Asymmetrie wäre das EWS vermutlich schon früher zusammengebrochen, da sich stark divergierende geldpolitische Vorstellungen in einem Rahmen aus nationalen Regierungen und Notenbanken nicht hätten zusammenführen lassen.

Das Problem des n-ten Landes. Ein asymmetrisches System unterliegt allerdings dem Problem des $n$-ten Landes - die Institutionen des Ankerwährungslandes können ihre Politik unabhängig von den übrigen Akteuren wählen, das System besitzt somit einen Freiheitsgrad. Während im Bretton-Woods-System das $n$-te Land (USA) seit der zweiten Hälfte der sechziger Jahre eine inflationäre Defizitpolitik betrieb und damit Inflation exporierte, verfolgte das $n$-te Land im EWS (Deutschland) aus Sicht vieler Partnerregierungen eine zu strikte Geldpolitik.

Das Anpassungsproblem. Trotz des erheblich engeren institutionellen Rahmens kam es auch im EWS nicht zu einer Konvergenz der Wirtschafts- und Geldpolitiken. Am ehesten gelang dies innerhalb des D-Mark-Blocks auf Basis einer mehr oder minder freiwilligen asymmetrischen Kooperation. Ansonsten aber überwog zumindest in Phase 1 das Übergewicht binnenwirtschaftlicher Ziele (Ausbeutung des kurzfristigen Phillipskurven-Trade-off) das Ziel außenwirtschaftlicher Stabilität. Auch in Phase 2 blieb diese Konvergenz brüchig, was

170 Siehe auch Abschnitt 3. 1. 5. 
letztlich zu den EWS-Krisen von 1992/93 führte. Erst in Phase 4, als der Ausschluß von der endgültigen Währungsunion als massive Sanktion im Hintergrund stand, fand diese Konvergenz statt. Ob sie in Zukunft innerhalb der Währungsunion erhalten bleibt, muß sich erst noch erweisen.

Ohne nominale Konvergenz sind aber regelmäßige Anpassungen der nominalen Wechselkurse nötig. Bleiben sie aus, kommt es im Fixkurssystem zu realen Aufwertungen der höher inflationierenden Währungen. Andererseits aber sind häufige Anpassungen der Leitkurse gerade nicht erwünscht. Im EWS wurden sie sogar bewußt erschwert, indem mit dem ECU eine Konstruktion gewählt wurde, die Leitkursänderungen an einstimmige Entscheidungen im Ministerrat knüpfte. Obwohl insgesamt 18 mal Paritätenänderungen vorgenommen wurden, kam es immer wieder zu Verzögerungen.

Das Glaubwürdigkeitsproblem. Mangelnde Konvergenz der Geld- und Wirtschaftspolitik und die träge, aber regelmäßige Anpassung der Leitkurse laden zur Spekulation ein. Häufige Änderungen der Paritäten sorgen für entsprechende Abwertungserwartungen, spekuliert wird dann über den Zeitpunkt und die Größe des Schrittes. Im EWS standen den Mitgliedsländern zwar umfangreiche Devisenkredite zur Verfügung. Doch auch diese waren begrenzt: Sie mußten zurückgezahlt werden. Unbegrenzte Interventionen waren daher nicht möglich. Zudem konnten andere Regierungen eine Änderung der Parität beantragen. Auch im EWS waren daher massive Unter- oder Überbewertungen nicht dauerhaft aufrechtzuerhalten ${ }^{171}$ - und somit Auslöser für Spekulation [Kenen 1995, Underhill 1996, Bartolini/Prati 1998)].

Spekulative Attacken wiederum schlagen um so massiver zu, je offener die Kapitalmärkte sind. Die Phasen 1 und Teile der Phase 2 des EWS waren geprägt von teilweise national abgeschotteten Märkten. Die Leitkurse ließen sich somit verteidigen, obwohl sie eigentlich hätten angepaßt werden müssen. Die Bundesbank (1997e: 123) hat diesen Effekt „Währungsunions-Illusion” genannt. Ohne die Liberalisierung der Finanzmärkte bis 1990 wären die EWS-Krisen von 1992/93 möglicherweise ausgeblieben, mindestens aber leichter unter Kontrolle zu bringen gewesen. Die Öffnung der Finanzmärkte sorgte dann jedoch letztlich dafür, daß die politischen Turbulenzen im Gefolge der Referenden in Frankreich und Dänemark zum faktischen Zusammenbruch des EWS führten. ${ }^{172}$

171 Unterbewertungen sorgen zwar nicht für den Verlust von Währungsreserven, schaffen aber Handelsungleichgewichte und inflationären Druck.

172 Die Deutsche Bundesbank (1997e: 119) bemerkt in diesem Zusammenhang: „Für die relativ harmonische Kursentwicklung im EWS dürfte allerdings nicht zuletzt eine Rolle gespielt haben, daß der Grad der Offenheit der Geld- und Kapitalmärkte der einzelnen EWS-Länder lange Zeit erhebliche Unterschiede aufwies, und dadurch verhindert wurde, daß die bestehenden Divergenzen in der Wirtschaftsentwicklung sowie in der wirtschafts- und geldpolitischen Orientierung an den Devisenmärkten zum Ausbruch kamen." 
Der Widerspruch zwischen unbeschränktem Kapitalverkehr und der Stabilität von Fixkurssystemen läßt sich nur durch eine enge Koordinierung der Politik lösen und damit letztlich durch mächtige gemeinsame Institutionen, bis hin zu einer gemeinsamen Staatlichkeit.

Vorbild für die Euro-Ära? Aller Probleme zum Trotz hat das EWS eine beachtliche Anpassungsfähigkeit an veränderte äußere Umstände bewiesen. Bemerkswert ist insbesondere, daß das EWS nicht einer Desintegration Platz machte, sondern letztlich zu einer weitergehenden Intergration und der Schaffung neuer gemeinsamer Institutionen führte (insbesondere der EZB), dies vor allem aus drei Gründen: erstens der räumlichen Nähe der beteiligten Länder und der daher großen erwarteten Integrationsgewinne, zweitens des stringenten institutionellen Rahmens [Wegner 1989: 115], drittens der Existenz eines relativ großen Landes, das sich dauerhaft und glaubwürdig zu einer ,harten” Geldpolitik verpflichtet hatte, sich daher als Anker anbot und letztlich freiwillig bereit war, seine Leitrolle beim Übergang zur dritten Stufe der Währungsunion.

Dennoch fällt die Bilanz des EWS aufgrund der oben genannten Probleme nicht sonderlich positiv aus. Selbst im engen europäischen Rahmen mit relativ ähnlichem Entwicklungsstand, einem bereits bestehenden übergeordneten institutionellen Rahmen sowie relativ ähnlichen kulturellen und institutionellen Traditionen war es nicht möglich, über eine Fixierung der Wechselkurse eine Koordinierung der (Geld-)Politik zu erreichen.

Übersetzt auf den internationalen Kontext lauten die Lehre des EWS: a) Ohne starke gemeinsame Institutionen (Leadership bzw. Hegemonie allein genügte nicht), ohne weitgehend koordinierte Geld- und Fiskalpolitik, ist ein System fester Wechselkurse bei offenen Kapitalmärkten nicht aufrechzuerhalten. Wie oben (5. 2. 1) erläutert, stellt sich hier die Fage nach der Glaubwürdigkeit gegenseitiger Beistandspakte. b) Gelingt es nicht die Geld- und Fiskalpolitik zu koordinieren, bedarf es eines glaubwürdigen Mechanismus zur regelmäßigen Anpassung der Kurse. Dies ist unter souveränen Staaten extrem schwierig zu erreichen. c) Regelmäßige, aber diskretionäre Anpassungen der Kurse fallen als Möglichkeit aus, da sie ebenfalls zur Spekulation einladen und somit das System destabilisieren.

\section{2. 3 Die Weltwirtschaftsgipfel $\left(G\right.$ 7) ${ }^{173}$}

Anders als beim Bretton-Woods-System und dem EWS handelt es sich bei den Weltwirtschaftsgipfeln nicht um ein eng koordiniertes System mit festen Spielregeln, sondern um ein Forum fallweiser, sponataner Kooperation durch die Regierungen und Notenbanken Staats- und Regierungschefs der sieben größten westlichen Industriestaaten USA, Kanada, Deutschland, Japan, Frankreich, Großbritannien und Italien (G 7). Sie stellen damit einen grundsätzlich anderen Ansatz

$173 \mathrm{Zu}$ diesem Abschnitt vgl. insbesondere Wagner (1995a: 80ff) sowie James (1997: 208ff). 
der internationalen Kooperation dar als das Bretton-Woods-System oder das EWS. Enstanden sind die G 7-Gipfel, wie oben bereits erwähnt, 1975 in einer Situation, da die Weltwirtschaft von einer ganzen Reihe ökonomischer und politischer Schocks getroffen wurde: die Folgen der Ölkrise, galloppierende Inflation bei steigender Arbeitslosigkeit (,Stagflation”), Watergate-Skandal, Niederlage in Vietnam, das Aufkommen des Linksterrorismus in Westeuropa (vor allem in Italien und der Bundesrepublik). Diese Schocks ereigneten sich in einer Phase, in der die internationale wirtschaftspolitische Kooperation auf einem Tiefpunkt angelangt war. Das System von Bretton Woods war zusammengebrochen, angeführt von den USA und Frankreich machten sich protektionistische Bestrebungen breit als Reaktion auf die stark volatilen Wechselkurse. Dies schärfte den Blick für bestehende gegenseitige Abhängigkeiten. Nach dem ersten Gipfel von Rambouillet im November 1975 wurden die G 7-Treffen zu einer regelmäßigen Einrichtung, die allerdings im Zeitablauf ihren Charakter deutlich änderte.

Ziele. Ursprüngliches Ziel war die gemeinsame Lösung der Wirtschaftskrise Mitte der siebziger Jahre, die Stabilisierung der politischen Systeme der Staaten des Westens und den Zusammenhalt im westlichen Block insgesamt. Angesichts der Existenz von „Spillover”-Effekten sollte unkooperatives Verhalten im Sinne einer „Beggar-thy-neighbour”-Politik verhindert werden, dies insbesondere durch die Wiederbelebung und Stärkung der internationalen Wirtschafts- und Währungsordnung und ihrer Institutionen (IWF, GATT). Allgemein gesprochen ist es das Ziel der G 7-Gipfel, eine offene internationale Wirtschaftsordnung zu erhalten und auftauchende Konflikte zu lösen. Daneben traten die G 7 auch als mächtige Gruppe gegenüber anderen Staaten auf, sei es gegenüber der Sowjetunion, der OPEC oder dem Irak. Die G 7 ist in diesem Kontext auch ein Gremium, das Initiativen auf anderen Gebieten anstößt, Blockaden aufzulösen sucht und Entscheidungen, etwa bei Welthandelsrunden des GATT, vorbereitet.

Die Währungspolitik hatte zu Beginn der G 7-Aktivitäten und auch in der zweiten Hälfte der achtziger Jahre einen relativ großen Stellenwert, war aber stets nur Mittel zum Zweck, um die größeren ökonomischen und politischen Ziele zu erreichen.

Zentrale Merkmale. Die jährlichen Treffen der häufig gleichen Personen sollten einen vertrauensbildenden Prozeß anstoßen. Im Rahmen der wiederkehrenden Sitzungen können Regierungen Reputation gegen ihren „Peers” aufbauen und ihrerseits „Peer pressure” ausüben. So können die Teilnehmer nach einer gewissen Phase der Vertrauensbildung davon ausgehen, daß die jeweils anderen Regierungen ihre eingegangenen Verpflichtungen einhalten.

Neben dieser Kooperation durch den Druck des Sich-wieder-in-die-Augen-sehen-müssens stießen die G 7 einen Lernprozeß in der Öffentlichkeit der teilnehmenden Ländern an. Für viele Bürger war es nicht per se einsichtig, warum eine Regierung zuweilen gegen unmittelbare nationale Interessen handeln soll, um die internationale Ordnung aufrecht zuerhalten. Die Europäer mögen heute daran 
gewöhnt sein, der Integrationsprozeß in Westeuropa dauert schon lange und ist wohl mittlerweile auch weit fortgeschritten. In den siebziger Jahren jedoch war freiwillige internationale Kooperation noch keineswegs selbstverständlich, in den USA und Japan herrscht diesbezüglich bis heute deutlich größere Skepsis als in (Kontinental-)Europa. Die G 7-Gipfel sind somit auch gegenüber der Öffentlichkeit in den beteiligten Ländern ein Symbol für die wirtschaftspolitischen Zwänge in einer interdependenten Welt.

Im Zeitablauf haben die G 7-Gipfel sich erheblich gewandelt. Sie begannen als intimes Tête-à-tête der Staats- und Regierungschefs, haben sich aber mittlerweile zu Massenereignissen entwickelt, an denen große Regierungsdelegationen teilnehmen und denen eine ausgefeilte Gipfeldiplomatie vorausgeht.

In der ersten Phase der G 7-Geschichte ging es vor allem darum, wechselseitig Vertrauen aufzubauen. So vereinbarte der Gipfel von Rambouillet konkrete Maßnahmen, insbesondere den baldigen Abschluß der Tokio-Runde des GATT und die Reform des IWF hin zu einem Überwachungssystem. Einmal kam es sogar zu einer konzertierten Konjunkturpolitik, nämlich beim Bonner Gipfel 1978. Damals einigten sich die Regierungen auf genau festgelegte quantifizierte Ziele: Der deutsche Kanzler, der italienische Ministerpräsident und der japanische Premier versprachen, das jeweilige BIP-Wachstum zu steigern, der französische Präsident sollte das Haushaltsdefizit des Staates um 0,5 Prozent erhöhen, der USPräsident die Inflation eindämmen und den Ölverbrauch der USA senken, der britische Premier gelobte, die Inflation zu dämpfen [Wagner 1995a: 89f]. Diese international koordinierte makroökonomische Steuerung ging deutlich schief, auch weil die Wirkungen der Maßnahmen zeitlich zusammenfielen mit dem zweiten Ölschock. Beide Ereignisse zusammen sorgten für einen raschen Anstieg der Inflation und Minuswachstum in der westlichen Welt.

Anfang der achtziger Jahre trafen sich die G 7-Regierungen zwar weiter, die Ergebnisse blieben jedoch unverbindlich. Dies änderte sich in der zweiten Hälfte der achtziger Jahre: Die Währungspolitik wurde für eine gewisse Zeit zum beherrschenden Thema. Wie schon zu Beginn der Gipfelaktivitäten zehn Jahre zuvor, übten sich die Regierungen und Notenbanken in häufigen Interventionen am Devisenmarkt, insbesondere mit dem Ziel den Dollar zu stabilisieren.

Seit Ende der achtziger Jahre sind die Gipfel Normalität geworden. Die Treffen beschäftigen sich in der Regel mit gerade aktuellen Probleme: von der Schuldenkrise der Dritten Welt über globale Umweltprobleme, der Hilfe für Osteuropa nach dem Fall des Eisernen Vorhangs 1989 oder die Emerging-MarketsKrise $1997 \mathrm{ff}$. Konkrete Maßnahmen gehen selten davon aus. Die Gipfel dienen mehr dazu, das Klima zu verbessern. Aus diesem Grund darf seit 1992 auch der russische Präsident als achter Teilnehmer beim politischen Teil der Treffen zugegen sein.

Was die währungspolitische Koordinierung angeht, so ist eine deutliche Akzentverschiebung zu beobachten. Die Emerging-Market-Krisen der neunziger 
Jahre haben eine internationale Überwachung der nationalen Politiken, eine Harmonisierung der nationalen statistischen Standards und der Aufsichtsregeln für Kreditinstitute und andere Finanzinstitutionen sowie eine verbesserte Koordinierung der internationalen Gremien und Organisationen auf die Tagesordnung gerückt. Dieser Ansatz, der vielfach als „neue internationale Finanzarchitektur” bezeichnet wird, stellt folglich einen Ordnungsrahmen dar, der das möglichst reibungslose Funktionieren der internationalen Finanzmärkte sicherstellen soll.

Institutionellen Niederschlag hat dieser Ansatz insbesondere im Financial Stability Forum (FSF) gefunden, einem Rat aus zehn Vertretern der G 7-Staaten und von internationalen Organisationen, insbesondere dem IWF, der Weltbank, der BIZ und der OECD. Daneben gibt es ein kleines Sekretariat, das dem Vorsitzenden zuarbeitet; erster Vorsitzender des Gremiums ist Andrew Crockett, General Manager der BIZ. Das FSF trifft mindestens zweimal jährlich zusammen und unterrichtet die Finanzminister und Notenbankgouverneure der G 7. Es ist angelegt mit Blick auf eine Erweiterung um weitere Staaten, insbesondere um Entwicklungsländer mit schwachen Behörden für die Finanzaufsicht [Tietmeyer 1999, Group of Seven 1999].

Probleme der G 7. In Endeffekt konnte der mittlerweile zweieinhalb Jahrzehnte andauernde G 7-Prozeß nicht verhindern, daß es immer wieder $\mathrm{zu}$ massiven Ungleichgewichten in der Weltwirtschaft kam, insbesondere Anfang der achtziger Jahre. Als Erfolg kann jedoch gewertet werden, daß trotz allem das internationale Handelssystem offen blieb und sogar weiter geöffnet wurde. Auch trugen die G 7-Gipfel entscheidend dazu bei, daß es überhaupt möglich war, im Falle grober Fehlbewertungen (insbesondere des US-Dollar) konzertiert auf den Devisenmärkten zu intervenieren.

Dennoch ist kaum bestreitbar, daß die Gipfel auch inhaltlich unter der großen Zahl der Teilnehmer leiden, da sie längst nicht mehr auf die höchste politische Ebene beschränkt sind. Sie nehmen dem Diskussionsprozeß seine Intimität, stellen allerdings die intergouvernementale Kooperation auf eine breitere Grundlage (Beamtenebene). Die schiere Größe des Teilnehmerkreises führt zu Schwerfälligkeit und zu verstärktem Einfluß der Bürokratien in den beteiligten Ländern. Diplomatische Finesse verdrängt ökonomische Einsicht und politischen Mut.

Immer wieder kam es zu Phasen, in denen die Regierungen keinen Konsens zu erzielen vermochten. $\mathrm{Zu}$ unterschiedlich waren die vorherrschenden ökonomischen Dogmen, insbesondere in der ersten Hälfte der achtziger Jahre machte der Streit um das „wahre Modell” Ansätze zu Kooperation zunichte. In einem Setting wie den G 7, die ja über keinen institutionellen Überbau verfügen, führt solcher Dissens quasi automatisch zu Stillstand: Ohne die Bereitschaft zur Kooperation aller Beteiligten tut sich nichts.

Auch die G 7 waren geprägt von der nach wie vor herrschenden Asymmetrie in den internationalen Wirtschaftsbeziehungen, die ein Dilemma aufweisen: Die USA als stärkste Macht waren am wenigsten auf internationale Kooperation 
angewiesen - ohne oder gar gegen sie aber war internationale Kooperation sinnlos. Der Erfolg der G 7-Gipfel hing daher unausweichlich mit der innenpolitischen Konstellation in den USA zusammen.

Problematisch ist auch die Länderzusammensetzung. Insgesamt verlieren die G 7-Staaten an ökonomischem Gewicht in einer Welt, da sich andere Regionen, insbesondere Asien, dynamisch entwickeln. Dies schafft ein Macht- wie auch ein Legitimationsproblem. Daß Rußland dem Kreis angegliedert wurde, hat vor allem sicherheitspolitische, nicht aber ökonomische Gründe. Dies alles trägt zu einer schleichenden Schwächung des Systems bei. Währungspolitik spielt aus folglich eine zunehmend untergeordnete Rolle im G 7-Mechanismus.

Die G 7 in der Euro-Ära. Vier der sieben Staaten gehören der EU an, drei - Deutschland, Frankreich und Italien - gehören zur Gruppe der EWU-Gründer. Es ist offensichtlich, daß dies die G 7 fundamental verändern wird. Dieser Wandel wird jedoch nicht abrupt stattfinden, sondern allmählich. Denn aufgrund des zur Zeit des EWU-Starts schwachen institutionellen Rahmens in der EU bleiben bis auf weiteres die nationalen Regierungen der EU-Staaten die Machtzentren, ohne allerdings die mächtigen Institutionen ihrer nationalen Notenbanken (insbesondere die Deutsche Bundesbank) zur Seite zu haben - was für eine mögliche vorübergehende Schwächung der Position der Europäer spricht. Mit zunehmender Dauer dürften die EWU-Staaten jedoch mehr und mehr Entscheidungen auf zentraler Ebene treffen. Je mehr dies der Fall ist, desto stärker werden die europäischen G 7-Staaten als Block auftreten. Mit anderen Worten: Im Zeitablauf werden sich die G 7 zu einer G 3 entwickeln: USA, Euroland und Japan.

Sofern die EU sich im Innern effizientere Entscheidungsstrukturen als heute gibt, bedeutet dies für die Weltwirtschaftsgipfel eine Senkung der Transaktionskosten. Sich zu einigen wird somit einfacher. Folglich besteht die Möglichkeit zu einer engeren Koordinierung als bisher. Hierfür ist jedoch eine prinzipielle Bereitschaft zur Kooperation nötig, bis hin zum Verzicht auf essentielle staatliche Souveränitätrechte.

In der Euro-Ära tritt aber ein neues Hindernis auf: Bisher waren die USA die einzige „Vetomacht” unter den G 7, die zugleich relativ wenig Interesse an internationaler Kooperation hatten. Mit dem Euroland tritt ein zweiter Spieler hinzu, dessen Interessen ganz ähnlich gelagert sind. Es ist daher gut möglich, daß die Chancen für eine erfolgreiche G 7-Zusammenarbeit künftig sogar schlechter stehen als in der Prä-Euro-Ära - allen Transaktionskosteneinsparungen zum Trotz. Wie auch immer konkret das Ergebnis aussehen wird, soviel ist sicher: Die EWU wird auf mittlere Sicht das G 7-Zusammenspiel grundlegend verändern.

\section{3 Frühere Vorschläge im Lichte der Euro-Ära}

Nachdem der vorangehende Abschnitt mögliche real existierende historische Vorbilder untersuchte, sollen im folgenden kurz einige kursierende Vorschläge zur Neuordnung des internationalen Währungssystems auf ihre Relevanz für die 
Euro-Ära beleuchtet werden. Vorstöße dieser Art gab es in den vergangenen zweieinhalb Jahrzehnten eine ganze Reihe. Der Anlaß dafür war die immer wieder auftretende Unzufriedenheit mit dem System floatender Wechselkurse. Das Mißvergnügen entzündete sich vor allem an drei Eigenschaften des Flexkurssystems: der Volatilität der nominalen und realen Wechselkurse, den anhaltenden Fehlbewertungen der wichtigsten Weltwährungen und der zeitweise ausgeprägten rein nationalen Fixierung der Geld- und Fiskalpolitik, ohne die außenwirtschaftlichen Folgen zu berücksichtigen.

Naturgemäß waren in den meisten Fällen akute Krisenerscheinungen Anlaß, Vorschläge zur Reform des internationalen Währungssystems vorzubringen. Dies gilt vor allem für die durch die Reagonomics ausgelösten Turbulenzen in der ersten Hälfte der achtziger Jahre. Aber auch in den ausgehenden neunziger Jahren lassen die Emerging-Market-Krisen erneut Unbehagen am Funktionieren eines Flexkurssystems bei offenen Kapitalmärkten aufkeimen.

Die im folgenden behandelten Vorschläge stehen ausnahmslos seit weit mehr als einem Jahrzehnt in der akademischen Diskussion. Aus diesem Grund werden sie auch lediglich knapp behandelt.

\section{3. 1 Zielzonen für Wechselkurse}

John Williamson vom Washingtoner Institute for International Economics hat diesen Vorschlag bereits 1983 in die Diskussion geworfen und ihn seither mehrfach erneuert [z. B. Williamson 1990]. ${ }^{174}$ Aktualität hat die Idee der Zielzonen in der jüngsten Vergangenheit in Deutschland gewonnen, insbesondere durch die Thesen des Ex-Staatssekretärs im deutschen Bundesfinanzministerium, Heiner Flassbeck, der Williamsons Konzept aufgreift [Flassbeck 1998].

Grundkonzeption. Williamson selbst charakterisiert seinen Vorschlag als Mittelweg zwischen völlig freien Wechselkursen und einem Fixkurssystem à la Bretton Woods: „[It] seeks to combine the real social benefits that exchange rate flexibility can bring while overcoming the weaknesses of unmanaged floating" [Williamson 1990: 3].

Im Zentrum des Vorschlags stehen relativ weite Zielzonen der nominalen Wechselkurse, etwa \pm 10 Prozent, zwischen den wichtigsten Währungen der Welt, in Williamsons Formulierung müßten mindestens US-Dollar, D-Mark und japanischer Yen, besser noch die übrigen G 7-Währungen dabei sein. Als Leitkurse werden „fundamentale Gleichgewichtskurse" (Fundamental Equilibrium Exchange Rate, FEER) kalkuliert. Diese definiert Williamson als diejenigen Wechselkurse, die auf mittlere Sicht den beteiligten Volkswirtschaften zugleich ein internes und ein externes Gleichgewicht bescheren. Die Regierungen der Staaten verhandeln ein solches Set von Gleichgewichtskursen.

174 Einen Überblick über die Diskussion dieses Vorschlags findet sich etwa bei Willms (1992: 166ff), Wagner (1995a: 132ff). 
Es ist zu beachten, daß die FEERs selbst von politischen Einschätzungen abhängen: Internes Gleichgewicht bezieht sich vor allem auf eine Übereinstimmung bezüglich der NAIRU, also der niedrigst möglichen Arbeitslosenquote, die noch bei Preisstabilität erreichbar ist. Das Konzept des externen Gleichgewichts erfordert ein Urteil über die angestrebte Leistungsbilanzposition.

Haben sich die Regierungen über diese Größen geeinigt, lassen sich die FEERs - und damit die Leitkurse - berechnen [Williamson 1990: 5f]. Diese Kalkulation soll der Internationale Währungsfonds übernehmen, ebenso wie eine regelmäßige Überprüfung der Leitkurse. Sie sollen entsprechend der herrschenden Inflationsdifferentiale angepaßt werden: Hochinflationsländer werten ab, Niedriginflationsländer auf. Sofern also nennenswerte Inflationsdifferentiale bestehen, handelt es sich um „Crawling bands”, die einem „Crawling peg” mit einer weiteren Schwankungsbreite entsprechen. Aber auch andere fundamentale Größen sollen berücksichtigt werden: unterschiedliche Produktivitätssteigerungen in den Sektoren für handelbare Güter, reale Schocks oder neue marktrelevante Informationen [Williamson 1990: 6]. Ziel ist es, die realen Wechselkurse konstant zu halten.

In internationalen Verhandlungen verpflichten sich die Regierungen, ihre Geld- und Fiskalpolitik unter Berücksichtigung des Wechselkursziels zu betreiben. Nähert sich der Wechselkurs einer der Grenzen der Zielzone, so ist zunächst die Geldpolitik gefragt: Im Falle einer Abwertung (Aufwertung) der betreffenden Währung, setzt die Notenbank die Leitzinsen herauf (herab). Wird dadurch das interne Gleichgewicht gestört, so ist die Fiskalpolitik zu einer Sekundärreaktion aufgefordert: Führt eine Zinserhöhung zu einer höheren Arbeitslosenquote, hat die Regierung mit binnennachfragebelebenden Maßnahmen zu reagieren. Sofern Regierungen und Zentralbanken eine solche Reaktion glaubwürdig darstellen können, dürften Zinsschritte häufig gar nicht nötig sein, sondern Interventionen und verbales Zähneknirschen („Jawboning”) ausreichen, um die Kurse in der Zone zu halten.

Alternativ zu solchen geld- und fiskalpolitischen Maßnahmen ist freilich auch eine Verschiebung der Zonen möglich. Dies wäre etwa gerechtfertigt, wenn es sich um eine bleibende Neupositionierung der Volkswirtschaft handelt, etwa wenn sie durch einen dauerhaften asymmetrischen Schock getroffen wurde. Eine Regierung könnte Konsultationen mit ihren internationalen Partnern anstrengen mit dem Ziel, ohne politische Gegenmaßnahmen den Wechselkurs aus der Zone heraustreiben zu lassen. Es gäbe dann eine Phase der Überprüfung. In dieser Zeit könnten Fachleute sich ein Urteil darüber bilden, um welche Art von Schock es handelt und welche politische Reaktion die beste wäre. Die Diskussionsphase und gegenseitigen Konsultationen der Regierungen führen zudem zu einer Verbreitung von Informationen auf den Märkten, die das Publikum möglicherweise sensibler für Fundamentaldaten machen - und somit weniger anfällig für spekulative Ralleys. Williamson nennt diese Art der weichen Zonengrenzen „Soft buffers”. 
In einem weitergehenden Vorschlag findet sich sogar eine Art globale Stabilisierungspolitik, die sich an aktiven Regeln und Zwischenzielen orientiert: a) Die Regierungen sollen sich auf eine durchschnittliche Wachstumsrate für das globale Bruttosozialprodukt einigen. Zeigen die Wachstumsprognosen, daß die Zielrate unterschritten (überschritten) wird, sollen die Notenbanken zu einer abgestimmten Aktion die Zinsen senken (anheben). Durch dieses symmetrische Vorgehen soll das Anker-Problem (Problem des $n$-ten Landes) vermieden werden. b) Die Zinsdifferenzen zwischen den Teilnehmerstaaten sollen geändert werden, um die Wechselkurse innerhalb der Zielzonen zu halten. c) Die Fiskalpolitik soll nationale Wachstumsziele erreichen helfen [Williamson 1990: 7f].

Beurteilung. Williamsons Vorschlag sucht eine neue Balance zwischen nationalstaatlicher Souveränität und internationaler Koordinierung. Das System basiert auf wenigen, relativ offenen Regeln, die viel Raum für diskretionäre Entscheidungen der politischen Entscheidungsträger lassen. Primäres Ziel ist es, einen permanenten Konsultationsprozeß zwischen den großen Wirtschaftsmächten über die Makropolitik in Gang zu bringen. Dies ist das generelle Thema der Zielzonenvorschlags, der unter dem damals aktuellen Eindruck der US-Politik unter der ersten Reagan-Administration entstand.

Der Grundtenor, daß jede Regierung die von ihr verursachten „Spillover”Effekte in ihr Kalkül einbeziehen sollte, ist ohne weiteres zu begrüßen. Indes hat der Vorschlag eine Menge gravierender Nachteile, von denen einige kurz angesprochen werden sollen:

Mehr Instabilität durch Koordinierung? Im Kern basiert das System auf einem diskretionären nachfragezentrierten Politikansatz. Dies ist dazu angetan, mehr Instabilität ins internationale Währungssystem zu tragen, nicht weniger. Denn die Marktteilnehmer werden über den Ausgang von Entscheidungsprozessen spekulieren. Den diskretionären Entscheidungen ist ein multilateraler Diskussions- und Evaluierungsprozeß vorgeschaltet, der äußerst zeitaufwendig sein dürfte, zumal Entscheidungen stets in gegenseitigem Einvernehmen fallen müssen. Dadurch entsteht eine lange administrative Verzögerung (,Inside lag”) [z. B. Issing 1996a: 174ff], die zu einem falschen Timing der Maßnahmen führt: Sie kommen zu spät und wirken daher mit einiger Wahrscheinlichkeit in die falsche Richtung. Nicht nur die Entscheidungen sind mit großer Unsicherheit behaftet, auch die Umsetzung in reale Politik dürfte Probleme bereiten. Denn dem System fehlt ein Sanktionsmechanismus. Es basiert einzig auf gegenseitigem Vertrauen.

Wechselkurse werden politisiert. Zwar kommt dem Internationalen Währungsfonds - und damit weitgehend unabhängigen Experten - eine prominente Rolle zu. Dennoch entscheiden letztlich die Regierungen über die Wechselkurse, und sie dürften sie zu ihren kurzfristigen Zwecken einsetzen. Dies wiegt noch schwerer, als die FEER kein allgemein akzeptiertes Maß für den „richtigen” Wechselkurs ist. Da regelmäßig eine umfassende Überprüfung der FEER erfolgen 
soll, dürften die Marktteilnehmer regelmäßig auf Neubewertungen hin spekulieren. Auch dies ist ein Herd der Instabilität.

Mangelnde Glaubwürdigkeit. Dem System fehlt es insgesamt an Glaubwürdigkeit. Einerseits äußert Williamson die Hoffnung, die Spekulation eindämmen zu können, da die Marktteilnehmer mit entsprechenden Gegenmaßnahmen seitens der Notenbanken und Regierungen rechnen können. Andererseits empfiehlt er, die Grenzen der Zielzonen als „Soft buffers” auszugestalten, die gerade solche Gegenmaßnahmen wieder in Frage stellen. Die erhoffte Stabilisierung der Erwartungen dürfte daher ausbleiben, entsprechend stark müssen die (zins-)politischen Maßnahmen ausfallen, um effektiv sein zu können.

Geldpolitik im Dienst der Konjunktur. Den Notenbanken kommt in dem System die Hauptrolle zu: Sowohl die Wechselkursstabilisierung als auch die globale Wachstumspolitik soll sich zuvörderst der Leitzinsen als Instrument bedienen. Das aber bedeutet, daß die Notenbanken ihre primäre Aufgabe verlieren, nämlich die Geldwertstabilität zu gewährleisten. Inwieweit das System überhaupt mit unabhängigen Notenbanken funktionsfähig ist, bleibt zweifelhaft - schließlich verhandeln ja die Regierungen über Wechselkursziele. Das starke Gewicht der Regierungen, die über einen relativ kurzen Zeithorizont verfügen, lassen einen allzu expansiven Kurs der Geldpolitik und eine Rückkehr der Inflation befürchten.

Ausreichender gegenseitiger finanzieller Beistand? Entschließen sich Regierungen und Notenbanken, einen Kurs zu verteidigen, indem sie symmetrisch intervenieren, benötigt dieses System einen sehr großzügigen finanziellen Beistandspakt, um den unter Druck geratenen Instituten die nötigen Mittel zur Verfügung zu stellen. Sind die beteiligten Staaten nicht dazu bereit, schafft dies ein weiteres Glaubwürdigkeitsproblem, daß zur Spekulation einlädt.175

Der Zielzonenvorschlag in der Euro-Ära. Die Einbindung des Euro in ein solches System würde große Gefahren bergen, insbesondere in den ersten Jahren der Währungsunion. Bevor die Europäische Zentalbank eine eigene stabilitätspolitische Tradition und Reputation aufbauen kann, würde sie in den Dienst der Wechselkurspolitik gestellt. Die Folgen wären ein erhöhter Risikozuschlag auf den Zins und damit verbundene Wachstumseinbußen.

Zum anderen kann das Euroland in seiner derzeitigen Verfassung kaum ein verläßlicher Verhandlungspartner sein. Statt bisher einer europäischen Regierung - der deutschen nämlich -, wären nun alle elf Euroland-Regierungen an den Verhandlungen beteiligt. ${ }^{176}$ Die Folge ist ein möglicherweise unübersichtlicher Verhandlungsprozeß mit großem Trägheitsmoment, insbesondere was Realignments von Kursen angeht. Noch schwieriger wird die Koordinierung, da auch die Fiskalpolitik zwischen den Teilnehmerstaaten eines solchen Systems mit einbezo-

175 Siehe auch die diesbezügliche Argumentation unter 5. 3. 1 und 5. 3. 2.

176 Siehe Abschnitt 2. 3. 
gen werden müßte. Wie in Kapitel 2 dargestellt, ist die Koordinierung der nationalen Fisci innerhalb der EU relativ locker.

Insgesamt erscheint der Vorschlag Williamsons nicht als Blaupause für die Euro-Ära geeignet. Statt größere Stabilität und höhere Wachstumsraten zu erreichen, spricht diese Art der Koordinierung eher dafür, daß der gegenteilige Effekt eintritt: ein Verlust an Vertrauen in die Notenbanken, folglich steigende Zinsen, eine höhere Wechselkursvolatilität und am Ende Wachstumsverluste.

\section{3. 2 Ein Währungsstandard für die Industriestaaten}

Während der Vorschlag Williamsons als eine Art globaler Keynesianismus bezeichnet werden kann, hat Ronald McKinnon im Laufe der achtziger Jahre verschiedendlich Vorstöß zugunsten eines globalen Monetarismus gemacht [ $\mathrm{z}$. B. McKinnon 1986, auch Willms 1992: 162ff, Wagner 1995a: 136ff].

Grundkonzeption. McKinnons Vorschlag ähnelt einem Goldstandard ohne Gold, letztlich also einer Währungsunion ohne gemeinsame Institutionen. Zentrales Element ist eine multilaterale Geldmengenregel, nach der die beteiligten Länder das Geldangebot steuern. Die drei größten Staaten - die USA, Japan, Deutschland (damit mittelbar in der Prä-Euro-Ära die übrigen EWS-Länder) sollen sich darauf verständigen, die Wachstumsrate der Weltgeldmenge zu verstetigen. Die Wachstumsrate des Geldangebots soll so festgelegt werden, daß das Preisniveau der handelbaren Güter in den beteiligten Ländern konstant bleibt. Daraus ergeben sich konstante nominale Wechselkurse (gemäß KKP).

Nach einer Übergangszeit ${ }^{177}$ mit relativ weiten Bandbreiten sollen die nominalen Wechselkurse innerhalb einer Bandbreite von nicht mehr als \pm 1 Prozent festgezurrt werden. Kommt es zu Bewegungen der Wechselkurse, greifen die Notenbanken mittels nichtsterilisierter Interventionen ein.

McKinnon sieht ein symmetrisches Vorgehen vor, wodurch das Problem des $n$-ten Landes ausgeschaltet wird: Gäbe es beispielsweise eine Aufwertungstendenz des Dollar gegenüber dem Yen, so würde die Fed die monetäre Basis ausweiten, die Bank of Japan hingegen würde das Gegenteil tun und ihr Angebot an Zentralbankgeld verknappen. Die kurzfristigen Zinsen, die Weltgeldmenge und die Wechselkurse blieben konstant.

Der Vorschlag setzt auf eine Stabilisierung der Erwartungen seitens des Publikums auf den Finanzmärkten. Da die Wechselkurse fundamental - das heißt, durch eine abgestimmte, stabilitätsorientierte Geldpolitik -, gerechtfertigt sind, ist die Ankündigung der Wechselkursziele glaubwürdig. Dafür spricht zum einen, daß die Reaktionsregeln der Notenbanken bekannt sind, zum anderen daß nicht die Regierungen diese Politik tragen, sondern die Notenbanken. Am Ende, so erwartet McKinnon, müßten die Notenbanken kaum noch intervenieren. Der gemeinsame Währungsstandard werde zum sich selbst stabilisierenden Prozeß.

177 Hierzu näher z. B. Wagner (1995a: 137f). 
Den Vorteil gegenüber einer formellen globalen Währungsunion sieht McKinnon darin, daß die nationalen Zentralbanken weiterhin die Aufsicht über das jeweilige Bankensystem ausüben und als „Lender of last resort” für die Regierungen fungieren könnten.

Beurteilung. Der Vorschlag McKinnons besticht durch seine einfache Eleganz. Das Problem, daß internationale Koordinierung häufig zu inflationären Tendenzen führt, versucht er dadurch zu lösen, daß die Notenbanken die maßgeblichen Akteure sind und auf eine strikte monetaristische Regel festgelegt werden. Der Vorteil liegt eindeutig im klaren Assignment der Aufgaben. Allerdings gibt es auch hier einige Einwände:

Genügt die Disziplin? Das System erfordert ein hohes Maß an Disziplin sowie sehr ähnliche stabilitätspolitische Vorstellungen. Nur wenn sich in den teilnehmenden Länder Regierungen und Tarifparteien den internationalen monetären Regeln unterordnen, kann es funktionieren. Falls die Regierungen in großem Umfang schuldenfinanzierte Programme fahren, wird sich das System nicht aufrecht erhalten lassen. Angenommen, die US-Regierung betriebe eine solche „Deficitspending"-Politik. Die Folge wäre Kapitalimport und damit eine Tendenz zur Aufwertung des Dollar. Gemäß der McKinnon-Regel müßte die Fed nun intervenieren, indem sie Dollars verkauft und die übrigen Währungen ankauft. Die übrigen Notenbanken agieren spiegelbildlich. In den USA herrschte ein doppelter expansiver Impuls, während die übrigen Länder einen kontraktiven Kurs steuern müssen. Es käme nicht nur zu einem erhöhten Inflationsdifferential mit entsprechendem Druck auf die Wechselkurse, sondern auch zu politischen Spannungen, die das ganze System zu sprengen drohen. Daher wird ein solcher Währungsstandard, wie die Europäische Währungsunion auch, nicht ohne ein Mindestmaß an fiskalpolitischer Koordinierung auskommen.

Fallen andererseits die Lohnabschlüsse der Tarifparteien in einem der beteiligten Länder zu hoch aus, entsteht von dieser Seite inflationärer Druck und damit eine Tendenz zur Abwertung der Währung. Um gegenzusteuern, ist die Notenbank verpflichtet, eigene Währung gegen Hergabe von Devisen anzukaufen. Die Symmetrie des Modells erfordert nun, daß auch die übrigen Notenbanken aktiv werden, und zwar in entgegengesetzter Richtung, mithin expansiv. Dies aber kann das Stabilitätsziel in den übrigen Ländern gefährden. In der Folge dürften diese Notenbanken versuchen, ihre Interventionen zu sterilisieren, wodurch hingegen die gesamte Anpassungslast bei der Notenbank des Landes mit den Inflationstendenzen liegt. Dies ist exakt die Strategie, welche die Bundesbank im EWS betrieben hat (siehe oben) und die letztlich die symmetrische Konzeption zu einem asymmetrischen Modell mit der D-Mark als Ankerwährung sich entwickeln lassen hat.

Abfederung von Schocks? Regierungen und Notenbanken geben die Geldund Wechselkurspolitik als nationale Politikinstrumente auf. Sie sind gezwungen, sich relativ engen Regeln zu unterwerfen. Auch wenn dies aus Ökonomensicht 
wünschenswert erscheinen mag: Es erscheint doch reichlich heroisch anzunehmen, daß real existierende Politiker eine solche Selbstkastration vornehmen würden.

Keine Sanktionen. Das System verfügt über keinerlei Sanktionsmechanismen. Wie werden die anderen Parteien sich verhalten, wenn ein Land gegen die Regeln verstößt? Aus der Unsicherheit darüber erwächst ein Glaubwürdigkeitsproblem. Dieser Mangel an Glaubwürdigkeit tritt insbesondere auf, wenn ein Land von einem asymmetrischen Schock getroffen wird. ${ }^{178}$ In diesem Fall bestehen starke Anreize, den Wechselkurs als Anpassungsinstrument einzusetzen. Möglicherweise ist dies sogar eine „First-best”-Strategie. Eine solche Kursanpassung aber schließt das McKinnon-System aus. Aus gutem Grund: Würde es sie zulassen, hätten die Marktteilnehmer immer wieder Anlaß über Realignments zu spekulieren, was eine Unsicherheitsquelle wäre. So aber steht das System vor einem Dilemma: Läßt es Kursanpassungen zu, schafft es Glaubwürdigkeitsdefizite, läßt es sie nicht zu, reizt es zur Spekulation über ein Ende des gesamten Systems.

Ein glaubwürdiger Kreditmechanismus? Auch beim McKinnon-System taucht das Problem auf, daß ein sehr großzügiger gegenseitiger Beistandspakt nötig ist, damit die Notenbanken den gegenseitigen Interventionsverpflichtungen in jedem Fall nachkommen können.

Jedes monetäre System braucht eine Balance aus Regeln und Spielräumen für diskretionäre Politik angesichts einer höchst unvollkommen vorhersehbaren Welt. Beim McKinnon-System scheint das Pendel zu weit in Richtung Regeln ausgeschlagen zu sein. Selbst als orthodox geltende Notenbanken wie die Deutsche Bundesbank haben sich in der Vergangenheit nicht an ein starres Geldmengenkonzept gehalten, sondern pragmatischerweise daneben ein ganzes Set von Indikatoren mit im Blick gehabt. Für die Anwendung in der realen Welt erscheint er daher nicht sonderlich brauchbar.

Der Währungsstandard in der Euro-Ära. Unter den Bedingungen der Europäischen Währungsunion ist es noch unwahrscheinlicher, daß das Euroland, die USA und Japan sich zu einem derart restriktiven System unterwerfen. Denn sie alle sind relativ geschlossene Volkswirtschaften, die realwirtschaftlichen Auswirkungen von Wechselkursvariationen dürten relativ gering sein. ${ }^{179}$ Der Nutzen, sich derart starren Regeln zu unterwerfen, ist daher weit geringer als bei eng miteinander verflochtenen Volkswirtschaften wie den EU-Staaten.

Die Ausrichtung der Geldpolitik an einem Wechselkursziel erscheint auch noch aus anderen polit-ökonomischen Gründen nicht wünschenswert. Die Verhandlungen über ein internationales Währungssystem führen notwendigerweise die Regierungen, die Notenbanken sind bestenfalls daran beteiligt. Dies ist gerade

178 Siehe hierzu Kapitel 2.

179 Siehe Kapitel 3. 
unter dem Setting der Europäischen Währungsunion schwierig, die ja eine ausgeprägte Asymmetrie zwischen politischer und geldpolitischer Integration vorsieht und die EZB vor die schwierige Situation stellt, mit recht heterogenen geldpolitischen Traditionen und Vorstellungen konfrontiert zu sein. Die Schaffung eines internationalen Währungssystems würde hier gerade in der Anfangsphase der Euro-Ära die Position der EZB schwächen statt sie zu stärken. Denn selbst wenn die ursprüngliche Intention eine andere wäre, letztlich käme es auch hier quasi zwangsläufig zu einer Politisierung der Wechselkurse und damit auch der Geldpolitik.

Abgesehen von solchen eher grundsätzlichen Überlegungen ergeben sich gerade in den ersten Jahren der Europäischen Währungsunion gravierende technische Probleme. Denn die Beziehungen zwischen Geldangebot und Preisentwicklung im Euroland sind höchst unsicher. Ob die Geldnachfrage überhaupt stabil ist - wie sie es in der Bundesrepublik war -, muß sich erst noch herausstellen. Aus diesem Grund ist es auch höchst unsicher, ob die EZB die Geldmengenstrategie der Bundesbank auf Euroland-Ebene fortsetzen kann. In Abwesenheit eines Modells für den Transmissionsmechanismus im neuen Währungsraum sollte auch noch ein Inflationsziel hinzutreten. Daneben wird die EZB auf ein ganzes Bündel von Indikatoren angewiesen sein [Schrader 1998, EZB 1999a]. Würde sie ihre Politik einzig auf den Wechselkurs hin ausrichten, wäre dies höchst gefährlich. Eine starre (globale) Geldmengensteuerung à la McKinnon ist daher schon aus technischen Gründen unmöglich. Wegen der beschriebenen Instabilitäten der Geldnachfrage sind auch andere Notenbanken, insbesondere die Fed, vom Geldmengenkonzept abgegangen und verfolgen nun einen pragmatischeren Kurs.

Möglich ist aber auch ein anderes Vorgehen: Es ist durchaus denkbar, daß sich der internationale institutionelle Wettbwerb als Koordinierungsinstrument bewährt und sich unter den Notenbankern eine allgemein anerkannte Inflationsnorm herausbildet. Eine solche informelle Form der Koordinierung käme ohne starre Regeln aus, sondern würde es den Notenbanken freistellen, mit welcher Strategie und welchen Instrumenten sie dieses Ziel zu erreichen gedenken. Wenn aber in allen wichtigen Industrieländern die Inflationsraten in etwa gleich hoch sind, fällt der wichtigste fundamentale Grund für Änderungen der Wechselkurse weg. Allein dies dürfte die Volatilität der Kurse dämpfen. ${ }^{180} \mathrm{Im}$ übrigen dürfte ein solch dezentrales System weit mehr Glaubwürdigkeit entwickeln, da es vor allem auf die Kontrolle der Institutionen durch die nationale (bzw. in der in der EU europäische) Öffentlichkeit setzt, die weit effektiver ist als die Kontrolle durch „Peer pressure” auf internationaler Ebene.

In gewisser Weise hat der monetaristische Konsens der späten achtziger und der neunziger Jahre eine solche wettbewerbsgesteuerte Koordinierung unter den großen Industrienationen bewirkt. Meist wird eine Inflationsrate von bei zu

180 Siehe Abschnitt 4. 4. 
zwei Prozent als mit Preisstabilität vereinbar angesehen. Freilich konnte McKinnon, als er sein Konzept in den frühen achtziger Jahren entwarf, diese Entwicklung nicht absehen.

\section{3. 3 Eine Steuer auf Devisentransaktionen (Tobin-Steuer)}

Anders als die Vorschläge von Williamson und McKinnon handelt es sich bei dem Konzept von James Tobin (1978) nicht um den Versuch, die Makropolitiken der Industrieländer enger zu koordinieren, sondern im Gegenteil um die Rückgewinnung nationaler Spielräume in einer Welt offener Kapitalmärkte. Regierungen und Notenbanken sollen wieder in die Lage versetzt werden, unterschiedliche Zinssätze zu erheben, ,[...] allowing national monetary policies to respond to domestic macroeconomic needs" [Eichengreen/Tobin/Wyplosz 1995: 164f]. Als Instrument hierzu schlägt Tobin die Einführung einer Steuer auf Devisentransaktionen vor („Tobin-Steuer”).

Grundkonzeption. Tobin folgt in seiner Analyse Dornbusch (1976), der den Grund für die große beobachtete Volatilität der Wechselkurse („Overshooting”, „Undershooting”) in einer unterschiedlichen Reaktionsgeschwindigkeit der Güter-, Arbeits- und Finanzmärkte sieht. Weil Güterpreise und Löhne sich erheblich träger anpassen als Assetpreise auf den Finanzmärkten, kommt es zu überschießenenden Reaktionen der Wechselkurse, die sich zurückbilden, wenn die Preise in den realwirtschaftlichen Sektoren sich angepaßt haben. Die Folgerung daraus lautet: „If some markets adjust imperfectly, welfare can be enhanced by intervening in the adjustment of others" [Eichengreen/Tobin/Wyplosz 1995: 164].

Dieser "Sand in the wheels of international finance" soll eine Devisenumsatzsteuer darstellen: eine Steuer auf alle Devisenkassa- und Devisentermintransaktionen. Da sich die Steuer bei kurzfristigen Geschäften erheblich stärker auswirkt als bei langfristigen Portfolio- bzw. Direktinvestitionen, soll sie kurzfristige, von adaptiven Erwartungen getriebene, spekulative Transaktionen unattraktiver machen, ohne die fundamental motivierten Langfristinvestitionen nennenswert zu beeinflussen. Auch den Güterhandel würde eine solche Steuer nicht merklich beeinflussen, da sie im Vergleich zu Transport- und sonstigen Transaktionskosten auf den Gütermärkten verschwindend niedrig wäre.

Ziel der Tobin-Steuer ist es, auf den superschnellen, supereffizienten Finanzmärkten ohne Kapitalverkehrsbeschränkungen die Entscheidungen des Publikums rationaler $\mathrm{zu}$ gestalten. Statt kurzfristige, fundamental ungerechtfertige Bewegungen ausznutzen, würden die Börsenhändler dazu angeregt, sich mehr von den Fundamentaldaten leiten zu lassen. Davon soll eine stabilisierende Wirkung auf die Kurse ausgehen. Dies ist sowohl in einem Regime flexibler als auch gepeggter Wechselkurse sinnvoll.

Eine Tobin-Steuer muß universell und uniform erhoben werden. Alle Länder der Erde müssen daran teilnehmen und sie in gleicher Höhe und mit gleichen Regeln erheben. Ansonsten kommt es zu Ausweichreaktionen in Richtung „Tax 
havens". Über die Einhaltung der international vereinbarten Regeln sollen die BIZ oder der IWF wachen.

Beurteilung. Den Ausgangspunkt der Argumentation würde wohl kaum jemand bestreiten: Daß Finanzmärkte kurzfristig eher von autoregressiven Erwartungen getrieben sind und sich daher „Bandwagon effects” einstellen sowie spekulative „Bubbles” aufbauen, darüber herrscht ein weitgehender Konsens. ${ }^{181}$ Auch darüber, daß diese Bewegungen auf den Finanzmärkten reale Effekte zeitigen, die soziale Kosten verursachen. Es stellen sich jedoch einige kritische Fragen:

Trifft eine solche Devisenumsatzsteuer tatsächlich die "Richtigen"? Die Argumentation Tobins und seiner Adepten unterstellt stets, daß die Kosten einer solchen Steuer gering seien. Handels- und Investitionsströme würden nur in vernachlässigbarem Umfang beeinträchtigt. Dies hängt stark von der Höhe des Steuersatzes ab. Zum anderen hat Spekulation nicht nur negative Folgen, sondern auch positive. Spekulanten halten die Finanzmärkte liquide und eröffnen damit auch längerfristig ausgerichteten Investoren die Möglichkeit, ständig gewünschte Transaktionen ausführen zu können. Zudem deckt die Spekulation sehr frühzeitig nicht haltbare fundamentale Trends auf. Würde dies verhindert, käme eine notwendige Anpassung der Politik zu spät. Insgesamt zieht also eine Tobin-Steuer möglicherweise relativ hohe Kosten nach sich.

Verhindert eine Tobin-Steuer wirklich spekulative Transaktionen? Antizipieren die Marktteilnehmer kleine Gewinnmöglichkeiten, mögen niedrige Steuersätze (die Rede ist meist von Größenordnungen von 0,5 bis 1 Prozent) genügen, um solche Transaktionen zu verhindern. Es ist aber durchaus möglich, daß die Marktteilnehmer hohe Gewinne erwarten, so daß sie trotz Steuer bereit sind, das Risiko der Spekulation einzugehen [Kenen 1995: 189]. Gerechtfertigt - und effizient - wäre solches Verhalten, wenn tatsächlich gravierende fundamentale Ungleichgewichte bestünden. Es ist aber ein verbreitetes Phänomen, daß eine pessimistische Stimmung gegenüber einem Land auf den Finanzmärkten Raum greift, einzig aufgrund relativ vager Schätzungen über die künftige Entwicklung. Baut sich auf solchen Prophezeihungen die Erwartung auf, daß eine spekulative Attacke am Ende die betreffende Regierung und Notenbank zu einer Politikänderung veranlassen wird, etwa weil die Devisenreserven zur Neige gehen, können auch hiermit große Gewinne verbunden sein. Die Spekulanten können dann damit rechnen, daß ihre Erwartungen zu „Self-fulfilling prophecies” werden, daran wird eine geringe Devisentransaktionssteuer nichts ändern. Es gibt also keineswegs die Gewähr, daß eine Tobin-Steuer die gewünschte Wirkung tatsächlich erzielt.

Kann die Tobin-Steuer zum ordnungspolitischen Sündenfall wider die offenen Weltmärkte werden? Da es gut möglich ist, daß die Verfechter einer solchen

181 Für eine einfache formale Modellierung siehe Abschnitt 4. 1. 1, „Alternative Wechselkurserwartungen". 
Abgabe den Nutzen über- und die Kosten unterschätzen, liegt es nahe, über mögliche polit-ökonomische Folgekosten nachzudenken. Angenommen, eine TobinSteuer würde global eingefuihrt, es stellte sich aber in der Praxis heraus, daß sie nicht die gewünschten Wirkungen erzielt. In diesem Fall würde die neue Regelung vermutlich nicht einfach wieder abgeschafft, sondern sogar noch verschärft: die Steuersätze erhöht, möglicherweise auch weitergehende Kapitalverkehrsbeschränkungen eingeführt. Dies würde mit Sicherheit hohe Kosten nach sich ziehen. Aus Sicht der beteiligten Regierungen kann eine solche Politik aber durchaus rational sein: Sie haben viel an Verhandlungskosten investiert, um überhaupt zu einer globalen Regelung zu kommen. Das Projekt einfach wieder aufzugeben hieße, diese Investitionen abzuschreiben.

Auch eine mit der Überwachung beauftragte internationale Institution wie der IWF hat ein Interesse daran, ihre neuen bürokratischen Kompentenzen zu behalten. Und schließlich werden diejenigen, denen die Einnahmen aus einer solchen Steuer zufließen sollten - seien es die Regierungen von Entwicklungsländern, seiens es Bürokraten internationaler Institutionen -, aus nachvollziehbarem Eigeninteresse die Einnahmen nicht wieder hergeben wollen. Insgesamt kann die Tobin-Steuer also zu einer Art „Einstiegsdroge” in den Dirigismus auf den internationalen Finanzmärkten werden.

Die Tobin-Steuer in der Euro-Ära. Unter den Bedingungen der europäischen Währungsunion ändert sich nichts an der Bewertung der Tobin-Steuer. Auch wird die Implementierung nicht einfacher: In Steuerfragen behalten die EUStaaten bis auf weiteres ein Vetorecht, es gilt Einstimmigkeit. Insbesondere die britische Regierung, Heimat des größten Devisenumschlagplatzes der Welt - London -, dürfte Vorbehalte gegen eine solche Steuer hegen, da ein Teil des Geschäfts verloren zu gehen droht. Obwohl in der Theorie interessant, sprechen die Unsicherheiten über ihre Wirkung, vor allem aber die zu erwartenden polit-ökonomischen Beharrungseffekte gegen eine solche Steuer.

\section{4 Ein Sicherheitsnetz für die Euro-Ära}

Bevor ein eigener Vorschlag für institutionelle Innovationen auf dem Gebiet der Währungspolitik ausgebreitet wird, bietet es sich an, einen normativen Beurteilungsrahmen aufzuspannen. Dazu werden im folgenden einige Kriterien formuliert, denen das Wechselkursmanagement im Dollar-Euro-Zeitalter genügen sollte:

\section{4. 1 Fünf Forderungen an das Wechselkursmanagement im Dollar-Euro- Zeitalter}

Forderung 1: Effizienz. Das Ziel der Effizienz betrifft zuvörderst den Preismechanismus. Nur wenn Preise frei veränderbar sind, können sie die auf dem Markt verfügbaren Informationen widerspiegeln, die eine optimale Allokation der 
Ressourcen ermöglichen. Auf die Währungspolitik angewandt bedeutet Effizienz zunächst Geldwertstabilität: Nur durch eine im Zeitablauf weitgehend konstante Kaufkraft kann Geld seine Funktionen als Zahlungs- und Wertaufbewahrungsmittel sowie als Recheneinheit erfüllen. Unterliegt es einem spürbaren Wertverlust (Wertzuwachs), bietet es den Privaten keinen Transaktionskostenvorteil mehr, sie gehen zu anderen, ihnen vorteilhafter scheinenden Gütern über, die nun ersatzweise Geldfunktionen übernehmen. Die gesamtwirtschaftliche Effizienz leidet erheblich. Ein internationales Währungssystem sollte daher keine inflationären oder deflationären Spannungen hervorrufen.

Der zweite relevante Preis in diesem Kontext ist der nominale Wechselkurs. Dieser sollte so flexibel sein, daß sich fundamentale Unterschiede in der ökonomischen Entwicklung zweier Währungsgebiete in der Wechselkursentwicklung widerspiegeln. Bedeutsam ist dies bei asynchron verlaufenden Konjunkturzyklen bzw. beim Auftreten eines asymmetrischen Schocks. Es ist einfacher und weniger kostspielig, einen einzigen Preis, nämlich den Wechselkurs, zu ändern, als alle Preise und Löhne der negativ betroffenen Volkswirtschaft. Allerdings gelten stark volatile Wechselkurse als effizienzmindernd. Insbesondere durch Spekulation getriebene Abweichungen von fundamental gerechtfertigten Kursen stehen im Verdacht, den Güterhandel zu behindern bzw. die globale Kapitalallokation zu verzerren [z. B. Bhagwati 1998].

Effizienzmindernd sind auch nationale und internationale Regulierungen auf den Güter- und Faktormärkten sowie Steuer- und Abgabensysteme, die preisverzerrend wirken. Auch hier besteht ein Zusammenhang zur Währungspolitik: Geld- und Wechselkurspolitik könnte dazu genutzt werden, die negativen Folgen ineffizienter nationaler Systeme zu mildern. Dies kann aber, wenn überhaupt, nur kurzfristig erfolgreich sein. Herrscht zum Beispiel hohe Arbeitslosigkeit aufgrund einer hohen Steuer- und Abgabenbelastung des Faktors Arbeit, kann es aus Sicht der wirtschaftspolitischen Entscheidungsträger attraktiv erscheinen, durch eine Abwertung der Währung oder einen fiskalpolitischen Stimulus den Beschäftigungsstand zu erhöhen. Im Sinne einer First-best-Strategie sollte ein internationales Währungssystem derartige Second-best- oder Third-best-Maßnahmen möglichst verhindern. ${ }^{182}$

Forderung 2: Stabilität. Eng verbunden mit der Forderung nach Effizienz ist die Forderung nach Stabilität. Ein Wechselkursregime, das nur kurze Zeit existiert oder dessen Regeln ständig modifiziert werden, verhindert eine Verstetigung der Erwartungen der Marktteilnehmer. In diesem Fall würde das internationale Wechselkursmanagement selbst zur Quelle von Risiken, wobei es es doch eigentlich Risiken mindern soll. Die Forderung nach Stabilität umfaßt daher auch die Regelbindung der Politik. Diskretionäre Maßnahmen erscheinen als Methode ungeeignet.

182 Zur Frage der Effizienz von Wechselkurssystemen vgl. auch Modery (1996). 
Forderung 3: Flexibilität. Ein internationales Regime, das nicht in der Lage ist, flexibel auf veränderte Umweltbedingungen (exogene Schocks) zu reagieren, wird nicht dauerhaft stabil sein können. Da die Schöpfer eines internationalen Kooperationsmechanismus keine vollständige Voraussicht haben können, können sie nicht den Anspruch verfolgen, alle Eventualitäten zu berücksichtigen, sondern sie müssen Lücken lassen. Flexibilität bedeutet daher auch, daß ein Regime in der Lage sein muß, sich Problemen anzunehmen, die neu auf die Agenda kommen.

Forderung 4: Glaubwürdigkeit. Wird im Sinne der Forderung 1 eine Rückkehr zu rigiden Kapitalverkehrsbeschränkungen ausgeschlossen, stellt sich für ein internationales Währungssystem das Problem der Glaubwürdigkeit. Anders als im Bretton-Woods-System sind die Notenbanken nicht mehr ohne weiteres Herrinnen der Lage: Auf offenen Finanzmärkten behalten sie ihren Einfluß nur, wenn sie glaubwürdig agieren. Zweifeln die Marktteilnehmer an der Entschlossenheit oder Fähigkeit, angekündigte Ziele einzuhalten, werden sie gegen die Notenbanken bzw. Regierungen spekulieren. Sofern sie gewinnen, kommt es zu einer Verletzung der Forderung nach Stabilität. Glaubwürdigkeit ist eine zentrale Forderung an das Funktionieren eines Systems. Und das heißt: Ziele, z. B. Schwankungsbreiten für Wechselkurse, müssen realistisch sein, realwirtschaftlich gerechtfertigt und für die wirtschaftspolitischen Akteure vorteilhaft. Zudem müssen die beteiligten Institutionen über die nötigen Instrumente verfügen, mittels derer sie für eine Zielerreichung sorgen können.

Forderung 5: Transparenz. Eine der Lehren aus den Emerging-MarketsKrisen der neunziger Jahre lautet: Die Marktteilnehmer müssen möglichst umfassend informiert sein. Nur dann können Märkte effizient wirken. Wirtschaftsdaten von Ländern und Unternehmen, amtliche Statistiken, kurz- und mittelfristige Budgetpläne der Regierungen, Entscheidungsregeln der geldpolitischen Instanzen - all das sollte frei zugänglich sein. ${ }^{183}$ Letztlich gehört dazu auch eine offene Bürgergesellschaft, die politische Grundrechte einräumt wie das Recht auf freie Meinungsäußerung, die Koalitions- und die Pressefreiheit. Nur so besteht die Möglichkeit, Risiken frühzeitig zu erkennen, statt sich in einer trügerischen Sicherzeit zu wiegen, die auch zu einer Verzerrung der Preise (der Zinsen sowie der Kurse für Anleihen, Aktien, Währungen) führt.

Die Forderung nach Transparenz ist noch in weiterer Hinsicht bedeutsam: Internationale Regime und Institutionen agieren weitgehend losgelöst von einer demokratischen Öffentlichkeit. Nach wie vor gibt es keine nennenswerte internationale Civil society, die diese Aufgabe übernehmen könnte. Vielmehr sind die

183 In diese Richtung zielt auch die Strategie des IWF, der künftig die Mitgliedstaaten zu einer Verbesserung der Datenbasis, einer verstärkte Überwachung der Politiken und auch ihrer Finanzsektoren anhalten und -leiten will [z. B. IWF 1998c: 33ff]. Dabei soll das oben (5. 2. 3) bereits erwähnte Financial Stability Forum eine tragende Rolle spielen [Group of Seven 1999]. 
Bezugsrahmen immer noch vorwiegend nationalstaatlich geprägt. Das gilt selbst innerhalb der Europäischen Union, erst recht auf internationaler Ebene. Dieser Mangel an Öffentlichkeit schafft ein Kontrollproblem: Weil es kaum Kontrolle durch die Bürgerschaft gibt, eröffnet sich die Gefahr einer Herrschaft der Bürokraten, die eigene Interessen verfolgen statt die der Bürger. Im Extremfall degeneriert ein solches System zu einer korrupten Oligarchie. Dies läßt sich nur verhindern, wenn größtmögliche Transparenz und Berechenbarkeit (,Accountability”) herrscht.

\title{
5. 4. 2 Spezieller Koordinierungsbedarf in der Euro-Ära
}

Wie die Diskussion der Abschnitte 5. 2 und 5. 3 gezeigt hat, sind Fixkurssysteme unter den Bedingungen offener Kapitalmärkte kaum aufrechtzuerhalten. Allerdings ist eine derart weitgehende Koordinierung auch gar nicht notwendig, um die möglichen Konflikte der Dollar-Euro-Ära zu bearbeiten. Auf der Suche nach institutionellen Vorkehrungen für das Weltwährungssystem in der neuen Ära bietet es sich daher an, sich zunächst noch einmal kurz zu vergegenwärtigen, worin eigentlich der spezifisch neue Koordinierungsbedarf besteht.

Mit der Eurozone betritt ein neuer Hauptdarsteller die Weltbühne. Das bislang asymmetrische Weltwährungssystem, das immer noch dollarzentriert ist, wandelt sich zu einem bipolaren System. In den Worten von C. Fred Bergsten:

\begin{abstract}
„We have never experienced a successful monetary regime managed by a committee of (even two) relatively equal powers. Most historical efforts to achieve such cooperative leadership have failed. (...) The EU could adopt a strategy of 'benign neglect,' arguing that the United States has done so repeatedly in the past and that its turn had now come. Trade protection could result from either course. Conflict between the two poles could easily arise" [Bergsten 1997a].
\end{abstract}

Die Analyse in Kapitel 4 präsentiert ein solches Konfliktszenario zwischen den USA und der Eurozone. Entscheidendes Ergebnis ist, daß es keinen durchgängigen Koordinierungsbedarf gibt: Sofern keine grobe Fehlbewertung der Währungen seitens der Märkte auftreten und/oder eine asynchrone konjunkturelle Entwicklung vorherrscht, bedarf es keiner Koordinierung.

Konfliktträchtig sind insbesondere folgende Konstellationen:

Symmetrischer konjunktureller Einbruch. In diesem Fall kann es zu einem Abwertungswettlauf kommen. Ohne Koordinierung ist es für beide Seiten eine dominante Strategie, die eigene Währung zu drücken. Da dies auch die interne Geldwertstabilität beeinträchtigt, drohen somit auch Konflikte zwischen Regierungen und Notenbanken im Innern [siehe auch Alogoskoufis / Portes 1997: 74f].

Gravierende Fehlbewertungen von Währungen bei asynchronem Kojunkturverlauf. Sofern es auf den Kapitalmärkten zu einer gravierenden Fehl- 
bewertung der Währungen kommt, ist womöglich ein symmetrisches Vorgehen der beiden Notenbanken gefordert, um den Kurs wieder in Einklang mit den Fundamentaldaten $\mathrm{zu}$ bringen. Es ist jedoch denkbar, daß das Interesse der beiden Seiten an einer solchen Kooperation höchst unterschiedlich sind. Dies gilt vor allem bei asynchronem Konjunkturverlauf in beiden Ländern: Ist die Währung des Landes mit höherer Arbeitslosigkeit unterbewertet, dürfte die Regierung aus beschäftigungspolitischen Motiven wenig Interesse an einer Korrektur haben.

In der Euro-Ära bedarf es folglich eines Mechanismus, der eine fallweise Koordinierung der Makropolitiken ermöglicht. Das Ziel des im folgenden vorgeschlagenen Mechanismus ist verglichen mit den oben diskutierten Fixkurssystemen relativ bescheiden: Er soll das System offener Güter- und Kapitalmärkte absichern. Sofern Konflikte über die Währungspolitik auftreten, soll eine Eskalation auf andere Bereiche vermieden werden. Einer stringenten, durchgängigen Koordinierung der Makropolitiken, wie sie bei Fixkurssystemen in der Regel nötig ist, bedarf es nicht. Es handelt sich somit um einen pragmatischen Ansatz. Damit soll sichergestellt werden, daß das spezifische Konfliktpotential in der heraufziehenden bipolaren Epoche begrenzt wird.

Weitere Schritte in Richtung einer möglichen engeren Koordinierung sind damit keineswegs ausgeschlossen. Ob sie aus ökonomischer Sicht sinnvoll sind, ist indes eine andere Frage. Jedenfalls ist kurz nach Beginn der Europäischen Währungsunion mit ihren unbestreitbaren institutionellen Defiziten wohl kaum der geeignete Zeitpunkt, um solche sehr weitgehenden internationalen Systeme zu implementieren. Zunächst bedarf es einer Phase der Konsolidierung: Die EU-Institutionen, die nationalen Regierungen, Verwaltungen, Unternehmen, Tarifparteien, das Publikum auf den internationalen Finanzmärkten, sie alle werden einige Jahre brauchen, um sich in den neuen Spielregeln zurechtzufinden. Gerade in dieser Phase ist die Gefahr besonders groß, daß sich Konflikte innerhalb der EU nach außen über die Wechselkurspolitik entladen, wie Kapitel 2 gezeigt hat. Dies aber sollte mittels einer Anpassung des internationalen institutionellen Rahmens verhindert werden.

\section{4. 3 Ein G 2-Mechanismus}

Bei einem solchen Ansatz geht es also nicht darum, ein Set von optimalen nominalen Wechselkursen festzulegen, sondern das Ziel ist bescheidener formuliert: das System der offenen Weltwirtschaft aufrecht zu erhalten. Der G 2-Mechanismus soll ein Sicherheitsheitsnetz für die neue Ära aufzuspannen. Im Normalfall findet keine Koordinierung statt. Der Mechanismus tritt erst in Kraft, wenn eine Regierung der Meinung ist, der Dollar/Euro-Kurs sei massiv falsch bewertet.

Baustein Nr. 1: Eine G 2-Schiedsstelle. Zwischen die Konfliktparteien vermittelt eine moderierende Instanz, die über den jeweiligen nationalen Interessen steht. Diese Rolle könnte eine G 2-Schiedsstelle übernehmen, die beim IWF 
angesiedelt ist. Sie ähnelt den „Panels“ der WTO, die bei Handelsstreitigkeiten vermitteln. Die Schiedsstelle kann nicht von sich aus aktiv werden, die Initiative würde stets vom Euroland oder von den USA ausgehen. Auch verfügt sie über keine Instrumente, Sanktionen zu verhängen. Ihre einzige Macht besteht darin, Öffentlichkeit herzustellen, indem sie Lösungsvorschläge publiziert und damit einen gewissen Druck auf die Regierungen ausübt.

Die Mitglieder der G 2-Schiedsstelle sollten anerkannte Fachleute und erfahrene Diplomaten sein. Dabei dürfte es von Vorteil sein, wenn die Mitglieder prominent sind, um zu gewährleisten, daß die Schiedsstelle von der internationalen Öffentlichkeit wahrgenommen wird; der Einfluß dieses Gremiums fußt ja vor allem auf seiner öffentlichen Wirkung, erst dadurch entsteht Druck auf die Konfliktparteien, sich zu einigen.

Die G 2-Schiedsstelle könnte beispielsweise ein Club von Elder Statesmen sein: Notenbankpräsidenten a. D., Ex-Regierungschefs, ehemalige Finanz- und Außenminister, Bankmanager im Ruhestand. Daneben sollte der Gruppe auch der Geschättsführende Direktor des IWF angehören, da er das Gewicht des Fonds mitbringt. ${ }^{184}$ Auf jeden Fall sollte die Größe des Gremiums überschaubar sein, das heißt bei maximal zehn Personen liegen, um die Transaktionskosten innerhalb dieser Gruppe möglichst gering zu halten und um zu verhindern, daß an dieser Stelle bürokratische Reibungsverluste auftreten.

Die Mitglieder der G 2-Schiedsstelle sollten sowohl aus den USA und dem Euroland als auch aus Drittländern stammen. Falls sie ausschließlich aus den USA und dem Euroland kämen, könnte ein transatlantischer Konflikt die Arbeit dieses Gremiums erschweren, indem er es in zwei Lager teilt. Dies würde zwar verhindert, wenn die Schiedsstelle ausschließlich mit Bürgern aus Drittstaaten bestückt würde, hätte aber den Nachteil, daß die Stelle möglicherweise von den G 2-Regierungen und der dortigen Öffentlichkeit nicht anerkannt würde. Sinnvoll erscheint daher eine Mischung, die etwa bei einem Drittel Europäer, einem Drittel Amerikaner, einem Drittel aus dem Rest der Welt liegen könnte.

Die Entscheidung, wer in einem solchen Gremium sitzen sollte, fällen die Regierungen des Eurolandes und der USA. Das verleiht diesen Persönlichkeiten größere Autorität, denn eine Regierung, die in ruhigen Zeiten selbst die Schlichter berufen hat, kann sie schlecht ignorieren, wenn ein Konflikt da ist. Bei der Berufung sollte auch der IWF beteiligt sein, der Personalvorschläge machen könnte, während die US-Finanzminister und der EU-Ministerrat zustimmen oder ablehnen.

184 Denkbar ist auch eine Teilung der G 2-Schiedsstelle in zwei Kammern: eine zusammengesetzt aus anerkannten, unabhängigen Fachleuten, die zweite aus international versierten Diplomaten. Eine dritte Variante könnte darin bestehen, den Elder Statesmen einen Stab aus Fachleuten und Experten zur Seite zu stellen [Müller 1999: 41ff]. 
Baustein Nr. 2: Eine Eskalationsleiter. Nicht nur über die Zusammensetzung des Beratungsgremiums sollten sich die beiden Seiten einigen bevor ein Konflikt ausbricht, sondern auch über die Spielregeln. Im voraus sollten sie eine Eskalationsleiter des Konflikts festlegen. Erst dadurch versehen sie den G 2-Mechanismus mit Zähnen: Können sie sich nicht einigen, droht eine abgestufte Folge von Sanktionen. Somit weiß jede Seite, was auf dem Spiel steht. Der Zwang, sich zu einigen, wächst.

Diese Eskalationsleiter könnte etwa wie folgt aussehen:

Schritt 1: Klage. Die US-Regierung oder die EU-Kommission im Auftrag des Ministerrats ruft die G 2-Schiedsstelle an, weil sie der Meinung ist, daß die Wechselkurse grob verzerrt sind und daß sich die andere Regierung durch ihre Politik unfaire Wettbewerbsvorteile verschafft.

Schritt 2: Anhörung. Vertreter beider Seiten legen vor der G 2-Schiedsstelle ihre Positionen dar. Die Schlichter veröffentlichen die Protokolle der Sitzungen. Sie haben auch die Möglichkeit, eine eigene Stellungnahme abzugeben.

Schritt 3: Assessment. Die Schiedsstelle überprüft die Argumente. Auf Basis aktueller und historischer Daten kalkuliert sie, welcher Dollar-Euro-Kurs gerechtfertigt wäre. Da verschiedene Konzepte zur Ermittlung gleichgewichtiger Wechselkurse konkurrieren, steht am Ende kein fester Wert, sondern eine Spanne - ein Korridor, innerhalb dessen der Kurs liegen sollte. Ein Beispiel dafür liefert Übersicht 5-1:

Übersicht 5-1: Schätzungen für US-Dollar KKP und FEER

\begin{tabular}{|c|c|c|c|c|c|c|}
\hline & \multirow{2}{*}{$\begin{array}{l}\text { Marktkurs } \\
\text { vis-à-vis } \\
\text { US-Dollar* }\end{array}$} & \multicolumn{2}{|c|}{ Kaufkraftparität (KKP) } & \multirow{2}{*}{$\begin{array}{c}\begin{array}{c}\text { KKP produktivitäts- } \\
\text { bereinigt }\end{array} \\
\text { Goldman Sachs }{ }^{\star}\end{array}$} & \multicolumn{2}{|c|}{$\begin{array}{l}\text { Fundamental Equlibrium } \\
\text { Exchange Rates (FEER) }\end{array}$} \\
\hline & & $\mathrm{OECD}^{+}$ & Penn" & & IIE* & SBC ${ }^{\circ}$ \\
\hline $\begin{array}{l}\text { D- } \\
\text { Mark }\end{array}$ & 1,77 & 2,02 & 2,12 & 1,51 & $1,45-1,50$ & 1,40 \\
\hline Yen & 132 & 169 & 188 & 124 & 100 & 95 \\
\hline
\end{tabular}

*Am 11. Mai $1998{ }^{+}$Jahresdurchschnitt $1997{ }^{\# 1992 ~ * A n f a n g ~} 1998$ "Institute for International Economics (John Williamson's 1996 informal update of estimates) "Swiss Bank Corporation. Quelle: BIZ (1998a)

Hier liegt der „korrekte” Mark/Dollar-Kurs in einem Korridor zwischen 1,40 und 2,12, der entsprechende Yen-Kurs zwischen 95 und 188. Der Spielraum ist sehr groß. Dennoch bietet er einen wertvollen Ausgangspunkt für den Beginn der Verhandlungen zwischen beiden Parteien. Zudem kann die G 2-Schiedsstelle den Korridor für einen fundamental gerechtfertigten Wechselkurs eingrenzen, insbesondere indem sie sich abzeichnende Entwicklungen berücksichtigt (z. B. Prognosen über Konjunkturverlauf, Inflation, Produktivitäten). Die Schiedsstelle veröffentlicht einen Bericht, der auch eine Analyse der Wirtschaftspolitiken 
beider Länder beinhaltet. Möglicherweise genügt schon die Veröffentlichung, damit die Märkte von sich aus die Bewertungen in die gewünschte Richtung korrigieren.

Schritt 4: Aufnahme der Verhandlungen. Sofern es nicht zu einer automatischen Kurskorrektur kommt, beginnen die Delegationen beider Seiten mit den Verhandlungen. Auch hierbei gilt: Je kleiner die Zahl der Teilnehmer, desto besser. Beteiligt sein sollten jedoch mindestens: jeweils ein Vertreter der Zentralbanken und der Regierungen, wobei für das Euroland die Kommission als Regierung verhandeln sollte. Dazu käme ein Moderator der G 2-Schiedsstelle

Schritt 5: Einigung. Beide Seiten einigen sich und vereinbaren Schritte zur Überwindung der Fehlbewertung. Sofern sie übereinkommen, einen Zielkurs oder eine Bandbreite für den bilateralen Wechselkurs festzulegen, sollten sie dieses Ziel öffentlich verkünden, um die Erwartungen der Märkte in die gewünschte Richtung zu lenken. Die Vereinbarung kann auch weitergehende Punkte enthalten. So liegt es zum Beispiel nahe, daß beide Seiten den gewünschten Zielkurs mit gemeinsamen Interventionen und/oder einem abgestimmten Zinsschritt der beiden Notenbanken untermauern, sofern das Ziel der Preisstabilität dadurch nicht gefährdet wird. Auch über die Fiskalpolitik können die G 2 Vereinbarungen treffen. So kann zum Beispiel das Verhandlungsergebnis darauf hinauslaufen, daß die eine Seite einen strikterer, die andere einen expansiverer Kurs steuert.

Schritt 6: Monitoring. Sofern sich nach einiger Zeit herausstellt, daß sich die Verhandlungsparteien nicht an die Absprachen halten oder daß sich das gewünschte Ergebnis nicht einstellt, obwohl die Maßnahmen verabredungsgemäß umgesetzt wurden, kann eine Seite beantragen, die Verhandlungen wiederaufzunehmen. In Schritt 5 können die G 2 aber auch die Schiedsstelle beauftragen, den Fortgang zu beobachten und von sich aus aktiv zu werden, sofern die Experten Verstöße gegen die Verabredung feststellen. In diesem Fall veröffentlicht die Schiedsstelle aus eigenem Antrieb einen Bericht.

Schritt 7: Erneute Verhandlungen. Sofern die Verabredungen von Schritt 5 nicht umgesetzt werden und die Unstimmigkeiten bestehen bleiben, beginnt eine erneute Verhandlungsrunde analog Schritt 4.

Schritt 8: Sanktionen. Während der Verhandlungen darf keine der beiden Parteien einseitig Sanktionen in Kraft setzen. Erst wenn Schritt 7 nicht zum Ergebnis führt, besteht für die klagende Partei die Möglichkeit, Sanktionen zu verhängen. Um eine Eskalation zu verhindern und um zu vermeiden, daß protektionistische „Pressure groups" in den Prozeß eingreifen, sind auch die möglichen Sanktionsschritte vorher festgelegt. Die Handelssanktionen sollten aus diesem Grund möglichst breit angelegt sein, also möglichst alle Importe aus einem Land treffen und nicht einzelne Produktgruppen herausgreifen. Sinnvoll erscheint es zum Beispiel, in einem ersten Schritt einen niedrigen Zollsatz auf alle Indutriegüter aus dem anderen Land zu erheben. Klagte etwa die EU gegen die USA, so hätte sie die Möglichkeit, nach Scheitern von Schritt 7 alle Importe aus den USA 
mit einem Strafzoll zu belegen. Durch die Androhung von Sanktionen gewinnt der Verhandlungsprozeß Glaubwürdigkeit - jeder Seite ist klar, was auf dem Spiel steht. Entsprechend groß ist der Zwang sich zu einigen.

\section{4. 5 Kann ein G 2-Mechanismus tatsächlich funktionieren?}

Einstieg in den Protektionismus? Gegen den Vorschlag eines G 2-Mechanismus läßt sich einwenden, daß auch damit ein Handelskrieg keineswegs ausgeschlossen werden kann. Möglicherweise wird er sogar noch wahrscheinlicher, da der Sanktionskatalog handelsbeschränkende Maßnahmen rechtfertigt. Diese Gefahr ließe sich allenfalls ausschalten, wenn die Sanktionen von einer übergeordneten Institution wie dem IWF verhängt würden - sie wären dann nationalen protektionistischen Interessen entzogen. Dies ist aber aufgrund der globalen Machtverteilung völlig unrealistisch. Andererseits: Die Drohung, daß eine Seite mit Handelssanktionen antwortet, sofern die andere sich unkooperativ zeigt, steht ohnehin immer im Hintergrund. Somit erscheint es sinnvoll, einen Strafenkatalog im voraus, also in weniger konfliktträchtigen Zeiten, zu vereinbaren, um die Sanktionen im vorgezeichneten Rahmen und den Konflikt in möglichst geordneten Bahnen zu halten.

Es stellen sich zwei weitere Fragen: Warum sollten sich die beiden ökonomischen Supermächte EWU und USA einem solchen Regelment unterwerfen? Und: Selbst wenn sie sich auf die Implementierung eines G 2-Mechanismus einlassen, werden sie sich im Konfliktfall daran halten?

Institutionelle Absicherung langfristiger Integrationsvorteile. Für beide Seiten bietet die internationale ökonomische Integration langfristige Vorteile. Kurzfristig hingegen können die Kosten der Integration den Nutzen übersteigen. Daher bedarf es in gewissem Umfang einer internationalen Koordinierung der Politik, mit dem Ziel, die langfristige Strategie der Öffnung der Grenzen gegen protektionistische Tendenzen abzusichern. Aus diesem Grund dürfte es nicht schwierig sein, sich auf einen solchen pragmatischen Ansatz der Konfliktvermeidung in Zeiten zu einigen, wenn kein Konflikt vorliegt.

Der Zeit-Faktor. Ob die Implentierung eines G 2-Mechanismus Realisierungschancen hat, hängt von der jeweiligen Situation ab. Entscheidend ist die Lage innerhalb des Eurolandes und in den USA. Solange die EWU-Volkswirtschaften konjunkturell im Aufwind und nicht von asymmetrischen Schocks getroffen sind, werden sich die Regierungen der Euroland-Staaten eher dazu bereiterklären, ihr vor Beginn der EWU gegebenes Versprechen, den Wechselkurs nicht als Instrument der Wirtschaftspolitik einzusetzen, im Rahmen eines G 2Mechanismus international abzusichern. ${ }^{185}$ Deutlich schwieriger dürfte eine solche Übereinkunft, die der einstimmigen Zustimmung aller EWU-Staaten bedarf, zu erreichen sein, wenn erst die „Pre-Ins” und erst recht wenn die MOEL beige-

185 Siehe Abschnitt 2. 3. 
treten sind - die EWU wird dann eine immer geschlossenere Ökonomie mit immer weniger Interesse an internationaler Kooperation, sie wird heterogener und damit anfälliger für asymmetrische Schocks, ${ }^{186}$ und die Schwelle für einstimmige Entscheidungen steigt. Umso attraktiver dürfte der Wechselkurs als Instrument für diskretionäre Politik erscheinen, die Regierungen werden diese Waffe nur schweren Herzens aus der Hand geben.

Wie das Krisenszenario in Kapitel 4 gezeigt hat, ist nicht allein die Lage in Europa entscheidend, sondern die konjunkturelle Position beider Seiten. Am besten stehen daher der Chancen, zu einer Übereinkunft über einen solchen Mechanismus zu kommen, in einer Phase, da sowohl die USA als auch das Euroland in einer konjunkturell entspannten Lage sind.

Reformbedarf seitens der EU. Der G 2-Mechanismus setzt voraus, daß sich die Euroland-Regierungen auf eine effizientere Außenvertretung einigen, als dies bislang der Fall ist. Die derzeitigen Regelungen erscheinen dafur untauglich. ${ }^{187}$ Es ist kaum vorstellbar, daß das Euroland angesichts der unklaren Kompentenzverteilung mit einer Stimme spricht. Bei Verhandlungen mit den USA wird es daher ein schwieriger Partner sein. Denn stets müssen elf Staaten sowie Kommission und EZB zusammenwirken, bevor das Euroland eine gemeinsame Position beziehen kann. Noch größere Verwirrung dürfte dadurch entstehen, daß die Präsidentschaft der Euro-11-Gruppe halbjährlich wechselt.

Es erscheint daher ratsam, der EU-Kommission eine prominentere Position in der Außenvertretung des Eurolandes einzuräumen. Sie müßte sich, wie bei den Welthandelsverhandlungen auch, ein Mandat des Ministerrates holen, über das der Rat vor Aufnahme von G 2-Verhandlungen mit Zweidrittelmehrheit abstimmt. Nach deren Abschluß bedürte es wiederum einer Zweidrittelmehrheit, um den G 2-Kompromiß anzunehmen. Bei einem transatlantischen Schlichtungsmechanismus wäre das Euroland also direkt nur noch die EZB und durch die EUKommission beteiligt. Eine solche Regelung zu vereinbaren wäre relativ einfach: Der Maastricht-Vertrag eröffnet die Möglichkeit dazu (EGV Artikel 109, Abs. 3).

186 Siehe Abschnitt 2. 6.

187 Siehe Abschnitt 2. 3. 
Henrik Müller - 978-3-631-75010-0

Downloaded from PubFactory at 01/11/2019 09:16:41AM

via free access 


\section{Zusammenfassung und Schlußfolgerung: Zehn Lehren für die Währungspolitik}

\section{Falls strukturelle Reformen im Euroland nicht vorankommen, kann der}

Wechselkurs zum Ventil für Konflikte werden. Die Staaten des Eurolands sind nicht sonderlich gut vorbereitet in die Währungsunion gestartet. Vor allem die großen kontinentalen Mitgliedsländer kommen bei der Flexibilisierung der Arbeitsmärkte nur langsam voran. Hohe Steuern und Abgaben belasten den Faktor Arbeit. Das Ergebnis ist hohe strukturelle Arbeitslosigkeit. Auch die Finanzpolitik der Mitgliedsländer bleibt bislang weit hinter ihrem Ziel zurück, in normalen konjunkturellen Situationen ausgeglichene Budgets vorzulegen.

Weder die Arbeitsmärkte, noch die nationalen öffentlichen Haushalte stehen also als Instrumente zur Verfügung, wenn es darum geht, eine Wirtschaftskrise abzufedern. Doch ökonomische Rückschläge wird es in den kommenden Jahren und Jahrzehnten mit Sicherheit geben - sei es, daß das gesamte Euroland in eine tiefe Rezession gerät, sei es daß einige Regionen in eine Krise schlittern. Im ersten Fall wäre eine gemeinsame Stabilisienungspolitik aller Euroland-Staaten notwendig, im zweiten Fall eine regional gezielte Stabilisierungspolitik.

Auf beide Aufgaben ist die EU nicht vorbereitet. Im Gegensatz zu den USA verfügt die EU nicht über ein Zentralbudget, das solche Schocks abfedern könnte. Die Finanzminister der Mitgliedsländer koordinieren ihre nationalen Politiken lediglich unverbindlich, so daß eine abgestimmte Konjunkturpolitik nur schwer möglich ist. Zugleich ist der zentrale EU-Haushalt nahezu ausschließlich auf Verteilungspolitik (insbesondere Landwirtschaft) ausgerichtet, nicht aber auf Stabilisierungspolitik.

Da alle übrigen „Shock absorber” versagen, liegt es nahe, daß die EurolandFinanzminister den Wechselkurs als konjunkturpolitisches Instrument einzusetzen versuchen. Dieser Schluß liegt vor allem deshalb nahe, weil schon eine relativ kleine Mehrheit der Euroland-Staaten Einfluß auf die Geldpolitik gewinnen kann.

2. Die erste große Bewährungsprobe könnte die Osterweiterung sein. Sowohl die Mittel- und Osteuropäischen Staaten (MOEL) als auch viele EU-Staaten streben eine rasche Erweiterung der Union an. Der Beitritt dieser weit schwächer entwickelten Volkswirtschaften zum Binnenmarkt wird erhebliche strukturelle Anpassungsprozesse auslösen - sowohl in den MOEL als auch in den ,alten Ländern" der EU.

Gemäß neoklassischem Paradigma dürften diese Anpassungsprozesse wie ein asymmetrischer Schock auf die EWU-Staaten wirken. Relativ reichlich mit dem Faktor Arbeit ausgestattete Regionen werden komparative Vorteile verlieren, für sie sind die Beitrittsländer direkte Konkurrenten. Zugleich werden die hochentwickelten, relativ kapitalreichen EU-Länder tendenziell von der Erweiterung 
profitieren, weil sich Importe verbilligen und die Exportnachfrage nach ihren kapital- und humankapitalintensiv produzierten Gütern steigt.

Wie die EU diesen absehbaren ,,asymmetrischen Schock" verdauen wird, ist unklar. Vermutlich wird sie sich wie so häufig für kurzfristiges Krisenmanagement entscheiden.

\section{Für die Stabilität des Euro ist die Wechselkurspolitik eine ständige offene}

Flanke. Aus gutem Grund weist der Maastricht-Vertrag die Kompetenz für die Geldpolitik der Europäischen Zentralbank und den nationalen Notenbanken im ESZB zu. Erfahrungsgemäß unterliegen gewählte Regierungen gelegentlich der Versuchung, kurzfristige expansive Wirkungen der Geldpolitik durch langfristige Kosten zu erkaufen. Konflikte zwischen den nationalen Regierungen und der Europäischen Zentralbank sind daher programmiert.

Die Regierungen im Ministerrat verfügen dabei über einen machtvollen Hebel, mittels dessen sie die Unabhängigkeit des ESZB unterminieren können: Es genügt eine Mehrheit von derzeit 43 Stimmen, um ,allgemeine Orientierungen für die Wechselkurspolitik" zu erlassen und der Europäischen Zentralbank zum Beispiel einen unilateralen Zielkurs gegenüber dem US-Dollar vorzugeben. Schon eine Koalition aus fünf Regierungen - zum Beispiel Deutschland, Frankreich, Italien, Spanien und Portugal - kann damit entscheidenden Einfluß auf die Geldpolitik gewinnen.

Die Versuchung, über den Umweg Wechselkurs die EZB zu Zinssenkungen zu bewegen, ist umso größer, je höher die Arbeitslosigkeit im Euroland ist und je stärker der Schuldendienst die nationalen Haushalte belastet.

\section{Die Versuchung, den Euro als wirtschaftspolitisches Instrument einzuset-} zen, steigt im Zeitablauf. Ein natürliches Korrektiv für wechselkurspolitische Maßnahmen der EWU-Regierungen sind die Finanzmärkte. Sofern ein Abweichen vom Stabilitätspfad mit hohen Risikoprämien bestraft wird, schränkt dies den Handlungsspielraum der Regierungen ein. Ein schwächerer Euro geht dann einher mit stark steigenden Zinsen, so daß es fraglich ist, ob sich die erwünschte expansive Wirkung überhaupt einstellt.

Allerdings spricht vieles dafür, daß die Disziplinierung durch die Finanzmärkte durch die Gründung der EWU abgenommen hat. Für private Anleger, für Notenbanker und für Finanzminister außerhalb der EU dürfte der Euro eine willkommene Alternative zum Dollar sein. Portfoliotheoretische Überlegungen sprechen daher für eine teilweise Umschichtung der Anlagen und Kreditaufnahme in die neue Währung. Entsprechend hat der Euro einen Bonus gegenüber seinen Vorläuferwährungen. Somit dürfte die Disziplinierung durch die Finanzmärkte abnehmen, die Finanzminister also wechselkurspolitische Handlungsspielräume hinzugewinnen, weil sie nicht mit drastisch steigenden Risikoprämien rechnen müssen. 
Diese Position hat die neue Währung allerdings nicht von Anfang an. Erst allmählich entwickelt sich der Euro zu einer wirklich internationalen Währung. Gerade in den ersten Jahren dürften sich die Finanzmärkte bei politischen Unsicherheiten im Euroland nicht so tolerant zeigen, denn das Eurosystem der Zentralbanken muß sich zunächst Glaubwürdigkeit erarbeiten. Je mehr sich der Euro jedoch etabliert, desto größer ist das Vertrauen in die langfristige Stabilität der Währung, desto größer dürfte die Toleranz gegenüber zeitweisen Abweichungen vom Stabilitätspfad sein.

5. Der Euro tritt in Konkurrenz zum Dollar. Zwischen dem US-Dollar und dem Euro wird sich eine strategische Konstellation herausbilden. Offen ist, welcher Art diese Konkurrenz sein wird. Prinzipiell gibt es zwei Möglichkeiten: Zum einen kann sich ein Wettbewerb darum entspinnen, welcher Währungsraum die attraktivsten Anlagemöglichkeiten bietet, das heißt, die niedrigsten Inflationsraten und die höchsten realen Nettorenditen. Dies würde für eine Härtung beider Währungen sprechen. Zum anderen kann es auch zu einem Abwertungswettlauf kommen, der darauf ausgerichtet ist, kurzfristige handels- bzw. konjunkturpolitische Vorteile zu erringen. Dieses Szenario würde zu steigenden Inflationsraten führen.

Welche Alternative realisiert wird, hängt vor allem von zwei Faktoren ab: erstens vom vorherrschenden wirtschaftspolitischen Paradigma beiderseits des Atlantiks, zweitens von der konjunkturellen Konstellation. Sofern die EurolandStaaten und die USA eine Politik verfolgen, die darauf abzielt, dauerhaft die Angebotsbedingungen zu verbessern, wird ein Härtungswettbewerb die Folge sein. $\mathrm{Ob}$ die Regierungen des Eurolandes zu einem solchen Kurs tatsächlich bereit sind, ist derzeit fraglich. Wenn langfristige Strukturverbesserungen aber nicht möglich oder nicht wünschenswert erscheinen, bietet sich den Regierungen die kurzfristige Ausbeutung eines Phillipskurven-Trade-off als Option. Diese auf schnelle Wirkungen kaprizierte Politik dürfte sich auch einstellen, wenn sowohl das Euroland als auch die USA von einer Rezession betroffen wären - besonders in diesem Fall droht ein Abwertungswettlauf.

6. Im Dollar-Euro-Duopol drohen ernsthafte Konflikte. Sollte das Euroland eine handels- bzw. konjunkturpolitisch orientierte Wechselkurspolitik betreiben, droht eine Destabilisierung des Welthandelssystems. Eine Ausweitung des Konflikts auf andere Felder ist naheliegend, bis hin zu einem Handelskrieg. Im Extremfall stünde damit die gesamte offene Weltwirtschaftsordnung der Nachkriegsepoche auf dem Spiel.

7. Auf internationaler Ebene wird währungspolitische Kooperation schwieriger. Gegen eine solche Eskalation sollten institutionelle Korsettstangen ins internationale Währungssystem eingezogen werden. Das Problem ist aber, daß auch die internationale Kooperation unter den Bedingungen der EWU eher schwieriger 
werden dürfte. Dieser Schluß folgt zum einen aus der Tatsache, daß sich nun zwei - bzw. inklusive Japan drei - große, relativ geschlossene Wirtschaftsräume gegenüberstehen. Das Interesse an internationaler Kooperation ist daher naturgemäß begrenzt. Zum anderen wird das Euroland ein schwieriger Verhandlungspartner sein, da elf Regierungen plus Europäische Zentralbank plus Europäische Kommission in der Außenvertretung mitentscheiden.

\section{Die Installation eines „Bretton Woods II” erscheint weder erreichbar noch} wünschenswert. Sowohl die japanische als auch die deutsche Regierung haben sich in jüngster Vergangenheit dafür eingesetzt, eine Art „Bretton Woods II” zu installieren: Nach diesen Vorstellungen sollten Dollar, Euro und Yen in ein Zielzonensystem eingebunden werden. In der Tat wäre dies eine stringente Art, die großen Wirtschaftsmächte auf eine kooperative Makropolitik zu verpflichten. Zumindest theoretisch könnte damit ein transatlantischer Antagonismus im Ansatz erstickt werden.

Allerdings hat ein solches System auf absehbare Zeit keine Realisierungschance. Erstens müßten die großen Wirtschaftsblöcke ihre Geld- und teilweise auch ihre Fiskalpolitik außenwirtschaftlichen Zielen unterordnen. Obwohl sie relativ geschlossene Volkswirtschaften sind, müßten sie Zielkonflikte zwischen binnen- und außenwirtschaftlicher Stabilität zugunsten der externen Verpflichtungen entscheiden. Zweitens bedeutet die Einbindung in eine Wechselkurssystem zwangsläufig eine Politisierung des Geldes. Indem die Regierungen den Notenbanken Zielkurse vorgeben, gewinnen sie dauerhaft Einfluß auf die Geldpolitik, die dadurch typischerweise in den Dienst einer kurzatmig ausgerichteten Konjunkturpolitik gestellt wird. Drittens ist der Koordinierungsbedarf innerhalb eines Wechselkurssystems so gro $ß$, daß erfahrungsgemäß nur asymmetrische Formen der Koordinierung stabil sind, wenn es also eine Ankerökonomie gibt, um die sich kleinere Länder scharen. Dies ist in der Euro-Ära nicht der Fall. Im Gegenteil wird hier die internationale Koordinierung noch dadurch erschwert, daß die Außenvertretung des Eurolands kompliziert, träge und undurchsichtig organisiert ist. Viertens wird ein Wechselkurssystem, das derartige Schwächen aufweist, bei offenen Finanzmärkten nicht stabil sein, da es nicht glaubwürdig ist. Es wird die Spekulation erst recht anfachen und damit für eine größere Volatilität sorgen.

9. Um einen Rückfall in Protektionismus zu verhindern, bedarf es eines Sicherheitsnetzes (G 2-Mechanismus). Angesichts der potentiell heraufziehenden währungspolitischen Konflikte zwischen den USA und dem Euroland sollte ein G 2-Mechanismus installiert werden. Eine stringente, permanente Koordinierung der Wirtschaftspolitik, wie sie ein Zielzonensystem erfordert, ist dazu nicht nötig. Es genügt eine institutionalisierte Konfliktlösung ähnlich den WTO-Schiedsgerichten („Panels”). Sofern eine Seite den Dollar-Euro-Kurs für massiv falsch bewertet hält, hat sie die Möglichkeit, die G 2-Schiedsstelle anzurufen, die beim IWF ange- 
siedelt sein sollte und als Vermittler auftritt. Es schließen sich bilaterale Verhandlungen an, moderiert von von der Schiedsstelle. Sollte es nach mehreren Runden nicht zu einem Ergebnis kommen, besteht für die klagende Seite die Möglichkeit, Sanktionen zu verhängen. Diese Maßnahmen folgen einer im voraus festgelegten Eskalationsleiter.

Die Ratio des G 2-Mechanismus lautet wie folgt: Indem sich beide Seiten in Zeiten, da kein Konflikt besteht, auf einen solchen Lösungsweg festgelegen, binden sie sich selbst. Ein Bruch dieses Versprechens ist mit hohen Kosten verbunden: Die jeweilige Regierung würde sowohl national als auch international einen Glaubwürdigkeitsverlust erleiden, der es ihr erschwerte, künftig andere Ziele zu erreichen. Zugleich wirken die im voraus vereinbarten Sanktionen abschreckend, so daß der Druck zur Einigung wächst.

10. Das Euroland braucht eine schlankere Außenvertretung. Damit ein G 2Mechanismus funktionieren kann, muß das Euroland allerdings seine Außenvertretung neuordnen. Es liegt nahe, daß am Verhandlungstisch die beiden Notenbankpräsidenten und die Finanzminister sitzen. Nun hat das Euroland allerdings elf Finanzminister. Auch wenn es nur den jeweiligen Präsidenten der Euro-11Gruppe entsenden würde, so wäre der interne Verhandlungsprozeß doch überaus zeitaufwendig, da stets eine Abstimmung zwischen allen Regierungen, der Kommission und der EZB stattfinden muß. Zudem wechselt die Präsidentschaft in dieser Gruppe halbjährlich. Sinnvollerweise sollte der für Währungsfragen zuständige EU-Kommissar ein Verhandlungsmandat erhalten - als eine Art EurolandFinanzminister. 
Henrik Müller - 978-3-631-75010-0

Downloaded from PubFactory at 01/11/2019 09:16:41AM

via free access 


\section{Literaturverzeichnis}

Alogoskoufis, George / Richard Portes (1997): The Euro, the Dollar, and the International Monetary System. In: Paul R. Masson / Thomas H. Krueger / Bart G. Turtleboom (Hrsg.): EMU and the International Monetary System, preceedings of a conference held in Washington D. C. on March 17-18, Washington D. C., S. 58-78

Ambrosius, Gerold (1996): Wirtschaftsraum Europa. Vom Ende der Nationalökonomien, Frankfurt am Main

Anckar, Patrik (1992): The Choice of the Transaction Currency and the European Currency Unit. Meddlanden Working Papers 251

Antzoulatos, Angelos A. / Jiawen Yang (1996): Exchange Rate Pass-Through in US Manufacturing Industries: A Demand-Side Story. The International Trade Journal, Vol. X, No. 3, Herbst 1996, S. 325-352

Arnold, Heinz (1995): Disparitäten in Europa: Die Regionalpolitik der Europäischen Union. Analyse, Kritik, Alternativen, Basel/Boston/Berlin

Arnold, Volker (1992): Theorie der Kollektivgüter, München

Artus, Patrick (1996): A Strong or a Weak Euro? CDC Working Paper

Axelrod, Robert (1984): The Evolution of Cooperation, New York

Bhagwati, Jagdish (1998): The Capital Myth. The Difference between Trade in Widgets and Dollars. Foreign Affairs 1998-3, S. 7-12

Bank für Internationalen Zahlungausgleich BIZ (1997a): $67^{\text {th }}$ Anual Report, Basel

- (1997b): International Banking and Financial Markets Developments, Basel

- (1998a): $68^{\text {th }}$ Annual Report, Basel

- (1998b): Triennial Central Bank Survey of Foreign Exchange and Derivatives Market Activity, Basel

- (1998c): Central Bank Survey of Foreign Exchange and Derivatives Market Activity in April 1998: Preliminary Global Data, Basel 
Barro, Robert J. / David B. Gordon (1983): Rules, Discretion and Reputation in a Model of Monetary Policy. Journal of Monetary Economics 12, S. 101-121

Bartolini, Leonardo / Alessandro Prati (1998): Soft Exchange Rate Bands and Speculative Attacks: Theory, and Evidence from the ERM sind August 1993. IMF Working Paper WP/98/156

Bayoumi, Tamin / Barry Eichengreen (1993): Shocking Aspects of European Monetary Union. In: Torres/Giavazzi (Hrsg.): Adjustment and Growth in the Europan Monetary Union, Cambridge

- (1994): Economic Performance under alternative Exchange Rate Regimes: some Historical Evidence. In: Peter B. Kenen (Hrsg.): The Monetary System, Cambridge, S. 257-293

- (1996): Ever Closer to Heaven? An Optimum-Currency-Area Index for European Countries. Center for International and Development Economics Research Working Paper No. C96-078

Bayoumi, Tamin / Alun Thomas (1994): Relative Prices and Economic Adjustment in the US and the EU: A Real Story about EMU. IMF Working Paper WP/94/65

Bayoumi, Tamin / Michael W. Klein (1997): A Provincial View on Economic Integration. IMF Working Paper WP/97/41

Belke, Ansgar (1996): Maastricht - Implikationen einer zentralisierten Geld- und Währungspolitik für die Beschäftigung in Europa. IEW-Working-Paper

Bénassy-Quéré, Agnès / Benoît Mojon / Jean Pisani-Ferry (1997): The Euro and Exchange Rate Stability. In: Paul R. Masson / Thomas H. Krueger / Bart G. Turtleboom (Hrsg.): EMU and the International Monetary System, preceedings of a conference held in Washington D. C. on March 17-18, Washington D. C., S. 157-193

Bergsten, C. Fred (1996a): Dilemmas of the Dollar. The Economics and Politics of United States International Monetary Policy, 2. Auflage, Armonk/London

- (1996b): Competetive Liberalisation and Global Free Trade: A Vision for the 21 rst Century. APEC Working Paper 96/15

- (1997a): The Dollar and the Euro. Foreign Affairs, Volume 76, 4 , S. 83-95 
- (1997b): The Imact of the Euro on Exchange Rates and International Policy Coordination. In: Paul R. Masson / Thomas H. Krueger / Bart G. Turtleboom (Hrsg.): EMU and the International Monetary System, preceedings of a conference held in Washington D. C. on March 17-18, Washington D. C., S. $17-48$

Berthold, Norbert (1996): Währungsunion, Sozialunion und Politische Union Anmerkungen zur Interdependenz der Ordnungen. In: Bankhistorisches Archiv, Zeitschrift zur Bankgeschichte, Währungsunion und politische Integration: Historische Erfahrungen und europäische Perspektiven, Beiheft 30, S. 5264

Bishop, Graham (1996): Die Einführung auf den europäischen Finanzmärkten ein interaktiver Prozeß. In: Reinhard Hummel (Hrsg.): Ein Markt - eine Währung. Countdown für die Eurowährung? 2. Auflage, Wien

Boadway, Robin / Sandra Roberts / Anwar Shah (1994): The Reform of Fiscal Systems in Developing and Emerging Market Economies - a Federalism Perspective. Policy Research Working Paper 1259

Bofinger, Peter (1998): „Es mangelt an Vertrauen“. Interview in „Deutsches Allgemeines Sonntagsblatt" vom 30. Januar 1998, S. 11

Boone, Laurence (1997): Symmetry and Asymmetry in Supply and Demand Shocks in the European Union: A Dynamic Analysis, Centre D‘Études Prospectives et D'Informations Internationales, Document de Travail No. 97-03

Borio, Claudio E. V. (1997): Monetary Operating Procedures in Industrial Countries. BIS Working Papers No. 40

Branson, William H. (1979): Exchange Rate Dynamics and Monetary Policy. In: H. Lindbeck (Hrsg.): Inflation and Employment in Open Economies, Amsterdam, S. 189-224.

Brok, Elmar (1997): Kein Papiertiger: der Vertrag von Amsterdam. Wirtschaftsdienst 7/1997, S. $375-378$

Bruha, Thomas / Thomas Straubhaar (1997): „EWR II“ Europäischer Warteraum oder Stufenplan für Mittel- und Osteuropa. Institut für Wirtschaftspolitik der Universität der Bundeswehr, Diskussionbeiträge zur Wirtschaftspolitik Nr. 70 
Cangiano, Marco / Eric Mottu (1998): Will Fiscal Policy Be Effective Under EMU? IMF Working Papers WP/98/176

Caporaso, James A. / David P. Levine (1992): Theories of Political Economy, Cambridge

Carruth, Alan / Heather Gibson / Euclid Tsakalotos (1994): Symmetric Shocks and Consumer Spending in the EU. University of Kent, Economics Department Working Paper

Cassard, Marcel / David Folkerts-Landau (1997): Risk Management of Sovereign Assets and Liabilities. IMF Working Paper WP/97/166

Catte, Pietro / Giampaolo Galli / Salvatore Rebecchini (1994): Concerted Interventions and the Dollar: An Analysis of Daily Data. In: Peter B. Kenen (Hrsg.): The Monetary System, Cambridge, S. 201-235

Chown, John (1992): Commentary on the Ruding Report. European Taxation Vol. 32, No. 4/5, S. 123-128

Claassen, Emil-Maria (1990): Exchange Rate Management and International Coordination. In: Emil-Maria Claassen (Hrsg.): International and European Monetary Systems, New York, S. 41-59

Collins, Susan M. (1990): PPP and the Peso Problem: Exchange Rates in the EMS, in: Emil-Maria Claassen (Hrsg.): International and European Monetary Systems, New York, S. 99-117

Committee of Independent Experts on Company Taxation (1992): Report of the Ruding Committee (Zusammenfassung), European Taxation Vol. 32, No. $4 / 5$, S. $105-123$

De Grauwe, Paul (1996): The Economics of Convergence: Towards Monetary Union in Europe. Weltwirtschaftliches Archiv Vol. 132 (1), S. 1-27

- (1997a): The Economics of Monetary Integration, 3. Auflage, Oxford

- (1997b): Exchange Rate Arrangements Between the Ins and the Outs. In: Paul R. Masson / Thomas H. Krueger / Bart G. Turtleboom (Hrsg.): EMU and the International Monetary System, preceedings of a conference held in Washington D. C. on March 17-18, Washington D. C., S. 97-118 
De Nardis, Sergio / Alessandro Goglio / Marco Malgarini (1996): Regional Specialization and Shocks in Europe: Some Evidence from Regional Data. Weltwirtschaftliches Archiv Vol. 132 (2), S. 197-214

De Silguy, Yves-Thibault (1999): L'euro, 4 Mois Après : Situation et Perspectives. Rede vor dem Unterausschuß Währung des Europäischen Parlaments am 20. April 1999 in Brüssel

Deutsche Bundesbank (1997a): Wechselkurs und Außenhandel. In: Monatsbericht $1 / 1997$, S. 43-62

- (1997b): Die Rolle der Mark als internationale Anlage- und Reservewährung. In: Monatsbericht 4/1997, S. 17-30

- (1997c): Geldpolitische Strategie und Instrumentarium des Europäischen Systems der Zentralbanken, Informationsbrief zur Europäischen Währungsunion Nr. 4

- (1997d): Weltweite Organisationen und Gremien im Bereich von Währung und Wirtschaft, Frankfurt am Main

- (1997e): Europäiche Organisationen und Gremien im Bereich von Währung und Wirtschaft, Frankfurt am Main

-(1998a): Die deutsche Zahlungsbilanz 1997. In: Monatsbericht 3/1998, S. 6578

- (1998b): Stellungnahme des Zentralbankrates zur Konvergenzlage in der Europäischen Union im Hinblick auf die Dritte Stufe der Wirtschafts- und Währungsunion, Frankfurt am Main

- (1998c): Geschäftsbericht der Deutschen Bundesbank 1997, Frankfurt am Main

- (1998d): Die technische Ausgestaltung des neuen europäischen Wechselkursmechanismus. In: Monatsbericht 10/1998, S. 19-25

- (1998e): Strukturveränderungen am deutschen Kapitalmarkt im Vorfeld der Europäischen Währungsunion. In: Monatsbericht 4/1998, S. 55-70

Deutsches Institut für Wirtschaftsforschung DIW (1996): Europäische Währungsunion: Reale Konvergenz unentbehrlich. DIW-Wochenbericht 31/1996 
- (1997): Rahmenbedingungen für den Arbeitsmarkt in einer erfolgreichen Wirtschafts- und Währungsunion, Gutachten im Auftrage des Bundesministers für Wirtschaft, Berlin

- (1998a): Abhängigkeit der deutschen Exporte vom realen Außenwert der DMark. DIW-Wochenbericht 4/1998

- (1998b): Starke Auweitung des Handels mit den Reformländern Mittel- und Osteuropas von 1992 bis 1997. DIW-Wochenbericht 7/1998

Devereux, Michael (1992): The Ruding Committee Report: An Economic Assessment. Fiscal Studies (1992), Vol. 13 No. 2, S. 96-107

Diehl, Markus / Rainer Schweickert (1997): Wechselkurspolitik im Aufholprozeß: Erfahrungen lateinamerikanischer, europäischer und asiatischer Länder, Tübingen

Döpke, Jörg / Klaus-Jürgen Gern / Enno Langfeldt / Joachim Scheide / Markus Schlie (1998): Quo vadis, Euroland? Kieler Diskussionsbeiträge 313

Dohse, Dirk / Christiane Krieger-Boden (1998): Währungsunion und Arbeitsmarkt. Auftakt zu unabdingbaren Reformen, Kieler Studien 290, Tübingen

Dominguez, Kathryn M. / Jeffrey A. Frankel (1993): Does foreign-exchange intervention work? Washington D. C.

Dornbusch, Rüdiger (1976): Expectations and Exchange Rate Dynamics. Journal of Political Economy, Vl. 84, S. 1161-1176

- (1982): Equilibrium and Disequilibrium Exchange Rates. Zeitschrift für Wirtschafts- und Sozialwissenschaften, Bd. 37, S. 573-599

- (1996): EMU won`t hurt the Dollar. Internet document auf Dornbuschs MITHomepage (http://mit.edu/rudi.www)

- (1999): The Euro: Implications for Latin America. Paper prepared for the World Bank

Dumke, Rolf, H. / Alexander Juchems / Heidemarie C. Sherman (1997): Währungsvielfalt behindert Vollendung des Europäischen Binnenmarktes. Studie des Münchner ifo-Instituts im Auftrag der Europäischen Union, München

Duisenberg, Willem F. (1998): Die internationale Rolle des Euro. Vortrag am Donnerstag am 22. Oktober 1998 bei der Konrad-Adenauer-Stiftung in Berlin 
Economist (1996): The Euro and the Dollar: Strut your Stuff. The Economist, 19. October 1996, S. 87-88

- (1998): Reviving Japan. Time to wake up. The Economist, 26. September 1998, S. 23-27

Eichengreen, Barry / Jürgen von Hagen (1995): Fiscal Policy and Monetary Union: Federalism, Fiscal Restrictions and the No-Bail-Out Rule. CEPR Discussion Paper No. 817

Eichengreen, Barry / James Tobin / Charles Wyplosz (1995): Two Cases for Sand in The Wheels of International Finance. The Economic Journal, Jan. 1995, S. 162-171

Europäische Kommission (1997a): Externe Aspekte der Wirtschafts- und Währungsunion. Arbeitdokument der Kommissionsdienststellen vom 23. April 1997

- (1997b): External Aspects of Economic and Monetary Union. Euro Papers No. 1

- (1997c): The Impact of the Introduction of the Euro on Capital Markets. Euro Papers No.3

- (1997d): Koordinierung der Steuerpolitik in der Europäischen Union, Maßnahmen zur Bekämpfung des schädlichen Steuerwettbewerbs, Brüssel

- (1997e): Agenda 2000 Band I und II, Brüssel

- (1998a): Bericht über den Konvergenzstand, Brüssel

- (1998b): Reports on Progress towards Accession by Each ot the Candidate Countries (Länderberichte über Bulgarien, Tschechien, Estland, Ungarn, Lettland, Litauen, Polen, Rumänien, die Slovakische Republik, die Türkei und Zypern), 4. November 1998, Brüssel

Europäischer Rat (1996): Tagung am 13. Und 14. Dezember 1996 in Dublin, Schlußfolgerungen des Vorsitzes

- (1997a): Tagung am 16. und 17. Juni 1997 in Amsterdam, Schlußfolgerungen des Vorsitzes

- (1997b): Außerordentliche Tagung am 20. und 21. November in Luxemburg, Schlußfolgerungen des Vorsitzes 
- (1997c): Europäischer Rat von Luxemburg 12./13. Dezember 1997: Resolution of the European Council on Economic Policy Co-ordination in Stage 3 of EMU an on Treats Articles 109 and 109b

- (1998): Europäischer Rat von Wien 11./12. Dezember 1998: Schlußfolgerungen des Vorsitzes

Europäisches Währungsinstitut EWI (1997a): The Single Monetary Policy in Stage Three: Elements of the Monetary Policy Strategy or the ESCB, Frankfurt am Main

- (1997b): The Single Monetary Policy in Stage Three: General Documentation on ESCB Monetary Policy Instruments and Procedures, Frankfurt am Main

- (1998): Nach Artikel 109 j des Vertrags zur Gründung der Europäischen Gemeinschaft vorgeschriebener Bericht (Konvergenzbericht), Frankfurt am Main

Europäische Zentralbank EZB (1998): A Stability-Oriented Monetary Strategy for the European System of Central Banks. Pressemitteilung vom 18. Oktober 1998

- (1999a): Monatsbericht 1/1999, Frankfurt am Main

- (1999b): Monatsbericht 2/1999, Frankfurt am Main

Fisch, Gerhard (1994): Integration und Kohäsion heterogener Staaten in der EU außenhandelstheoretische und entwicklungsrelevante Probleme, Wiesbaden

Fischer, Stanley (1977): Long-Term Contracts, Rational Expectations, and the Optimal Money Supply Rule, Journal of Political Economy 85 (Februar): S. 191-205

Fischer, Stanley / Ratna Sahay / Carlos A. Végh (1998): How Far ist Eastern Europe from Brussels? IMF Working Paper WP/98/53

Flassbeck, Heiner (1998): „Eins auf die Nuß“. Interview in „Der Spiegel“ $42 / 1998$, S. $132-135$

Franz, Wolfgang (1994): Arbeitsmarktökonomik, 2. Auflage, Berlin/Heidelberg/New York/Tokio

Friedman, Milton (1968): The Role of Monetary Policy. American Economic Review 58 (März), S. 1-17 
Fröhlich, Hans-Peter / Hans-Peter Klös / Rolf Kroker / Claus Schnabel / Christoph Schröder (1997): Lohnpolitik in der Europäischen Union. Beiträge zur Wirtschafts- und Sozialpolitik Heft 234, Institut der deutschen Wirtschaft Köln

Funke, Norbert / Mike Kennedy (1997): International Implications of European Economic and Monetary Union. OECD Economics Department Working Papers No. 174

Garber, Peter M. (1996): The Use of the Yen as a Reserve Currency. Monetary and Economics Studies, Vol. 14, No. 2 December 1996, S. 1-22

Garber, Peter M. / Mark P. Taylor (1995): Sand in the Wheels of the Foreign Exchance Markets: A Special Note. The Economic Journal, Jan. 1995, S. 173180

Genser, Bernd / Barbara Schaden / Magarita Steinhart (1992): Die Vorschläge des Ruding-Komitees zur Körperschaftsteuerharmonisierung in der Europäischen Gemeinschaft. Universität Konstanz, Sonderforschungsbericht 178

Gill, S. / D. Law (1988): The Global Political Economy, Herfortshire

Gilpin, Robert (1987): The Political Economy of International Relations, Princeton

Goldfajn, Ilan / Rodrigo O. Valdés (1997): Are Currency Crisis Predictable? IMF Working Paper WP/97/159

Goldstein, Morris (1994): Improving Economic Policy Coordination: Evaluating some new and some not-so-new Proposals. In: Peter B. Kenen (Hrsg.): The Monetary System, Cambridge, S. 298-324

Goodhart, Charles A. E. (1994): European Monetary Union: A Progress Report. LSE Special Paper No. 63

- (1996): Financial Globalization, Derivatives, Volatility, and the Challenge for the Policies of Central Banks. In: Horst Siebert (Hrsg.): Monetary Policy in an Integrated World Economy, Tübingen, S. 61-90

Gros, Daniel (1995): Towards a Crdible Excessive Deficits Procedure. Working Document, Centre für European Policy Studies

- (1996a): Germany`s Stake in Exchange Rate Stability. Intereconomics, Sept./Oct. 1996, S. 236-240 
- (1996b): A Reconsideration of the Cost of EMU. The Importance of External Shocks and Labour Mobility. EUI Working Paper RSC N. 96/15

Group of Seven $G 7$ (1999): Communiqué der Finanzminister und Notenbankengouverneure der G 7 beim Treffen am 20. Februar 1999 in Bonn. IMF Survey 5/1999 vom 5. März 1999, S. 66-69

Häde, Ulrich (1996): Währungsunion und Finanzausgleich., Baden-Baden

Hallet, Martin (1997): National and Regional Development in Central and Eastern Europe: Implications for EU Structural Assistance. Europäische Kommission, Economic Papers No. 120

Hartmann, Philipp (1996): The Future of the Euro as an International Currency. A Transactions Perspective, LSE Financial Markets Group Special Paper No. 91

Hasse, Rolf H. (1997): Alternativen zum Stabilitätspakt von Dublin. Wirtschaftsdienst 1/1997, S. 15-19

Häuser, Karl (1997): Deutsche Währungsunion nach 1871 - Modell einer Europäischen Währungsunion? Deutsche Bundesbank, Auszüge aus Presseartikeln vom 20. Februar 1997

Henke, Klaus-Dirk (1997): Die Finanzierung der EU. Wirtschaftsdienst 1997/I, S. $45-49$

Henning, C. Randall (1998): Europe`s Monetary Union, the United States, and International Cooperation. Testimony given before the Subcommittee on Domestic and International Monetary Policy Committee on Banking and Financial Services United States House of Representatives, 18. April 1998

Henrichsmeyer, Wilhelm / Heinz Peter Witzke (1994): Agrarpolitik Band 2, Bewertung und Willensbildung, Stuttgart

Hillman, Ayre L. (1989): The Political Economy of Protection, Chur

Hoeller, Peter / Marie-Odile Louppe / Patrice Vergriete (1996): Fiscal Relations within the European Union. OECD Economic Department Working Papers 162

Holler, Manfred J. / Gerhard Illing (1996): Einführung in die Spieltheorie, 3. Auflage, Berlin 
Hrbek, Rudolf (1997): Der Vertrag von Amsterdam - eine neue Etappe im EUIntegrationsprozeß. Wirtschaftsdienst 7/1997, S. 378-381

Hufbauer, Gary C. / Jeffrey J. Schott / Kimberly A. Elliott (1990): Economic Sanctions Reconsidered. History and Current Policy, 2. Auflage, Washington D. C.

Hufbauer, Gary C. / Kimberly A. Elliott / Tess Cyrus / Elizabeth Winston (1996): US Economic Sanctions: Their Impact on Trade, Jobs, and Wages. Institute for International Economics Working Papers

Huntington, Samuel P. (1996): Kampf der Kulturen. Die Neugestaltung der Weltpolitik im 21. Jahrhundert. München/Wien

Inman, Robert P. / Daniel L. Rubinfeld (1991): Fiscal Federalism in Europe: Lessons from the United States Experience. NBER Working Paper No. 3941

Institut der deutschen Wirtschaft IW (1997): EU-Regionalentwicklung: Angleichung im Schneckentempo. In: IW-Dienst Nr. 16/1997, S. 4-5

- (1998): Arbeitsmarkt: Arbeitslosigkeit - eine Frage der Statistik, In: IWDienst Nr. 15/1998, S.4-5

Internationaler Währungsfonds IWF (1997): World Economic Outlook, Part III „EMU and the World Economy“, Washington D. C., S. 51-77

- (1998a): World Economic Outlook - Financial Crises: Causes and Indicators, Mai 1998, Washington D. C.

- (1998b): World Economic Outlook, September 1998, Washington D. C.

- (1998c): Annual Report, Washington D. C.

- (1999): Chronic Unemployment in the Euro Aera: Causes and Cures. In: World Economic Outlook April 1999, Washington D. C., S. 40-101

Issing, Otmar (1995): Einführung in die Geldtheorie, 10. Auflage, München

- (1996a): Einführung in die Geldpolitik, 6. Auflage, München

- (1996b): Mögliche Auswirkungen der Europäischen Währungsunion auf die internationalen Finanzmärkte. Deutsche Bundesbank, Auszüge aus Presseartikeln vom 6. Dezember 1996 
- (1997): Der Euro im Weltwährungssystem. Vortrag auf dem Symposium der Adolf Weber Stiftung am 15. April 1997

James, Harold (1997): Rambouillet, 15. November 1975 - Die Globalisierung der Wirtschaft, München

Jarchow, Hans-Joachim / Peter Rühmann (1988): Monetäre Außenwirtschaft Band 1. Monetäre Außenwirtschaftstheorie, 2. Auflage, Tübingen

Jarchow, Hans-Joachim / Peter Rühmann (1984): Monetäre Außenwirtschaft Band 2. Internationale Währungspolitik, Tübingen

Kachelrieß, Martin (1999): Euro versus Dollar - Währungskonkurrenz statt Monopol. HypoVereinsbank, Euro!, Ausgabe vom 15. Januar 1999

Kaiser, Helmut / Werner Kramer / Markus Herrmann (1997): Europäische Währungsunion - Auswirkungen auf die Marktstrukturen. Deutsche Bank Reserach, EWU-Monitor Nr. 28

Karczmar, Mieczyslaw (1996): Die USA und die europäische Währungsunion: Was halten die Amerikaner von der EWU? Deutsche Bank Research, EWUMonitor Nr. 16

Kenen, Peter B. (1969): The Theory of Optimum Currency Areas: An Eclectic View. In: Robert Mundell et al. (Hrsg.): Monetary Problems of the international Economy, Chicago, S. 42-60

- (1994): Exchange Rates and the Monetary System. Selected Essays of Peter B. Kenen, Brookfield

- (1995): Capital Controls, the EMS and EMU. The Economic Journal, Jan. 1995, S. 181-191

- (1998): EMU and Transatlantic Economic Relations. HWWA-Diskussionpapier Nr. 60

Kennedy, Paul (1989): Aufstieg und Fall der großen Mächte, Frankfurt am Main (Original: The Rise and Fall of the Great Powers, New York 1987)

Keohane, R. O. (1989): The Demand for International Regimes. In: R. O. Keohane: International Institutions and State Power, Boulder, S. 101-131 
Kiehl, Melanie / Heinz Werner (1998): Die Arbeitsmarktsituation von EU-Bürgern und Angehörigen von Drittstaaten in der EU. IAB Werkstattbericht Nr. 7 vom 30. Juli 1998

Kilper, Heiderose / Roland Lhotta (1996): Föderalismus in der Bundesrepublik. Eine Einführung, Opladen

Kindleberger, Charles P. (1986): The World in Depression 1929-1939. Überarbeitete und erweiterte Ausgabe, Berkley/London/Los Angeles

Klodt, Henning / Jürgen Stehn et al. (1994): Standort Deutschland: Strukturelle Herausforderungen im neuen Europa. Kieler Studien 265, Tübingen

Kopits, George (1997): Are Europe`s Social Security Finances Compatible with EMU? IMF Working Papers WP/97/3

Krugman, Paul (1991a): Geography and Trade, Cambridge

- (1991b): History and Industry Location: The Case of the Manufactoring Belt, American Economic Review, Mai 1991, S. 80-83

- (1991c): Cities in Space: Three simple Models. NBER Working Paper No. 3607

- (1998): The Confidence Game. The New Republic, October 51998

Lafontaine, Oskar (1998): „Mit dem Unvollkommenen leben“. Interview in „Der Spiegel" 41/1998, S. 33-35

- / Christa Müller (1998): Keine Angst vor der Globalisierung. Arbeit und Wohlstand für alle, Bonn

- / Dominque Strauss-Kahn (1999): Euro - sozial und stark. Märkte brauchen die ordnende Hand des Staates. Die Zeit 3/99, S. 17

Laurens, Bernard / Erique G. de la Piedra (1998): Coordination of Monetary and Fiscal Policies. IMF Working Paper WP/98/25

Leahy, Michael P. (1996): The Dollar as an Official Reserve Currency Under EMU. Open Economies Review 7, 1996, S. 371-390

Lucas, Robert E. jr. (1972): Expectations and the Neutrality of Money. Journal of Economic Theory 4 (April), S. 103-124 
MacDonald, Ronald (1997): What Determines Real Exchange Rates? The long and short of it. IMF Working papers 97/21

Masson, Paul R. / Bart G. Turtleboom (1997): Charateristics of the Euro, the Demand for Reserves, and Policy Coordination under EMU. IMF Working Paper WP/97/58

McCauley, Robert N. (1997): The Euro and the Dollar. BIS Working Paper No. 50

- / William R. White (1997): The Euro and European Financial Markets. BIS Working Paper No. 41

McKinnon, Robert (1963): Optimum Currency Areas. American Economic Review, Vol. 53, S. 717-725

McKinnon, Ronald (1984): An International Standard for Monetary Stabilization. Institute for International Economics, Policy Analysis in International Economics No. 8

Meier, Carsten-Patrick (1997): Assessing Convergence to Purchasing Power Parity: A Panel Study for Ten OECD Countries. Weltwirtschaftliches Archiv Vol 133 (2), S. 297-311

Meister, Edgar (1997): Aktuelle Fragen der europäischen Währungsunion und Beschäftigungspolitik. Vortrag im Rahmen der gemeinsamen Konferenz der Landtagspräsidentinnen und Landtagspräsidenten der Bundesländer der Bundesrepublik Deutschland, der Republik Österreich und von Südtirol am 3. Juni 1997 in Spittal/Drau (Kärnten)

Modery, Wolfgang (1996): Internationale währungspolitische Arrangements auf dem Prüfstand ökonomischer Effizienz, Frankfurt am Main/Bern/New York/Paris/Wien

Müller, Henrik (1997a): Kursbuch Euro. Die neue Währung in der Praxis, Frankfurt am Main

- (1997b): Euro-Poker. Zur politischen Ökonomie der Auswahl der EWU-Teilnehmer. Blätter für deutsche und internationale Politik, Juni 1997, S. 704713

- (1998a): Europa unter Solidaritätszwang. Blätter für deutsche und internationale Politik, Mai 1998, S. 565-574 
- (1998b): Eurolands Rolle in der Weltwirtschaft. Ein wechselkurspolitisches Konfliktszenario für die Ära der Europäischen Währungsunion. Institut für Wirtschaftspolitik der Universität der Bundeswehr, Diskussionbeiträge zur Wirtschaftspolitik Nr. 92

- (1999): Währungspolitik in der Euro-Ära. Studie für das Liberale Institut der Friedrich-Naumann-Stiftung

- / Thomas Straubhaar (1998): Die Stellung des Euro im internationalen Währungssystem. Wirtschaftsdienst 5/1998, S. 284-292

Muet, Pierre-Alain (1996): Labour Market Adjustment and EMU: The Case of France. Paper prepared for the Observatoire Social Européen Conference

Mundell, Robert (1961): A Theory of Optimum Currency Areas. American Economic Review, Vol 51, S. 657-664

Musgrave, Richard A. (1959): The Theory of Public Finance, New York

- / Peggy B. Musgrave / Lore Kullmer (1993): Die öffentlichen Finanzen in Theorie und Praxis, Band 2. 5., völlig überarbeitete Auflage, Tübingen

Muth, John (1961): Rational Expectations and the Theory of Price Movements. Econometrica 30 (Juli), S. 315-334

Myrdal, Gunnar (1958): Internationale Wirtschaft, Berlin

Nikolakaki, Maria (1997): Is Europe an Optimum Currency Area?: A Reconsinderation of the Evidence. Center for Economic Performance Discussion Paper No. 342

Nossal, K. R. (1989): International Sanctions as International Punishment. International Organisation, Vol. 43, 2

Ochel, Wolfgang (1996): Die Europäische Wirtschafts- und Währungsunion Chancen und Risiken. Ifo-Schnelldienst 9/1996, S. 21-34

Organisation of Economic Cooperation and Development OECD (1997): Implementing the OECD Job Strategy. Lessons from Member Countries` Experience, Paris

- (1999): EMU. Facts, Challenges, and Policies, Paris 
Padoa Schioppa, Tommaso (1985): Policy Cooperation and the EMS Experience. In: Willem H. Buiter / Richard C. Marston (Hrsg.): International Economic Policy Coordination, Cambridge, S. 331-354

Peffekoven, Rolf (1992): Finanzpolitische Konsequenzen der Europäischen Währungsunion. Vortrag vor dem Giessener Arbeitskreis für wirtschaftspolitische Studien am 21. Mai 1992

- (1994): Die Finanzen der Europäischen Union, Mannheim

Phelps, Edmund S. (1967): Phillips Curves, Expectations of Inflation and Optimal Unemployment over Time. Economica 34, S. 254-281

Phillips, A. W. (1958): The Relationship between Unemployment and the Rate of Change of Money Wages in the United Kingdom. Economica 25 (November), S. 283-299

Pollak, Jacques J. (1988): Economic Objectives and Policymaking in the Major Industrial Countries. In: Wilfried Guth (Hrsg.): Economic Policy Coordination, Washington D. C.

- (1997): The IMF and Its EMU Members. In: Paul R. Masson / Thomas H. Krueger / Bart G. Turtleboom (Hrsg.): EMU and the International Monetary System, preceedings of a conference held in Washington D. C. on March 17-18, Washington D. C., S. 491-511

Prati, Alessandro / Garry J. Schinasi (1997): European Monetary Union and Capital Markets: Structural Implications and Risks. IMF Working Paper WP/97/62

Ranki, Snimaaria (1993): The ECU as the Future Currency of Financial Transactions. Bank of Finland Discussion Paper 11/93

Ricci, Lucca Antonio (1997): Exchange Rate Regimes and Location. IMF Working Paper WP/97/69

Richter, Rudolf (1994): Institutionen ökonomisch analysiert, Tübingen

Romer, David (1996): Advanced Macroeconomics, New York

Sala-i-Martin, Xavier / Jeffrey Sachs (1992): Fiscal Federalism and Optimum Currency Areas: Evidence for Europe from the United States. CEPR Discussion Paper No. 632 
Samuelson, Paul A. / Robert M. Solow (1960): Analytical Aspekts of Anti-Inflation Policy. American Economic Review 50 (Mai), S. 177-194

Sargent, Thomas J. / Neil Wallace (1975): 'Rational Expectations', the Optimal Monetary Instrument and the Optimal Money Supply Rule. Journal of Political Economy 83 (April), S. 241-254

Scheide, Joachim / Ralph Solveen (1997): Should the European Central Bank worry about Exchange Rates? Kiel Working paper No. 800

Schlesinger, Helmut (1997): Stabilität und Solidarität - Perioden der Währungspolitik 1922 - 2002, in Deutsche Bundesbank: Auszüge aus Presseartikeln vom 20. Februar 1997

Schmidt, Christian / Thomas Straubhaar (1995): Maastricht II: Are real convergence criteria needed? Intereconomics, September/Oktober 1995, S. 211 220

Schrader, Alexander (1998): Strategie der Euro-Geldpolitik: Geldmengenziel cum Inflationsprognose. HypoVereinsbank, Euro! vom 12. Oktober 1998

Seifert, Werner G. (1996): EWWU: Ein weiterer „Meilenstein“ auf dem Weg zu einem Europäischen Börsensystem? In: Reinhard Hummel (Hrsg.): Ein Markt eine Währung. Countdown für die Eurowährung? 2. Auflage, Wien

Shapiro, Carl / Hal R. Varian (1999): Information Rules: A Strategic Guide to The Network Economy, Boston

Siebert, Horst (Hrsg.) (1990): Reforming Capital Income Taxation, Tübingen

- (1991): Außenwirtschaft, 5. Auflage, Stuttgart

- (1997): Stabilitätspakt - Die Geldpolitik in der Währungsunion ent-politisieren. Wirtschaftsdienst 1/1997, S. 7-10

Sinn, Hans-Werner (1990): Tax Harmonisation and Tax Competition in Europe. European Economic Review 34 (1990), S. 489-504

Smets, Frank (1997): Measuring Monetary Policy Shocks in France, Germany and Italy: The Role of the Exchange Rate. BIS Working Paper No. 42

Solveen, Ralph (1998): Der Einfluß der Unabhängigkeit auf die Politik der Zentralbanken. Kieler Studien 288, Tübingen 
Stark, Jürgen (1997): Political and Economic Issues of EMU in Europe. Implications for the US. Adress at the Deutsche Bank AG and the Council of Foreign Relations in New York on March 13. In: Deutsche Bundesbank: Auszüge aus Presseartikeln vom 25. März 1997

Straubhaar, Thomas / Achim Wolter (1996): Aktuelle Brennpunkte der europäischen Migrationsdiskussion. Wirtschaftsdienst 9/1996, S. 481-490

Tanzi, Vito / Howell H. Zee (1998): Consequences of the Economic and Monetary Union for the Coordination of Tax Systems in the European Union: Lessons from the U. S. Experience. IMF Working Papers WP/98/115

Tatom, John. A. (1995): Curreny Appreciation and 'Deindustrialisation': A European Perspective. The World Economy, Vol. 18, 1995, No. 4, S. 519-541

Theurl, Theresia (1996): Währungsunion ohne politische Integration: Die Lateinische und die Skandinavische Münzunion. Währungsunion und politische Integration: Historische Erfahrungen und europäische Perspektiven. Bankhistorisches Archiv, Zeitschrift zur Bankgeschichte. Beiheft 30, S. 15-34

Thurow, Lester C. (1996): Die Zukunft des Kapitalismus, Düsseldorf/München (Originaltitel: The Future of Capitalism. How Today`s Economic Forces Shape Tomorrow`s world, New York 1996)

Thygesen, Niels (1997): Relations Among the IMF, the ECB, and the IMF's EMU Members. In: Paul R. Masson / Thomas H. Krueger / Bart G. Turtleboom (Hrsg.): EMU and the International Monetary System, preceedings of a conference held in Washington D. C. on March 17-18, Washington D. C., S. 512530

Tietmeyer, Hans (1999): Financial Stability Forum Convened to Promote Cooperation in Supervision of Global Markets, IMF Survey 5/99 vom 5. März 1999, S. 69-71

Tobin, James (1978): A Proposal for International Monetary Reform. Eastern Economic Journal, Vol. 4, S. 153-159

Underhill, Geoffrey R. D. (1996): Financial Market Integration, Global Capital Mobility, and the ERM Crisis 1992 -1995. Working Paper, Warwick

Van der Wee, Herman (1984): Der gebremste Wohlstand: Geschichte der Weltwirtschaft im 20. Jahrhundert Band 6, München 
Varian, Hal R. (1990): Intermediate Microeconomics: a modern approach, 2. Auflage, New York/London

Vaubel, Roland (1996): Das Tauziehen um die Europäische Währungsunion. Aus Politik und Zeitgeschichte vom 5. Januar 1996

- (1997): Kein Pakt für Preisstabilität. Wirtschaftsdienst 1/1997, S. 10-15

Von Hagen, Jürgen (1996): Monetäre, fiskalische und politische Integration: Das Beispiel der USA. Währungsunion und politische Integration: Historische Erfahrungen und europäische Perspektiven, Bankhistorisches Archiv, Zeitschrift zur Bankgeschichte, Beiheft 30, S 35 - 51

Wagner, Helmut (1995a): Einführung in die Weltwirtschaftspolitik, 3. Auflage, München/Wien

- (1995b): Europäische Wirtschaftspolitik, Perspektiven einer Europäischen Wirtschafts- und Währungsunion, Berlin/Heidelberg

Weber, Albrecht (1994): Die Wirtschafts- und Währungsunion nach dme Maastricht-Urteil des BVerfG. Juristenzeitung 2/1994, S. 53 - 60

Weber, Axel A. (1996): Foreign Exchange Intervention and International Policy Coordination: Comparing the G3 and EMS experience. In: Canzonieri/Ethier/Grilli (Hrgs.): The New Transatlantic Economy, Cambridge

Wegner, Manfred (1989): The European Monetary System: A Regional Bretton Woods or an Institutional Innovation? In: Hans-Jürgen Vosgerau (Hrsg.): New Institutional Arrangements in the World Economy, Berlin/Heidelberg, S. 89118

Weidenfeld, Werner / Christian Jung (1994): Das Entscheidungsgefüge in der Europäischen Union: Institutionen, Prozesse und Verfahren, in: Weidenfeld, Werner (Hrsg.): Maastricht in der Analyse, Strategien und Optionen für Europa, Gütersloh

Williamson, John (1990): Target Zones \& Monetary Systems. In: Classen, EmilMaria (Hrsg.): International and European Monetary Systems, Oxfort, S. 3-14

Willms, Manfred (1992): Internationale Währungspolitik, München

Wolter, Achim / Rolf E. Hasse (1997): Gemeinsame Beschäftigungspolitik: Überfällig oder überflüssig? Wirtschaftsdienst 7/1997, S. 386-389 


\section{SCHRIFTEN ZUR WIRTSCHAFTSTHEORIE UND WIRTSCHAFTSPOLITIK}

Herausgegeben von Rolf Hasse, Jörn Kruse, Wolf Schäfer, Thomas Straubhaar, Klaus W. Zimmermann

Band 1 Lars Bünning: Die Konvergenzkriterien des Maastricht-Vertrages unter besonderer Berücksichtigung ihrer Konsistenz. 1997.

Band 2 Andreas Henning: Beveridge-Kurve, Lohnsetzung und Langzeitarbeitslosigkeit. Eine theoretische Untersuchung unter Berücksichtigung des Insider-Outsider-Ansatzes und der Entwertung des Humankapitals. 1997.

Band 3 Iris Henning: Die Reputation einer Zentralbank. Eine theoretische Untersuchung unter besonderer Berücksichtigung der Europäischen Zentralbank. 1997.

Band 4 Rüdiger Hermann: Ein gemeinsamer Markt für Elektrizität in Europa. Optionen einer Wettbewerbsordnung zwischen Anspruch und Wirklichkeit. 1997.

Band 5 Alexander Tiedtke: Japan und der Vorwurf des Trittbrettfahrerverhaltens in der US-amerikanisch-japanischen Allianz. 1997.

Band 6 Wolfgang Grimme: Ordnungspolitisches Konzept der Regionalpolitik. Darstellung der Defizite und des Reformbedarfs der Regionalpolitik am Beispiel Mecklenburg-Vorpommerns. 1997.

Band 7 Christian Ricken: Determinanten der Effektivität der Umweltpolitik. Der nationale Politikstil im Spannungsfeld von Ökonomie, Politik und Kultur. 1997.

Band 8 Christian Schmidt: Real Convergence in the European Union. An Empirical Analysis. 1997.

Band 9 Silvia Marengo: Exchange Rate Policy for MERCOSUR: Lessons from the European Union. 1998.

Band 10 Jens Kleinemeyer: Standardisierung zwischen Kooperation und Wettbewerb. Eine spieltheoretische Betrachtung. 1998.

Band 11 Stefan M. Golder. Migration und Arbeitsmarkt. Eine empirische Analyse der Performance von Ausländem in der Schweiz. 1999.

Band 12 Stefan Kramer. Die Wirkung einer Internationalisierung des Yen auf die japanischen Finanzmärkte, die japanische Geldpolitik und die Usancen der Fakturierung. 1999.

Band 13 Antje Marielle Gerhold: Wirtschaftliche Integration und Kooperation im asiatisch-pazifischen Raum. Die APEC. 1999.

Band 14 Tamim Achim Dawar: Deutsche Direktinvestitionen in Australien. Eine Evaluation der theoretischen Erklärungsansätze und der Standortattraktivität des Produktions- und Investitionsstandortes Australien. 1999.

Band 15 Hans-Markus Johannsen: Die ordnungspolitische Haltung Frankreichs im Prozeß der europäischen Einigung. 1999.

Band 16 Annette Schönherr. Vereinigungsbedingte Dimensionen regionaler Arbeitsmobilität. Wirkungen unter analytisch einfachen Bedingungen und potentielle individuelle Migrationsgewinne in Deutschland nach der Vereinigung. 1999.

Band 17 Henrik Müller. Wechselkurspolitik des Eurolandes. Konfliktstoff für die neue währungspolitische Ära. 1999. 